\title{
Preoperative interventions in patients with severe knee osteoarthritis undergoing total knee replacement : neuromuscular training and patient education
}

Citation for published version (APA):

Huber, E. O. (2015). Preoperative interventions in patients with severe knee osteoarthritis undergoing total knee replacement : neuromuscular training and patient education. [Doctoral Thesis, Maastricht University]. Datawyse / Universitaire Pers Maastricht. https://doi.org/10.26481/dis.20151210eh

Document status and date:

Published: 01/01/2015

DOI:

10.26481/dis.20151210eh

Document Version:

Publisher's PDF, also known as Version of record

Please check the document version of this publication:

- A submitted manuscript is the version of the article upon submission and before peer-review. There can be important differences between the submitted version and the official published version of record.

People interested in the research are advised to contact the author for the final version of the publication, or visit the DOI to the publisher's website.

- The final author version and the galley proof are versions of the publication after peer review.

- The final published version features the final layout of the paper including the volume, issue and page numbers.

Link to publication

\footnotetext{
General rights rights.

- You may freely distribute the URL identifying the publication in the public portal. please follow below link for the End User Agreement:

www.umlib.nl/taverne-license

Take down policy

If you believe that this document breaches copyright please contact us at:

repository@maastrichtuniversity.nl

providing details and we will investigate your claim.
}

Copyright and moral rights for the publications made accessible in the public portal are retained by the authors and/or other copyright owners and it is a condition of accessing publications that users recognise and abide by the legal requirements associated with these

- Users may download and print one copy of any publication from the public portal for the purpose of private study or research.

- You may not further distribute the material or use it for any profit-making activity or commercial gain

If the publication is distributed under the terms of Article 25fa of the Dutch Copyright Act, indicated by the "Taverne" license above, 


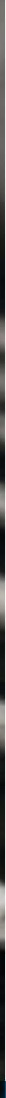

Preoperative interventions in patients with severe knee osteoarthritis undergoing total knee replacement

Neuromusculartraining and patienteducation

Erika 0 Huber 
(C) copyright Erika O Huber, Maastricht 2015 All rights reserved

Published by Datawyse | Universitaire Pers Maastricht ISBN 9789461594907 


\title{
Preoperative interventions in patients with severe knee osteoarthritis undergoing total knee replacement
}

Neuromuscular training and patient education

\author{
DISSERTATION \\ to obtain the degree of Doctor at Maastricht University, \\ on the authority of the Rector Magnificus, Prof. dr. L.L.G. Soete \\ in accordance with the decision of the Board of Deans, \\ to be defended in public on \\ Thursday $10^{\text {th }}$ December 2015, at 14:00 hours
}

by

Erika Huber

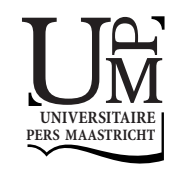




\section{SUPERVISOR}

Prof. dr. R. A. de Bie

Prof. dr. H. A. Bischoff-Ferrari, Zürich, Switzerland

Prof. dr. E. M. Roos, Odense, Denmark

\section{ASSESSMENT COMMITTEE}

Prof. dr. A. Boonen (chairman)

Prof. dr. S. M. A. Bierma-Zeinstra, Erasmus UMC, Rotterdam

Prof. dr. M. D. Iversen, Boston, U.S.A.

Prof. dr. N. van Meeteren

Prof. dr. L. W. van Rhijn

The research presented in this thesis was conducted at the Centre on Aging and Mobility, University of Zurich, Switzerland, at the Institute of Physiotherapy, Zurich University of Applied Sciences, Winterthur, Switzerland and at the School for Public Health and Primary Care: CAPHRI, Department of Epidemiology, of Maastricht University. CAPHRI participates in the Netherlands School of Primary Care Research CaRe. 


\section{CONTENTS}

List of Abbreviations

CHAPTER 1 General introduction

CHAPTER 2 Development of the knee osteoarthritis patient education questionnaire (KOPEQ): A new measure for evaluating preoperative patient education programs for patients undergoing total knee replacement

CHAPTER 3 Effect of preoperative neuromuscular training on functional outcome after total knee replacement: Study protocol of a randomized controlled trial

CHAPTER 4 Effect of preoperative neuromuscular training (NEMEX-TJR) on functional outcome after total knee replacement: An assessor-blinded randomized controlled trial

CHAPTER 5 Early outcomes following unilateral total or partial knee replacement (TKR/PKR) due to knee osteoarthritis: Change in function and pain at the contralateral knee

CHAPTER 6 Effect of functional stability exercise programs designed to improve pain and lower limb disability in people with knee osteoarthritis: A systematic review and meta-analysis of randomized controlled trials

CHAPTER 7 Construct validity of change scores of the Chair Stand Test versus Timed Up and Go test, KOOS questionnaire and the isometric muscle strength test in patients with severe knee osteoarthritis undergoing total knee replacement

CHAPTER 8 General discussion

Summary / Zusammenfassung

Valorisation

Acknowledgment

About the author 


\title{
List of Abbreviations
}

\author{
ACR American College of Rheumatology \\ ADL Activities of daily living \\ ANOVA Analysis of variance \\ BMI Body mass index \\ $\mathrm{Cl} \quad$ Confidence interval \\ CONSORT Consolidated Standards of Reporting Trials \\ COSMIN COnsensus-based Standards for the selection of health Measurement IN- \\ struments \\ CST Chair Stand Test \\ ICF \\ International Classification of Functioning, Disability and Health \\ (E)FA (Exploratory) factor analysis \\ EQ-5D EuroQoL -5 dimensions \\ ES Effect size \\ EULAR European League Against Rheumatism \\ FSE Functional stability exercise \\ FTSTS Five-time-sit-to-stand \\ ICC \\ Intraclass correlation coefficient \\ IMS Isometric muscle strength test \\ IQR Interquartile range \\ ITT Intention-to-treat \\ $\mathrm{KL} \quad$ Kellgren and Lawrence \\ KOOS Knee Injury and Osteoarthritis Outcome Score \\ KOPEI Knee Osteoarthritis Patient Education Intervention \\ KOPEQ Knee Osteoarthritis Patient Education Questionnaire \\ KS \\ Knee school \\ LEP Leistungserfassung in der Pflege (workload management in nursing) \\ LMM Linear mixed model \\ LOS Length of stay \\ MDC Minimal detectable change \\ MET Metabolic equivalent task \\ MID Minimal important difference \\ ML Maximum likelihood \\ MOST US Multicenter Osteoarthritis Study \\ NEMEX-TJR Neuromuscular exercise training program-total joint replacement \\ NHANES National Health And Nutrition Survey \\ NSAIDs Non-steroidal anti-inflammatory drugs
}


OA Osteoarthritis

OARSI Osteoarthritis Research Society International

PEMAT Patient Education Materials Assessment Tool

PKR Partial knee replacement

PRISMA Preferred Reporting Items for Systematic Reviews and Meta-Analyses

PRO Patient-reported outcome

QOL Quality of life

RAPT Risk Assessment and Predictor Tool

RCT Randomized controlled trial

ROM Range of motion

SD Standard deviation

SE Standard error

SF-36 Short Form-36 health survey

STS Sit-to-stand

TKR Total knee replacement

TUG Timed Up and Go test

WOMAC Western Ontario and McMaster Universities Osteoarthritis Index 

CHAPTER 1

\section{General introduction}

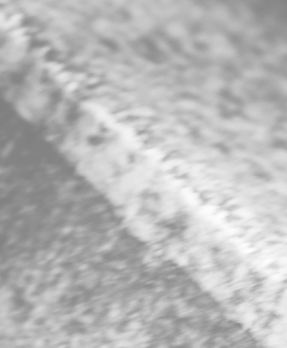


During my varied career as a physical therapist, I have worked as a clinician, managed a large team of physical and occupational therapists at the University Hospital in Zurich and also been active as vice-president and president of Physioswiss, the Swiss national professional physical therapy organization. I have always been a keen supporter of research in the field of physical therapy, but had never myself been active in this field. My curiosity to become involved personally was awoken through the task of co-organizing a Master's program in physiotherapy sciences in Switzerland in cooperation with Maastricht University. Four people inspired me to write my PhD thesis.

I first met Prof. Dr. Rob A. de Bie in 2003 at a conference in Germany. I asked him whether he would be interested in establishing a co-operation between our Master's program and that of the Maastricht University. He liked the idea and readily agreed. As a result of our contact and discussions during this cooperation, I realized that there was an opportunity to apply for a PhD studentship at Maastricht University with Rob as Promotor. Despite the fact that I was no longer at the start of my working career, the idea was firmly planted in my head.

It was while I was working at the University Hospital in Zurich that I met Prof. Dr. Heike Bischoff-Ferrari. She started her employment there as a researcher in 2006 and established a team on Aging Research, with special focus on osteoarthritis and the role of vitamin D. When I told her of my PhD ideas, she spontaneously offered her support and gave me a research opportunity in the field of osteoarthritis.

In the meantime, I had also met Prof. Dr. Nico van Meeteren. We maintained regular contact and, in June 2007, I invited him to Zurich to give a lecture to our team of physical therapists. The topic was "The strategy of acute care physiotherapy" and the concept he developed was called "Better in - Better out (BiBo)". He had just started with research in this field.

I was so enthusiastic about Bibo that I took advantage of the World Confederation of Physical Therapy Congress in June 2007, "Bringing the physical therapy community together", to discuss my PhD idea with Rob. He agreed to start with a study proposal on preoperative intervention in patients undergoing total knee replacement.

Finally, in September 2008 I met Prof. Dr. Ewa Roos in Zurich. We discussed the draft protocol of my planned randomized controlled trial (RCT) and she helped me clarify the preoperative intervention to be applied.

By the end of December 2008, the ethics protocol was submitted and my PhD journey had started.

\section{KNEE OSTEOARTHRITIS AND THERAPEUTIC EXERCISE}

Osteoarthritis (OA) is the most common form of arthritis and is expected to be the fourth largest cause of disability by 2020 [1]. Lifetime prevalence of symptomatic knee OA is estimated to lie at $44.7 \%$ [2]. OA develops slowly over decades and pain is the 
main complaint, followed by functional limitations in daily activities. Patients are less physically active when compared to the same age group in a general population [3]. Therapeutic exercises are regarded to be a cornerstone treatment for knee OA, with strong evidence for its pain relieving effect. High quality evidence indicates that landbased therapeutic exercise provides short-term benefit in terms of reduced knee pain, and moderate-quality level shows improvement in physical function among people with knee OA [4]. Since it is associated with only rare, non-serious adverse events, it is recommended in the Osteoarthritis Research Society International (OARSI) guidelines for the non-pharmacological treatment of knee OA [5]. The European League Against Rheumatism (EULAR) recommends patient education, exercise and weight loss as firstline treatments in degenerative knee disease [6].

Muscle strengthening and aerobic training show positive effects in terms of reduced pain and improved physical function [7] and most research focuses on quadriceps strengthening programs [8]. Research also shows that patients with degenerative knee disease have muscle activation deficiencies, reduced proprioceptive acuity [8,9] and also functional knee instability [10]. From this perspective, it can be argued that exercise programs should address several aspects of sensorimotor function and stabilization to improve sensorimotor control and achieve compensatory functional stability [11-14]. Specific exercises designed to improve functional stability should focus on neuromuscular control [15-18], core strength [19], proprioception/balance [14, 20-22] and functional limb alignment [13].

A well-described and feasible exercise program addressing functional stability in OA patients is the individualized goal-based neuromuscular exercise program-total joint replacement (NEMEX-TJR) [13]. This aims to improve sensorimotor control, achieve compensatory functional stability and relieves symptoms in patients with knee OA [13, 23-25].

\section{TOTAL KNEE REPLACEMENT AND EXERCISE BEFORE SURGERY}

Total knee replacement (TKR) is a widely preferred treatment option to significantly improve pain and function for end stage OA $[26,27]$. The incidence of the latter is increasing due to demographic changes in the Western World and the growing segment of the senior population $[28,29]$. Health-care expenditures will rise due to the absolute increase in TKR surgery [28]. Indication for TKR is based on knee pain, limited range of motion, deformity, degree of arthritis and limitation in physical function [30, 31].

Decreased physical activity, as is the case in patients awaiting TKR, is a critical sideeffect before, during and after hospitalization [32]. The surgical procedure itself may induce a stress response, including physiological effects that directly impair cardiopulmonary, muscular and neurological function [33]. Hoogeboom et al. [34] depicted the phenomena in which preoperative functional status plays a key role in the adaptive 


\section{CHAPTER 1}

responses to hospitalization and surgery (Figure 1). Therefore, preoperative exercise might increase the postoperative functional recovery of patients undergoing TKR.

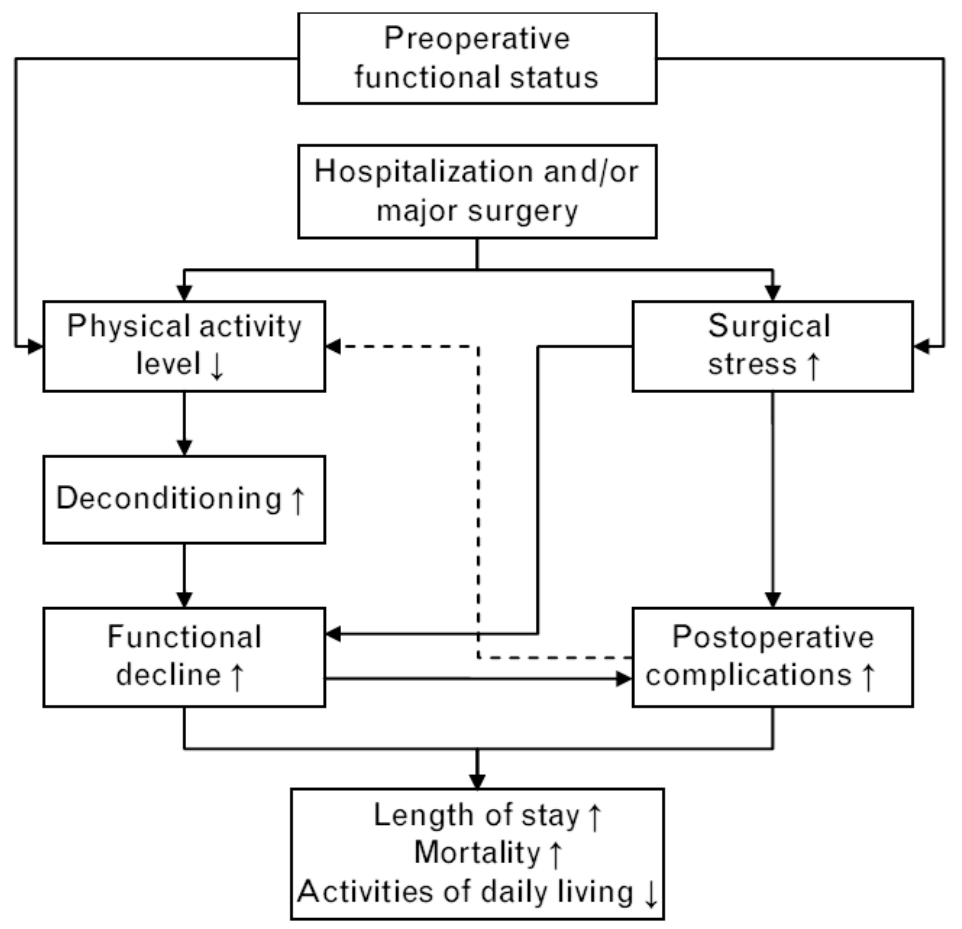

Figure 1: Depiction of possible effects of surgery and hospitalization in older patients and the role of preoperative functional status. Hoogeboom et al. (2014), with permission.

\section{CURRENT EVIDENCE}

Up to the point in time that I planned the main study of my PhD thesis (a randomized controlled trial (RCT) on the effect of preoperative neuromuscular training on functional outcome after TKR) two previous reviews had investigated preoperative physical therapy for patients undergoing hip and knee replacement. They had concluded that these programs were not effective in improving outcome [35, 36]. However, the small number of patients studied, and the heterogeneous interventions and comparators could have led to these negative findings. The limitations of previous trials plus a positive trend in the trial by Rooks et al. [37], which showed a small improvement in function in a study sample of 46 persons above 65 years of age, indicated that there was still a need for future research in this field. 


\section{OBJECTIVES OF THE PHD THESIS}

The purpose of this thesis is

(1) To assess the effect of preoperative neuromuscular training plus knee osteoarthritis patient education intervention on lower extremity function and pain compared to knee osteoarthritis patient education intervention alone, in individuals on a waiting list for TKR due to severe knee osteoarthritis.

(2) To explain the results from a broader perspective.

To achieve these objectives, 6 studies have been conducted; studies 1 to 3 deal with objective (1) and studies 4 to 6 with objective (2).

Chapter 2 reports on the development of a measurement instrument. The aim of this study was to develop a generic instrument for the use of patients, named the "Knee Osteoarthritis Patient Education Questionnaire" (KOPEQ), to assess the validity of a preoperative educational intervention and to preliminarily test its psychometric properties. The instrument was designed using the conceptual framework of Wilson and Cleary as a methodological guide $[38,39]$.

Chapter 3 reports on the study protocol of the primary evaluation study: Effect of preoperative neuromuscular training on functional outcome after total knee replacement: a randomized controlled trial.

Chapter 4 reports on the results of the primary evaluation study: Effect of preoperative neuromuscular training (NEMEX-TJR) on functional outcome after total knee replacement: an assessor-blinded randomized controlled trial. The aim of the study was to compare the change after TKR between groups in lower extremity function from baseline (6-12 weeks prior to surgery) to 3 months after surgery. Each group followed either NEMEX-TJR plus a knee school educational package (KS) or KS alone.

Chapter 5 reports on the results of the secondary evaluation study: Early outcomes following unilateral total or partial knee replacement (TKR/PKR) due to knee OA: Change in function and pain at the contralateral knee. The aim of this study was to investigate the change in WOMAC function and pain at the contralateral knee from baseline (1-2 weeks prior to surgery) to after surgery (8-10 weeks after surgery).

Chapter 6 reports on the results of a systematic review and meta-analysis to estimate the effect of functional stability exercise programs designed to improve pain and lower limb disability in people with knee OA. Five biographic databases were searched.

Chapter 7 reports on the testing of a performance-based measure: Construct validity of change scores of the Chair Stand Test (CST) versus Timed Up and Go (TUG) test, KOOS questionnaire and the isometric muscle strength (IMS sum) test in patients with severe knee osteoarthritis undergoing total knee replacement. We hypothesize that the strength of the correlations between CST and TUG compared to CST and KOOS and compared to CST and IMS sum will decrease. 
Chapter 8 includes a general discussion, presentation of the main results and a critical appraisal of the results with regard to the objectives.

\section{OUTLINE OF THE THESIS}

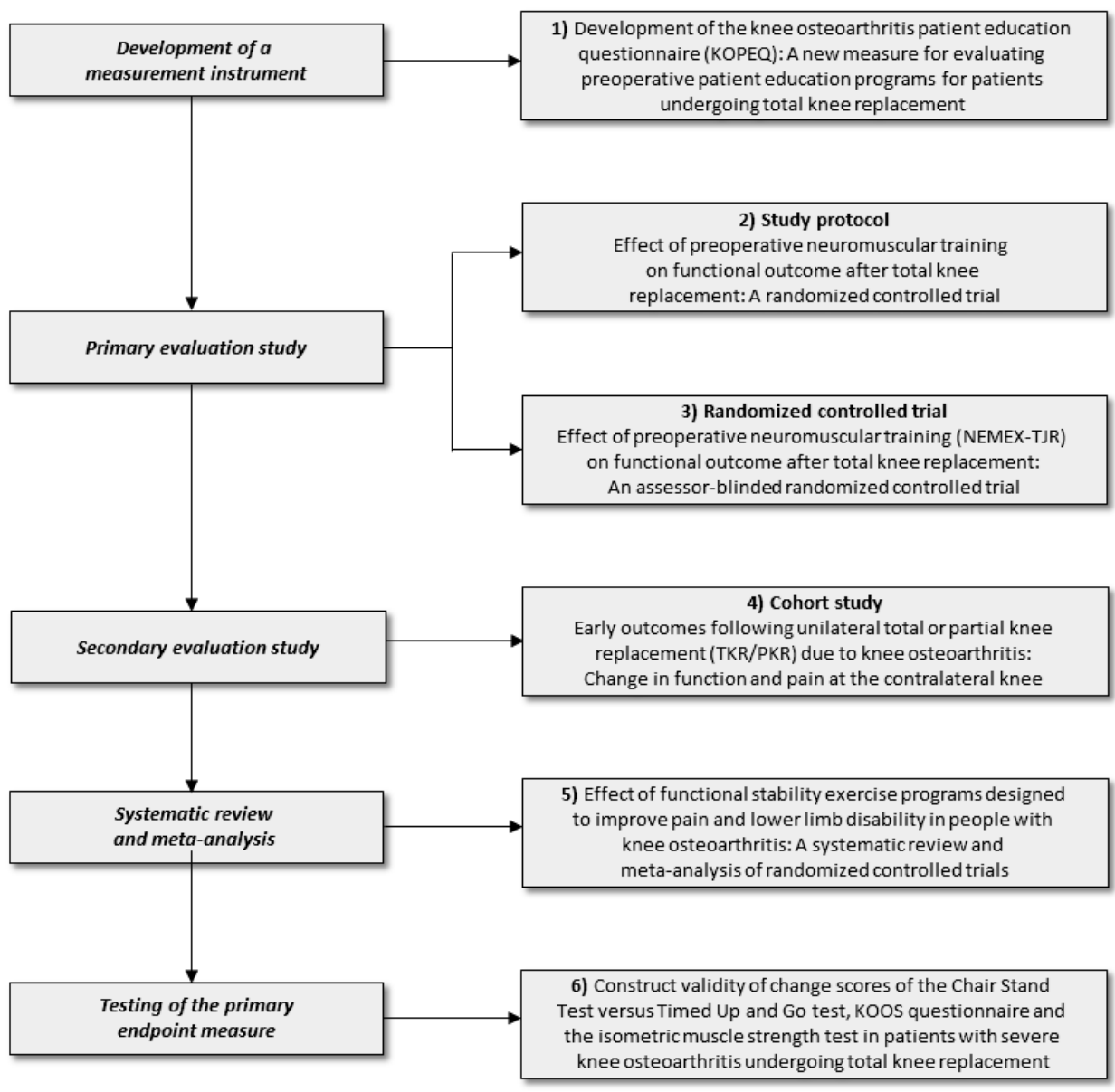

Figure 2: Outline of the thesis 


\section{REFERENCES}

1. Woolf AD, Pfleger B: Burden of major musculoskeletal conditions. Bulletin of the World Health Organization 2003, 81(9):646-656.

2. Murphy L, Schwartz TA, Helmick CG, Renner JB, Tudor G, Koch G, Dragomir A, Kalsbeek WD, Luta G, Jordan JM: Lifetime risk of symptomatic knee osteoarthritis. Arthritis and rheumatism 2008, 59(9):12071213.

3. Fontaine $\mathrm{KR}$, Heo M, Bathon J: Are US adults with arthritis meeting public health recommendations for physical activity? Arthritis and rheumatism 2004, 50(2):624-628.

4. Fransen M, McConnell S, Harmer AR, Van der Esch M, Simic M, Bennell KL: Exercise for osteoarthritis of the knee. The Cochrane database of systematic reviews 2015, 1:CD004376.

5. McAlindon TE, Bannuru RR, Sullivan MC, Arden NK, Berenbaum F, Bierma-Zeinstra SM, Hawker GA, Henrotin $\mathrm{Y}$, Hunter DJ, Kawaguchi $\mathrm{H}$ et al: OARSI guidelines for the non-surgical management of knee osteoarthritis. Osteoarthritis and cartilage / OARS, Osteoarthritis Research Society 2014, 22(3):363-388.

6. Fernandes L, Hagen KB, Bijlsma JW, Andreassen O, Christensen P, Conaghan PG, Doherty M, Geenen R, Hammond A, Kjeken I et al: EULAR recommendations for the non-pharmacological core management of hip and knee osteoarthritis. Annals of the rheumatic diseases 2013, 72(7):1125-1135.

7. Uthman OA, van der Windt DA, Jordan JL, Dziedzic KS, Healey EL, Peat GM, Foster NE: Exercise for lower limb osteoarthritis: systematic review incorporating trial sequential analysis and network meta-analysis. British journal of sports medicine 2014, 48(21):1579.

8. Bennell KL, Wrigley TV, Hunt MA, Lim BW, Hinman RS: Update on the role of muscle in the genesis and management of knee osteoarthritis. Rheumatic diseases clinics of North America 2013, 39(1):145-176.

9. Roos EM, Herzog W, Block JA, Bennell KL: Muscle weakness, afferent sensory dysfunction and exercise in knee osteoarthritis. Nature reviews Rheumatology 2011, 7(1):57-63.

10. Fitzgerald GK, Piva SR, Irrgang JJ: Reports of joint instability in knee osteoarthritis: its prevalence and relationship to physical function. Arthritis and rheumatism 2004, 51(6):941-946.

11. Ageberg E, Roos EM: Neuromuscular exercise as treatment of degenerative knee disease. Exercise and sport sciences reviews 2015, 43(1):14-22.

12. Ericsson $Y B$, Dahlberg LE, Roos EM: Effects of functional exercise training on performance and muscle strength after meniscectomy: a randomized trial. Scandinavian journal of medicine \& science in sports 2009, 19(2):156-165.

13. Ageberg E, Link A, Roos EM: Feasibility of neuromuscular training in patients with severe hip or knee OA: The individualized goal-based NEMEX-TJR training program. BMC Musculoskelet Disord 2010, 11:7.

14. Knoop J, Dekker J, van der Leeden M, van der Esch M, Thorstensson CA, Gerritsen M, Voorneman RE, Peter WF, de Rooij M, Romviel S et al: Knee joint stabilization therapy in patients with osteoarthritis of the knee: a randomized, controlled trial. Osteoarthritis and cartilage / OARS, Osteoarthritis Research Society 2013, 21(8):1025-1034.

15. Williams GN, Chmielewski T, Rudolph K, Buchanan TS, Snyder-Mackler L: Dynamic knee stability: current theory and implications for clinicians and scientists. The Journal of orthopaedic and sports physical therapy 2001, 31(10):546-566.

16. Williams GN, Barrance PJ, Snyder-Mackler L, Axe MJ, Buchanan TS: Specificity of muscle action after anterior cruciate ligament injury. Journal of orthopaedic research : official publication of the Orthopaedic Research Society 2003, 21(6):1131-1137.

17. Hortobagyi T, Westerkamp L, Beam S, Moody J, Garry J, Holbert D, DeVita P: Altered hamstringquadriceps muscle balance in patients with knee osteoarthritis. Clinical biomechanics (Bristol, Avon) 2005, 20(1):97-104.

18. Mills K, Hunt MA, Leigh R, Ferber R: A systematic review and meta-analysis of lower limb neuromuscular alterations associated with knee osteoarthritis during level walking. Clinical biomechanics (Bristol, Avon) 2013, 28(7):713-724. 
19. Myer GD, Brunner HI, Melson PG, Paterno MV, Ford KR, Hewett TE: Specialized neuromuscular training to improve neuromuscular function and biomechanics in a patient with quiescent juvenile rheumatoid arthritis. Physical therapy 2005, 85(8):791-802.

20. Hurley MV, Scott DL, Rees J, Newham DJ: Sensorimotor changes and functional performance in patients with knee osteoarthritis. Annals of the rheumatic diseases 1997, 56(11):641-648.

21. Chaipinyo K, Karoonsupcharoen $\mathrm{O}$ : No difference between home-based strength training and home-based balance training on pain in patients with knee osteoarthritis: a randomised trial. The Australian journal of physiotherapy 2009, 55(1):25-30.

22. Sharma L, Cahue S, Song J, Hayes K, Pai YC, Dunlop D: Physical functioning over three years in knee osteoarthritis: role of psychosocial, local mechanical, and neuromuscular factors. Arthritis and rheumatism 2003, 48(12):3359-3370.

23. Ageberg $E$, Nilsdotter A, Kosek E, Roos EM: Effects of neuromuscular training (NEMEX-TJR) on patientreported outcomes and physical function in severe primary hip or knee osteoarthritis: a controlled beforeand-after study. BMC Musculoskelet Disord 2013, 14(1):232.

24. Skou ST, Odgaard A, Rasmussen JO, Roos EM: Group education and exercise is feasible in knee and hip osteoarthritis. Danish medical journal 2012, 59(12):A4554.

25. Villadsen A, Overgaard S, Holsgaard-Larsen A, Christensen R, Roos EM: Immediate efficacy of neuromuscular exercise in patients with severe osteoarthritis of the hip or knee: a secondary analysis from a randomized controlled trial. The Journal of rheumatology 2014, 41(7):1385-1394.

26. Felson DT, Lawrence RC, Dieppe PA, Hirsch R, Helmick CG, Jordan JM, Kington RS, Lane NE, Nevitt MC, Zhang $Y$ et al: Osteoarthritis: new insights. Part 1: the disease and its risk factors. Annals of internal medicine 2000, 133(8):635-646.

27. Grayson CW, Decker RC: Total joint arthroplasty for persons with osteoarthritis. PM R 2012, 4(5 Suppl):S97-103.

28. Kurtz SM, Ong KL, Lau E, Widmer M, Maravic M, Gomez-Barrena E, de Pina Mde F, Manno V, Torre M, Walter WL et al: International survey of primary and revision total knee replacement. International orthopaedics 2011, 35(12):1783-1789.

29. Carr AJ, Robertsson O, Graves S, Price AJ, Arden NK, Judge A, Beard DJ: Knee replacement. Lancet 2012, 379(9823):1331-1340.

30. Dieppe P, Basler HD, Chard J, Croft P, Dixon J, Hurley M, Lohmander S, Raspe H: Knee replacement surgery for osteoarthritis: effectiveness, practice variations, indications and possible determinants of utilization. Rheumatology (Oxford, England) 1999, 38(1):73-83.

31. Van Manen MD, Nace J, Mont MA: Management of primary knee osteoarthritis and indications for total knee arthroplasty for general practitioners. The Journal of the American Osteopathic Association 2012, 112(11):709-715.

32. Palleschi L, Fimognari FL, Pierantozzi A, Salani B, Marsilii A, Zuccaro SM, Di Cioccio L, De Alfieri W: Acute functional decline before hospitalization in older patients. Geriatrics \& gerontology international 2014, 14(4):769-777.

33. Desborough JP: The stress response to trauma and surgery. British journal of anaesthesia 2000, 85(1):109-117.

34. Hoogeboom TJ, Dronkers JJ, Hulzebos EH, van Meeteren NL: Merits of exercise therapy before and after major surgery. Current opinion in anaesthesiology 2014, 27(2):161-166.

35. Ackerman IN, Bennell KL: Does pre-operative physiotherapy improve outcomes from lower limb joint replacement surgery? A systematic review. The Australian journal of physiotherapy 2004, 50(1):25-30.

36. Dauty $\mathrm{M}$, Genty M, Ribinik P: Physical training in rehabilitation programs before and after total hip and knee arthroplasty. Ann Readapt Med Phys 2007, 50(6):462-468, 455-461.

37. Rooks DS, Huang J, Bierbaum BE, Bolus SA, Rubano J, Connolly CE, Alpert S, Iversen MD, Katz JN: Effect of preoperative exercise on measures of functional status in men and women undergoing total hip and knee arthroplasty. Arthritis and rheumatism 2006, 55(5):700-708.

38. Wilson IB, Cleary PD: Linking clinical variables with health-related quality of life. A conceptual model of patient outcomes. Jama 1995, 273(1):59-65. 
General introduction

39. Wilson IB, Kaplan S: Clinical practice and patients' health status: how are the two related? Med Care 1995, 33(4 Suppl):AS209-214. 



\section{CHAPTER 2}

\section{Development of the knee osteoarthritis}

patient education questionnaire (KOPEQ):

A new measure for evaluating preoperative patient education programs for patients undergoing total knee replacement 


\section{Chapter 2}

\section{ABSTRACT}

\section{Objective}

The aim of this study was to develop a generic instrument for the use of patients, named the "Knee Osteoarthritis Patient Education Questionnaire" (KOPEQ), to assess the validity of a preoperative educational intervention and to make a preliminarily test of its psychometric properties.

\section{Methods}

A patient-reported outcome instrument was designed, using the conceptual framework of Wilson and Cleary as a methodological guide. Likert items with a five point scale were chosen for the scoring option. The feasibility and interpretability of administering the KOPEQ was tested through conducting interviews with targeted patients. Items of the KOPEQ were linked to the International Classification of Functioning, Disability and Health (ICF). Psychometric testing contained internal consistency for reliability and factor analysis for validity properties.

\section{Results}

A final list of 16 items was derived and linked to the ICF. Targeted patients confirmed in interviews, that all 16 questions were highly understandable and that the length of the questionnaire was feasible and acceptable. There was a good internal consistency for the 16-item KOPEQ with a Cronbach's alpha of 0.83 (95\% Cl: $0.71,0.94) .61 \%$ of the variance was explained by a four-factor model and they were named "didactics", "addressability", "empowerment" and "theory". Results of a factor analysis provided a loading of the separate items between 0.469 and 0.958 .

\section{Conclusions}

The KOPEQ can help to provide health professionals with reliable feedback on how patients assessed the applied patient education intervention. Interviews with patients and a factor analysis revealed new and important insight. 


\section{INTRODUCTION}

Patients scheduled for total knee replacement (TKR) have a long history of osteoarthritis (OA) which, over the years, has made them into experts on their own disease and its management. The impending TKR is a new event and it is important to understand patients' perceptions and concerns. This knowledge will be of assistance in preoperative preparation, postsurgical recovery, rehabilitation and discharge planning [1]. Several studies have confirmed that patients have questions about immediate perioperative issues and the recuperation process [2-5]. For TKR, semi-structured interviews of German patients found that they were mainly interested in information on the operation and recovery [6]. Trousdale et al. found that pain immediately after surgery, length of recovery, ability to walk, and ability to return to recreational activities were the 4 most important concerns of patients undergoing TKR [7]. Moran et al. demonstrated that cancellation of surgery, no decrease in pain, risk of losing the leg, risk of joint infection and risk of dying were the top 5 concerns [8].

The benefit of preoperative education on postoperative outcomes was recently evaluated in a review by the Cochrane collaboration [9]. Postoperative outcomes were anxiety, pain, function, health-related quality of life and side effects (such as infection or deep vein thrombosis). All types of surgical intervention and its postoperative rehabilitation delivered by a health professional within six weeks of surgery were accepted. The format of education ranged from one-to-one verbal communication, patient group sessions, to video or booklet with no verbal communication. The authors were uncertain as to whether it offers benefits over usual care in terms of reducing anxiety, or to surgical outcomes, such as pain, function and adverse events.

In all studies the content of the educational intervention itself was not evaluated and patients were not asked whether the content of the education program actually suited their needs. It is necessary, not only to evaluate the impact of the knee school on functioning domains, but also to evaluate the validity of the intervention itself [10]. Sjöling et al. pointed out in their study, that issues of validity were raised, because it seemed that some patients had problems in understanding and answering questions [11].

The aim of this study was to develop a generic instrument for the use of patients, named the "Knee Osteoarthritis Patient Education Questionnaire" (KOPEQ), to assess the validity of a preoperative educational intervention and to make a preliminarily test of its psychometric properties. Furthermore we hypothesized that this questionnaire would be reliable and that an exploratory factor analysis would generate at maximum a four-factor model. 


\section{Chapter 2}

\section{METHODS}

The development of the first version of the KOPEQ consisted of two phases, the development of the questionnaire itself, and the psychometric testing of internal consistency and factor analysis.

\section{Development of the knee osteoarthritis patient education questionnaire (KOPEQ)}

\section{Design}

A patient-reported outcome (PRO) instrument to measure validity and outcome of the knee school intervention was designed. Items were developed by the same four persons (expert team), who had developed the content of the KOPEI. The conception of the KOPEl is shown in table 1.

\section{Conceptual framework}

During the development of the items, we used the conceptual framework of Wilson and Cleary as a methodological guide $[12,13]$. It shows the relationship between construct and items and has implications for the scores and its examinations. In the reflective model the construct is reflected by the items, meaning that they will correlate with each other and also may replace each other. In the formative model, the items 'cause' or 'form' the construct, meaning that each item contributes to a part of the construct. In this case, Items do not necessarily correlate with each other and one item cannot be replaced by another. The conceptual framework of the first topic is a formative model and of the second topic a reflective model (Figure 1).

\section{Item selection and scoring}

In a first step, an initial list of 25 questions was assembled and discussed via a brainstorming conference by the expert team. Based on the concept of the knee school, four dimensions were identified as being important for the formative model: general impression, content, didactics and material. Two to six items were developed for each dimension. Based on reported questions to patients who were undergoing lower extremity joint replacement reported [7, 14], three dimensions were identified as being important for the reflective model: less fear after surgery, benefit during and after hospitalization until 6 weeks after surgery. The physical therapists decided to formulate only one item per dimension, in order to leave as much openness for patients to answer the questions. 
Table 1: Conception of the Knee Osteoarthritis Patient Education Intervention (KOPEI)

\begin{tabular}{|c|c|}
\hline Overall aim & $\begin{array}{l}\text { The overall aim of the KOPEI is to enable the individual patient to take control of this } \\
\text { situation and to take a more active part in the postoperative recuperation process. }\end{array}$ \\
\hline Underlying goal & $\begin{array}{l}\text { The underlying goal is to impart practical knowledge, including information and illustrative } \\
\text { material on the anatomy of the knee joint and adjacent functional structures, recommended } \\
\text { activities with a prosthesis and postoperative pain management, as well as details on the } \\
\text { postoperative rehabilitation phase. }\end{array}$ \\
\hline $\begin{array}{l}\text { Didactical } \\
\text { elements } \\
\text { and materials }\end{array}$ & $\begin{array}{l}\text { Didactical elements and materials to be used include: models of the knee joint and the } \\
\text { lower extremity, working sheets, photos and videos, activities pyramid, hand-outs, } \\
\text { PowerPoint presentations, discussion and exchange of experience. }\end{array}$ \\
\hline Organization & The content is apportioned over three self-contained sessions with no hier \\
\hline $\begin{array}{l}\text { Content } \\
\text { Session } 1\end{array}$ & $\begin{array}{l}\text { Functional anatomy: } \\
\text { a) What does the knee joint do? } \\
\text { Anatomy: bones; muscles; other soft tissues } \\
\text { Function: flexion / extension; function of the patella } \\
\text { b) Vicious circle } \\
\text { Pain => Dysfunction => Protection => Pain } \uparrow \\
\text { c) Legacy } \\
\text { After a knee replacement the joint is "new" while the muscles and other soft tissues } \\
\text { remain "old". } \\
\text { d) Consequence } \\
\text { As a result, training following a knee replacement is very important. }\end{array}$ \\
\hline $\begin{array}{l}\text { Content } \\
\text { Session } 2\end{array}$ & $\begin{array}{l}\text { Recommended Activities and Postoperative Pain Reduction } \\
\text { a) How does the musculature function? } \\
\text { Function: isometric / concentrically / eccentrically } \\
\text { what activities need how much mobility? } \\
\text { Examples: sitting, standing-up, standing, walking, climbing steps, bicycle riding } \\
\text { b) Muscle effort and impact on the joints } \\
\text { with gravity / without gravity / against gravity } \\
\text { soft surface / hard surface } \\
\text { small range of motion / large range of motion, impacts / jumps } \\
\text { c) Postoperative pain reduction } \\
\text { Leg elevation / bandaging } \\
\text { Quark compress / possibly ice (according to the clinic) } \\
\text { Pain medication (prescribed by a doctor) }\end{array}$ \\
\hline Content & Postoperative Rehabilitation \\
\hline Session 3 & $\begin{array}{l}\text { a) Time Schedule } \\
\text { Discussion of the treatment regime in the respective clinic of the acute care hospital and } \\
\text { the procedure after discharge from hospital. Focus will be laid on physiotherapeutic care } \\
\text { and the active participation of the patient in relation to reaching the objectives. } \\
\text { b) Wound healing } \\
\text { Inflammation phase, proliferation phase, remodulation phase }\end{array}$ \\
\hline ICF & $\begin{array}{l}\text { In terms of the ICF the domain of contextual factors was addressed such as services, systems } \\
\text { and policies (e5). In terms of the ICF the functioning domains addressed were: mental } \\
\text { functions (b1), sensory functions and pain (b2), neuromusculoskeletal and movement- } \\
\text { related functions (b7), mobility (d4), self-care (d5), domestic life (d6) and interpersonal } \\
\text { interactions and relationships (d7). }\end{array}$ \\
\hline
\end{tabular}




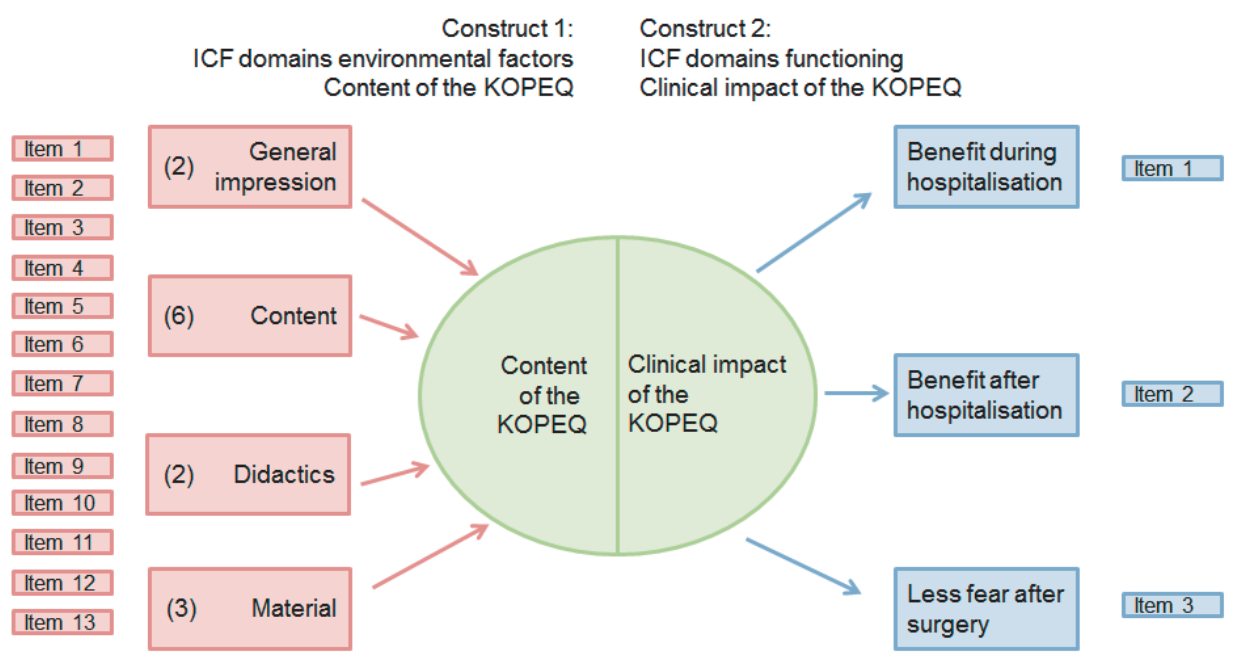

( ) = number of items

Figure 1: Conceptual framework of the Knee Osteoarthritis Patient Education Questionnaire (KOPEQ) ICF = International Classification of Functioning, Disability and Health

The second step was to reduce items by looking at their similarity, so that the survey took no longer than 5 minutes to complete. The third step involved formulation of the items, taking care to use simple language, avoid words with multiple meanings, choose specific terms, ask only one question per item and avoid negative wordings.

A Likert five class scale with a range from 1 to 5 was chosen for the scoring. The KOPEQ has two subscales (content and clinical impact) and item scores within the subscales were just summed together.

\section{Comprehensibility, response options and length of the questionnaire}

Feasibility and interpretability of administering the KOPEQ was conducted. Targeted patients answered questions on the comprehensibility of questions, the response options and the length of the KOPEQ. Using a think-aloud methodology (cognitive interview) [15], patients were also asked to formulate in words which benefits they expected to receive from the KOPEI during and after hospitalization.

\section{Linking the items to the ICF}

For clinical practice or for research purposes, information on the specific content at item level is required [16]. The ICF provides an instrument to evaluate the content of a measure (item) in a systematic way [17]. Therefore, the items were linked to the ICF, respecting patient's words from the think-aloud methodology. The linking process was done by an experienced ICF-linking expert (F.ME) [18]. 


\section{Preliminary psychometric testing}

Study design, patients and ethical approval

The study used a cross-sectional design, which was embedded within a randomized controlled trial [19]. Participants were patients with severe knee OA on a waiting list for primary TKR. The intervention consisted of the KOPEI. Patients had to be proficient in German and have a Mini-Mental State Examination score of greater than 24/30 [20]. All of the participants gave their informed written consent. The study was approved as an amendment of the main study by the Ethics Committee of the Cantons Aargau and Solothurn, Switzerland, approval number 2009/12 and the trial is registered with ClinicalTrials.gov, identifier: NCT00913575.

\section{Descriptive statistics}

Descriptive statistics were performed to describe the demographic variables of the target population.

\section{Internal consistency}

The internal consistency was investigated, using Cronbach's alpha [21]. A score above 0.70 was set as an indication of sufficient reliability [22].

\section{Exploratory factor analysis}

An exploratory factor analysis (EFA) of the 16 items of the KOPEQ was performed to model their underlying covariance structure. EFA is usually applied in the development phase of an instrument. It is based on a formal model predicting observed variables from theoretical latent factors. FA identifies factors containing items that correlate highly with each other and explain as much as possible of the covariance with a minimal number of factors. A modern approach to estimate the parameters of the FA model is via maximum likelihood (ML) [23]. Therefore, we fitted the model by optimizing the log likelihood assuming multivariate normality over the errors. Within the ML approach, we could test whether $k=1,2, \ldots$ factors were sufficient by constructing a likelihood-ratio-test, comparing the null hypothesis: " $k$ factors are sufficient" versus the alternative: " $k$ factors are not sufficient". In addition, a parallel analysis was performed by extracting factors until the eigenvalues of the reduced correlation matrix were less than the corresponding eigenvalues of a random data set of the same size [24]. In the FA-model, the factor loadings are identified only up to orthogonal rotations. The varimax rotation was applied to the extracted factors [25]. This solution maximizes the sum of the variances of the squared loadings, leading to a rotation that aims to clarify the structure of the loadings matrix. The statistician was blinded to the meaning of the items.

All analyses were conducted with $R$ version 2.14 .1 software [26]. 


\section{RESULTS}

\section{Development of the instrument (KOPEQ)}

\section{Results of the item development}

Based on the conceptual framework a total of 25 items were developed. After discussion within the group of experts, 9 items were excluded, on the basis of similarity or relevance. Finally, the wording was carefully reconsidered and the list edited to a total of 16 items.

\section{Results from interviews with patients}

Targeted patients confirmed in interviews, that all 16 questions were highly understandable and that the length of the questionnaire was feasible and acceptable. Patients were satisfied with the two different response options for the two subscales. Only one patient was rather expecting a 4-point scale, without the option of a middle position answer. Overall, it seemed that the items of the KOPEQ covered most of the issues that were of importance to the patients.

Patients also formulated in words the benefits they expected from the KOPEI both during and after hospitalization. During hospitalization they generally expected less fear, empowerment to better cope with pain and facilitated walking with canes and stair climbing. One patient pointed out that there is information overload on entrance day. Pre-surgery information is, therefore, very much estimated and allows the focus in hospital to be on what is really important at that moment. Another patient was happy about being empowered to understand health professionals better. Another patient remarked that she was not a person who felt comfortable in group sessions.

After hospitalization, they expected motivational support for exercising at home and empowerment to walk and undertaking the activities of daily living in general. One patient pointed out how important it is to get advice on how far (in distance) to walk. Another patient underlined the importance of being patient, which is easier when knowing more about the healing and recovery process.

Results of the linking process of the items to the ICF

The list with the items of the KOPEQ and their linking to the ICF is presented in table 2. 
Table 2: List of the items of the KOPEQ linked to the ICF

\begin{tabular}{|c|c|c|c|}
\hline Item & & Concept & For analysis \\
\hline \multicolumn{4}{|c|}{ topic 'education and training services' } \\
\hline 1 & Overall impression of the knee school & \multirow{14}{*}{$\begin{array}{l}\text { Content (1-13): } \\
\text { Health services, systems and } \\
\text { policies, } \\
\text { Education and training services }\end{array}$} & \multirow[t]{13}{*}{ e580, e585 } \\
\hline 2 & Division into 3 sessions & & \\
\hline 3 & Comprehensibility of the text in the hand outs & & \\
\hline 4 & Completeness of the hand outs & & \\
\hline 5 & $\begin{array}{l}\text { Relation between theory and active } \\
\text { participation }\end{array}$ & & \\
\hline 6 & Session "anatomy and function" & & \\
\hline 7 & Session "recommended activities" & & \\
\hline 8 & Session "Rehabilitation phases after surgery" & & \\
\hline 9 & Answers to patients questions & & \\
\hline & Comprehensibility of the imparted knowledge & & \\
\hline & Arrangement of the hand outs & & \\
\hline & PowerPoint presentations & & \\
\hline & Material to look at & & \\
\hline \multicolumn{3}{|c|}{ topic 'functioning domains' } & \\
\hline & Benefit during hospitalisation & $\begin{array}{l}\text { Clinical impact: pain, walking, } \\
\text { washing oneself, caring for body } \\
\text { parts, toileting, dressing, formal } \\
\text { relationships }\end{array}$ & $\begin{array}{l}\text { b280, d450 d510, } \\
\text { d520 d530 d540, } \\
d 740\end{array}$ \\
\hline & Benefit after hospitalisation & $\begin{array}{l}\text { Clinical impact: pain, walking, } \\
\text { washing oneself, caring for body } \\
\text { parts, toileting, dressing, acquisition } \\
\text { of goods and services, preparing } \\
\text { meals, doing housework }\end{array}$ & $\begin{array}{l}\text { b280, d450 d510, } \\
\text { d520 d530 d540, } \\
\text { d620, d630, d640 }\end{array}$ \\
\hline & Fear of the time after surgery & Clinical impact: emotional functions & b152 \\
\hline
\end{tabular}

The Linking of the items of the KOPEQ to the ICF was approved by Monika E. Finger on $24^{\text {th }}$ July 2014.

\section{Preliminary psychometric testing}

From May 2009 to June 2012 a total of 35 patients from a waiting list for TKR were recruited and assessed for this study. The mean age was 69.5 (Standard Deviation (SD) = 7.9) years, Body Mass Index was 30.5 (5.5) and 18 of 35 patients were male. The characteristics of the 16 items of the KOPEQ are presented in table 3. 
Chapter 2

Table 3: Characteristics of the items of the KOPEQ

\begin{tabular}{|c|c|c|c|c|}
\hline Items & Mean (SD) & Median & Min & Max \\
\hline 1 & $4.5(0.56)$ & 4.0 & 3 & 5 \\
\hline 2 & $4.3(0.47)$ & 4.0 & 4 & 5 \\
\hline 3 & $4.5(0.51)$ & 5.0 & 4 & 5 \\
\hline 4 & $4.4(0.56)$ & 4.0 & 3 & 5 \\
\hline 5 & $4.4(0.60)$ & 4.0 & 3 & 5 \\
\hline 6 & $4.6(0.50)$ & 5.0 & 4 & 5 \\
\hline 7 & $4.6(0.55)$ & 5.0 & 3 & 5 \\
\hline 8 & $4.4(0.74)$ & 5.0 & 2 & 5 \\
\hline 9 & $4.7(0.44)$ & 5.0 & 4 & 5 \\
\hline 10 & $4.7(0.52)$ & 5.0 & 3 & 5 \\
\hline 11 & $4.4(0.55)$ & 4.0 & 3 & 5 \\
\hline 12 & $4.5(0.61)$ & 5.0 & 3 & 5 \\
\hline 13 & $4.5(0.70)$ & 5.0 & 2 & 5 \\
\hline 14 & 4.4. (0.70) & 4.0 & 2 & 5 \\
\hline 15 & $4.3(0.85)$ & 4.5 & 1 & 5 \\
\hline 16 & $4.2(1.26)$ & 5.0 & 1 & 5 \\
\hline
\end{tabular}

Results of the internal consistency

There was a good internal consistency for the 16-item KOPEQ with a Cronbach's alpha of 0.83 (95\% Cl: $0.71,0.94)$.

Results of the factor analysis

Parallel analysis suggested four factors. Equivalently, the likelihood-ratio-tests for the four-factor model suggested that four factors were sufficient. $61 \%$ of the variance was explained by a four-factor model and they were named "didactics", "addressability", "empowerment" and "theory". The loading of the separate items was between 0.469 and 0.958 (Table 4). 
Table 4: Factor analysis with loadings of the 16 items of the KOPEQ on the 4 extracted factors*

\begin{tabular}{|c|c|c|c|c|c|}
\hline Items & Description & $\begin{array}{l}\text { Factor } 1 \\
\text { Didactics }\end{array}$ & $\begin{array}{l}\text { Factor } 2 \\
\text { Address- } \\
\text { ability }\end{array}$ & $\begin{array}{l}\text { Factor } 3 \\
\text { Empower- } \\
\text { ment }\end{array}$ & $\begin{array}{l}\text { Factor } 4 \\
\text { Theory }\end{array}$ \\
\hline Item 14 & $\begin{array}{l}\text { Benefit of the imparted knowledge during } \\
\text { hospitalisation }\end{array}$ & 0.800 & & & \\
\hline Item 10 & How comprehensible was the imparted knowledge & 0.702 & & & \\
\hline Item 12 & How were the PowerPoint presentations & 0.625 & & & \\
\hline Item 11 & How was the arrangement of the hand outs & 0.625 & & & \\
\hline Item 13 & How was the material to look at & 0.616 & & & \\
\hline Item 9 & How were my questions answered & 0.601 & & & \\
\hline Item 15 & Benefit of the imparted knowledge after hospitalisation & 0.569 & & & \\
\hline Item 2 & Division into 3 sessions & & 0.840 & & \\
\hline Item 1 & Overall impression of the knee school & & 0.752 & & \\
\hline Item 3 & $\begin{array}{l}\text { How was the comprehensibility of the text in the hand } \\
\text { outs }\end{array}$ & & 0.658 & & \\
\hline Item 4 & How was the completeness of the hand outs & & 0.546 & & \\
\hline Item 8 & $\begin{array}{l}\text { How was the session "Rehabilitation phases after } \\
\text { surgery" }\end{array}$ & & & 0.930 & \\
\hline Item 7 & How was the session "recommended activities" & & & 0.632 & \\
\hline Item 16 & $\begin{array}{l}\text { Less fear of the time after surgery by the imparted } \\
\text { knowledge }\end{array}$ & & & 0.469 & \\
\hline Item 5 & $\begin{array}{l}\text { How was the relation between theory and active } \\
\text { participation }\end{array}$ & & & & 0.958 \\
\hline Item 6 & How was the session "anatomy and function" & & & & 0.487 \\
\hline \multicolumn{2}{|c|}{ Sum of squares loadings } & 3.38 & 2.73 & 2.00 & 1.61 \\
\hline \multicolumn{2}{|c|}{ Proportion Variance } & 0.21 & 0.17 & 0.12 & 0.10 \\
\hline \multicolumn{2}{|c|}{ Cumulative Variance } & 0.21 & 0.38 & 0.51 & 0.61 \\
\hline
\end{tabular}

$61 \%$ of the variance was explained by a four-factor model.

*Factors extracted by maximum likelihood estimation, extracted factors rotated with varimax.

\section{DISCUSSION}

This article reports on the development and preliminary psychometric testing of the Knee Osteoarthritis Patient Education Questionnaire (KOPEQ), a new instrument to evaluate the validity of preoperative patient education interventions such as the Knee Osteoarthritis Patient Education Intervention (KOPEI). The development process was based on a conceptual framework and was guided by a group of experts. The KOPEQ had strong internal consistency and a four-factor model was able to explain $61 \%$ of the variance. 
The characteristics of the items of the KOPEQ demonstrated that for each item at least one person had chosen the ultimate score (5). When evaluating a personalized intervention there is always a certain risk that patients aim to please. Therefore, it is not unexpected that the ultimate score appears in each item. The difference between the minimal and maximal score is $\geq 2$ in 12 out of 16 items, which is sufficient. The residual 4 items (2, 3, 6 and 9) show a difference of 1 . Item 2 asks for the division of the intervention into 3 sessions and had a load of 0.840 in the FA. The division of the intervention into three sessions is important. Item 6 is the same type of question as items 7 and 8. Interestingly, the range in item 6 is 1 , whereas in item 7 it is 2 and in item 8 it is 3 . Therefore, we don't believe that we need to reconsider the formulation of item 6 . However, the formulation of items 3 and 9 ("How was the comprehensibility of the text in the hand-outs?") and ("How were my questions asked?" respectively) should be reconsidered. Maybe the wording used was too suggestive.

The factor analysis revealed important insights on how "education and training services" and "functioning domains" might be linked together by patients. Factor 1 "didactics" shows the importance of the manner, or how information and knowledge are imparted. Arrangement, layout and comprehensibility of handouts seem to be related to the quality of the answers from the perspective of patients. All aspects are important and all different approaches, and especially their combination, are necessary. These results are supported by Feicke et al, who identified a need to include didactical knowledge to patient education interventions [27].

Factor 2 "addressability" illustrates the overall appearance of the intervention, which is strongly related to the division of the intervention into three sessions. It seems that patients need more than one session, to consolidate the imparted knowledge, which makes sense from the didactical point of view. We have all experienced in different situations, how questions only arise after a delay. The second and third sessions, therefore, are also used to clarify questions from the previous session.

Factor 3 "empowerment" demonstrates that practical knowledge on "How will the rehabilitation phase be" and "What can I do to help myself" are important issues. Practical knowledge empowers patients to take responsibility and to take control over their situation in some way. This empowerment can also lead to a reduction in fear, which has previously been described by several authors [28-30].

Factor 4 "theory" leads us to believe that patients need information on theory, such as anatomy and function. This knowledge allows them to connect theory and practice and increases the chance that they are able and willing to transfer theoretical knowledge into their daily activities.

The interviews with patients generated important information. Firstly, patients are focused on walking with canes and climbing stairs, which is understandable since these are often functional discharge criteria [31]. Secondly, patients expect practical advices on as an example the distance they are recommended to walk after discharge and they expect motivational support for home exercise. Both expectations are not covered by 
outcome measures typically used in knee OA. Thirdly, none of the patients expressed higher expectations in consequence, as some authors have reported [3, 32, 33]. One patient mentioned explicitly, that the imparted knowledge helped her to modify her expectations regarding recovery and be more patient. Mancuso et al showed that patients' expectation can be modified by preoperative education [34].

There is increasing interest in the validation of aspects of patient education interventions. Shoemaker et al. recently presented the "Patient Education Materials Assessment Tool (PEMAT)", a new measure of understandability and actionability for print and audiovisual patient information [35]. The PEMAT can help lay persons and health professionals select patient education materials that reduce health literacy demands. It ca be used to identify understandable and actionable patient education materials. Understandability of print material (or "addressability") is also an important aspect of our study. In contrast to PEMAT, the KOPEQ includes other aspects to evaluate the validity of a patient education intervention, e.g. didactics, empowerment and theory. Eschalier et al. reported on the validation of an educational booklet targeted at patientcandidates for total knee arthroplasty [36]. The dissemination of an education booklet can ensure uniformity of information delivered by all the professionals involved. It was shown to be effective in improving knowledge in preoperative patients, but not in the postoperative patients. It had no influence on beliefs. In contrast to this study, the KOPEQ was designed to evaluate patient education interventions, measuring impacts from one week before to six weeks after TKR surgery. In summary, both groups used the term patient education but focused only on patient information, such as print or audiovisual material. The definition of patient education encompasses much more than patient information. Newman et al. defined patient education as "any combination of planned and organized learning experiences designed to facilitate voluntary adoption of behavior and / or beliefs conducive to health" [37]. In our opinion, in order to increase understanding and motivation, it is important to embed discussion and exchange of experience in patient education interventions.

Our study has several strengths. Firstly, the KOPEQ has undergone psychometric testing and its internal consistency is strong. Secondly, it has been tested qualitatively in patients to understand how they link the content of an educational intervention with its clinical benefit. Thirdly, the FA revealed new insights into how patients link aspects of the intervention with clinical outcomes.

Although specially designed for evaluation of the KOPEI, the principles in this patient education intervention could be applied to other patient education interventions, since all the important aspects of patient education are included.

As with all newly-developed questionnaires, the KOPEQ can be improved through further development and use in the field. This includes further validation with a larger sample of patients, followed by translation into other languages from the original German and a corresponding cross-cultural adaption. 


\section{LIMITATIONS}

Our study has some limitations. The relatively small convenience sample of patients $(n=35)$ may have driven results and, therefore, limited the generalizability of the results.

\section{CONCLUSIONS}

The KOPEQ can help to provide health professionals with a valid feedback on how patients assessed the applied patient education intervention. It is important to evaluate not only the outcome of a patient education intervention, but also its validity. Interviews with patients and a factor analysis revealed new and important insights. 


\section{REFERENCES}

1. Hall M, Migay AM, Persad T, Smith J, Yoshida K, Kennedy D, Pagura S: Individuals' experience of living with osteoarthritis of the knee and perceptions of total knee arthroplasty. Physiotherapy theory and practice 2008, 24(3):167-181.

2. Chang HJ, Mehta PS, Rosenberg A, Scrimshaw SC: Concerns of patients actively contemplating total knee replacement: differences by race and gender. Arthritis Rheum 2004, 51(1):117-123.

3. Marcinkowski K, Wong VG, Dignam D: Getting back to the future: a grounded theory study of the patient perspective of total knee joint arthroplasty. Orthopaedic nursing / National Association of Orthopaedic Nurses 2005, 24(3):202-209.

4. McGregor AH, Rylands H, Owen A, Dore CJ, Hughes SP: Does preoperative hip rehabilitation advice improve recovery and patient satisfaction? The Journal of arthroplasty 2004, 19(4):464-468.

5. Lithner M, Zilling T: Pre- and postoperative information needs. Patient education and counseling 2000, 40(1):29-37.

6. Hoermann S, Doering S, Richter R, Walter MH, Schussler G: [Patients' need for information before surgery]. Psychotherapie, Psychosomatik, medizinische Psychologie 2001, 51(2):56-61.

7. Trousdale RT, McGrory BJ, Berry DJ, Becker MW, Harmsen WS: Patients' concerns prior to undergoing total hip and total knee arthroplasty. Mayo Clinic proceedings 1999, 74(10):978-982.

8. Moran M, Khan A, Sochart DH, Andrew G: Evaluation of patient concerns before total knee and hip arthroplasty. The Journal of arthroplasty 2003, 18(4):442-445.

9. McDonald S, Page MJ, Beringer K, Wasiak J, Sprowson A: Preoperative education for hip or knee replacement. The Cochrane database of systematic reviews 2014, 5:CD003526.

10. Hoogeboom TJ, Oosting E, Vriezekolk JE, Veenhof C, Siemonsma PC, de Bie RA, van den Ende $\mathrm{CH}$, van Meeteren NL: Therapeutic validity and effectiveness of preoperative exercise on functional recovery after joint replacement: a systematic review and meta-analysis. PloS one 2012, 7(5):e38031.

11. Sjoling M, Nordahl G, Olofsson N, Asplund K: The impact of preoperative information on state anxiety, postoperative pain and satisfaction with pain management. Patient education and counseling 2003, 51(2):169-176.

12. Wilson IB, Cleary PD: Linking clinical variables with health-related quality of life. A conceptual model of patient outcomes. JAMA : the journal of the American Medical Association 1995, 273(1):59-65.

13. Wilson IB, Kaplan S: Clinical practice and patients' health status: how are the two related? Med Care 1995, 33(4 Suppl):AS209-214

14. Macario A, Schilling P, Rubio R, Bhalla A, Goodman S: What questions do patients undergoing lower extremity joint replacement surgery have? BMC health services research 2003, 3(1):11.

15. Using the think aloud method (cognitive labs) to evaluate test design for students with disabilities and English language learners (Technical Report 44). Available from: [http//education.umn.edu/ NCEO/OnlinePubs/Tech44/. 26 July 2014]

16. Schepers VP, Ketelaar M, van de Port IG, Visser-Meily JM, Lindeman E: Comparing contents of functional outcome measures in stroke rehabilitation using the International Classification of Functioning, Disability and Health. Disability and rehabilitation 2007, 29(3):221-230.

17. World Health Organization. International Classification of Functioning, Disability and Health. Geneva, Switzerland

18. Alviar MJ, Olver J, Brand C, Hale T, Khan F: Do patient-reported outcome measures used in assessing outcomes in rehabilitation after hip and knee arthroplasty capture issues relevant to patients? Results of a systematic review and ICF linking process. Journal of rehabilitation medicine 2011, 43(5):374-381.

19. Huber EO, Roos EM, Meichtry A, de Bie RA, Bischoff-Ferrari HA: Effect of preoperative neuromuscular training (NEMEX-TJR) on functional outcome after total knee replacement: an assessor-blinded randomized controlled trial. BMC musculoskeletal disorders 2015, 16:101.

20. Folstein MF, Folstein SE, McHugh PR: "Mini-mental state". A practical method for grading the cognitive state of patients for the clinician. J Psychiatr Res 1975, 12(3):189-198. 
21. Cronbach $\amalg$ : Coefficient alpha and the internal structure of tests. Psychometrika 1951, 16:297-334.

22. Terwee CB, Bot SD, de Boer MR, van der Windt DA, Knol DL, Dekker J, Bouter LM, de Vet HC: Quality criteria were proposed for measurement properties of health status questionnaires. Journal of clinical epidemiology 2007, 60(1):34-42.

23. Lawley DN, Maxwell AE: Factor analysis as a statistical method: American Elsevier Pub. Co.; 1971.

24. Ledesma RDaPV-M: Determining the Number of Factors Retain in EFA: An easy-to-use computer program for carrying out Parallel Analysis. Practical Assessment Research \& Evaluation 2007, 12(2):1-11.

25. Kaiser $\mathrm{H}$ : The varimax criterion for analytic rotation in factor analysis. Psychometrika 1958, 23(3):187-200.

26. R Core Team. R: A language and environment for statistical computing [http://www.R-project.org/.]

27. Feicke J, Sporhase U: [Improvements in patient education from the didactical point of view]. Die Rehabilitation 2012, 51(5):300-307.

28. Loft M, McWilliam C, Ward-Griffin C: Patient empowerment after total hip and knee replacement. Orthopaedic nursing / National Association of Orthopaedic Nurses 2003, 22(1):42-47.

29. MacDonald V, Arthur B, Parent S: The Vancouver General Hospital joint replacement rapid recovery program: Optimizing outcomes through focused pathways. Journal of Orthopaedic Nursing 2005, 9(2):95102.

30. Lucas B: Preparing patients for hip and knee replacement surgery. Nursing standard (Royal College of Nursing (Great Britain) : 1987) 2007, 22(2):50-56; quiz 58.

31. Jones S, Alnaib M, Kokkinakis M, Wilkinson M, St Clair Gibson A, Kader D: Pre-operative patient education reduces length of stay after knee joint arthroplasty. Annals of the Royal College of Surgeons of England 2011, 93(1):71-75.

32. Hawker GA: Who, when, and why total joint replacement surgery? The patient's perspective. Current opinion in rheumatology 2006, 18(5):526-530.

33. Mahomed NN, Liang MH, Cook EF, Daltroy LH, Fortin PR, Fossel AH, Katz JN: The importance of patient expectations in predicting functional outcomes after total joint arthroplasty. The Journal of rheumatology 2002, 29(6):1273-1279.

34. Mancuso CA, Graziano S, Briskie LM, Peterson MG, Pellicci PM, Salvati EA, Sculco TP: Randomized trials to modify patients' preoperative expectations of hip and knee arthroplasties. Clinical orthopaedics and related research 2008, 466(2):424-431.

35. Shoemaker SJ, Wolf MS, Brach C: Development of the Patient Education Materials Assessment Tool (PEMAT): a new measure of understandability and actionability for print and audiovisual patient information. Patient education and counseling 2014, 96(3):395-403.

36. Eschalier B, Descamps S, Boisgard S, Pereira B, Lefevre-Colau MM, Claus D, Coudeyre E: Validation of an educational booklet targeted to patients candidate for total knee arthroplasty. Orthopaedics \& traumatology, surgery \& research : OTSR 2013, 99(3):313-319.

37. Newman S, Mulligan K, Steed L: What is meant by self-management and how can its efficacy be established? Rheumatology (Oxford, England) 2001, 40(1):1-4. 


\section{CHAPTER 3}

\section{Effect of preoperative neuromuscular training}

\section{on functional outcome after}

total knee replacement: Study protocol of a randomized controlled trial

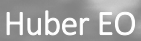
de Bie RA Roos EM Bischoff-Ferrari HA 


\section{Chapter 3}

\section{ABSTRACT}

\section{Background}

Total Knee Replacement (TKR) is the standard treatment for patients with severe knee osteoarthritis (OA). Significant improvement in pain and function are seen after TKR and approximately $80 \%$ of patients are very satisfied with the outcome. Functional status prior to TKR is a major predictor of outcome after the intervention. Thus, improving functional status prior to surgery through exercise may improve after surgery outcome. However, results from several previous trials testing the concept have been inconclusive after surgery.

\section{Methods/Design}

In a randomized controlled trial (RCT) we will test the effect of a pre-operative neuromuscular training program versus an attention control program on lower extremity function - before and after surgery. We will enroll 80 participants, aged between 55-90 years, who are scheduled for TKR. In this single-blinded RCT, the intervention group will receive a minimum of 8 and a maximum of 24 training sessions plus 3 educational sessions of the knee school. The control group will receive the 3 educational sessions only. Assessments are performed immediately before and after the intervention (before surgery), at 6 weeks, 3 months and 12 months (after surgery).

The primary outcome will include the Chair Stand Test as a measure of leg strength and reaction time. Secondary outcomes are knee function and pain assessed with the self-reported Knee Injury and Osteoarthritis Outcome Score (KOOS). All measurements will be carried out by a specially trained physical therapist, blinded to group allocation.

\section{Discussion}

To our knowledge this is the first single-blinded RCT to test the effect of preoperative neuromuscular training plus knee school against knee school alone - on knee function and pain assess immediately after the interventions before surgery and then repeatedly after surgery. 


\section{BACKGROUND}

Osteoarthritis (OA) is the most common joint disorder and a common cause of pain, loss of function and disability in older adults [1]. It is the second most common diagnosis made in older adults seeking medical care [2] and the leading cause of disability at older age [3]. When suffering from severe OA, Total Joint Replacement (TJR) is the preferred treatment option to significantly improve function and pain [2, 4]. Given the demographic change with growing segment of the senior population in the Western World, the rate of these procedures will rise exponentially over the next decade. This will result in high health-care expenditures due to the absolute increase in TJR surgery (both direct hospital charges and indirect costs) [5].

The current EULAR (European League Against Rheumatism) recommendations include exercise as an effective treatment in the improvement of pain and function in patients with moderate to severe knee OA (effect size for validated outcome measures of pain and function versus placebo range from 0.57 to 1.0) [6]. Similarly, the OARSI (Osteoarthritis Research Society International) supports the benefits of exercise in patients with knee OA, both on pain and function [7].

Notably, exercise alone may delay but not prevent TJR in severe OA [8]. Similarly, however, TJR does not fully restore function in many patients undergoing the procedure [9-11], which in part may be due to long-term mechanical impairments of the joint.

The most recent review published on pre-operative interventions for patients with hip or knee osteoarthritis awaiting joint replacement was published in 2011 and included 23 trials [12].The authors concluded that there was low to moderate quality evidence for the benefit of pre-operative exercise for Total Knee Replacement (TKR). These data are consistent with three earlier systematic reviews [13-15].

Considering the evidence from the available formal reviews, two factors may have prevented a benefit from these programs: $(A)$ : Four trials had very small groups with a combined total of 137 subjects and were probably underpowered [16-19]. (B): The therapeutic validity as described by Hoogeboom et al was not sufficient enough, making it unlikely, that interventions evaluated in these studies would have relevant effects [20].

In this study we aim to test a well-defined and feasible training program plus a knee school educational package against the educational package alone on lower extremity function and pain before and after TKR. The trial is powered based on pilot data and includes a detailed assessment of adherence to the program.

\section{Objective}

To study the effect of a pre-operative neuromuscular training plus knee school educational program compared to the educational program alone on lower extremity function and pain in individuals age 50-90 on a waiting list for TKR due to severe knee OA. 


\section{Hypothesis}

Primary Endpoint: We hypothesize that patients undergoing a pre-operative neuromuscular training in addition to the educational program will be significantly quicker in performing the Chair Stand Test (test of lower extremity function) compared with those receiving the educational program alone immediately after the intervention and after TKR surgery.

Secondary Endpoints: We hypothesize that patients undergoing a pre-operative neuromuscular training in addition to the educational program will have a greater improvement in function and pain (KOOS subscales)compared with those receiving the educational program alone immediately after the intervention and after TKR surgery.

\section{METHODS/DESIGN}

\section{Design}

The study design is a single-blinded randomized controlled trial.

Outcomes are measured at baseline (6-12 weeks pre-operative: primary and secondary endpoints), 1 week pre-operative (after the intervention: primary and secondary endpoints), 6 weeks after surgery (secondary endpoints only), 3 months after surgery (primary and secondary endpoints) and 1 year after surgery (secondary endpoints only).

Prior to the baseline assessment eligible patients receive an information package on the study. The package includes detailed information, including their rights when participating in a research project and a written informed consent form. Ethic approval was granted by the Ethics Committee of the cantons Aargau and Solothurn, Switzerland, approval number 2009/012.

Reporting of the RCT follows the recommendations of CONSORT guidelines for reporting of clinical trials and will be based on intent-to-treat [21]. In addition, a perprotocol analysis will be performed.

\section{Participants and recruitment}

We include Individuals age 55-90 years on a waiting list for TKR due to severe primary or secondary OA. Individuals need to also be community dwelling and understand German as a written and spoken language. Exclusion criteria are cognitive impairment, revision surgery for TKR, plans to leave Switzerland before or after surgery, history of inflammatory arthritis and inability to walk at least 3 meters with or without walking aid.

The trial recruits at the Cantonal Hospital Olten and the Cantonal Hospital Aarau, which both perform about 200 TKRs per year. Recruitment and eligibility assessment are conducted by the orthopedic surgeon at the time of consultation, when the patient has decided to undergo TKR surgery and is placed on the waiting list. Eligible patients 
are referred to the study center (Centre on Aging and Mobility, University of Zurich) by fax. The referring surgeon gives eligible patients a one-page summary of the study. After confirming their interest, eligible individuals receive detailed participant information about the study procedure and 4-7 days later, they are contacted by phone (EOH) to answer additional questions. Eligible and willing individuals then provide their written informed consent. Two experienced physical therapists (assessors), not working at the recruitment sites and not being involved in the neuromuscular training and the knee school, have been specifically trained for the assessments of this study and are blinded to the randomization.

Neuromuscular training and knee school take place at the recruitment sites. Several experienced physical therapists working at the recruitment sites, have been specially trained either for the neuromuscular training or the knee school. Individuals of the intervention group and individuals of the control group were not together in the knee school.

\section{Baseline assessment and randomization}

After informed consent, the assessor performs the baseline assessment at the recruitment site. Additionally, demographics and covariates that affect outcomes are documented: age, gender, height, weight, cognitive impairment (assessed with the Folstein Mini Mental score) [22] and risk of extended inpatient rehabilitation questionnaire (measured with the Risk Assessment and Predictor Tool (RAPT) [23].

Participants will be randomized using block allocation with a block size of four. The list is computer generated by the independent randomization center.

The coordinating investigator $(\mathrm{EOH})$ informs the participant about the group allocation and schedules the treatment sessions as allocated by the independent randomization center.

\section{INTERVENTIONS}

\section{Neuromuscular training program (NEMEX-TJR training program)}

The neuromuscular training follows the principles of neuromuscular and biomechanical training as described in the neuromuscular training method NEuroMuscular EXercise (NEMEX) [24], and aims to improve neuromuscular control (also called sensorimotor control) and to achieve compensatory functional stability. Neuromuscular control is defined as the ability to produce controlled movement through coordinated muscle activity. Movement starts with the non-affected leg to facilitate the bilateral transfer effect of motor learning. Exercises are mainly performed in closed kinetic chains in the lying, sitting or standing position to achieve muscular co-activation in an appropriate position of the joints with hip, knee and foot well aligned. These activities emphasize 
the improvement of the stabilizing functions of the weight-bearing muscles for better postural control in static and dynamic situations. Open kinetic chains are only performed to improve muscle strength of the knee and hip muscles.

The training takes place in groups under the supervision of an experienced and especially trained physical therapist and consists of three parts:

- Part 1: Warming up: The warm-up period consists of ergometer cycling for 10 minutes. The workload is set individually and can be increased during the 10 minutes.

- Part 2: Circuit program: The circuit program comprises four exercise circles, with the key elements: core stability/postural function, functional alignment, lower-extremity muscle strength and functional exercises. Usually two exercises, sometimes one, are performed in each circle. Each exercise is performed 2-3 sets * 10-15 repetitions, with rest between each exercise and circle. To allow progression three levels of difficulty are defined. Progression is provided by varying in number, direction and velocity of the movements, by increasing the load and/or by changing the support surface. Progression is made when an exercise is performed of 3 sets * 15 repetitions with good neuromuscular control and good quality of performance (based on visual inspection by the physical therapist) and with minimal exertion and control of the movement (perceived by the patient).

- Part 3: Cooling down: The cooling down period of about 10 minutes consists of forward and backward walking exercises, about 10 meters in each direction, mobility exercises for the lower extremities and stretching exercises for the lower-extremity muscles.

The exercises included in the training program are described in detail in the additional file 1 [24].

Documentation of the training program includes the number of training sessions, level of difficulty per session, pain on a 0 to 10 scale before and after each session and 24 hours after each session.

Patients also document how physically active they were per training week (activity levels $\mathrm{A}-\mathrm{C}$ ), notified in minutes per activity level. Level A consists of competitive sports activities, intensive enough to cause heavy sweating. Level B consists of endurance or muscle strengthening activities, intense enough to cause light sweating and faster breathing while still allowing one to talk, i.e. increased walking, running, cycling, swimming, cross-country skiing or muscle strength training. Level $\mathrm{C}$ consists of activities of daily living, i.e. walking, climbing stairs, housekeeping or garden work [25].

\section{Knee school}

The knee school was designed to educate participants about knee OA, the preparation phase before undergoing TKR and the acute rehabilitation phase afterwards. The concept of the knee school is adapted from the hip school, described by Klassbo [26]. The 
knee school is taught by an experienced and especially trained physical therapist over 3 individual or group sessions, one session per week, starting about 4 weeks before the operation. Knee school sessions are separately organized for participants of the intervention group and those of the control group to avoid contamination.

The content of the school includes information about anatomy of the knee joint and adjacent functional structures, recommended activities with prosthesis and postoperative pain management, and details on the postoperative rehabilitation phase. Didactical elements include models of the knee joint and the lower extremity, working sheets, photos and videos, handouts, PowerPoint presentations and peer discussions.

\section{Intervention group}

Participants of the intervention group receive 8-24 sessions of the neuromuscular training program prior to TKR surgery depending on location of the waiting list for surgery. Participants also receive 3 sessions of the knee school starting about 4 weeks before surgery.

\section{Control group}

Participants of the control group receive 3 sessions of the knee school, starting about 4 weeks before surgery.

\section{Outcome measures}

We include one objective (Chair Stand Test) and two patient-reported outcome measures (pain and function subscale of the KOOS questionnaire) in this trial to test the effect of the intervention on lower extremity function (see Table 1)

\section{Primary outcome measure}

The primary outcome is the Chair Stand Test, also known as the repeated sit-to-stand test. It is commonly used as a measure of lower extremity strength, balance and reaction time [27-29]. The subject is asked, to stand up from a chair without armrests to a fully erect standing position five times as quickly as possible without pushing off [30]. The time needed is measured by a stop watch in seconds. The Chair Stand Test is easy to perform in clinical practice and has shown excellent intra- and inter-rater reliability (Inter Class Correlation, 0.89 [31]. The Chair Stand Test was also found to predict disability across populations accurately [32]. 
Table 1 Summary of measures to be collected

\begin{tabular}{|c|c|c|c|c|c|c|}
\hline & $\begin{array}{c}\text { 6-12 weeks } \\
\text { pre-op. }\end{array}$ & $\begin{array}{l}1 \text { week } \\
\text { pre-op. }\end{array}$ & at discharge & $\begin{array}{l}6 \text { weeks } \\
\text { post-op. }\end{array}$ & $\begin{array}{l}3 \text { months } \\
\text { post-op. }\end{array}$ & $\begin{array}{l}1 \text { year } \\
\text { post-op. }\end{array}$ \\
\hline \multicolumn{7}{|l|}{ Primary outcome measure } \\
\hline Chair Stand Test & $x$ & $x$ & & & $x$ & \\
\hline \multicolumn{7}{|l|}{ Secondary outcome measure } \\
\hline $\begin{array}{l}\text { Subscales pain and function of } \\
\text { the KOOS }\end{array}$ & $x$ & $x$ & & $x$ & $x$ & $x$ \\
\hline \multicolumn{7}{|l|}{ Additional outcome measures } \\
\hline Muscle strength & $x$ & $x$ & & & $x$ & \\
\hline Knee-bending/30s & $x$ & $x$ & & & $x$ & \\
\hline Range of motion of the knee & $x$ & $x$ & & & $x$ & \\
\hline $20 \mathrm{~m}$ walk test & $x$ & $x$ & & & $x$ & \\
\hline Timed up and go & $x$ & $x$ & & & $x$ & \\
\hline Physical activity level & $x$ & $x$ & & $x$ & $x$ & $x$ \\
\hline Adapted NHANES III & $x$ & $x$ & & $x$ & $x$ & $x$ \\
\hline SF 36 & $x$ & $x$ & & $x$ & $x$ & $x$ \\
\hline$E Q-5 D$ & $x$ & $x$ & & $x$ & $x$ & $x$ \\
\hline \multicolumn{7}{|l|}{ Health Service Utilization } \\
\hline RAPT & $x$ & & & & & \\
\hline LOS & & & $x$ & & & \\
\hline Minutes of nursing care & & & $x$ & & & \\
\hline
\end{tabular}

\begin{tabular}{ll}
\hline KOOS & Knee injury and Osteoarthritis Outcome Score \\
NHANES & National Health And Nutrition Examination Survey \\
SF 36 & Short Form-36 health survey \\
EQ-5D & EuroQol -5 dimensions \\
RAPT & Risk Assessment and Predictor Tool \\
LOS & Length of stay
\end{tabular}

\section{Secondary outcome measure}

Secondary outcomes are knee pain and function assessed by the KOOS questionnaire. The KOOS is a commonly used patient-reported outcome with overall acceptable psychometric properties to evaluate patients with knee injury and knee OA [33], including those having TKR [34]. KOOS holds 5 subscales with a total of 42 items: 1) pain, 2) other symptoms, 3) function in daily living (ADL), 4) function in sport and recreation and 5) knee-related quality of life. Since exercise training is aiming to improve function we are particularly interested in the KOOS ADL subscale for the functional outcome measure.

The German version of the KOOS is used in this trial [35]. Its user's guide including scoring instructions, are available from http://www.koos.nu. 


\section{Additional outcome measures}

\section{Lower limb function}

Isometric muscle strength of knee flexors and extensors, hip flexors, hip extensors, hip adductors and hip abductors are measured with a hand-held pull gauge $[36,37]$.The ability to alternate rapidly between concentric and eccentric work of the extensor muscles of the hip and knee is impaired in many patients with knee OA [38]. The ability of rapid alternation between concentric and eccentric function is measured using maximal number of knee-bending in 30 seconds, which is a valid and reliable test (ICC, 0.80) [24, 39]. Range of Motion is measured with a long-arm goniometer [40]. Walking speed is assessed with the $20 \mathrm{~m}$ walk test (ICC, 0.93) [24], a reliable modification of the short walk test used in many epidemiological and clinical studies. The test measures the time it takes to walk 20 meters at the participant's usual walking pace, along with the number of steps that they take to walk 20 meters [41]. Lower extremity mobility is further assessed with the Timed Up and Go test, which requires a person to rise from a stair, walk 3 meters, turn $180^{\circ}$, return to the chair and sit down [42].

\section{Physical activity and health-related quality of life}

Physical activity is measured by the SenseWear armband, a device for quantifying physical activity in daily life $[43,44]$. It collects the following data: energy expenditure, average MET's, physical activity duration, steps per day and the physical activity distribution (sedentary, moderate, vigorous and very vigorous). In addition, physical activity is measured by 10 activity questions assessed and validated in NHANES III [45, 46]. Healthrelated quality of life is measured by the generic questionnaire SF-36 [47, 48]. General health status is measured by the EuroQoL (EQ-5D). The EQ-5D is used to complement the SF-36, allowing health economic evaluation and comparison to other knee OA populations [49].

\section{Health Service Utilization}

Discharge potential is measured by the Risk Assessment and Predictor Tool (RAPT), a 6 question tool which scores patients into low, middle or high risk for extended inpatient rehabilitation [23].

Length of Stay (LOS) and minutes of care by the nursing staff (including all activities delivered to the patients, e.g. mobilization, washing, medication) are measured by LEP ${ }^{\circledR}$, which is a tool used for workload management in nursing [50]. Both measurements are taken at discharge in the acute care hospital. 


\section{Sample Size Calculation}

The sample size calculation is based on the primary endpoint - the Chair Stand Test. We assume that the mean difference in change over time between groups is 7.3 seconds (corresponding to means of 8.3 and 1.0, respectively) and the common within-group standard deviation is 7.3. This effect was selected based on pilot data of an uncontrolled trial in knee OA patients [24], assuming that our control group (without exercise training) would not improve over time while awaiting TKR. It is also assumed that the effect size is reasonable, in the sense that an effect of this magnitude could be anticipated in this field of research. Alpha has been set at 0.05 and the power has been set at 0.9. In each group 25 patients are needed.

Assuming a drop-out rate of $12 \%$, we will include 40 patients per group.

\section{ANALYSIS PLAN}

All analyses are based on intent-to-treat, including all randomized individuals who had at least 1 intervention session. We will use linear regression to evaluate the effect of our training program plus knee school against knee school alone for both the primary and secondary endpoints - after the training and at 3 months after surgery. The multivariate analyses for the primary endpoint (Chair Stand Test) and secondary endpoints (subscales pain and function of the KOOS) will control for baseline function of the respective endpoint, age in years, gender, and baseline body mass index. To account for the reduced exposure time to the training intervention for participants who were on a short waiting list or were less adherent we will perform subgroup analyses by training exposure groups (we will use the median as a cut-off for lower and higher intensity of the training program based on number of training sessions attended).

To evaluate a benefit of the training program on patient-reported pain and function across all time points, we will use repeated measures linear regression analyses controlling for baseline strength/function, time, age, gender, and body mass index.

Analyses will be conducted with $R$ version 2.14 .1 software. All $P$ values are twosided.

\section{DISCUSSION}

This randomized controlled trial will compare the effect of pre-operative neuromuscular training plus knee school with knee school alone on lower extremity function. The feasible training program tested aims to improve the activity-oriented outcome measures tested. The knee school serves both as an addition to the training as well as an attention control strategy in the control group. As an integral part of this trial, we assess adher- 
ence to the training intervention, which will allow per protocol analyses in addition to the primary intent-to-treat analyses.

$\mathrm{OA}$ is a key driver of disability at older age and is the fourth most common condition in older women and the eight most common in older men [6,51]. Given the demographic development with a rising segment of the senior population, and therefore improving functionality in individuals with $\mathrm{OA}$ is a public health target. Our trial aims to contribute important knowledge on whether to what extend a pre-operative training among patients on a waiting list for TKR will improve their functionality before and after surgery. The interest in the effect of pre-operative interventions has increased in the last decade, which is seen by the increasing number of publications. The evidence is up to now for different reasons moderate and a conclusive answer is not yet possible [12, 52].

Our trial will also contribute to evidence-based guidelines to help physicians and patients make informed decisions [53]. With respect to patient functional status, the major predictor of patient functional status postoperatively is pre-operative status [54]. It is therefore important to test the benefit of pre-operative training in patients undergoing TKR and our trial could contribute to a definition of pre-operative treatment recommendations or guidelines.

\section{Additional material}

Additional file: NEMEX-TJR training program with detailed description of the exercises.

\section{Competing interests}

The authors declare that they have no competing interests.

\section{Author's contributions}

$\mathrm{EOH}$ originated the idea of the study. $\mathrm{EOH}$ and HBF designed the trial protocol with assistance from EMR and RAB. EOH drafted the manuscript and the other authors revised it critically, corrected draft versions and approved the final manuscript.

\section{Acknowledgements}

The authors would like to acknowledge Eva Lundberg and Anne Link, Department of Health Sciences Lund University, Lund, Sweden for their support by the instruction of the physical therapists, who treat the participants in the intervention group.

The project is supported by the Albert Böni Stiftung, Zurich, Switzerland, a foundation for research in Rheumatology and Physical Medicine. 


\section{REFERENCES}

1. Arden N, Nevitt MC: Osteoarthritis: epidemiology. Best Pract Res Clin Rheumatol 2006, 20(1):3-25.

2. Harris WH, Sledge CB: Total hip and total knee replacement (2). N Engl J Med 1990, 323(12):801-807.

3. Guccione AA, Felson DT, Anderson JJ, Anthony JM, Zhang Y, Wilson PW, Kelly-Hayes M, Wolf PA, Kreger $B E$, Kannel WB: The effects of specific medical conditions on the functional limitations of elders in the Framingham Study. Am J Public Health 1994, 84(3):351-358.

4. Harris WH, Sledge CB: Total hip and total knee replacement (1). N Engl J Med 1990, 323(11):725-731.

5. Schweizerisches Gesundheitsobservatorium: Gesundheit in der Schweiz. Nationaler Gesundheitsbericht 2008. Bern; 2009.

6. Jordan KM, Arden NK, Doherty M, Bannwarth B, Bijlsma JW, Dieppe P, Gunther K, Hauselmann H, Herrero-Beaumont G, Kaklamanis $P$ et al: EULAR Recommendations 2003: an evidence based approach to the management of knee osteoarthritis: Report of a Task Force of the Standing Committee for International Clinical Studies Including Therapeutic Trials (ESCISIT). Ann Rheum Dis 2003, 62(12):1145-1155.

7. Zhang W, Nuki G, Moskowitz RW, Abramson S, Altman RD, Arden NK, Bierma-Zeinstra S, Brandt KD, Croft $P$, Doherty $M$ et al: OARSI recommendations for the management of hip and knee osteoarthritis: part III: Changes in evidence following systematic cumulative update of research published through January 2009. Osteoarthritis Cartilage 2010, 18(4):476-499.

8. Ethgen O, Bruyere O, Richy F, Dardennes C, Reginster JY: Health-related quality of life in total hip and total knee arthroplasty. A qualitative and systematic review of the literature. J Bone Joint Surg Am 2004, 86-A(5):963-974.

9. Bischoff-Ferrari HA, Lingard EA, Losina E, Baron JA, Roos EM, Phillips CB, Mahomed NN, Barrett J, Katz $\mathrm{JN}$ : Psychosocial and geriatric correlates of functional status after total hip replacement. Arthritis Rheum 2004, 51(5):829-835.

10. Nilsdotter AK, Petersson IF, Roos EM, Lohmander LS: Predictors of patient relevant outcome after total hip replacement for osteoarthritis: a prospective study. Ann Rheum Dis 2003, 62(10):923-930.

11. Karlson EW, Mandl LA, Aweh GN, Sangha O, Liang MH, Grodstein F: Total hip replacement due to osteoarthritis: the importance of age, obesity, and other modifiable risk factors. Am J Med 2003, 114(2):93-98.

12. Wallis JA, Taylor NF: Pre-operative interventions (non-surgical and non-pharmacological) for patients with hip or knee osteoarthritis awaiting joint replacement surgery--a systematic review and meta-analysis. Osteoarthritis Cartilage 2011, 19(12):1381-1395.

13. Coudeyre E, Jardin C, Givron P, Ribinik P, Revel M, Rannou F: Could preoperative rehabilitation modify postoperative outcomes after total hip and knee arthroplasty? Elaboration of French clinical practice guidelines. Ann Readapt Med Phys 2007, 50(3):189-197.

14. Ackerman IN, Bennell KL: Does pre-operative physiotherapy improve outcomes from lower limb joint replacement surgery? A systematic review. Aust J Physiother 2004, 50(1):25-30.

15. Dauty $M$, Genty $M$, Ribinik P: Physical training in rehabilitation programs before and after total hip and knee arthroplasty. Ann Readapt Med Phys 2007, 50(6):462-468, 455-461.

16. Weidenhielm L, Mattsson E, Brostrom LA, Wersall-Robertsson E: Effect of preoperative physiotherapy in unicompartmental prosthetic knee replacement. Scand J Rehabil Med 1993, 25(1):33-39.

17. D'Lima DD, Colwell CW, Jr., Morris BA, Hardwick ME, Kozin F: The effect of preoperative exercise on total knee replacement outcomes. Clin Orthop Relat Res 1996(326):174-182.

18. Rodgers JA, Garvin KL, Walker CW, Morford D, Urban J, Bedard J: Preoperative physical therapy in primary total knee arthroplasty. J Arthroplasty 1998, 13(4):414-421.

19. Rooks DS, Huang J, Bierbaum BE, Bolus SA, Rubano J, Connolly CE, Alpert S, Iversen MD, Katz JN: Effect of preoperative exercise on measures of functional status in men and women undergoing total hip and knee arthroplasty. Arthritis Rheum 2006, 55(5):700-708.

20. Hoogeboom TJ, Oosting E, Vriezekolk JE, Veenhof C, Siemonsma PC, de Bie RA, van den Ende CH, van Meeteren NL: Therapeutic validity and effectiveness of preoperative exercise on functional recovery after joint replacement: a systematic review and meta-analysis. PloS one 2012, 7(5):e38031. 
21. Boutron I, Moher D, Altman DG, Schulz KF, Ravaud P: Extending the CONSORT statement to randomized trials of nonpharmacologic treatment: explanation and elaboration. Ann Intern Med 2008, 148(4):295309.

22. Folstein MF, Folstein SE, McHugh PR: "Mini-mental state". A practical method for grading the cognitive state of patients for the clinician. J Psychiatr Res 1975, 12(3):189-198.

23. Oldmeadow LB, McBurney $H$, Robertson VJ: Predicting risk of extended inpatient rehabilitation after hip or knee arthroplasty. J Arthroplasty 2003, 18(6):775-779.

24. Ageberg E, Link A, Roos EM: Feasibility of neuromuscular training in patients with severe hip or knee OA: the individualized goal-based NEMEX-TJR training program. BMC Musculoskelet Disord 2010, 11:126.

25. Swiss Federal Office of Sports SFOoPH, Health Promotion Switzerland, Network HEPA Switzerland: Health Enhancing Physical Activity. A Base Document. Magglingen, 2006.

26. Klassbo M, Larsson G, Harms-Ringdahl K: Promising outcome of a hip school for patients with hip dysfunction. Arthritis Rheum 2003, 49(3):321-327.

27. Bohannon RW: Alternatives for measuring knee extension strength of the elderly at home. Clin Rehabil 1998, 12(5):434-440.

28. Bohannon RW: Sit-to-stand test for measuring performance of lower extremity muscles. Percept Mot Skills 1995, 80(1):163-166.

29. Lord SR, Murray SM, Chapman K, Munro B, Tiedemann A: Sit-to-stand performance depends on sensation, speed, balance, and psychological status in addition to strength in older people. J Gerontol A Biol Sci Med Sci 2002, 57(8):M539-543.

30. Whitney SL, Wrisley DM, Marchetti GF, Gee MA, Redfern MS, Furman JM: Clinical measurement of sit-tostand performance in people with balance disorders: validity of data for the Five-Times-Sit-to-Stand Test. Phys Ther 2005, 85(10):1034-1045.

31. Villadsen A, Roos EM, Overgaard S, Holsgaard-Larsen A: Agreement and reliability of functional performance and muscle power in patients with advanced osteoarthritis of the hip or knee. American journal of physical medicine \& rehabilitation / Association of Academic Physiatrists 2012, 91(5):401-410.

32. Guralnik JM, Ferrucci L, Simonsick EM, Salive ME, Wallace RB: Lower-extremity function in persons over the age of 70 years as a predictor of subsequent disability. N Engl J Med 1995, 332(9):556-561.

33. Collins NJ, Misra D, Felson DT, Crossley KM, Roos EM: Measures of knee function: International Knee Documentation Committee (IKDC) Subjective Knee Evaluation Form, Knee Injury and Osteoarthritis Outcome Score (KOOS), Knee Injury and Osteoarthritis Outcome Score Physical Function Short Form (KOOSPS), Knee Outcome Survey Activities of Daily Living Scale (KOS-ADL), Lysholm Knee Scoring Scale, Oxford Knee Score (OKS), Western Ontario and McMaster Universities Osteoarthritis Index (WOMAC), Activity Rating Scale (ARS), and Tegner Activity Score (TAS). Arthritis Care Res (Hoboken) 2011, 63 Suppl 11:S208228.

34. Roos EM: Effectiveness and practice variation of rehabilitation after joint replacement. Curr Opin Rheumatol 2003, 15(2):160-162.

35. Kessler S, Lang S, Puhl W, Stove J: [The Knee Injury and Osteoarthritis Outcome Score--a multifunctional questionnaire to measure outcome in knee arthroplasty]. Z Orthop Ihre Grenzgeb 2003, 141(3):277-282.

36. Stoll T, Huber E, Seifert B, Michel BA, Stucki G: Maximal isometric muscle strength: normative values and gender-specific relation to age. Clin Rheumatol 2000, 19(2):105-113.

37. Huber EO: Zuverlässigkeit und Normperzentilen einer neuen isometrischen Muskelkraftmessmethode. Physiotherapie 1997.

38. Hortobagyi T, Garry J, Holbert D, Devita P: Aberrations in the control of quadriceps muscle force in patients with knee osteoarthritis. Arthritis Rheum 2004, 51(4):562-569.

39. Roos EM, Bremander AB, Englund $M$, Lohmander LS: Change in self-reported outcomes and objective physical function over 7 years in middle-aged subjects with or at high risk of knee osteoarthritis. Ann Rheum Dis 2008, 67(4):505-510.

40. Lenssen AF, van Dam EM, Crijns YH, Verhey M, Geesink RJ, van den Brandt PA, de Bie RA: Reproducibility of goniometric measurement of the knee in the in-hospital phase following total knee arthroplasty. $B M C$ Musculoskelet Disord 2007, 8:83. 


\section{Chapter 3}

41. Faulkner KA, Redfern MS, Rosano C, Landsittel DP, Studenski SA, Cauley JA, Zmuda JM, Simonsick EM, Kritchevsky SB, Newman AB: Reciprocal influence of concurrent walking and cognitive testing on performance in older adults. Gait Posture 2006, 24(2):182-189.

42. Podsiadlo D, Richardson S: The timed "Up \& Go": a test of basic functional mobility for frail elderly persons. J Am Geriatr Soc 1991, 39(2):142-148.

43. Pitta F, Troosters T, Probst VS, Spruit MA, Decramer M, Gosselink R: Quantifying physical activity in daily life with questionnaires and motion sensors in COPD. Eur Respir J 2006, 27(5):1040-1055.

44. Holsgaard-Larsen A, Roos EM: Objectively measured physical activity in patients with end stage knee or hip osteoarthritis. Eur J Phys Rehabil Med 2012, 48(4):577-585.

45. Bischoff-Ferrari HA, Dietrich T, Orav EJ, Hu FB, Zhang Y, Karlson EW, Dawson-Hughes B: Higher 25hydroxyvitamin $D$ concentrations are associated with better lower-extremity function in both active and inactive persons aged > or $=60$ y. Am J Clin Nutr 2004, 80(3):752-758.

46. Nelson KM, Reiber G, Boyko EJ: Diet and exercise among adults with type 2 diabetes: findings from the third national health and nutrition examination survey (NHANES III). Diabetes Care 2002, 25(10):17221728.

47. Ware JE: Measuring patients' views: the optimum outcome measure. BMJ 1993, 306(6890):1429-1430.

48. Ware JE, Jr., Sherbourne CD: The MOS 36-item short-form health survey (SF-36). I. Conceptual framework and item selection. Med Care 1992, 30(6):473-483.

49. Rabin R, de Charro F: EQ-5D: a measure of health status from the EuroQol Group. Ann Med 2001, 33(5):337-343.

50. LEP - Leistungen sichtbar machen [http://www.lep.ch]

51. Zhang W, Doherty M, Peat G, Bierma-Zeinstra MA, Arden NK, Bresnihan B, Herrero-Beaumont G, Kirschner S, Leeb BF, Lohmander LS et al: EULAR evidence-based recommendations for the diagnosis of knee osteoarthritis. Ann Rheum Dis 2010, 69(3):483-489.

52. Gill SD, McBurney $\mathrm{H}$ : Does exercise reduce pain and improve physical function before hip or knee replacement surgery? A systematic review and meta-analysis of randomized controlled trials. Archives of Physical Medicine and Rehabilitation (0).

53. Westby MD: Exercise can improve the outcomes in hip and knee replacement surgery. The Rheumatologist 2008, 2.

54. Katz JN: Total joint replacement in osteoarthritis. Best Pract Res Clin Rheumatol 2006, 20(1):145-153. 


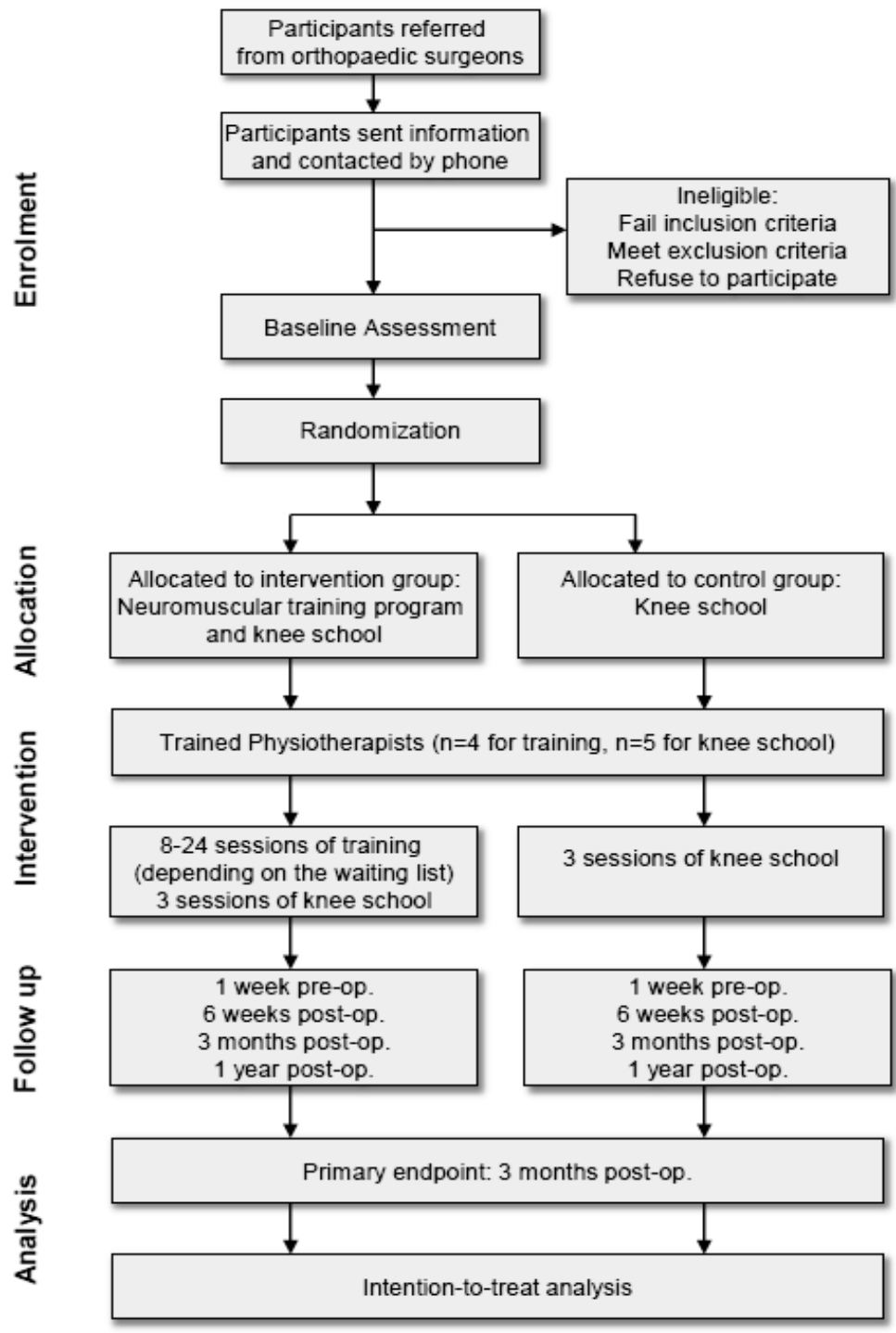

Figure 1 Flow chart of research design 


\section{Chapter 3}

\section{Additional file 1}

\section{NEMEX-TJR training program}

The NEuroMuscular Exercise training program for patients with knee or hip osteoarthritis (OA) assigned for total joint replacement (TJR), the NEMEX-TJR training program, is based on principles of neuromuscular training with the aim of improving sensorimotor control and achieving compensatory functional stability.

Training takes place in groups, under the supervision of an experienced physical therapist, and consists of three parts: warming up, a circuit program, and cooling down (described in detail below). A training session lasts 60 minutes. Patients continuously enter the group training, i.e., the group holds both novice patients and those who have participated in several training sessions and, thus, are more familiar with the training. The quality of the performance in each exercise with an appropriate position of the joints in relation to each other, i.e., with the hip, knee and foot well aligned, is emphasized (Figure 1).

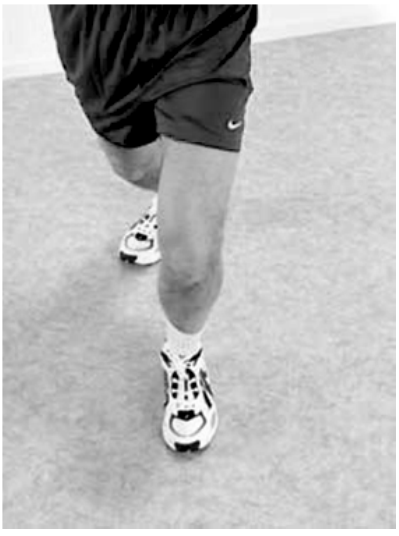

Figure 1A. "Knee-over-toe- position", i.e., joints in lower extremity well aligned with appropriate position in lower extremity not aligned; knee is inappropriately of knee over foot.

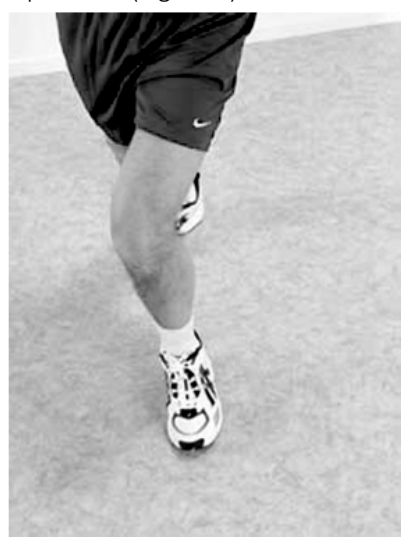

Figure 1B. "Knee-medial to- foot-position", i.e., joints placed medial to foot.

A visual analog scale (VAS) graded from 0 to 10 is used for monitoring pain during and after training, where 0 is "no pain" and 10 "pain as bad as it could be" (Figure 2) (Thomeé 1997). Self-reported pain up to 2 on the VAS is considered "safe", pain up to a level of 5 is considered "acceptable", and pain above 5 is considered "high risk". The day after training, pain should subside to "pain as usual" and not increase over time. "Pain as usual" is defined as the pain level prior to exercise.

$\begin{array}{lllll} & \text { Safe } & \text { Acceptable } & & \text { High risk } \\ 0 & 2 & 5 & 10\end{array}$

No pain

Pain as bad as it could be

Figure 2. VAS for monitoring pain during and after training (Thomeé 1997).

\section{Part 1. Warming up}

The warm-up period consists of ergometer cycling for 10 minutes (Figure 3). The work load is set individually, and can be increased during the 10 minutes, aiming at reaching a perceived exertion of "somewhat hard". 


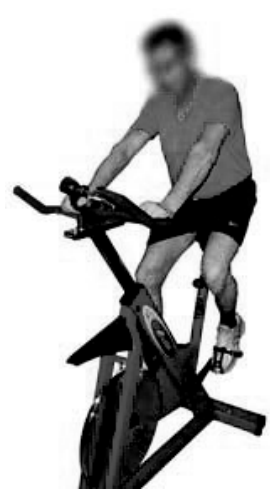

Figure 3. Warming up on a cycle ergometer.

\section{Part 2. Circuit program}

The circuit program comprises four exercise circles, with the key elements: core stability/postural function; postural orientation; lower extremity muscle strength; and functional exercises. Usually two exercises (A, B), sometimes one, are performed in each circle. Each exercise is performed 2-3 sets * 10-15 repetitions, with rest, corresponding to one set, between each set and exercise. Each patient is monitored individually, so that the exercises are performed at a training level according to their neuromuscular function. To allow for progression, three levels of difficulty are given for each exercise. Progression is provided by; varying the number of, direction, and velocity of the movements; increasing the load; and/or changing the support surface. Progression is made when an exercise is performed with good sensorimotor control and good quality of the performance (based on visual inspection by the physical therapist), and with minimal exertion and control of the movement (perceived by the patient). The exercises are performed with both the affected and the nonaffected leg, although focus is on the affected leg. Some exercises are performed in front of a mirror, in order to provide visual feedback of the performance.

\section{Exercise circle 1: Core stability/postural function}

This circle includes exercises with focus on core stability and postural function.

Level 1

Exercises

A. Pelvic-lift with flexed knees and short lever arm, putting load on both legs (Figure 4)

B. Sit-ups with flexed knees, both legs on ball, arms along the sides (short lever arm) (Figure 5).

Level 2

Exercises

A. Pelvic-lift with semi-flexed knees and long lever arm, putting load on both legs.

B. Sit-ups with flexed knees, both legs on ball, arms crossed over chest (medium lever arm).

Level 3

Exercises

A. Pelvic-lift as above, alternately putting load on the affected and non-affected legs.

B. Sit-ups with flexed knees, both legs on ball, hands behind neck (long lever arm). 


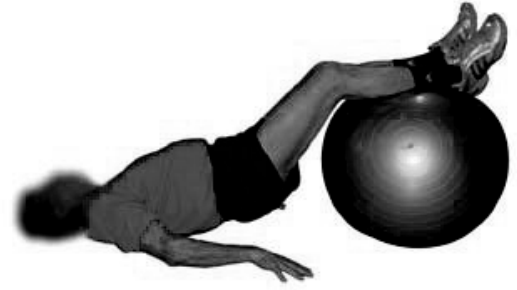

Figure 4. Pelvic-lift, level 1.

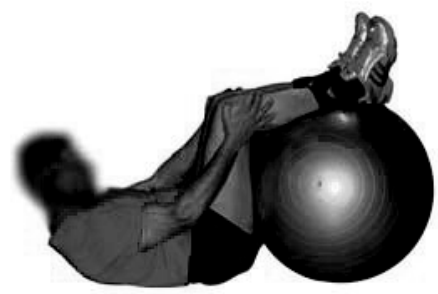

Figure 5. Sit-ups, level 1

\section{Exercise circle 2: Postural orientation}

This circle includes exercises with emphasis on an appropriate position of the joints in relation to each other (postural orientation), i.e., with the hip, knee and foot joints well aligned (Figure 1).

\section{Level 1}

Exercises

A. Slide-exercise forward-backward: Standing, weight-bearing on one leg, other leg on sliding surface. Slide backwards - forwards with "sliding leg", while flexing - extending the knee of the weight-bearing leg and keeping an appropriate position of the joints in relation to each other (Figure 6).

B. Slide-exercise sideways: Standing, weight-bearing on one leg, other leg on sliding surface. Slide sideways with "sliding leg", while flexing - extending the knee of the weight-bearing leg and keeping an appropriate position of the joints in relation to each other.

Level 2

Exercises

A. Slide-exercise forwards - backwards: as above, standing on uneven surface (e.g., foam pillow or thick mattress).

B. Slide-exercise sideways: as above, standing on uneven surface (Figure 7).

Level 3

Exercises

A. Forward lunge: Standing position, take a large step forward and then return. Hand support for balance if needed (Figure 8).

B. Sideway lunge: Standing position, take a large step sideways and then return. Hand support for balance if needed.
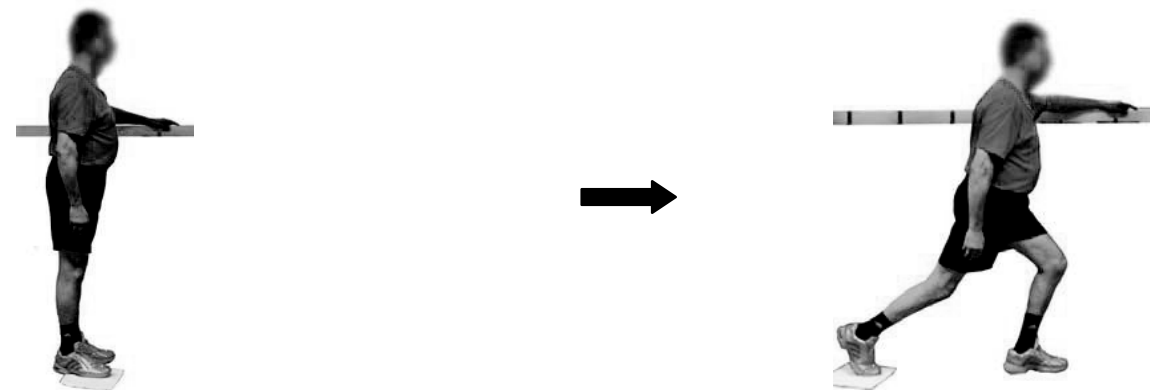

Figure 6. Slide-exercise backward-forward, level 1. 


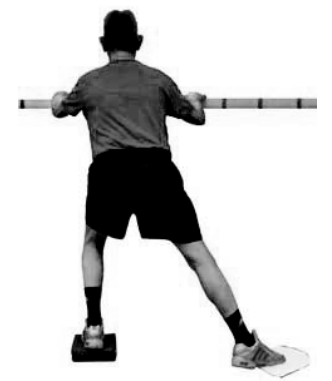

Figure 7. Slide-exercise sideways, level 2.
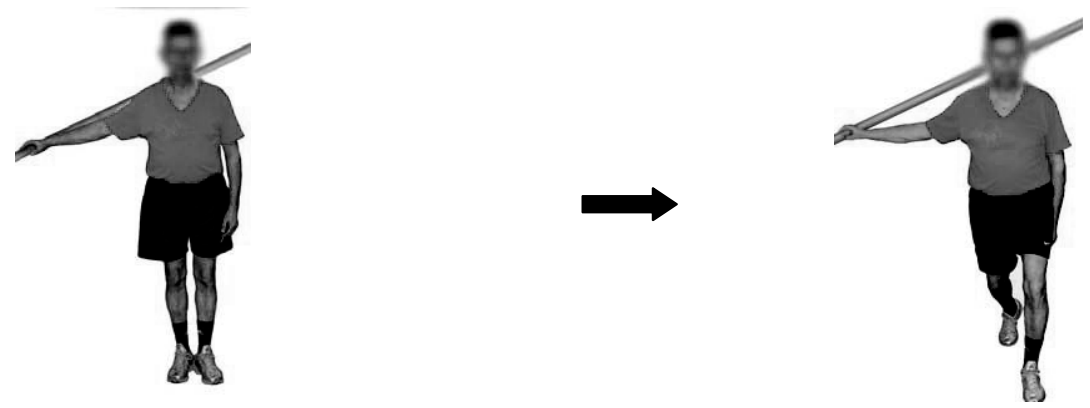

Figure 8. Forward lunge, level 3.

\section{Exercise circle 3: Lower extremity muscle strength}

This circle includes exercises in open and closed kinetic chains to improve strength of hip and knee muscles.

Level 1

Exercises

A. Hip abductors/hip adductors: Standing on one leg, rubber band other leg. Pull rubber band out (hip abductors) and in (hip adductors). Make sure there is tension in the rubber band also in resting position. Focus is on the hip abductors of the standing leg, keeping an appropriate position of the joints in the lower extremity in relation to each other (Figure 1) and in relation to the trunk, i.e., without lateral displacement of the hip-pelvis region.

B. Knee extensors/knee flexors: Sitting position. Rubber band around one foot. Pull rubber band forward (knee extensors) and backwards (knee flexors). Make sure there is tension in the rubber band also in resting position.

Level 2

Exercises

A. Hip abductors/hip adductors: As above, rubber band with increasing resistance (Figure 9).

B. Knee extensors/knee flexors: As above, rubber band with increasing resistance (Figures 10-11).

Level 3

Exercises 


\section{Chapter 3}

A. Hip abductors/hip adductors: As above, standing on uneven surface (e.g., foam pillow or thick mattress).

B. Knee extensors/knee flexors: As above, rubber band with increasing resistance.

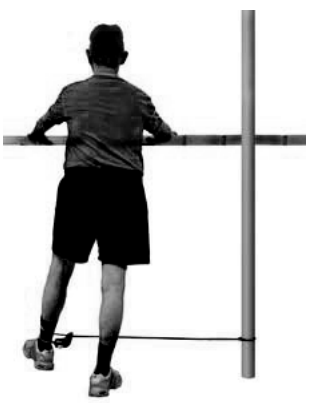

Figure 9. Hip abductors, level 2.

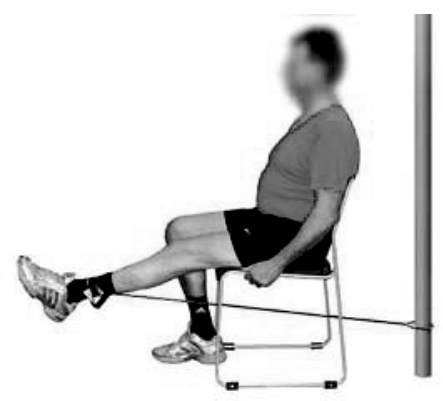

Figure 10. Knee extensors, level 2.

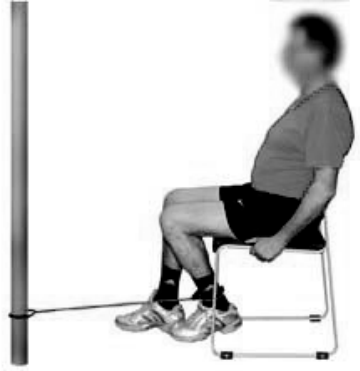

Figure 11. Knee flexors, level 2.

\section{Exercise circle 4: Functional exercises}

This circle includes exercises resembling activities of daily life.

Level 1

Exercises

A. Chair stands: Start in a seated position, feet parallel, putting load on both legs, slight hand support for balance

B. Stair climbing: Step-up (concentric muscle activation) and step-down (eccentric muscle activation) on low step-board, with or without slight hand support for balance.

Level 2

Exercises

A. Chair stands: Start in a seated position, feet parallel, putting load on both legs, without hand support (Figure 12).

B. Stair climbing: Step-up and step-down on medium high step-board, with or without bar bells.

Level 3

Exercises

A. Chair stands: Start in a seated position, one foot in front of the other, with or without slight hand support for balance (Figure 13).

B. Stair climbing: Step-up and step-down on high step-board, with or without bar bells(Figure 14). 


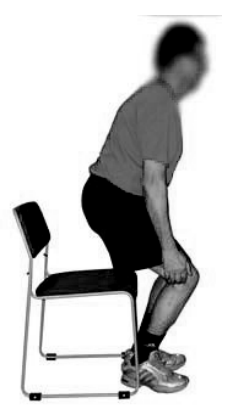

Figure 12. Chair stands, level 2.

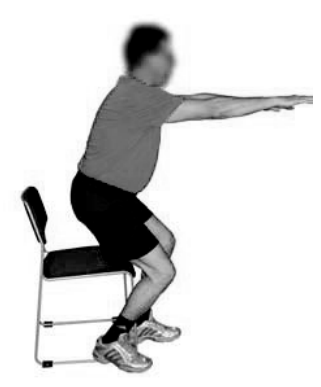

Figure 13. Chair stands, level 3.

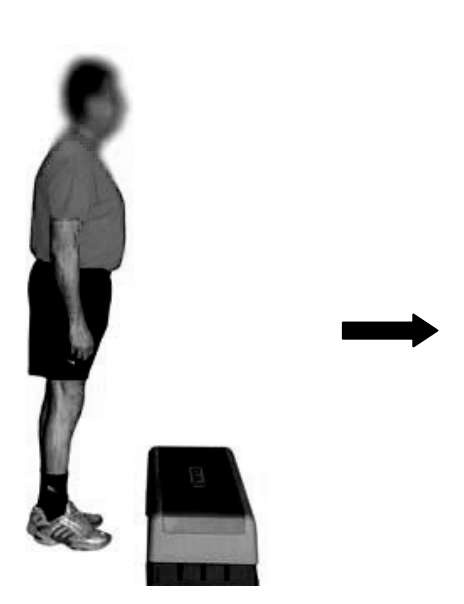

Figure 14. Stair climbing, level 3

\section{Figure 13. Chair stands, level 3.}
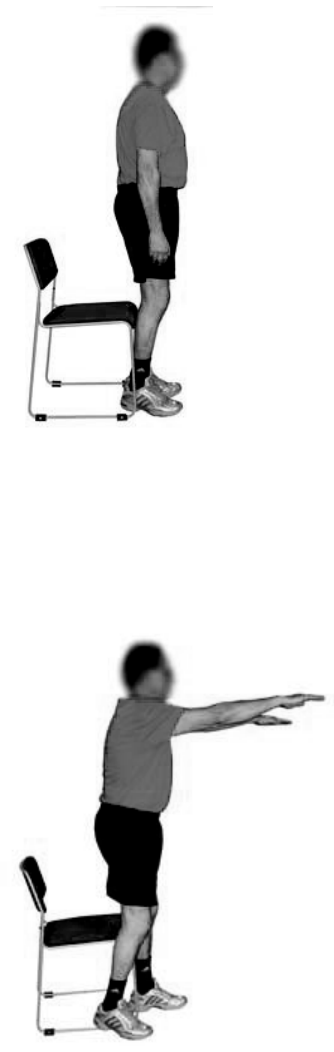
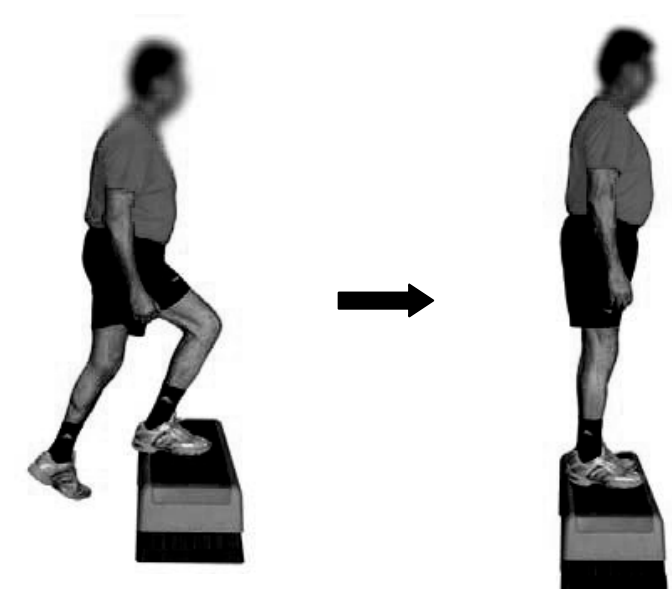


\section{Chapter 3}

\section{Part 3. Cooling down}

The cooling down part consists of walking exercises forward and backwards, about 10 meters in each direction, in front of mirror (Figure 15), mobility exercises for the lower extremities (Figure 16) and stretching exercises for the lower extremity muscles for a total of about 10 minutes.

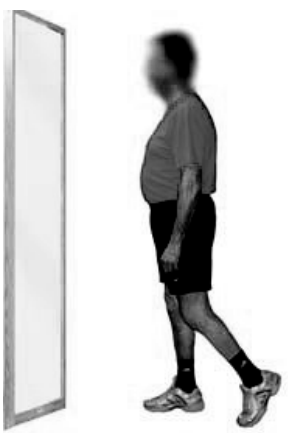

Figure 15. Walking forwards and backwards, about 10 meters in each direction, in front of mirror
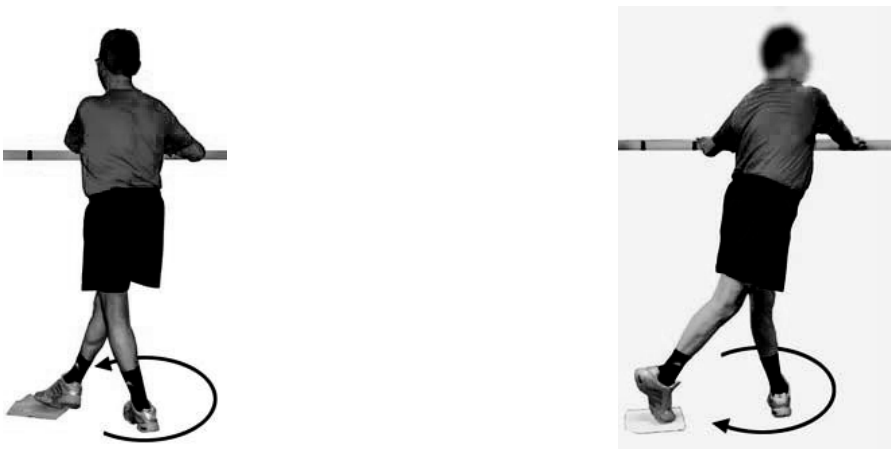

Figure 16. Mobility exercise, hip rotation during loading. Note: This mobility exercise is used for patients with hip OA, but not for patients with knee OA (because of pain and a feeling of functional instability when performing the exercise). 


\section{CHAPTER 4}

\section{Effect of preoperative neuromuscular training}

(NEMEX-TJR) on functional outcome after total knee replacement: An assessor-blinded randomized controlled trial 


\section{ABSTRACT}

\section{Background}

Improving functional status preoperatively through exercise may improve postoperative outcome. Previous knowledge on preoperative exercise in knee osteoarthritis is insufficient. The aim of the study was to compare the difference in change between groups in lower extremity function from baseline to 3 months after Total Knee Replacement (TKR) following a neuromuscular exercise programme (NEMEX-TJR) plus a knee school educational package (KS) or KS alone.

\section{Methods}

45 patients (55-83 years, 53\% male, waiting for TKR) were randomized to receive a minimum of 8 sessions of NEMEX-TJR plus 3 sessions of KS or 3 sessions of KS alone. Function was assessed with the Chair Stand Test (CST, primary endpoint) and the Knee Injury and Osteoarthritis Outcome Score (KOOS) subscales focusing on daily living function (ADL) and pain (secondary endpoints). Assessments were performed immediately before and after the intervention, and at 6 weeks, 3 months and 12 months after surgery by a physiotherapist, blinded to group allocation.

\section{Results}

After intervention but before surgery we observed a small improvement for all primary and secondary endpoints in both groups, which did not differ significantly between groups: comparing the exercise to the control group the treatment effect for the CST was -1.5 seconds $(95 \% \mathrm{Cl}:-5.3,2.2)$, for KOOS ADL and KOOS pain the treatment effect was 1.3 points $(-10.1,12.8)$ and $-2.3(-12.4,7.9)$ respectively. At 3 months after surgery we observed a small improvement in the primary endpoint in the control group and a significant improvement in the secondary endpoints in both exercise and control groups, which did not differ significantly between groups: comparing the exercise group to the control group the treatment effect in the Chair Stand Test was 2.0 points $(-1.8$, $5.8)$, for KOOS ADL and KOOS pain the treatment effect was -4.9 points $(-16.3,6.5)$ and 3.3 points $(-13.5,6.8)$ respectively.

\section{Conclusions}

A median (IQR) of $10(8,14)$ exercise sessions before surgery showed an additional small but non-significant improvement in all functional assessments compared to patient education alone. These benefits were not sustained after TKR. Our trial does not give a conclusive answer to whether additional preoperative exercise on postoperative functional outcomes is beneficial.

\section{Keywords}

Osteoarthritis, Total Knee Replacement, Total Knee Arthroplasty, preoperative exercise, preoperative training, NEMEX-TJR 


\section{BACKGROUND}

Osteoarthritis $(\mathrm{OA})$ is the second most common diagnosis made in older adults seeking medical care [1] and the leading cause of disability at older age [2]. For sufferers from severe knee OA, Total Knee Replacement (TKR) is the preferred treatment option to significantly improve function and pain [3, 4]. Given the growing segment of the senior population in the Western World, the rate of these procedures will rise exponentially over the next decade. This will result in high health-care expenditures, due to an absolute increase in TKR surgery [5].

Most patients undergoing TKR experience pain-relief [6, 7], but up to $30 \%$ of patients continue to have significant pain and functional problems after TKR [8-12]. These continuing problems might be addressed through, (a) fostering postoperative functional recovery by offering a preoperative exercise program to optimize the preoperative functional status of patients awaiting TKR [13] and (b) modifying patients' expectations by offering an educational program before surgery [14].

The most recent review and meta-analysis on preoperative exercise on functional recovery after joint replacement was published in 2012 and included 12 trials [15]. The authors concluded that "preoperative therapeutic exercise for total joint replacement did not demonstrate beneficial effects on postoperative functional recovery. However, poor therapeutic validity of the therapeutic exercise programs may have hampered potentially beneficial effects".

Exercise programs should include mixed activities, including aerobic, strength and proprioceptive exercises [16]. Sensorimotor deficiencies, in terms of lower limb muscle weakness and altered muscle activation patterns, should be addressed specifically [17]. A well-described exercise programme that addresses these deficiencies, and previously found to be feasible in OA patients waitlisted for TKR, is the neuromuscular exercise programme-total joint replacement (NEMEX-TJR) [18].

Alternatively, patients may have to be better informed and take more responsibility for their care and need to be prepared for both the surgical procedure and the recovery period in advance [19]. An educational program during the waiting period for TKR may help patients to prepare themselves for their rehabilitation after surgery [20] and modify patients' preoperative expectations [14].

\section{Objectives}

To study the effect of a preoperative neuromuscular training (NEMEX-TJR) plus knee school educational program (KS) compared to the KS alone on lower extremity function and pain in individuals aged 55-90 years on a waiting list for TKR due to severe knee OA. 


\section{Hypothesis}

Primary endpoint: we hypothesize that patients undergoing the NEMEX-TJR in addition to the KS will be quicker in performing the Chair Stand Test (performance test of lower extremity function) compared with those receiving the KS alone, both when measured immediately after the intervention and 3 months after TKR surgery.

Secondary endpoints: we hypothesize that patients undergoing the NEMEX-TJR in addition to the KS will have a greater improvement in the patient-reported outcome (PRO) measure KOOS (subscales ADL function and pain) compared with those receiving the KS alone, both when measured immediately after the intervention as well as 6 weeks, 3 months and 1 year after TKR surgery.

\section{METHODS}

\section{Study design}

The study design was an assessor-blinded randomized controlled trial. Outcomes were measured at baseline (6-12 weeks preoperative), 1 week preoperative, 6 weeks postoperative, 3 months postoperative and 12 months postoperative, with the primary endpoint being 3 months postoperative. Ethical approval was granted by the Ethics Committee of the Cantons Aargau and Solothurn, Switzerland, approval number 2009/12 and the trial is registered with ClinicalTrials.gov, identifier: NCT00913575.

\section{Participants and randomization}

Participants were eligible when: they were on a waiting list for primary TKR at the Cantonal Hospital Olten or the Cantonal Hospital Aarau and sufficient time existed before the operation date in order to take at minimum 8 sessions of the training programme, aged 55 to 90 years; understood German; and lived at home. Originally it was planned to only include patients aged 60 and above. However, during the recruitment phase the age was lowered to 55 to increase the number of participants. The Ethics Committee accepted an amendment under the same approval number. Exclusion criteria were: revision surgery; history of inflammatory arthritis; cognitive impairments; absence before or after surgery; and inability to walk at least 3 meters with or without a walking aid. Although our last exclusion criteria defined a low threshold for functionality to be enrolled in the trial, none of the study participants was unable to perform the lower extremity tests defined in the protocol. Recruitment and eligibility assessment were conducted by the orthopedic surgeon at the time the patient was placed on the waiting list. Eligible patients were referred to the study center (Centre on Aging and Mobility, University of Zurich) by fax. After confirming their interest, eligible individuals received 
detailed participant information about the study procedure. Informed written consent was obtained on the day of baseline assessment.

Allocation was concealed and conducted by a study nurse of the independent randomization center after baseline assessment. Participants were randomized using block allocation with a block size of four from a computer generated list. Allocation to the intervention or control group was performed by telephone.

\section{Surgical and rehabilitation procedure}

All operations were performed by four senior orthopedic surgeons, using a standard anterior skin incision followed by medial parapatellar arthrotomy, in an effort to minimize disruption in the medial lymphatic and saphenous nerve branches. The implants used were all a posterior cruciate ligament-retaining system performed in a femur first technique with measured femoral sizing and rotation. The implants were fully cemented using a second generation sandwich technique.

The post-surgical rehabilitation process followed an individualized treatment plan. In the acute care hospital, physiotherapy treatments aimed to improve passive and active range of motion, to reduce swelling and to improve walking capacity with canes. Patients were discharged after 7-10 days. The post-acute rehabilitation took place either in an outpatient physiotherapy practice (ranging from 9-18 treatment sessions) or in an inpatient rehabilitation clinic (on average 2-3 weeks, corresponding to 10-15 treatment days with at least two treatment sessions per day). At both sites treatments aimed to improve active range of motion, muscle strength and activities of daily living, such as walking capacity and climbing stairs.

\section{Interventions}

Patients of the intervention group attended knee school preoperatively (starting about 4 weeks before surgery) and a neuromuscular training program (for 4-12 weeks, depending on their location on the waiting list for surgery). Patients of the control group attended only the three sessions of knee school.

The neuromuscular training followed the principles of neuromuscular and biomechanical training as described in the neuromuscular training method (neuromuscular exercise programme-total joint replacement, NEMEX-TJR) [18]. The programme is feasible in patients with severe hip or knee OA, in terms of safe self-reported pain following training, decreased or unchanged pain during the training period, few joint-specific adverse events, and achieved progression of training level during the training period. In a controlled before-and-after study NEMEX-TJR (mean 12 weeks (SD 5.6) of training) improved self-reported outcomes (7-20\%) and physical function $(5-19 \%)(p<0.005)$ [21]. Between $39 \%$ and $61 \%$ of knee patients displayed a clinically meaningful improvement $(\geq 15 \%)$ in KOOS subscales through the training. 
The training took place in groups under the supervision of an experienced, speciallytrained physiotherapist and consisted of a 10-minute aerobic warm-up on a stationary exercise bike, followed by a four-exercise circuit programme, and finishing with a cool down period of about 10 minutes.

The key elements of the circuit programme were stability/postural function, functional alignment, lower-extremity muscle strength and functional exercises. Each exercise was performed for 10-15 repetitions and for 2-3 cycles, with rest between each exercise and cycle. To allow progression, three levels of difficulty were defined. Progression was provided by varying the number, direction and velocity of the movements, by increasing the load and/or by changing the support surface. Progression was made when an exercise could be performed with 15 repetitions and 3 cycles with good neuromuscular control and good quality of performance (based on visual inspection by the physiotherapist) and with minimal exertion and control of the movement (perceived by the patient). Training programme documentation included the number of training sessions, level of difficulty per session, pain on a 0 to 10 scale before and after each session and 24 hours after each session.

The knee school was taught by an experienced and specially-trained physiotherapist over 3 individual or group sessions, one session per week, starting about 4 weeks before the operation. Knee school sessions were separately organized for participants of the intervention group and those of the control group to avoid contamination. The content of the knee school included information on anatomy of the knee joint and adjacent functional structures, recommended activities with prosthesis and post-operative pain management, and details on the post-operative rehabilitation phase. Didactical elements included models of the knee joint and the lower extremity, working sheets, photos and videos, hand-outs, PowerPoint presentations and peer discussions.

A description of the intervention has been published previously, where the details of the programme are described in the additional file [22]

\section{Assessment}

Outcomes were measured at baseline (6-12 weeks preoperative, all measures), 1 week preoperative (after the intervention, all measures), 6 weeks postoperative (PROs only), 3 months postoperative (all measures) and 1 year postoperative (PROs only). A special clinical examination room with standardized equipment was used to perform all the measures at all time-points at both sites. Two experienced physiotherapists (assessors), not working at the recruitment sites and not involved in the neuromuscular training and the knee school, had been specifically trained for the assessments in this study and were blinded to group allocation. Participants were instructed not to mention the allocation. 


\section{Outcomes}

The effect of the intervention on lower extremity function was evaluated by performance tests and by PRO measures. In the trial registration we chose as primary endpoints the Chair Stand Test and the KOOS subscales ADL and pain. During the recruitment phase we made adaptions in our endpoints for clearer interpretability, keeping only the Chair Stand Test as primary endpoint. The KOOS subscales became secondary endpoint and all other measures became additional outcome measures.

\section{Primary outcome measure}

The primary outcome is the Chair Stand Test, also known as the repeated sit-to-stand test. It is commonly used as a measure of lower extremity strength, balance and reaction time [23-25]. The time required for five repetitions of rising from a chair and sitting down again was performed according to the OsteoArthritis Initiative manual, including detailed standardization and instructions (available from: http//:oai.epi-ucsf.org). Patients sat on a standard chair without armrests. Feet were placed comfortably on the floor with knees flexed slightly greater than 90 degrees. Patients were asked to stand up to a fully erected standing position five times as quickly as possible without using their hands (arm folded across the chest). Timing with a stopwatch started on "go" (after a countdown form 3) and ended on the fifth stand. After an exercise phase, the test was performed once. The Chair Stand Test is easy to perform in clinical practice and has shown excellent intra- and inter-rater reliability (ICC, 0.89) in patients with severe hip or knee OA [26]. The Chair Stand Test was also found to predict disability across populations accurately [27].

\section{Secondary outcome measure}

Secondary outcomes are knee pain and function, assessed by the KOOS questionnaire. The KOOS is a commonly used patient-reported outcome with overall acceptable psychometric properties to evaluate patients with knee injury and knee OA [28], including those having TKR [29]. KOOS contains 5 subscales with a total of 42 items: 1) pain; 2) other symptoms; 3) function in daily living (ADL); 4) function in sport and recreation (Sport/Rec); and 5) knee-related quality of life (QOL). Each question receives a score from 0 to 4 and the scores are transformed to a 0 to 100 score $(0=$ extreme symptoms, $100=$ no symptoms). Since exercise training is aiming to improve function, we are particularly interested in the KOOS ADL subscale for the functional outcome measure.

The German version of the KOOS is used in this trial [30]. The User's Guide, including scoring instructions, are available from http://www.koos.nu. 


\section{Additional outcome measures}

Lower limb function:

KOOS subscales other symptoms, Sport/Rec and QOL, assessed by the KOOS questionnaire [30]. Isometric muscle strength of knee flexors and extensors, measured with a hand-held pull gauge [31, 32].The ability to alternate rapidly between concentric and eccentric work of the extensor muscles of the hip and knee is impaired in many patients with knee OA [33]. The ability of rapid alternation between concentric and eccentric function is measured using maximal number of knee-bending in 30 seconds, which is a valid and reliable test (ICC, 0.96) $[18,34]$. Range of Motion is measured with a long-arm goniometer [35]. Walking speed is assessed with the $20 \mathrm{~m}$ walk test (ICC, 0.93) [26], a reliable modification of the short walk test used in many epidemiological and clinical studies. The test measures the time it takes to walk 20 meters at the participant's usual walking pace, along with the number of steps that they take to walk 20 meters [36]. Lower extremity mobility is further assessed with the Timed Up and Go test, which requires a person to rise from a standard stair, walk to a line that is 3 meters away, turn 180 degrees, return to the chair and sit down [37].

Physical activity and health-related quality of life:

Physical activity is measured by the SenseWear armband, a device for quantifying physical activity in daily life [38, 39]. It collects the following data: energy expenditure, average MET's, physical activity duration, steps per day and the physical activity distribution (sedentary, moderate, vigorous and very vigorous). In addition, physical activity is measured by 10 activity questions in NHANES III [40], from which MET values can be calculated [41]. Health-related quality of life is measured by the generic questionnaire SF-36 [42, 43]. General health status is measured by the EuroQoL (EQ-5D, including EQVAS). The EQ-5D is used to complement the SF-36, allowing health economic evaluation and comparison to other knee OA populations [44].

\section{Sample size calculation}

The sample size calculation is based on the primary endpoint - the Chair Stand Test. We assume that the mean difference in change over time between groups is 7.3 seconds (corresponding to means of 8.3 and 1.0, respectively) and the common within-group standard deviation is 7.3. This effect was selected based on pilot data of an uncontrolled trial in knee OA patients, assuming that our control group (without exercise training) would not improve over time while awaiting TKR. It is also assumed that the effect size is reasonable, in the sense that an effect of this magnitude could be anticipated in this field of research. Alpha has been set at 0.05 and the power has been set at 0.9. In each group 25 patients are needed. Assuming a drop-out rate of $12 \%$, we will include 40 patients per group. 


\section{Statistical analysis}

The data for primary, secondary and additional outcomes were analyzed according to the intention-to-treat principle, including all randomized individuals. Descriptive statistics were evaluated for patient characteristics. For baseline between-group comparisons, we performed the Wilcoxon-RankSum Test for continuous and the Chi squared test for categorical variables.

For each outcome, we fitted a linear mixed model (LMM) to the data with time, group and group-time interaction as fixed effects and subject as a random intercept. In a primary analysis we adjusted for gender, BMI and age. Random intercept models are equivalent to repeated measures ANOVA and take into account the correlation between repeated measurements. In contrast to classical repeated measures ANOVA, they can deal better with missing observations while retaining power. For the details of the model see Additional file 1.

Our primary interest was in the treatment effects, which are equivalent to the group-time interactions. Likelihood ratio tests for nested models were performed for model selection. We controlled for the potential confounding factors and tested whether age, gender or BMI could be removed from the model. Specific contrasts such as within-group changes and group-time interactions between specific time points were estimated. All simultaneous inference procedures controlled the family-wise error rate $\alpha=0.05$. Residual analysis was performed to check model assumptions.

All analyses were conducted with $R$ version 2.14 .1 software $[45,46]$.

\section{RESULTS}

From May 2009 to June 2012 a total of 72 patients were eligible, of those 27 declined participation and 45 patients were assessed and randomized to the two groups. The 22 patients in the exercise group and the 23 patients in the control group were comparable with respect to age, gender, BMI, time to surgery and baseline assessments without significant differences in any of the baseline characteristics outlined in table 1.

Figure 1 shows the flow diagram of patients participating in this study.

Table 1: Baseline characteristics of study participants

\begin{tabular}{llll}
\hline & Intervention group $(\mathrm{n}=22)$ & Control group $(\mathrm{n}=23)$ & $p$-value \\
\hline Age - years & $68.8 \pm 8.0$ & $71.9 \pm 8.1$ & 0.198 \\
Females (\%) & $11(50)$ & $10(43.5)$ & 0.889 \\
$\mathrm{BMI}-\mathrm{kg} / \mathrm{m}^{2}$ & $30.8 \pm 4.9$ & $29.9 \pm 5.5$ & 0.507 \\
Time to surgery - weeks & $8.9 \pm 3.6$ & $8.5 \pm 3.0$ & 0.790 \\
Primary and secondary outcome measures & & \\
Chair Stand Test & $16.3 \pm 8.3$ & $16.0 \pm 4.7$ & 0.581 \\
KOOS pain & $48.1 \pm 17.6$ & $47.3 \pm 16.8$ & 0.864 \\
KOOS ADL & $51.7 \pm 17.8$ & $49.9 \pm 19.1$ & 0.716 \\
\hline
\end{tabular}




\begin{tabular}{|c|c|c|c|}
\hline & Intervention group $(\mathrm{n}=22)$ & Control group $(n=23)$ & $p$-value \\
\hline \multicolumn{4}{|l|}{ Additional outcome measures } \\
\hline KOOS symptoms & $47.4 \pm 13.5$ & $49.1 \pm 15.1$ & 0.982 \\
\hline KOOS sport and recreation & $18.3 \pm 17.5$ & $16.9 \pm 17.6$ & 0.680 \\
\hline KOOS quality of life & $26.4 \pm 14.5$ & $26.8 \pm 15.3$ & 0.900 \\
\hline \multicolumn{4}{|l|}{ Muscle strength } \\
\hline Knee extension op & $244.8 \pm 91.7$ & $247.6 \pm 100.5$ & 1.000 \\
\hline Knee extension contra & $285.0 \pm 97.8$ & $315.4 \pm 123.1$ & 0.386 \\
\hline Knee flexion op & $165.4 \pm 61.9$ & $151.9 \pm 53.8$ & 0.447 \\
\hline Knee flexion contra & $176.6 \pm 65.6$ & $185.4 \pm 66.9$ & 0.525 \\
\hline Knee-bendings/30s & $13.1 \pm 3.9$ & $11.4 \pm 5.5$ & 0.406 \\
\hline \multicolumn{4}{|l|}{ ROM of the knee } \\
\hline Flexion op & $115.7 \pm 11.5$ & $115.0 \pm 12.0$ & 0.748 \\
\hline Flexion contra & $119.5 \pm 8.0$ & $122.9 \pm 11.5$ & 0.219 \\
\hline Extension op & $6.6 \pm 4.7$ & $6.7 \pm 4.4$ & 0.708 \\
\hline Extension contra & $1.6 \pm 2.8$ & $3.0 \pm 3.9$ & 0.203 \\
\hline $20 \mathrm{~m}$ walk test & $17.6 \pm 2.9$ & $17.9 \pm 4.8$ & 0.658 \\
\hline Timed up and go & $9.7 \pm 2.4$ & $11.5 \pm 7.2$ & 0.329 \\
\hline \multicolumn{4}{|l|}{ Physical activity level } \\
\hline METs (kcal/h/kg) & $28.5 \pm 4.5$ & $29.3 \pm 4.5$ & 0.617 \\
\hline Steps (daily average) & $6158.7 \pm 3317.4$ & $6145.0 \pm 2810.9$ & 0.967 \\
\hline Adapted NHANES III METs & $24.4 \pm 23.6$ & $21.2 \pm 29.0$ & 0.244 \\
\hline \multicolumn{4}{|l|}{ SF 36} \\
\hline Physical functioning & $43.4 \pm 17.5$ & $44.1 \pm 19.1$ & 0.906 \\
\hline Role physical & $43.2 \pm 45.8$ & $35.2 \pm 44.8$ & 0.575 \\
\hline Bodily pain & $41.9 \pm 15.5$ & $43.7 \pm 14.3$ & 0.706 \\
\hline General health & $62.6 \pm 15.2$ & $64.4 \pm 17.4$ & 0.467 \\
\hline Vitality & $57.1 \pm 20.3$ & $52.3 \pm 19.4$ & 0.723 \\
\hline Social functioning & $87.5 \pm 18.1$ & $83.5 \pm 22.6$ & 0.580 \\
\hline Role emotional & $77.3 \pm 40.4$ & $62.1 \pm 47.5$ & 0.305 \\
\hline Mental health & $79.5 \pm 14.2$ & $73.6 \pm 16.6$ & 0.215 \\
\hline \multicolumn{4}{|l|}{$E Q-5 D$} \\
\hline Mobility & $1.7 \pm 0.5$ & $1.7 \pm 0.5$ & 0.755 \\
\hline Self-care & $1.0 \pm 0.0$ & $1.1 \pm 0.4$ & 0.081 \\
\hline Usual Activities & $1.4 \pm 0.5$ & $1.3 \pm 0.5$ & 0.764 \\
\hline Pain/discomfort & $2.1 \pm 0.4$ & $2.0 \pm 0.2$ & 0.335 \\
\hline Anxiety/Depression & $1.2 \pm 0.4$ & $1.2 \pm 0.4$ & 0.724 \\
\hline EQ-VAS & $64.6 \pm 18.2$ & $67.7 \pm 16.0$ & 0.684 \\
\hline RAPT & $9.4 \pm 1.5$ & $9.4 \pm 1.4$ & 0.298 \\
\hline
\end{tabular}

Values are the mean \pm SD for continuous variables (Wilcoxon Rank Sum test) and the number (percentage) for categorical variables (Chi-square test). There were no significant between group differences for all variables. Legend:

BMI, body mass index; op, operated leg; contra, contralateral leg; ROM, range of motion; MET, metabolic equivalent task; KOOS, Knee Injury and Osteoarthritis Outcome Score; NHANES, National Health And Nutrition Examination Survey; SF 36, Short Form-36 health survey; EQ-5D, EuroQol - 5 dimensions; EQ-VAS, EuroQol Visual Analog Scale; RAPT, Risk Assessment and Prediction Tool. 


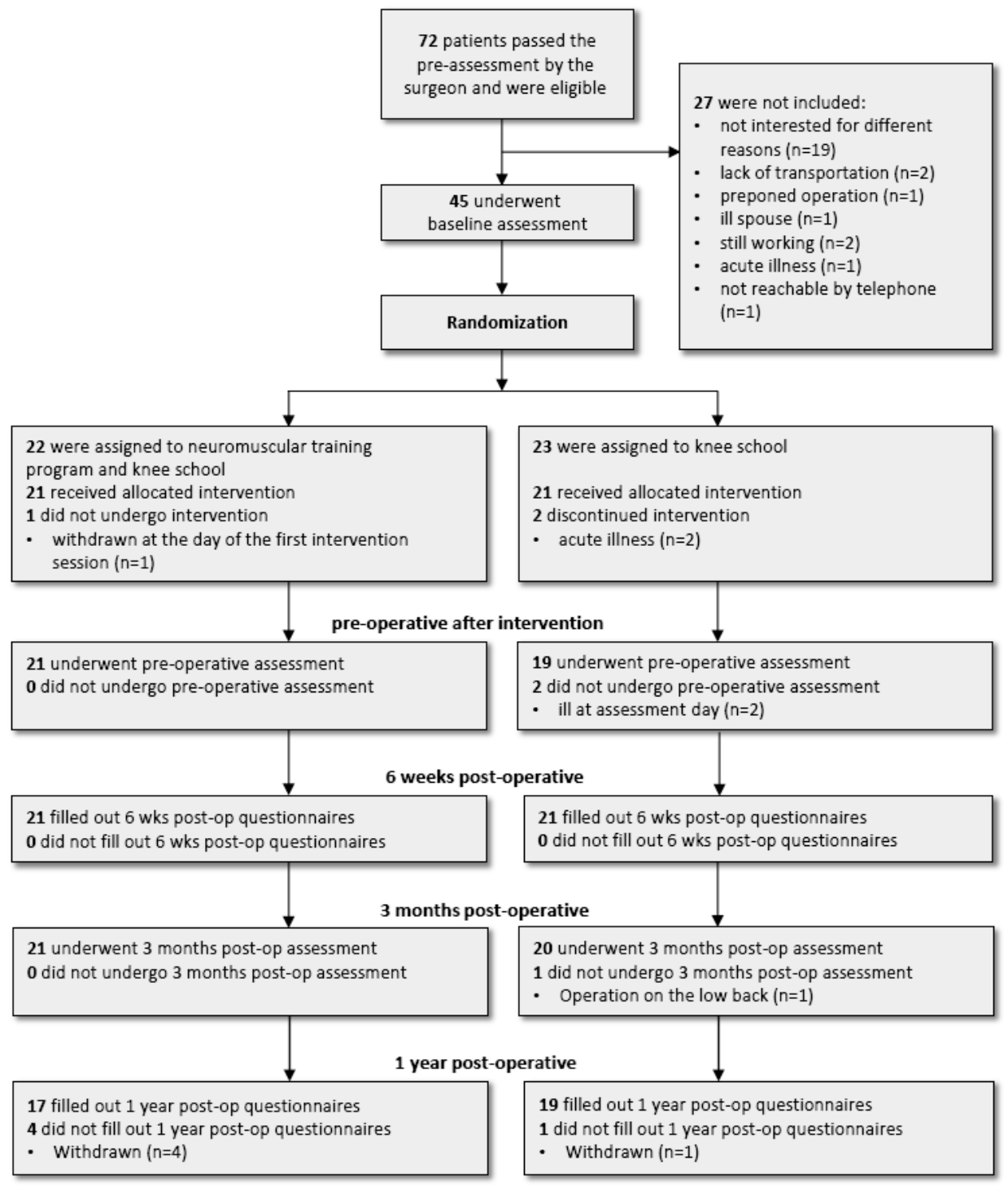

Figure 1: Flow diagram of patients participating in this study

\section{Description of exercise program performance}

Progression: The mean training level at the first session was $1.17( \pm 0.4)$ and at the last session $1.4( \pm 0.6)$. In total, $28.6 \%$ of the patients increased their training level, $71.4 \%$ stayed at the start level and none deteriorated.

Self-reported pain before and after training sessions: The mean self-reported pain on a numerical rating scale from 0 to 10 was $2.79( \pm 1.7)$ immediately before training, 2.8 


\section{Chapter 4}

$( \pm 1.7)$ immediately after training and $3.1( \pm 1.7)$ one day after training. $63.6 \%$ of the patients in the exercise group reported increased pain twenty-four hours after training $(3.4( \pm 1.6))$. One patient had increased pain $>5$ and missed the subsequent two sessions of training.

Adherence and joint-specific adverse events: The median number of attended sessions was 10 (IQR: 8, 14). 76.2\% of the patients attended the pre-defined goal of 8 or more treatment sessions, while $23.8 \%$ attended less. The reasons for attending less than 8 sessions, were pre-scheduled surgery or in one patient withdrawal on the day of the first training session. In total, 231 (82\%) of 282 sessions were attended and one patient missed 2 sessions due to increased pain, which was determined as a jointspecific adverse event.

\section{Additional objectively assessed physical activity}

Besides the NEMEX-TJR, these patients reported an average activity performance of 17.9 hours per week (74\% ADL activity, 25\% endurance and strength, $1 \%$ sport).

\section{Treatment effects in the primary and secondary endpoints}

After intervention but before surgery: We observed a small improvement for all primary and secondary endpoints in both exercise and control groups (see Table 3), which did not differ significantly between groups. Comparing the exercise to the control group the treatment effect for the Chair Stand Test was -1.5 seconds $(95 \% \mathrm{Cl}:-5.3,2.2)$, for KOOS $\mathrm{ADL}$ and KOOS pain the treatment effect was 1.3 points $(-10.1,12.8)$ and $-2.3(-12.4$, 7.9) respectively.

6 weeks after surgery: Comparing the exercise to the control group the treatment effect for KOOS ADL and KOOS pain was -2.0 points $(-13.3,9.3)$ and $-6.4(-16.5,3.6)$ respectively.

Three months after surgery: Comparing the exercise to the control group the treatment effect in the Chair Stand Test was 2.0 points $(-1.8,5.8)$. For KOOS ADL and KOOS pain the treatment effect was -4.9 points $(-16.3,6.5)$ and -3.3 points $(-13.5,6.8)$ respectively.

12 months after surgery compared to three months after surgery: Comparing the exercise to the control group the treatment effect for KOOS ADL and KOOS pain was 3.5 points $(-8.5,15.7)$ and $2.3(-8.5,13.0)$ respectively.

All results are presented in Table 2 and Figure 2 and 3. 
Table 2: Estimated treatment effects

\begin{tabular}{|c|c|c|c|c|}
\hline & $\begin{array}{l}\text { Baseline to } \\
1 \text { week } \\
\text { pre-op }\end{array}$ & $\begin{array}{l}\text { Baseline to } \\
6 \text { weeks } \\
\text { post-op }\end{array}$ & $\begin{array}{l}\text { Baseline to } \\
3 \text { months } \\
\text { post-op }\end{array}$ & $\begin{array}{l}3 \text { months to } \\
12 \text { months } \\
\text { post-op }\end{array}$ \\
\hline \multicolumn{5}{|l|}{ Primary endpoint } \\
\hline Chair Stand Test $^{\circ}$ & $-1.5(-5.3,2.2)$ & Not assessed & $2.0(-1.8,5.8)$ & Not assessed \\
\hline \multicolumn{5}{|l|}{ Secondary endpoints } \\
\hline KOOS ADL function ${ }^{\circ}$ & $1.3(-10.1,12.8)$ & $-2.0(-13.3,9.3)$ & $-4.9(-16.3,6.5)$ & $3.6(-8.5,15.7)$ \\
\hline KOOS pain ${ }^{\circ}$ & $-2.3(-12.4,7.9)$ & $-6.4(-16.5,3.6)$ & $-3.3(-13.5,6.8)$ & $2.3(-8.5,13.0)$ \\
\hline \multicolumn{5}{|l|}{ Additional outcomes } \\
\hline \multicolumn{5}{|l|}{ Lower limb function } \\
\hline KOOS symptoms ${ }^{\circ}$ & $2.2(-7.4,11.8)$ & $2.4(-7.2,11.9)$ & $4.6(-5.0,14.2)$ & $3.8(-6.4,14.0)$ \\
\hline $\begin{array}{l}\text { KOOS sport and } \\
\text { recreation }{ }^{\circ}\end{array}$ & $-5.1(-24.5,14.4)$ & $12.2(-8.8,33.2)$ & $1.0(-19.9,21.8)$ & $-4.1(-25.6,17.5)$ \\
\hline KOOS quality of life ${ }^{\circ \circ}$ & $5.5(-7.2,18.1)$ & $6.1(-6.6,18.7)$ & $-5.9(-18.5,6.8)$ & $5.9(-7.5,19.3)$ \\
\hline Muscle strength (Newton) ${ }^{\circ}$ & & Not assessed & & Not assessed \\
\hline Knee extension op & $8.8(-40.0,57.8)$ & & $-3.5(-52.7,45.6)$ & \\
\hline Knee extension contra & $14.2(-29.8,58.2)$ & & $35.4(-8.9,79.4)$ & \\
\hline Knee flexion op & $23.2(-0.1,46.5)$ & & $-12.7(-36.2,10.8)$ & \\
\hline Knee flexion contra & $2.0(-20.8,24.7)$ & & $-6.7(-29.7,16.2)$ & \\
\hline Knee-bending $/ 30 \mathrm{~s}^{\circ}$ & $3.8(-0.5,8.0)$ & Not assessed & $-3.3(-7.4,0.8)$ & Not assessed \\
\hline ROM of the knee (degrees) $^{\circ}$ & & Not assessed & & Not assessed \\
\hline Flexion op & $1.9(-4.4,8.2)$ & & $-3.9(-10.2,2.4)$ & \\
\hline Flexion contra & $0.1(-3.4,3.7)$ & & $-1.6(-5.2,1.9)$ & \\
\hline Extension op & $0.8(-2.4,4.0)$ & & $1.4(-1.8,4.5)$ & \\
\hline Extension contra & $1.2(-0.5,2.8)$ & & $1.4(-0.2,3.0)$ & \\
\hline $20 \mathrm{~m}$ walk test ${ }^{\circ}$ & $-0.6(-2.0,0.9)$ & Not assessed & $-0.5(-2.0,1.0)$ & Not assessed \\
\hline Timed up and go ${ }^{\circ}$ & $0.2(-1.5,2.0)$ & Not assessed & $1.6(-0.1,3.3)$ & Not assessed \\
\hline \multicolumn{5}{|l|}{ Physical activity } \\
\hline METs 7 day $(\mathrm{kcal} / \mathrm{h} / \mathrm{kg})^{\circ}$ & $0.3(-2.2,2.7)$ & Not assessed & $0.3(-2.3,2.9)$ & Not assessed \\
\hline Steps (daily average) ${ }^{\circ}$ & $\begin{array}{l}-687.2(-2172 \\
798)\end{array}$ & Not assessed & $165.7(-1288,1620)$ & Not assessed \\
\hline Adapted NHANES III METs ${ }^{\circ}$ & $10.0(-12.6,32.7)$ & $1.6(-20.9,24.0)$ & $0.4(-22.3,23.0)$ & $2.6(-21.3,26.4)$ \\
\hline \multicolumn{5}{|l|}{ Health-related quality of life } \\
\hline SF 36 Physical functioning ${ }^{\circ}$ & $7.1(-5.3,19.5)$ & $0.5(-11.8,12.7)$ & $-6.6(-8.5,17.5)$ & $4.5(-8.5,17.5)$ \\
\hline Role physical $^{\circ \circ}$ & $-10.8(-39.9,18.3)$ & $-5.2(-34.2,23.9)$ & $-3.2(-32.2,25.9)$ & $-1.1(-31.7,29.5)$ \\
\hline Bodily pain ${ }^{\circ}$ & $4.9(-7.2,17.0)$ & $2.8(-9.2,14.9)$ & $-3.4(-15.5,8.7)$ & $4.9(-7.8,17.7)$ \\
\hline General health ${ }^{\circ}$ & $3.3(-5.9,12.4)$ & $3.4(-5.7,12.5)$ & $-2.8(-12.0,6.3)$ & $2.5(-7.2,12.1)$ \\
\hline Vitality $^{\circ}$ & $-2.3(-13.9,9.3)$ & $-1.0(-12.5,10.5)$ & $-8.3(-20.0,3.3)$ & $3.3(-8.9,15.5)$. \\
\hline Social functioning ${ }^{\circ}$ & $5.0(-7.1,17.2)$ & $2.4(-9.7,14.4)$ & $-1.6(-13.7,10.5)$ & $-0.7(-13.4,12.1)$ \\
\hline Role emotional $^{\circ \circ}$ & $-10.8(-34.3,12.7)$ & $-11.1(-34.5,12.3)$ & $-10.2(-34.0,13.5)$ & $-9.3(-34.2,15.7)$ \\
\hline Mental health ${ }^{\circ}$ & $2.6(-6.6,11.7)$ & $-1.6(-10.7,7.5)$ & $-3.0(-12.2,6.1)$ & $0.4(-9.2,10.0)$ \\
\hline EQ-5D Mobility ${ }^{\circ 0}$ & $0.1(-0.3,0.4)$ & $0.0(-0.3,0.4)$ & $-0.1(-0.4,0.2)$ & $0.1(-0.3,0.4)$ \\
\hline Self-care ${ }^{\circ 00}$ & $-0.0(-0.2,2.2)$ & $0.1(-0.2,0.3)$ & $0.1(-0.1,0.3)$ & $0.0(-0.2,0.2)$ \\
\hline Usual Activities ${ }^{\circ 0}$ & $-0.0(-0.4,0.4)$ & $-0.1(-0.5,0.2)$ & $0.0(-0.4,0.4)$ & $-0.1(-0.4,0.3)$ \\
\hline
\end{tabular}




\begin{tabular}{lllll}
\hline & $\begin{array}{l}\text { Baseline to } \\
\text { 1 week } \\
\text { pre-op }\end{array}$ & $\begin{array}{l}\text { Baseline to } \\
6 \text { weeks } \\
\text { post-op }\end{array}$ & $\begin{array}{l}\text { Baseline to } \\
3 \text { months } \\
\text { post-op }\end{array}$ & $\begin{array}{l}3 \text { months to } \\
12 \text { months } \\
\text { post-op }\end{array}$ \\
\hline Pain/discomfort $^{\circ 00}$ & $-0.1(-0.4,0.2)$ & $0.1(-0.3,0.4)$ & $-0.0(-0.5,0.3)$ & $-0.1(-0.4,0.3)$ \\
Anxiety/Depression $^{\circ \circ}$ & $-0.1(-0.3,0.3)$ & $0.0(-0.2,0.2)$ & $-0.0(-0.3,0.3)$ & $0.1(-0.2,0.3)$ \\
EQ-VAS $^{\circ 0}$ & $7.1(-2.5,16.7)$ & $2.1(-7.4,11.6)$ & $1.2(-8.4,10.8)$ & $-0.1(-10.2,10.0)$ \\
\hline
\end{tabular}

Values are differences in mean changes between intervention and control group. Results from a linear mixed model and adjusted for age, gender and BMI.

- Continuous variable (time in seconds, Newton, degree, number, METs, steps).

${ }^{\circ}$ Scores range from 0 to 100 with higher scores indicating fewer problems.

$\cdots$ Scores range from 1 to 3 with lower score indicating fewer problems.

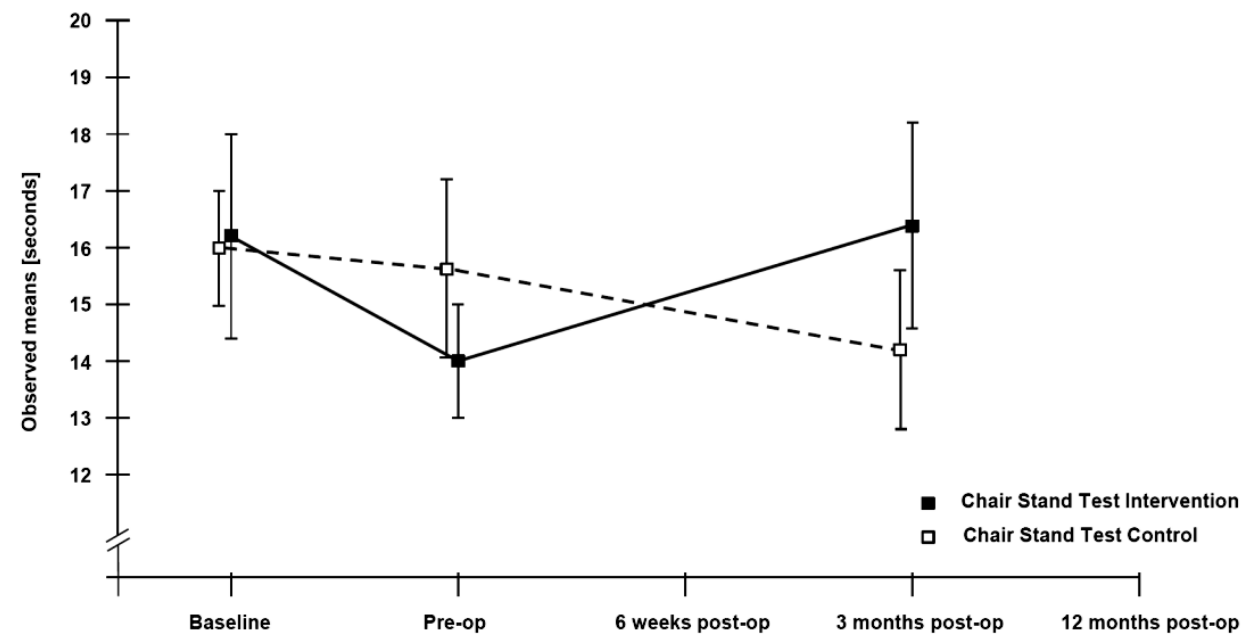

Figure 2: Primary endpoint results

Observed means +/- 1 Standard Error of the Chair Stand Test values for the two groups, at baseline, prior to surgery and 3 months after surgery. Baseline is treated as outcome, making no assumptions about group differences in the mean response at baseline, adjusted for age, gender and BMI. 


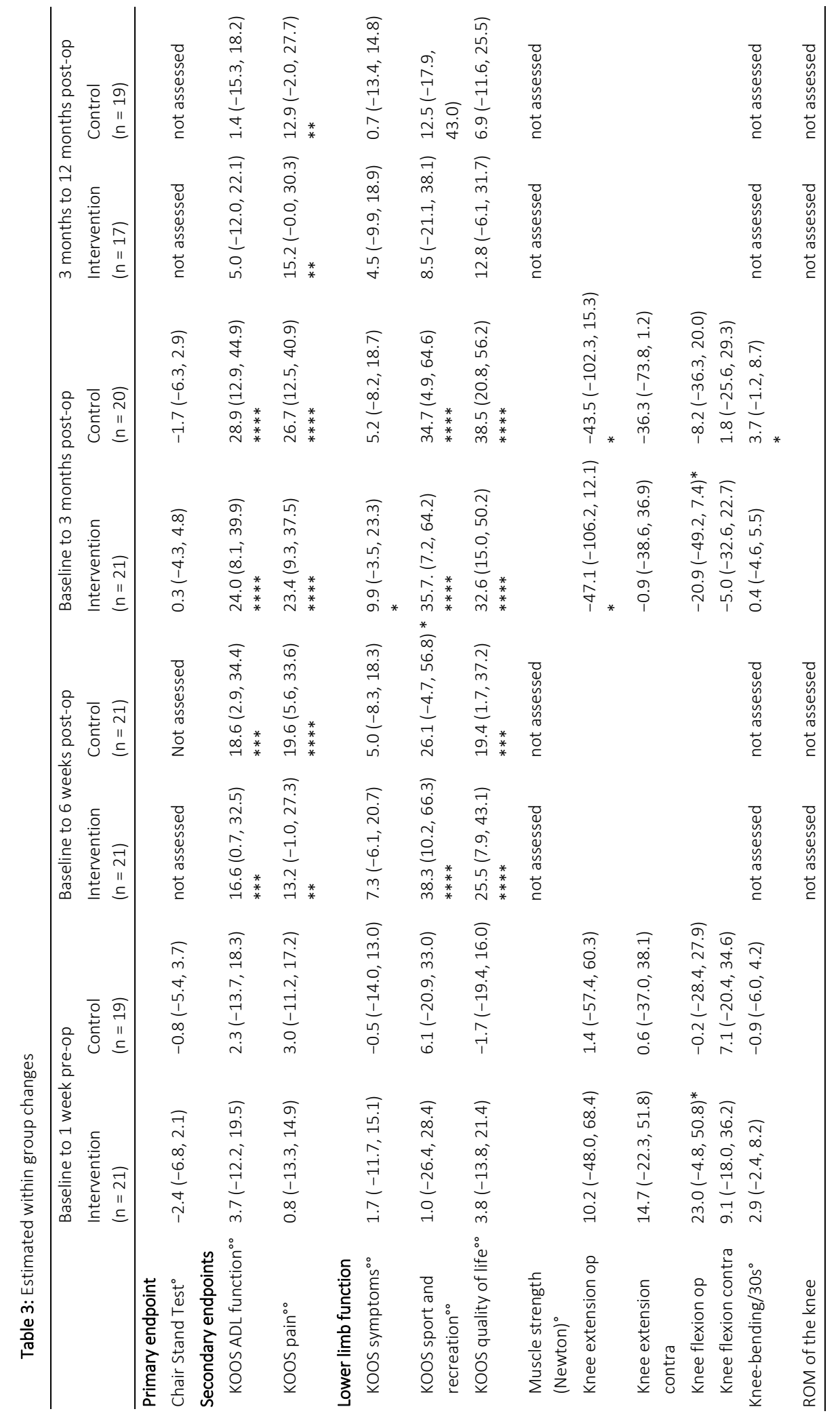




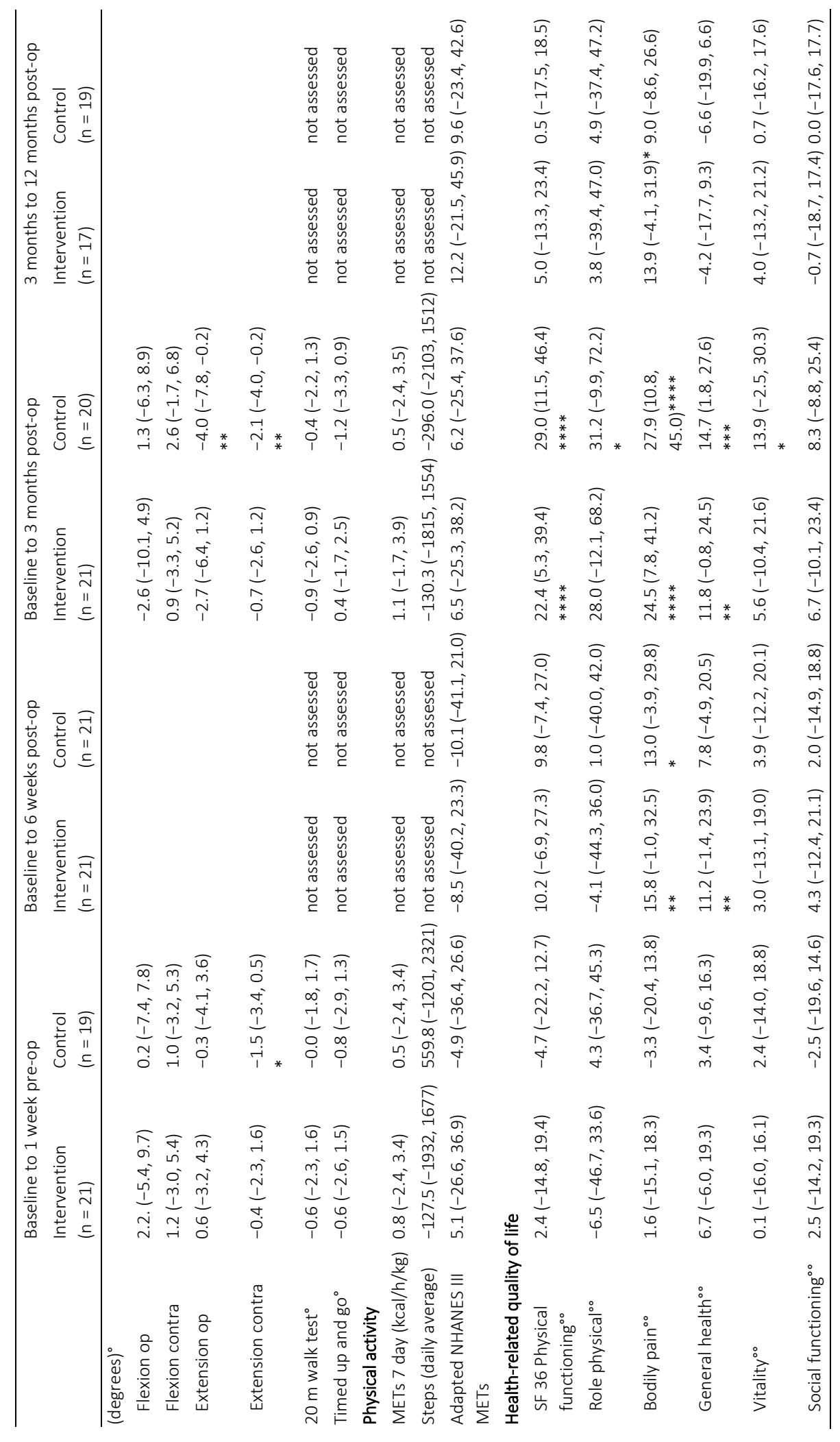




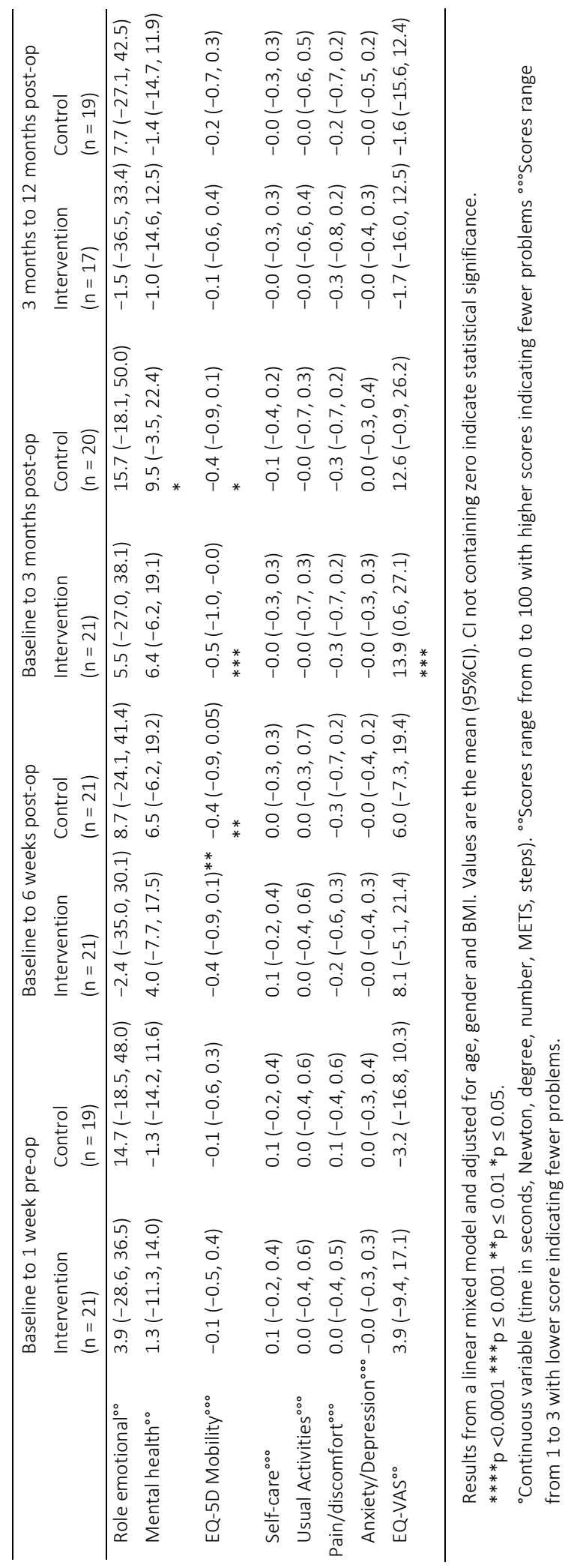




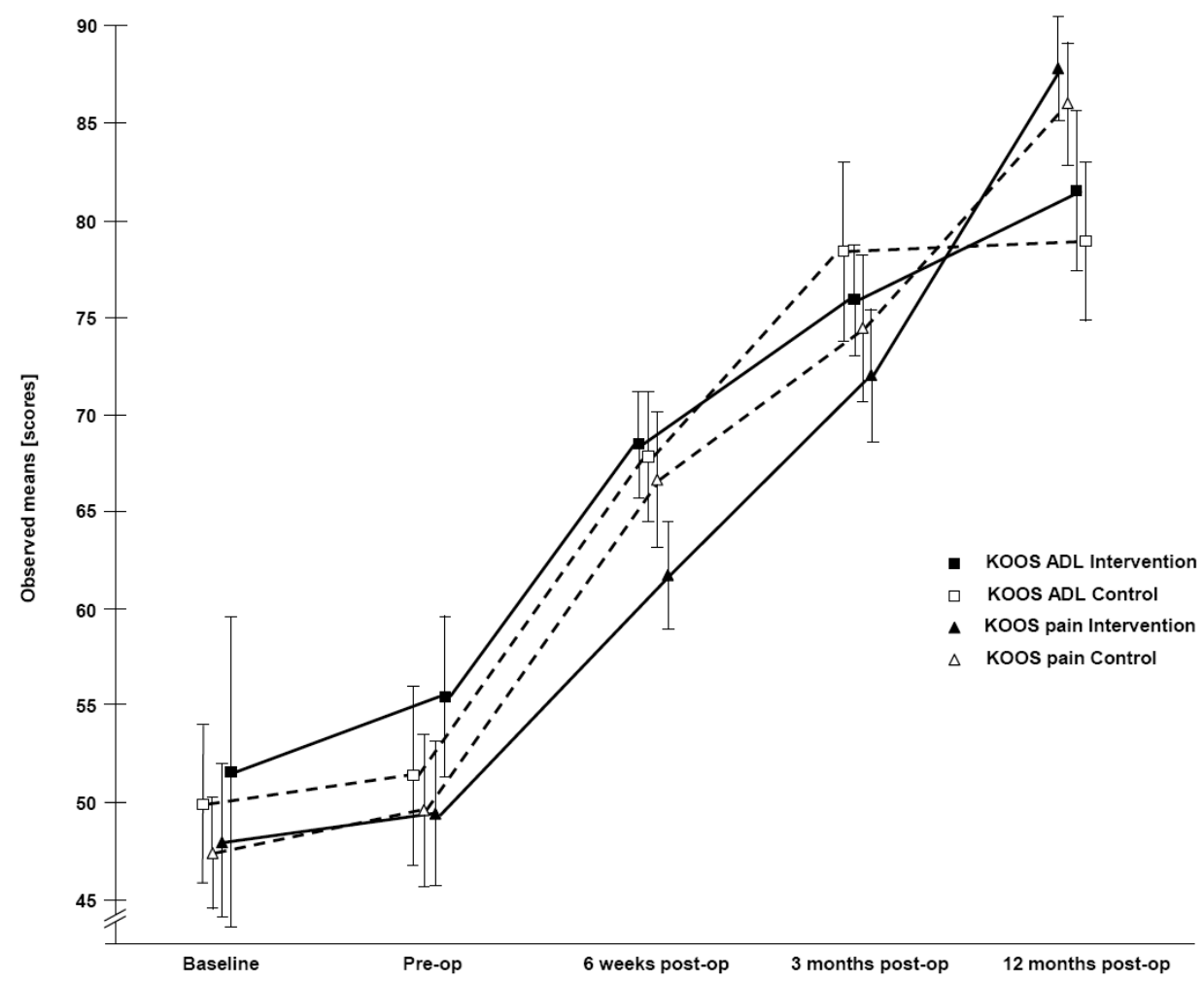

Figure 3: Secondary endpoints results

Observed means +/- 1 Standard Error of the KOOS ADL and KOOS pain scores for the two groups, at baseline, prior to surgery, 6 weeks, 3 months and 12 months after surgery. Baseline is treated as outcome, making no assumptions about group differences in the mean response at baseline, adjusted for age, gender and BMI

\section{Treatment effects in the additional outcome measures}

At all time-points, comparing the exercise to the control group we found no significant treatment effect in any additional outcome measures.

All results are presented in Table 2.

\section{Change within groups}

In within groups we observed at 1 week preoperatively a significant improvement in the isometric muscle strength of the knee flexors of the operated leg in the exercise group $(23.0(-4.8,50.8)$ and in the range of motion of the knee extension of the contralateral leg in the control group $(-1.5(-3.4,0.5)$.

At 6 weeks postoperatively a significant improvement in all KOOS subscales beside symptoms was seen (KOOS ADL: $16.6(0.7,32.5)$ in the intervention group and 18.6 (2.9, 
$34.4)$ in the control group; KOOS pain: $13.2(-1.0,27.3$.$) and 19.6. (5.6,33.6)$ respectively; KOOS Sport/Rec: $38.3(10.2,66.3)$ and $26.1(-4.7,56.8)$ respectively; KOOS QOL: 25.5 $(7.9,43.1)$ and $19.4(1.7,37.2)$ respectively) as well as in some dimensions of the SF 36 (bodily pain: $15.8(-1.0,32.5)$ and $13.0(-3.9,29.8)$ respectively; general health: 11.2 ($1.4,23.9)$ in the intervention group) and in EQ-5D mobility $(-0.4(-0.9,0.1)$ and $-0.4(-$ $0.9,0.1$ ) respectively).

At 3 months postoperatively we identified in both groups a significant improvement in all KOOS subscales beside symptoms in the control group (KOOS ADL $(24.0(8.1,39.9)$ and $28.9(12.9,44.9)$ respectively; KOOS pain: $23.4,(9.3,37.5)$ and $26.7(12.5,40.9)$ respectively; KOOS Sport/Rec: $35.7(7.2,64.2)$ and $34.7(4.9,64.6)$ respectively; KOOS QOL: $32.6(15.0,50.2)$ and $38.5(20.8,56.2)$ respectively; KOOS symptoms: 9.9 (-3.5, $23.3)$ in the intervention group), as well as in some dimensions of the SF-36 (physical functioning: $22.4(5.3,39.4)$ and $29.0(11.5,46.4)$ respectively; bodily pain: 24.5 (7.8, $41.2)$ and $27.9(10.8,45.0)$ respectively; general health: $11.8(-0.8,24.5)$ and $14.7(1.8$, 27.6) respectively; role physical: $31.2(-9.9,72.2)$ in the control group; vitality: 13.9 ($2.5,30.3)$ in the control group; mental health: $9.5(-3.5,22.4)$ in the control group), the EQ-5D mobility $(-0.5(-1.0,-0.0)$ and $-0.4(-0.9,0.1)$ respectively) and the EQ-VAS (13.9 $(0.6,27.1)$ in the intervention group.

Between 3 and 12 months postoperatively booth groups improved significantly in KOOS pain $(15.2(-0.0,30.3)$ and $12.9(-2.0,27.7)$ respectively) and the intervention group improved also significantly in SF 36 bodily pain (13.9 (-4.1, 31.9).

All results are presented in Table 3.

\section{DISCUSSION}

This randomized, assessor-blinded, controlled trial evaluated the effect of a preoperative neuromuscular training (NEMEX-TJR) in addition to patient education compared to patient education alone of patients undergoing TKR on functional outcomes at 3 months postoperatively. We could not confirm our hypothesis that patients undergoing the NEMEX-TJR have improve in functional outcome at 3 months after surgery. We observed no improvement in the primary endpoint and a significant improvement in the secondary endpoints in both exercise and control groups, which did not differ significantly between groups. Noticeably, after the intervention but before surgery we observed a small improvement for all primary and secondary endpoints in both exercise and control groups, which also did not differ significantly between groups.

The program was well tolerated based on our adverse event assessment and probably offered some benefit to the patients.

After the intervention but before surgery we found a small and non-significant benefit in favor of the exercise group. In support, a Danish trial using the same exercise intervention with a higher average number of training sessions (13 compared to 10) 
found a moderate and significant effect in favor of the exercise group. However this trial included both hip and knee patients and a sub group analysis revealed that the improvement in the hip patients was driving the overall effect [47]. Our results are in line with a meta-analysis of four trials with 240 participants [48], which provided moderate quality of evidence that exercise interventions compared with standard care were effective in reducing pain from knee osteoarthritis prior to knee replacement. In addition, our trial showed improvement in performed function which is in disagreement with the meta-analysis.

At 6 weeks postoperatively we found no between-group differences in KOOS ADL and pain which is in contrast with the Danish trial, where the authors found significantly greater improvements in ADL and pain from exercise [49]. Other studies showed comparable within group results for pain and self-reported function in their exercise and control groups from preoperative time point through 6-8 week postoperative follow up $[50,51]$.

At 3 months postoperatively (primary endpoint), no additional benefits were seen from the preoperative neuromuscular training. This is consistent with the Danish trial where the faster post-operative improvement in ADL and pain from exercise was blunted after surgery at 3 months follow-up [49]. Two other RCTs, evaluating the effect of preoperative training on post-operative outcome, also reported only within group changes without between group differences $[52,53]$. Interestingly the positive trajectory of self-reported KOOS ADL scores in both groups does not reflect the nonimprovement or the worsening in the objective CST. Several studies confirm these results, noting improvement in self-reported measures but not in performance tests [5456].

We formulated no hypothesis for 12 months postoperative because, based on literature, we did not expect a significant difference between-groups mean changes, since, over the long term, the effects of exercise and control group on functional performance seem to converge [57]. Yet, we found significant within-group improvements in both groups, but no between-group difference in KOOS pain from 3 months to 12 months postoperatively.

The performance level of our study population with respect to the Chair Stand Test was similar to other studies with the same patient group at baseline $(16.3 \pm 8.3$ in our study compared to $14.3 \pm 6.8$ and $13.5 \pm 5.9)[21,49]$. It was therefore unexpected, that Chair Stand Test performance did not improve significantly in the exercise group at 3 months compared to baseline. An explanation might be that patients used the contralateral leg as a compensation to complete the function task [58]. Also, the KOOS showed similar results in all five subscales at baseline compared with other studies of the same patient population [21, 49, 59]. 3 months postoperatively, we identified statistically significant differences between groups in KOOS ADL, pain and QOL of $3-6$ points in favor of the exercise group. The question is whether this difference at group level calls for the implementation of pre-operative exercise in clinical practice. It is increasingly recognized 
that minimal important change (MIC) is dependent on context factors, such as patient characteristics, type of intervention, time to follow-up, dimension evaluated, method applied to calculate the MIC, and cut-off chosen for the anchor question [60]. As a consequence, "there is no universal MIC, despite the appeal of the notion" [60]. Additionally it should be kept in mind that the MIC can be calculated both at an individual level for use in clinical decision making, and at a group level for use in research. In research, hypothesis testing and statistical analysis is used to determine the result, and in this study the average minimal important difference (MID) between groups ranged from 3-6 points. These between-group differences of 3-6 points are greater than the smallest detectable differences reported on a group level $(1.3-2.4)$ in the only available study giving these data relating to the KOOS [61], indicating that the current study is most probably powered to detect between group differences significantly different from zero. It should be kept in mind, however, that there is a lack of studies stating the measurement error in terms of the smallest detectable difference for groups in older patients or those having a TKR.

In our study, four senior orthopedic surgeons performed all operations, but surgical procedures were not optimally standardized, which might be a possible cause of bias. It was also not possible to standardize the rehabilitation procedure in an optimal form, meaning that some of the patients were discharged to an inpatient rehabilitation facility and others were discharged home and received treatment in an outpatient physiotherapy practice. That could also be a source of bias.

Our study has several strengths. First, our RCT was conducted according to the CONSORT statement $[62,63]$ with a rigorous study design, a clinically feasible intervention and good adherence to the programme. Inclusion criteria were kept broad to reflect daily clinical practice as far as possible. Second, the blinding of the assessor was ensured through restriction of access to obtained data and patient discretion. Third, we assessed outcomes over the entire time period from baseline to 1 week preoperative and 6 weeks, 3 months and 12 months postoperative respectively. Further, the conducted intervention was safe. Moreover, to control of attention bias, we offered a knee school for all participants.

There are also some limitations to our trial, including the relatively small recruited sample size of 45 patients instead of the planned 80 patients. Because of a change in the reimbursement system in the acute care hospitals, a reduction in preoperative waiting-time occurred during the recruitment phase, thus, our trial is underpowered due to logistical recruitment problems that we had to adapt to. Additionally, our assumptions made in November 2008 for calculating the sample size seem, in retrospect, and in the light of several recently published studies, too optimistic $[21,47]$. The presented $p$ values und confidence intervals in this study will help the reader to interpret our data realistically. Further, we assumed that functional status of all patients was reduced and a chance of improvement plausible. However, only 16 out of 21 patients started at the lowest exercise level when starting with the NEMEX-TJR. This may have been avoided by 
excluding patients with higher functional levels. On the other hand the preoperative KOOS scores of our participants are consistent with the literature of patients undergoing $\operatorname{TRK}[21,47,49]$. Also, due to slow recruitment, most training did not take place in groups and the expected positive effect of group training, in terms of more effective learning compared with individual practice sessions, was therefore diminished [64]. Moreover, the median of completed sessions in our study was 10, which is at the lower limit in terms of adequate dosage [15] and only 19\% of patients progressed to a more difficult training level, although self-reported pain seemed not to be a limiting factor. In comparison to previous studies in the Scandinavian countries $[21,49]$, very few patients progressed to more difficult training levels. This may reflect a cultural difference among patients or therapists in the role of exercise as osteoarthritis treatment. Delivering a sham exercise instead of a knee school educational programme would have been optimal, but was not realistic due to the difficulty in designing a credible placebo intervention.

\section{CONCLUSIONS}

Viewed over the entire period from baseline to 12 months postoperatively, a median (IQR) of $10(8,14)$ exercise sessions (NEMEX-TJR) before surgery showed only a small and non-significant improvement in all functional assessments compared to patient education alone. Also, this benefit was not maintained after surgery.

Out trial does not give a conclusive answer to whether additional preoperative exercise on postoperative functional outcome is beneficial. However, we acknowledge the small size of our trial as a limitation that may have prevented us to document small and sustained benefits.

\section{Competing interests}

The authors declare that they have no competing interests.

\section{Author's contributions}

$\mathrm{EOH}, \mathrm{EMR}, \mathrm{RAB}$ and $\mathrm{HBF}$ were responsible for concept and design. EOH was responsible in collection and assembly of data and drafting of the article. $\mathrm{EOH}$ and $\mathrm{AM}$ were responsible for the analysis of the data. EOH, EMR, AM, RAB and HBF were responsible for the interpretation of the results. EMR, AM, RAB and $H B F$ were responsible for critical revision of the article for important intellectual content. All authors read and approved the final manuscript. 


\section{ACKNOWLEDGEMENTS}

The authors would like to thank the patients for their willingness to participate. We acknowledge Dr Christoph Schwaller, Ursula Nauer, Hanspeter Studer, Evelyn Kurmann, Samuel Gerber, Mirjam Hafner, Andrea Blaser and André Steiger, Kantonsspital Olten, Olten, Dr Marc Zumstein, Ilona Märki-Wettstein, Lorenz Moser, Irene Knecht, Manuela Huber and Ruth Winkler, Kantonsspital Aarau, Aarau, and the independent assessors Manuela Lüthi-Tuor and Madeleine Salathe, Olten and Liestal, Switzerland, for their support by the conducting of this trial.

The project was supported by the Albert Böni Stiftung, Zurich, Switzerland, a foundation for research in Rheumatology and Physical Medicine. 


\section{REFERENCES}

1. Harris WH, Sledge CB: Total hip and total knee replacement (2). N Engl J Med 1990, 323(12):801-807.

2. Guccione AA, Felson DT, Anderson JJ, Anthony JM, Zhang Y, Wilson PW, Kelly-Hayes M, Wolf PA, Kreger $B E$, Kannel WB: The effects of specific medical conditions on the functional limitations of elders in the Framingham Study. Am J Public Health 1994, 84(3):351-358.

3. Felson DT, Lawrence RC, Dieppe PA, Hirsch R, Helmick CG, Jordan JM, Kington RS, Lane NE, Nevitt MC, Zhang $Y$ et al: Osteoarthritis: new insights. Part 1: the disease and its risk factors. Ann Intern Med 2000, 133(8):635-646.

4. Seed SM, Dunican KC, Lynch AM: Osteoarthritis: a review of treatment options. Geriatrics 2009, 64(10):20-29.

5. Kurtz SM, Ong KL, Lau E, Widmer M, Maravic M, Gomez-Barrena E, de Pina Mde F, Manno V, Torre M, Walter WL et al: International survey of primary and revision total knee replacement. Int Orthop 2011, 35(12):1783-1789.

6. Meneghini RM, Russo GS, Lieberman JR: Modern perceptions and expectations regarding total knee arthroplasty. J Knee Surg 2014, 27(2):93-97.

7. Hamilton DF, Clement ND, Burnett R, Patton JT, Moran M, Howie CR, Simpson AH, Gaston P: Do modern total knee replacements offer better value for money? A health economic analysis. Int Orthop 2013, 37(11):2147-2152.

8. Beswick AD, Wylde V, Gooberman-Hill R, Blom A, Dieppe P: What proportion of patients report long-term pain after total hip or knee replacement for osteoarthritis? A systematic review of prospective studies in unselected patients. BMJ Open 2012, 2(1):e000435.

9. Alzahrani K, Gandhi R, Debeer J, Petruccelli D, Mahomed N: Prevalence of clinically significant improvement following total knee replacement. The Journal of rheumatology 2011, 38(4):753-759.

10. Judge A, Welton NJ, Sandhu J, Ben-Shlomo Y: Equity in access to total joint replacement of the hip and knee in England: cross sectional study. BMJ 2010, 341:c4092.

11. Singh JA, O'Byrne MM, Harmsen WS, Lewallen DG: Predictors of moderate-severe functional limitation 2 and 5 years after revision total knee arthroplasty. The Journal of arthroplasty 2010, 25(7):1091-1095, 1095 e1091-1094.

12. Scott CE, Howie CR, MacDonald D, Biant LC: Predicting dissatisfaction following total knee replacement: a prospective study of 1217 patients. The Journal of bone and joint surgery British volume 2010, 92(9):1253-1258.

13. Hoogeboom TJ, van den Ende CH, van der Sluis G, Elings J, Dronkers JJ, Aiken AB, van Meeteren NL: The impact of waiting for total joint replacement on pain and functional status: a systematic review. Osteoarthritis Cartilage 2009, 17(11):1420-1427.

14. Mancuso CA, Graziano S, Briskie LM, Peterson MG, Pellicci PM, Salvati EA, Sculco TP: Randomized trials to modify patients' preoperative expectations of hip and knee arthroplasties. Clinical orthopaedics and related research 2008, 466(2):424-431.

15. Hoogeboom TJ, Oosting E, Vriezekolk JE, Veenhof C, Siemonsma PC, de Bie RA, van den Ende CH, van Meeteren NL: Therapeutic validity and effectiveness of preoperative exercise on functional recovery after joint replacement: a systematic review and meta-analysis. PLoS One 2012, 7(5):e38031.

16. Beckwee D, Vaes P, Cnudde M, Swinnen E, Bautmans I: Osteoarthritis of the knee: why does exercise work? A qualitative study of the literature. Ageing research reviews 2013, 12(1):226-236.

17. Bennell KL, Wrigley TV, Hunt MA, Lim BW, Hinman RS: Update on the role of muscle in the genesis and management of knee osteoarthritis. Rheumatic diseases clinics of North America 2013, 39(1):145-176.

18. Ageberg E, Link A, Roos EM: Feasibility of neuromuscular training in patients with severe hip or knee OA: the individualized goal-based NEMEX-TJR training program. BMC Musculoskelet Disord 2010, 11:126.

19. Johansson K, Nuutila L, Virtanen H, Katajisto J, Salantera S: Preoperative education for orthopaedic patients: systematic review. J Adv Nurs 2005, 50(2):212-223. 
20. Nunez M, Nunez E, Segur JM, Macule F, Quinto L, Hernandez MV, Vilalta C: The effect of an educational program to improve health-related quality of life in patients with osteoarthritis on waiting list for total knee replacement: a randomized study. Osteoarthritis Cartilage 2006, 14(3):279-285.

21. Ageberg E, Nilsdotter A, Kosek E, Roos EM: Effects of neuromuscular training (NEMEX-TJR) on patientreported outcomes and physical function in severe primary hip or knee osteoarthritis: a controlled beforeand-after study. BMC Musculoskelet Disord 2013, 14(1):232.

22. Huber EO, de Bie RA, Roos EM, Bischoff-Ferrari HA: Effect of pre-operative neuromuscular training on functional outcome after total knee replacement: a randomized-controlled trial. BMC Musculoskelet Disord 2013, 14:157.

23. Bohannon RW: Alternatives for measuring knee extension strength of the elderly at home. Clin Rehabil 1998, 12(5):434-440.

24. Bohannon RW: Sit-to-stand test for measuring performance of lower extremity muscles. Percept Mot Skills 1995, 80(1):163-166.

25. Lord SR, Murray SM, Chapman K, Munro B, Tiedemann A: Sit-to-stand performance depends on sensation, speed, balance, and psychological status in addition to strength in older people. J Gerontol A Biol Sci Med Sci 2002, 57(8):M539-543.

26. Villadsen A, Roos EM, Overgaard S, Holsgaard-Larsen A: Agreement and reliability of functional performance and muscle power in patients with advanced osteoarthritis of the hip or knee. Am J Phys Med Rehabil 2012, 91(5):401-410.

27. Guralnik JM, Ferrucci L, Simonsick EM, Salive ME, Wallace RB: Lower-extremity function in persons over the age of 70 years as a predictor of subsequent disability. N Engl J Med 1995, 332(9):556-561.

28. Collins NJ, Misra D, Felson DT, Crossley KM, Roos EM: Measures of knee function: International Knee Documentation Committee (IKDC) Subjective Knee Evaluation Form, Knee Injury and Osteoarthritis Outcome Score (KOOS), Knee Injury and Osteoarthritis Outcome Score Physical Function Short Form (KOOSPS), Knee Outcome Survey Activities of Daily Living Scale (KOS-ADL), Lysholm Knee Scoring Scale, Oxford Knee Score (OKS), Western Ontario and McMaster Universities Osteoarthritis Index (WOMAC), Activity Rating Scale (ARS), and Tegner Activity Score (TAS). Arthritis Care Res (Hoboken) 2011, 63 Suppl 11:S208228.

29. Roos EM: Effectiveness and practice variation of rehabilitation after joint replacement. Curr Opin Rheumatol 2003, 15(2):160-162.

30. Kessler S, Lang S, Puhl W, Stove J: [The Knee Injury and Osteoarthritis Outcome Score--a multifunctional questionnaire to measure outcome in knee arthroplasty]. Z Orthop Ihre Grenzgeb 2003, 141(3):277-282.

31. Stoll T, Huber E, Seifert B, Michel BA, Stucki G: Maximal isometric muscle strength: normative values and gender-specific relation to age. Clin Rheumatol 2000, 19(2):105-113.

32. Huber EO: Zuverlässigkeit und Normperzentilen einer neuen isometrischen Muskelkraftmessmethode. Physiotherapie 1997.

33. Hortobagyi T, Garry J, Holbert D, Devita P: Aberrations in the control of quadriceps muscle force in patients with knee osteoarthritis. Arthritis and rheumatism 2004, 51(4):562-569.

34. Roos EM, Bremander AB, Englund M, Lohmander LS: Change in self-reported outcomes and objective physical function over 7 years in middle-aged subjects with or at high risk of knee osteoarthritis. Ann Rheum Dis 2008, 67(4):505-510.

35. Lenssen AF, van Dam EM, Crijns YH, Verhey M, Geesink RJ, van den Brandt PA, de Bie RA: Reproducibility of goniometric measurement of the knee in the in-hospital phase following total knee arthroplasty. $B M C$ Musculoskelet Disord 2007, 8:83.

36. Faulkner KA, Redfern MS, Rosano C, Landsittel DP, Studenski SA, Cauley JA, Zmuda JM, Simonsick EM, Kritchevsky SB, Newman AB: Reciprocal influence of concurrent walking and cognitive testing on performance in older adults. Gait Posture 2006, 24(2):182-189.

37. Podsiadlo D, Richardson S: The timed "Up \& Go": a test of basic functional mobility for frail elderly persons. J Am Geriatr Soc 1991, 39(2):142-148.

38. Pitta F, Troosters T, Probst VS, Spruit MA, Decramer M, Gosselink R: Quantifying physical activity in daily life with questionnaires and motion sensors in COPD. Eur Respir J 2006, 27(5):1040-1055. 
39. Holsgaard-Larsen A, Roos EM: Objectively measured physical activity in patients with end stage knee or hip osteoarthritis. Eur J Phys Rehabil Med 2012, 48(4):577-585.

40. Nelson KM, Reiber G, Boyko EJ: Diet and exercise among adults with type 2 diabetes: findings from the third national health and nutrition examination survey (NHANES III). Diabetes Care 2002, 25(10):17221728.

41. Ainsworth BE, Haskell WL, Herrmann SD, Meckes N, Bassett DR, Jr., Tudor-Locke C, Greer JL, Vezina J, Whitt-Glover MC, Leon AS: 2011 Compendium of Physical Activities: a second update of codes and MET values. Medicine and science in sports and exercise 2011, 43(8):1575-1581.

42. Ware JE: Measuring patients' views: the optimum outcome measure. BMJ 1993, 306(6890):1429-1430.

43. Ware JE, Jr., Sherbourne CD: The MOS 36-item short-form health survey (SF-36). I. Conceptual framework and item selection. Med Care 1992, 30(6):473-483.

44. Rabin R, de Charro F: EQ-5D: a measure of health status from the EuroQol Group. Ann Med 2001, 33(5):337-343.

45. R Core Team. R: A language and environment for statistical computing [http://www.R-project.org/.]

46. Ime4: Linear mixed-effects models using Eigen and S4. R package version 1.1-6. [http://CRAN.Rproject.org/package=Ime4]

47. Villadsen A, Overgaard S, Holsgaard-Larsen A, Christensen R, Roos EM: Immediate efficacy of neuromuscular exercise in patients with severe osteoarthritis of the hip or knee: a secondary analysis from a randomized controlled trial. The Journal of rheumatology 2014, 41(7):1385-1394.

48. Wallis JA, Taylor NF: Pre-operative interventions (non-surgical and non-pharmacological) for patients with hip or knee osteoarthritis awaiting joint replacement surgery--a systematic review and meta-analysis. Osteoarthritis Cartilage 2011, 19(12):1381-1395.

49. Villadsen A, Overgaard S, Holsgaard-Larsen A, Christensen R, Roos EM: Postoperative effects of neuromuscular exercise prior to hip or knee arthroplasty: a randomised controlled trial. Ann Rheum Dis 2014, 73(6):1130-1137.

50. Rooks DS, Huang J, Bierbaum BE, Bolus SA, Rubano J, Connolly CE, Alpert S, Iversen MD, Katz JN: Effect of preoperative exercise on measures of functional status in men and women undergoing total hip and knee arthroplasty. Arthritis and rheumatism 2006, 55(5):700-708.

51. McKay C, Prapavessis H, Doherty $\mathrm{T}$ : The effect of a prehabilitation exercise program on quadriceps strength for patients undergoing total knee arthroplasty: a randomized controlled pilot study. PM $R$ 2012, 4(9):647-656.

52. Gstoettner M, Raschner C, Dirnberger E, Leimser H, Krismer M: Preoperative proprioceptive training in patients with total knee arthroplasty. Knee 2011, 18(4):265-270.

53. Topp R, Swank AM, Quesada PM, Nyland J, Malkani A: The effect of prehabilitation exercise on strength and functioning after total knee arthroplasty. PM R 2009, 1(8):729-735.

54. Parent $\mathrm{E}$, Moffet $\mathrm{H}$ : Comparative responsiveness of locomotor tests and questionnaires used to follow early recovery after total knee arthroplasty. Archives of physical medicine and rehabilitation 2002, 83(1):70-80.

55. Maly MR, Costigan PA, Olney SJ: Determinants of self-report outcome measures in people with knee osteoarthritis. Archives of physical medicine and rehabilitation 2006, 87(1):96-104.

56. Stratford PW, Kennedy DM: Performance measures were necessary to obtain a complete picture of osteoarthritic patients. Journal of clinical epidemiology 2006, 59(2):160-167.

57. Farquhar SJ, Reisman DS, Snyder-Mackler L: Persistence of altered movement patterns during a sit-tostand task 1 year following unilateral total knee arthroplasty. Physical therapy 2008, 88(5):567-579.

58. Mizner RL, Snyder-Mackler L: Altered loading during walking and sit-to-stand is affected by quadriceps weakness after total knee arthroplasty. J Orthop Res 2005, 23(5):1083-1090.

59. Holm B, Bandholm T, Lunn TH, Husted H, Aalund PK, Hansen TB, Kehlet H: Role of preoperative pain, muscle function, and activity level in discharge readiness after fast-track hip and knee arthroplasty. Acta orthopaedica 2014:1-5

60. King MT: A point of minimal important difference (MID): a critique of terminology and methods. Expert review of pharmacoeconomics \& outcomes research 2011, 11(2):171-184. 
61. Paradowski PT, Witonski D, Keska R, Roos EM: Cross-cultural translation and measurement properties of the Polish version of the Knee injury and Osteoarthritis Outcome Score (KOOS) following anterior cruciate ligament reconstruction. Health and quality of life outcomes 2013, 11:107.

62. Moher D, Hopewell S, Schulz KF, Montori V, Gotzsche PC, Devereaux PJ, Elbourne D, Egger M, Altman DG: CONSORT 2010 Explanation and Elaboration: Updated guidelines for reporting parallel group randomised trials. Journal of clinical epidemiology 2010, 63(8):e1-37.

63. Altman DG, Schulz KF, Moher D, Egger M, Davidoff F, Elbourne D, Gotzsche PC, Lang T: The revised CONSORT statement for reporting randomized trials: explanation and elaboration. Ann Intern Med 2001, 134(8):663-694.

64. McNevin NH, Wulf G, Carlson C: Effects of attentional focus, self-control, and dyad training on motor learning: implications for physical rehabilitation. Physical therapy 2000, 80(4):373-385. 


\section{Additional file 1}

\section{Details of the model}

The model for observation $Y_{i j k}$ (jth measure of subject $k$ in group $i$ ) was

$Y_{i j k}=\mu+\alpha_{i}+\beta_{j}+(\alpha \beta)_{i j}+U_{i k}+$ covariates $+\epsilon_{i j k} i=1,2 ; j=1, \ldots, 5(3) ; k=1, \ldots, n_{i}$, with $\alpha_{i}$ as the ith group effect (time averaged group difference), $\beta_{j}$ as the jth time effect (group averaged time differences), $(\alpha \beta)_{i j}$ as the ijth group-time interaction (difference between the within-group changes, equivalent to the treatment effect), $U_{i k}$ as the random intercept of subject $k$ in group $i$ and $\epsilon_{i j k}$ as measurement error. For our LLM, we assumed that the $U_{i k}$ and the $\epsilon_{i j k}$ are each independent and normally distributed with betweensubject variance $v^{2}$ and within-subject variance $\tau^{2}$, respectively, leading to a uniform within-subject correlation between two different measurements on the same subject. 


\section{CHAPTER 5}

Early outcomes following unilateral total or partial knee replacement (TKR/PKR) due to knee osteoarthritis:

Change in function and pain at the contralateral knee

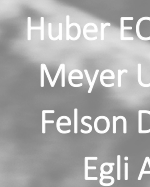

Schietzel S DegenT Meyer O

Wanner G

Guggi T
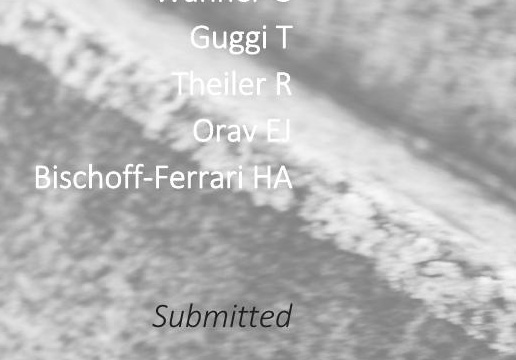


\section{Chapter 5}

\section{ABSTRACT}

\section{Objective}

The aim of the study was to assess function and pain of the contralateral nonoperated knee at 6 to 10 weeks following TKR/PKR.

\section{Methods}

From patients scheduled to undergo unilateral TKR/PKR due to severe knee OA, we enrolled 272 persons aged 60 years or older (mean age 70.3 ( \pm 6.4 ); 53.7\% women). Pain and function of both knees were assessed at 1-2 weeks prior to surgery and 6-10 weeks following surgery using the pain and function subscales of the Western Ontario and McMaster Universities Osteoarthritis Index (WOMAC).

\section{Results}

Prior to surgery, there was moderate correlation between knees for both WOMAC function $(r=0.51 ; p<0.001)$ and pain $(r=0.35 ; p<0.001)$, which was attenuated at 6 to 10 weeks after surgery for both function $(r=0.34 ; p<0.001)$ and pain $(r=0.17 ; p=0.05)$. Mean WOMAC function/pain improved significantly in the operated knee: function from 37.2 to 25.8 ( $p<0.001$ ) and pain from 42.1 to 28.5 ( $p<0.001)$; and in the contralateral knee: function from 10.4 to 4.3 ( $p<0.0001$ ) and pain from 10.0 to 4.7 ( $p<0.001$ ). Baseline function/pain in the contralateral knee was a significant predictor of function at 6 to 10 weeks following TKR/PKR in the operated knee, independent of baseline function/pain of the operated knee, age, BMI and gender.

\section{Conclusion}

Both the function and pain of the operated and contralateral knees improved significantly following surgery. 


\section{INTRODUCTION}

Osteoarthritis of the knee and hip joint (OA) is the leading cause of disability in later age [1]. Current interventions in patients with OA are limited to symptomatic pain relief. This is initially achieved through the use of analgesics, anti-inflammatories (NSAIDs) and exercise, followed later by total joint replacement $[2,3]$.

Furthermore, individuals age 65 years and older undergoing total joint replacement due to unilateral knee or hip OA have a more than $50 \%$ chance of the disease affecting the contralateral joint [4-6] and this joint is at high risk of rapid progression [4], which is likely to have a negative impact on function after surgery. Smith et al. reported in the Kinemax Outcomes Study, with a cohort of 772 patients undergoing unilateral TKR/PKR that $10-20 \%$ of these patients had bilateral osteoarthritis and $6 \%$ had TKR surgery on the contralateral knee within twelve months of the first operation [7].

Since many patients scheduled for unilateral TKR/PKR also report pain and functional impairment in the contralateral knee, the status of the contralateral knee has gained increasing attention in recent outcome research. Maxwell et al. [8] found an association between pain at the contralateral knee prior to surgery with poor self-reported function and slow walking speed at 6+ months after surgery among 271 participants in the US Multicenter Osteoarthritis Study (MOST). In addition, Desmeules et al. [9] documented that pain of the contralateral knee prior to surgery was a significant determinant of health-related quality of life at 6 months post-surgery. Kahn et al. [10] similarly reported a significant association between the severity of osteoarthritic symptoms in the contralateral knee and the outcome of the operated knee at an average follow-up time of 2.9 years after TKR.

Mechanistically, the symptoms of the contralateral knee prior to surgery may be partly explained by the underlying osteoarthritis, but also by the additional burden transferred to the contralateral knee in the attempt to relieve weight on the severely affected knee scheduled for TKR/PKR. For these reasons, we aimed to investigate the change in WOMAC function and pain in the contralateral knee from baseline (1-2 weeks prior to surgery) to early after surgery (6-10 weeks after surgery). In addition, we were interested in whether function and pain in the contralateral knee prior to surgery influences early outcome of the knee undergoing TKR/PKR, and to what extent.

\section{METHODS}

\section{Study design}

This study used pre-baseline and baseline data from a double-blind randomized controlled trial $(\mathrm{RCT})$ that tested the effect of vitamin D supplementation on rate of falls, pain and function after unilateral TKR/PKR (ClinicalTrials.gov, identifier: NCT00599807). 


\section{Chapter 5}

Enrollment took place between October 2007 and February 2013 at the Centre on Aging and Mobility, University of Zurich, Switzerland.

The conditions and methods of the RCT were approved by the Ethical Committee of the Canton of Zurich, Switzerland, approval number STZ 20/07, and the trial was registered with the ClinicalTrials.gov, identifier: NCT00599807. The study was funded by a Swiss National Foundations Professorship Grant (Prof. H.A. Bischoff-Ferrari; PPOOB114864) and the Velux Foundation.

\section{Participants}

Patients scheduled for unilateral TKR/PKR, aged 60 years or older with severe knee OA, were enrolled from one large orthopedic hospital (Schulthess Clinic, Zurich, Switzerland). Exclusion criteria were history of inflammatory arthritis, severe cognitive/visual/aural impairments, planned bilateral TKR/PKR within the next two years, absence (non-attendance) after surgery, inability to walk at least 3 meters with or without a walking aid. Patients had to be proficient in German (oral and written) and have a Mini-Mental State Examination score greater than 24/30 [11]. All patients gave their written informed consent.

\section{Outcomes}

The primary measures of interest in this study were knee pain and function in the nonreplaced contralateral knee as assessed by a patient-reported outcome measure. All patients completed the questionnaire for both knees 1-2 weeks prior to and 6-10 weeks following surgery. The questionnaire provided two columns for the responses, one for the affected and the other for the contralateral knee.

\section{Measures}

Function and pain were assessed using the respective subscales of the Western Ontario and McMaster Universities Osteoarthritis Index (WOMAC). The WOMAC is a validated and commonly used self-reported outcome $[12,13]$ to evaluate patients with knee OA [14], including those undergoing TKR/PKR [15]. It consists of 24 items divided into 3 subscales: pain (5 items), stiffness ( 2 items) and physical function (17 items), each scored on a 5-point Likert scale (none, mild, moderate, severe, and extreme). For each subscale, the scores were transformed to a 0 to 100 score $(0=$ no symptoms, $100=$ extreme symptoms). We used a knee-specific paper-version of the German WOMAC 3.1. [16]

\section{Statistical analysis}

Descriptive statistics were used to summarize participants' characteristics and are presented as means \pm standard deviations (SD), unless stated otherwise. Differences in 
participants' characteristics between men and women were determined by unpaired Student's t-tests for continuous variables and Chi-square-tests for categorical variables.

Pre- and post-surgery differences between the knees, as well as differences between pre- and post-surgery status, were calculated using paired Student's t-tests. Spearman correlation coefficients were calculated for the pre- and post-surgery relationship between WOMAC statuses of both knees. To test the associations between (1) pre-surgery pain and function of one knee and post-surgery function of the ipsilateral knee, and between (2) pre-surgery pain and function of one knee and post-surgery function of the contralateral knee, we used a linear regression model with post-surgery WOMAC function as outcome and pre-surgery WOMAC pain or function as the explanatory variable. The model was adjusted for gender, age (60-69 years versus 70+ years) and BMI. Models calculating the association between pre-surgery status of the nonoperated knee and post-surgery function of the operated knee were additionally adjusted for pre-surgery status of the operated knee and vice versa.

All reported $p$-values are 2 -tailed with an alpha value of 0.05 . Correlations were defined as low if the coefficient was less than 0.3, moderate if it was between 0.3 and 0.5 , and strong if it was greater than 0.5 [17]. All analyses were conducting with SAS software, version 9.4 (SAS Institute, Cary, NC, USA).

\section{RESULTS}

Of the 1500 patients screened for unilateral TKR/PKR surgery due to severe knee OA and aged $\geq 60$ years, $272(18.1 \%)$ were enrolled in this study. Participants had a mean age of $70.3( \pm 6.4)$ years and $53.7 \%$ were women. Baseline characteristics by gender are outlined in Table 1 . Women underwent surgery at a lower pain and functional impairment level than men. Overall, 35.9\% of patients reported some functional impairment (WOMAC function score > 10 on the transformed 0-100 scale) and 30.7\% reported some pain (WOMAC pain score > 10) in the contralateral knee at baseline.

\section{Function and pain in the operated and contralateral knee - pre- and post-surgery}

Mean WOMAC function improved in the operated knee (from 37.2 to 25.8; $p<0.001$ ) and in the contralateral knee (from 10.4 to 4.3; $p<0.0001$ ). Mean WOMAC pain also improved in the operated knee (from 42.1 to $28.5 ; p<0.001$ ) and in the contralateral knee (from 10.0 to 4.7; $p<0.001$ ). See Table 2. 


\section{Chapter 5}

Table 1: Baseline characteristics of study participants $(n=272)$

\begin{tabular}{|c|c|c|c|c|}
\hline \multicolumn{5}{|c|}{$\begin{array}{l}\text { Values are the mean (standard deviation) for continuous variables and the number (percentage) for } \\
\text { categorical variables. }\end{array}$} \\
\hline & Women & Men & All & p-value* \\
\hline $\mathrm{N}$ & $146(53.7 \%)$ & $126(46.3 \%)$ & 272 & \\
\hline Age - years & $70.4 \pm 6.1$ & $70.3 \pm 6.9$ & $70.3 \pm 6.4$ & 0.934 \\
\hline Body Mass Index BMI - kg/m² & $26.9 \pm 4.1$ & $27.6 \pm 3.8$ & $27.2 \pm 4.0$ & 0.115 \\
\hline Normal weight $\left(\mathrm{BMI} \leq 24.9 \mathrm{~kg} / \mathrm{m}^{2}\right)-\mathrm{n}(\%)$ & $55(37.7 \%)$ & $30(23.8 \%)$ & $85(31.2 \%)$ & \\
\hline Overweight (BMI $\left.25.0-29.9 \mathrm{~kg} / \mathrm{m}^{2}\right)-\mathrm{n}(\%)$ & $56(38.4 \%)$ & $75(59.5 \%)$ & $131(48.2 \%)$ & 0.002 \\
\hline Obese $\left(\mathrm{BMI} \geq 30.0 \mathrm{~kg} / \mathrm{m}^{2}\right)-\mathrm{n}(\%)$ & $35(24.0 \%)$ & $21(16.6 \%)$ & $56(20.6 \%)$ & \\
\hline Right knee operated (\%) & $78(53.4 \%)$ & $56(44.4 \%)$ & $134(49.3 \%)$ & 0.140 \\
\hline \multicolumn{5}{|l|}{ Pre-surgery WOMAC pain score } \\
\hline Scheduled knee & $45.2 \pm 16.0$ & $38.5 \pm 14.6$ & $42.1 \pm 15.7$ & $<0.001$ \\
\hline Contralateral knee & $12.1 \pm 14.0$ & $7.9 \pm 12.4$ & $10.0 \pm 13.4$ & 0.007 \\
\hline \multicolumn{5}{|l|}{ Pre-surgery WOMAC function score } \\
\hline Scheduled knee & $39.9 \pm 17.2$ & $34.0 \pm 16.7$ & $37.2 \pm 17.2$ & 0.005 \\
\hline Contralateral knee & $12.8 \pm 15.9$ & $7.6 \pm 12.1$ & $10.4 \pm 14.4$ & 0.002 \\
\hline \multicolumn{5}{|c|}{$\begin{array}{l}\text { Patients with some impairment in the contra-lateral } \\
\text { knee (\%) }\end{array}$} \\
\hline$\%>10$ for WOMAC pain score & $55(37.7 \%)$ & $30(23.8 \%)$ & $85(31.3 \%)$ & 0.014 \\
\hline$\%>10$ for WOMAC function score & $66(45.2 \%)$ & $33(26.2 \%)$ & 99 (36.4\%) & 0.001 \\
\hline
\end{tabular}

Legend:

BMI, body mass index; WOMAC, Western Ontario and McMaster Universities Arthritis Index on a scale from 0 (no pain/perfect function) to 100 (severe pain/worst function).

* Differences between men and women based on unpaired Student's t-tests for continuous, and Chi-squaretests for categorical variables

Table 2: Comparison between operated and contralateral knee - before and after surgery Values are means and standard deviation, Correlation Coefficient is presented as Spearman's $r$.

\begin{tabular}{llllll}
\hline & Pre-surgery & $r$ & Post-surgery & $r$ & $p$ value \\
\hline WOMAC pain operated & $42.10(15.71)$ & 0.35 & $28.54(15.00)$ & 0.17 & $<.0001$ \\
WOMAC pain contralateral & $10.04(13.43)$ & & $4.70(8.15)$ & $<.0001$ \\
$p$ value & $<.0001$ & & $<.0001$ & & $<.0001$ \\
WOMAC function operated & $37.16(17.21)$ & & $25.77(13.81)$ & 0.34 & $<.0001$ \\
WOMAC function contralateral & $10.38(14.43)$ & & $4.26(8.01)$ & & \\
$p$ value & $<.0001$ & & $<.0001$ & & \\
\hline
\end{tabular}

WOMAC = Western Ontario and McMaster Universities Arthritis Index on a scale from 0 (no pain/perfect function) to 100 (severe pain/worst function).

WOMAC function and pain scores of the operated knee showed a negative change (indicating an improvement) from pre-surgery to post-surgery in $73.2 \%$ and $68.3 \%$ of all participants, respectively. For the contralateral knee, WOMAC function and pain im- 
proved in $49.3 \%$ and $42 \%$ of participants, respectively including some participants who had scores of $<10$ at baseline.

\section{Correlation of function and pain between knees - pre- and post-surgery}

Prior to surgery there was a moderate correlation between knees for both WOMAC function ( $r=0.51 ; p<0.001)$ and pain $(r=0.35 ; p<0.001)$, which was attenuated at 6 to 10 weeks after surgery ( $r=0.34$ for function; $p<0.001$ and $r=0.17$ for pain; $p=0.005)$.

\section{Influence of pre-surgery function and pain of the contralateral knee on post- surgery function and pain of the operated knee}

Pre-surgery function and pain of the contralateral knee had a small but significant effect on the outcome of the operated knee: for each decrease of 10 WOMAC pain score units pre-surgery in the contralateral knee, we found a 2.00 worse function score $(95 \% \mathrm{Cl}$ 0.71 to $3.28 ; p=0.002$ ) after surgery in the operated knee. For each decrease of 10 WOMAC function score units pre-surgery in the contralateral knee, we found a 2.21 lower function score $(95 \% \mathrm{Cl} 0.99$ to $3.43 ; p \leq 0.001)$ after surgery in the operated knee. These effects were independent of baseline function/pain in the operated knee, and of gender, BMI, or age (see Table 3). Notably, pre-surgery function and pain status of the operated knee did not affect the outcome early after surgery in the contralateral knee.

Table 3: Association of pre-surgery pain and function on post-surgery function 3a: Association between pre-surgery WOMAC pain and function of the contralateral knee and post-surgery WOMAC function of the operated knee

\begin{tabular}{llll}
\hline & \multicolumn{4}{l}{ WOMAC function, operated knee } \\
\cline { 2 - 4 } & B-coefficient & 95\% confidence interval & p-value \\
\hline Pre-surgery WOMAC pain, contralateral knee $^{\circ}$ & 0.1995 & 0.71 to 3.28 & 0.002 \\
Pre-surgery WOMAC function, contralateral knee & 0.2209 & 0.99 to 3.43 & $\leq 0.001$ \\
\hline
\end{tabular}

- adjusted for age category (70+ years versus younger), gender, BMI and pre-surgery WOMAC pain score in the operated knee

${ }^{\circ}$ adjusted for age category (70+ years versus younger), gender, BMI and pre-surgery WOMAC function score in the operated knee

WOMAC = Western Ontario and McMaster Universities Arthritis Index on a scale from 0 (no pain/perfect function) to 100 (severe pain/worst function). 
3b: Association between pre-surgery WOMAC pain and function of the operated knee and post-surgery WOMAC function of the contralateral knee

\begin{tabular}{llll}
\hline & \multicolumn{3}{l}{ WOMAC function, contralateral knee } \\
\cline { 2 - 4 } & b-coefficient & 95\% confidence interval & p-value \\
\hline Pre-surgery WOMAC pain, operated knee* & -0.0226 & -0.82 to 0.377 & 0.4528 \\
Pre-surgery WOMAC function, operated knee** & -0.0199 & -0.73 to 0.33 & 0.4627 \\
\hline
\end{tabular}

* adjusted for age category (70+ years versus younger), gender, BMI and pre-surgery WOMAC pain score in the contralateral knee

** adjusted for age category (70+ years versus younger), gender, BMI and pre-surgery WOMAC function score in the contralateral knee

WOMAC = Western Ontario and McMaster Universities Arthritis Index on a scale from 0 (no pain/perfect function) to 100 (severe pain/worst function).

\section{DISCUSSION}

From patients scheduled for unilateral TKR/PKR, our study enrolled 272 persons aged 60 years or older in order to investigate the role of the contralateral knee with respect to early outcome following TKR/PKR. Notably, even amongst our patients with no plan for bilateral replacement within a 2-year period after enrollment, more than $30 \%$ reported some functional impairment and/or some pain in the contralateral knee prior to surgery. Pain and function were moderately correlated between knees. Following surgery, both knees improved significantly and remained weakly correlated for pain and function. Furthermore, impaired functional status and pain in the contralateral knee had a small, but significant and independent negative influence on early outcome after TKR/PKR. This might be one explanation when patients improve less than expected in function and pain in the early postoperative phase. We therefore recommend that measures prior to surgery should not only include the scheduled knee but also the contralateral knee.

WOMAC pain and function in the contralateral knee improved significantly at 6 to 10 weeks following surgery, suggesting that the contralateral knee improves soon after unilateral TKR/PKR. Several explanations could be considered. Firstly, in the acute and post-acute rehabilitation phases, the contralateral leg of the patient is also included in therapeutic exercises and physical activity. Thus, the surgery could serve as a mechanism for patients to receive the necessary physical therapy treatment on their contralateral knee. Secondly, since the contralateral joint is rested as a consequence of surgery, injurious painful demands are avoided. Thirdly, treatment of one knee can have bilateral effects through central nervous system connections. Creamer et al. [18] demonstrated that the injection of local anesthetic in one knee not only reduce pain in the injected knee but also resulted in pain relief in the contralateral non-injected knee. Several authors [19-21] have reported that strengthening exercise of the affected limb showed a small contralateral training effect. 
Notably, Kahn et al [10] reported an improvement (2.1 units) of pre-surgery WOMAC function in the contralateral knee up to 2.9 years after unilateral TKR. In our study, contralateral knee pain improved by 5.3 units and function by 6.1 units at 6 to 10 weeks post unilateral TKR/PKR. In the largest cohort of 772 patients after unilateral KR in the Kinemax Outcomes Study [7], WOMAC pain scores in the contralateral knee were assessed at 3, 12 and 24 months post-surgery. The authors observed a significant improvement in WOMAC pain of both knees at the 3 month follow-up, with a small deterioration thereafter of 3.5 WOMAC units per year in the contralateral knee, which was not predicted by pain in the operated knee shortly after surgery. The conclusion from the 3-month findings in our study and the larger Kinemax study is that the contralateral knee improves soon after surgery. In our study pain and function of the operated knee prior to surgery did not predict pain and function in the contralateral knee post-surgery, which is consistent with the findings of Kinemax study.

Few studies have investigated the role of pre-surgery functional impairment and pain of the contralateral knee on outcome after unilateral TKR/PKR. Our data confirm and extend the findings of Maxwell et al. [8] who investigated a similar number of participants enrolled in the US MOST study to determine outcomes of both knees after unilateral TKR at $6+$ months. In this study, participants were slightly older (mean age 77), 72\% female and mean WOMAC pain scores 4.2 (corresponding to a score of 21 on the scale used in our study) in the contralateral knee before surgery, compared with mean 10.0 at the contralateral knee in our study. This may best be explained by the fact that we excluded patients with a pre-planned bilateral TKR/PKR in the 2 years following recruitment. Two smaller studies of 138 [9], and 171 [10] patients also support the conclusion that contralateral knee pain contributes to worse physical function at 6 months and up to 2.9 years in the operated knee following unilateral TKR. Given this short and long-term influence of the contralateral knee on functional outcome after unilateral TKR, these authors concluded that pre-surgery pain and impaired function in the contralateral knee may be a useful clinical marker of prognosis after unilateral TKR. This is consistent with our findings

Strengths of our study are its moderately large sample size, the selection of patients with a defined unilateral TKR/PKR and the exclusion of patients with bilateral surgery planned within 2 years after enrollment. Our study also confirms and extends the results of prior studies with respect to: 1 . the recovery of pain and function observed at the contralateral knee at only 6 to 10 weeks after unilateral TKR/PKR; and 2. patients that reported in more than $30 \%$ of cases with some functional impairment and/or pain in the contralateral knee prior to surgery. Our study assessed the WOMAC score for both knees in all participants at baseline (1-2 weeks prior to surgery) and following surgery (6-10 weeks after surgery).

A limitation of our study is the lack of longer-term follow-up assessments after surgery. However, our data fits well with the existing literature from studies with extended follow-up assessments at 6 months [8, 9], 2 years [7], 2.5-2.9 years [8, 10], and up to 5 


\section{Chapter 5}

years [8]. A further limitation is the lack of pre-surgery standardized radiology reports on the contralateral knee. However, Kahn et al. found no association between contralateral knee KL grades and operated knee outcomes [10]. A further strength of our study is the single-center approach in one large orthopedic hospital with a team specialized in TKR surgery and a standardized rehabilitation access for all participants at the inpatient and out-patient level.

In summary, our data are encouraging to both patients and their physicians, suggesting that not only the operated but also the contralateral knee improves after unilateral TKR/PKR in the early postoperative phase. Clinical implications are that surgeons could inform patients with bilateral knee OA on the likelihood of recovery of the contralateral knee and recommend that they delay TKR/PKR surgery of the second knee for at least 3 months after TKR/PKR surgery on the first knee. This recommendation is in line with a recent consensus statement from the consensus conference on bilateral total knee arthroplasty group [22].

\section{Competing interests}

The authors declare that they have no competing interests.

\section{Author's contributions}

HBF is the PI of Zurich Multiple Endpoint Vitamin D Trial in Knee OA Patients (NCT00599807) and designed with input of EOH the analyses presented in this paper. HBF supervised UM who performed data analyses for this manuscript. EOH and HBF drafted the manuscript with input by all authors. All authors have read and approved the final manuscript. EJO is the head biostatistician of the trial. 


\section{REFERENCES}

1. Guccione AA, Felson DT, Anderson JJ, Anthony JM, Zhang Y, Wilson PW, Kelly-Hayes M, Wolf PA, Kreger $B E$, Kannel WB: The effects of specific medical conditions on the functional limitations of elders in the Framingham Study. American journal of public health 1994, 84(3):351-358.

2. Harris WH, Sledge CB: Total hip and total knee replacement (1). N Engl J Med 1990, 323(11):725-731.

3. Harris WH, Sledge CB: Total hip and total knee replacement (2). N Engl J Med 1990, 323(12):801-807.

4. Felson DT: Epidemiology of osteoarthritis. Brandt KD, Doherty M, Lohmander LS eds Osteoarthritis 2003, New York: Oxford Univ P:9-17.

5. Felson DT: Relation of obesity and of vocational and avocational risk factors to osteoarthritis. J Rheumatol 2005, 32(6):1133-1135.

6. Gunther KP, Sturmer T, Sauerland S, Zeissig I, Sun Y, Kessler S, Scharf HP, Brenner H, Puhl W: Prevalence of generalised osteoarthritis in patients with advanced hip and knee osteoarthritis: the Ulm Osteoarthritis Study. Ann Rheum Dis 1998, 57(12):717-723.

7. Smith HK, Wylde V, Lingard EA, Blom A, Metcalfe C, Ben-Shlomo Y: The effect of pain after total knee arthroplasty on the contralateral, nonreplaced knee. The Journal of bone and joint surgery American volume 2013, 95(4):315-322.

8. Maxwell J, Niu J, Singh JA, Nevitt MC, Law LF, Felson D: The influence of the contralateral knee prior to knee arthroplasty on post-arthroplasty function: the multicenter osteoarthritis study. The Journal of bone and joint surgery American volume 2013, 95(11):989-993.

9. Desmeules F, Dionne CE, Belzile EL, Bourbonnais R, Champagne F, Fremont P: Determinants of pain, functional limitations and health-related quality of life six months after total knee arthroplasty: results from a prospective cohort study. BMC sports science, medicine and rehabilitation 2013, 5:2.

10. Kahn TL, Soheili AC, Schwarzkopf R: Poor WOMAC Scores in Contralateral Knee Negatively Impact TKA Outcomes: Data From the Osteoarthritis Initiative. The Journal of arthroplasty 2014, 29(8):1580-1585.

11. Folstein MF, Folstein SE, McHugh PR: "Mini-mental state". A practical method for grading the cognitive state of patients for the clinician. J Psychiatr Res 1975, 12(3):189-198.

12. Bellamy N, Buchanan WW, Goldsmith CH, Campbell J, Stitt LW: Validation study of WOMAC: a health status instrument for measuring clinically important patient relevant outcomes to antirheumatic drug therapy in patients with osteoarthritis of the hip or knee. The Journal of rheumatology 1988, 15(12):18331840.

13. Bellamy N: WOMAC: a 20-year experiential review of a patient-centered self-reported health status questionnaire. The Journal of rheumatology 2002, 29(12):2473-2476.

14. Brazier JE, Harper R, Munro J, Walters SJ, Snaith ML: Generic and condition-specific outcome measures for people with osteoarthritis of the knee. Rheumatology (Oxford, England) 1999, 38(9):870-877.

15. Bombardier C, Melfi CA, Paul J, Green R, Hawker G, Wright J, Coyte P: Comparison of a generic and a disease-specific measure of pain and physical function after knee replacement surgery. Medical care 1995, 33(4 Suppl):AS131-144.

16. Stucki G, Meier D, Stucki S, Michel BA, Tyndall AG, Dick W, Theiler R: [Evaluation of a German version of WOMAC (Western Ontario and McMaster Universities) Arthrosis Index]. Zeitschrift fur Rheumatologie 1996, 55(1):40-49

17. Cohen J: Statistical Power Analysis for the Behavioral Sciences, Second Edition: Lawrence Erlbaum Assoc Inc; 1988.

18. Creamer P, Hunt M, Dieppe P: Pain mechanisms in osteoarthritis of the knee: effect of intraarticular anesthetic. The Journal of rheumatology 1996, 23(6):1031-1036.

19. Arai M, Shimizu H, Shimizu ME, Tanaka Y, Yanagisawa K: Effects of the use of cross-education to the affected side through various resistive exercises of the sound side and settings of the length of the affected muscles. Hiroshima journal of medical sciences 2001, 50(3):65-73. 
20. Carroll TJ, Herbert RD, Munn J, Lee M, Gandevia SC: Contralateral effects of unilateral strength training: evidence and possible mechanisms. Journal of applied physiology (Bethesda, Md : 1985) 2006, 101(5):1514-1522.

21. Munn J, Herbert RD, Hancock MJ, Gandevia SC: Training with unilateral resistance exercise increases contralateral strength. Journal of applied physiology (Bethesda, Md: 1985) 2005, 99(5):1880-1884.

22. Memtsoudis SG, Hargett M, Russell LA, Parvizi J, Cats-Baril WL, Stundner O, Sculco TP: Consensus statement from the consensus conference on bilateral total knee arthroplasty group. Clinical orthopaedics and related research 2013, 471(8):2649-2657. 


\section{CHAPTER 6}

\section{Effect of functional stability exercise programs}

designed to improve pain and lower limb disability in people with knee osteoarthritis: A systematic review and meta-analysis of randomized controlled trials

Huber EO Juhl C

Roos EM Lund $\mathrm{H}$ 


\section{Chapter 6}

\section{ABSTRACT}

\section{Study design}

Systematic review and meta-analysis.

\section{Objectives}

To estimate the effect on pain, disability and performance-based function of functional stability exercise programs for the lower limb in people with knee osteoarthritis (OA).

\section{Background}

Functional stability exercise programs may have a beneficial effect on pain and function in patients with knee OA.

\section{Methods}

Five databases were searched up to October 8, 2014. A meta-analysis was undertaken to estimate the effect of functional stability exercise on self-reported pain, self-reported disability and performance-based lower limb function.

\section{Results}

Eleven studies (697 participants) were included. The interventions included balance, agility, perturbation and other stability improving exercises, either additional to, or in comparison with, a variety of control treatments. The effect size (ES) of pain reduction was $0.25(95 \% \mathrm{Cl} 0.09,0.41)$ in favor of the intervention group. For disability and performance-based lower limb function, corresponding values were $0.26(95 \% \mathrm{Cl} 0.09$, $0.46)$ and $0.21(95 \% \mathrm{Cl}-0.05,0.47)$, respectively. Studies using a passive control group revealed higher ES than studies using an active comparator.

\section{Conclusion}

An analysis of the prediction interval of all three outcomes indicates that further research is needed. Thus, no final conclusion can be made on the effect size of stabilizing exercise for patients with knee osteoarthritis.

\section{Keywords}

Neuromuscular exercise, agility, perturbation, proprioception 


\section{INTRODUCTION}

Increases in life expectancy and aging populations are expected to make osteoarthritis (OA) the fourth leading cause of disability worldwide by the year 2020 [1]. The lifetime prevalence of symptomatic knee OA in an US population is estimated at $44.7 \%$ [2].

The Osteoarthritis Research Society International (OARSI) guidelines for nonpharmacological treatment of knee OA recommend therapeutic exercise as a cornerstone treatment for knee $\mathrm{OA}$, due to the strong evidence of its pain and disability relieving effects and the occurrence of only rare and non-serious adverse events [3]. Although exercise does show a beneficial effect, different results and high heterogeneity have been observed in various systematic reviews $[4,5]$. Based on the results from more than 40 studies evaluating exercise for patients with knee OA, no clear recommendations for type, dose and progression have been made [6]. Previous systematic reviews could not show a clear superiority of one type of exercise over another $[4,7,8]$. In addition, very different mechanisms for exercise to diminish pain in patients with knee OA have been suggested. $[9,10]$ To improve the prescription of exercise therapy in clinical practice, it is imperative to evaluate different aspects of the exercise intervention.

Findings from recently published studies and reviews suggest that patients with knee OA have sensorimotor deficiencies, reflected in lower limb muscle weakness, altered muscle activation patterns, as well as sensory dysfunction and reduced functional performance $[11,12]$. It is also recognized that a considerable number of patients with knee OA suffer from "give away" or functional knee instability and mal-alignment between the ankle, knee and hip, which has been shown to correlate with reduced functional ability [13-16] and passive mechanical stiffness [17]. It could thus be argued that, in order to diminish pain and improve function, patients with knee OA not only need greater muscle strength and improved aerobic capacity but also need more control of the movements during daily activities. By improving functional stability of the knee through specific exercise aimed at improving neuromuscular control, a beneficial decrease in pain and disability may be observed.

Recently a conceptual approach, neuromuscular exercise, was described for use in patients with OA [18-22], in order to improve sensorimotor control and achieve compensatory functional stability. This approach targets the exercise more specifically in order to combat altered muscle activation patterns, sensory dysfunction and reduced functional performance. However, two studies did not show any additional effect of neuromuscular exercise $[20,22]$. In order to fully evaluate this approach, it is necessary to synthesize the results from all earlier studies comparing this kind of exercise with a control group. Based upon this synthesis, implications for both research and clinical practice can be more precisely described.

Exercise programs aimed at improving stability and control of the knee and adjacent joints have not yet been fully defined. However, they may include a combination of 


\section{Chapter 6}

motor control and strengthening exercises specifically aiming at enabling patients to move and perform daily activities (e.g. stair climbing) with less pain and disability. We chose to denote the various exercise programs with this aim as functional stability exercise (FSE).

A systematic search in MEDLINE on February 13, 2015 using the search terms 'Osteoarthritis, knee' [MeSH] AND 'exercise' [MeSH] with the filters 'review' and 'published', revealed 34 reviews during the last 5 years. Sixteen of these reviews investigated exercise in patients with knee $O A$, but none specifically evaluated exercise programs aimed at improving functional stability [7, 8, 10, 23-35].

The aim of this current review is to synthesize the results from all randomized controlled trials designed to compare exercise programs that could be classified as FSE to a control group and their impact on self-reported pain, and self-reported disability in people with knee OA.

\section{METHODS}

The study selection process, data extraction and statistical analyses in this systematic review were conducted according to the Cochrane Collaboration guidelines [36]. The review was registered on the PROSPERO database (2014:CRD42014013951).

\section{Search}

A search for eligible studies was conducted in the following electronic databases between inception and October 8, 2014: MEDLINE via PubMed, EMBASE, via Ovid; CINAHL (including preCINAHL) via EBSCO; Web of Science; and the Cochrane Central Register of Controlled Trials (CENTRAL). Searches were performed using the combined and/or truncated key terms. The patient group was identified by performing the following search strategy in MEDLINE: ('Osteoarthritis, knee' [MeSH] OR 'knee osteoarthritis' [tiab]) OR ('knee' [MeSH] AND 'osteoarthr*' [tiab]). Functional stability exercise interventions were identified by searching: ('neuromusc*' [tiab] OR ('functional' [tiab] OR 'agility' [tiab] OR 'perturbation' [tiab]) AND ('exercise therapy' [MeSH/tiab] OR 'exercise therapies' [MeSH/tiab] OR 'exercise' [MeSH/tiab]). In order to identify RCTs the following filters were used: 'randomized' [tiab] OR 'randomised' [tiab] OR 'randomized controlled trial*' [publication type] OR 'randomized controlled trials as topic' [MeSH] OR 'allocation, random' [MeSH] OR 'control group*' [MeSH/tiab] OR 'crossover stud*' [tiab] OR 'cross-over stud*' [tiab]. The above search strategy was adjusted for searches in the other databases. The reference lists of identified systematic reviews and included randomized controlled trials, in addition to references recommended by personal contacts or lists distributed by institutions or other sources were checked for potential eligible studies. The search was not limited by language or year of publication. 


\section{Eligibility Criteria}

Studies had to include patients with OA in either one or both knee(s) as defined by: clinical criteria described by the American College of Rheumatology (ACR) [37]; a combination of radiographic $O A$ and pain; patients on the waiting list for TKR, who were not suffering from any other arthritic conditions or any other disease which might have affected the joints. All degrees of OA, both primary and secondary, were eligible. Studies which included a mixture of patients with different rheumatic diseases were only included when it was possible to extract the data from the participants with knee OA.

Studies were included if they were either randomized controlled trials comparing an exercise therapy regime that could be classified as FSE (see below) with a control (care as usual), or, when FSE combined with control treatment was given to participants with knee $O A$ in the intervention group. In the eligible trials, at least one of the four described components of functional stability exercise (see below) had to be included in the intervention and at least half of the exercise program had to consist of FSE (including warm-up and cool-down time). Supervised interventions were included, performed in groups or individually, in a home-based or institution-based setting. Studies in which total knee replacement was part of the intervention were excluded.

\section{Study Selection}

Two members of the study team ( $\mathrm{EOH}$ and $\mathrm{HL}$ ) independently screened titles and abstracts for study eligibility. When studies were judged eligible by at least one reviewer, full-text articles were obtained. The same two reviewers judged the retrieved full-text articles and consensus on inclusion was reached through discussion.

\section{Intervention}

The interventions were exercise programs designed to improve lower extremity functional stability, here denoted as FSE. To support the authors in study selection, four representative components were described a priori and served as selection guidelines.

\section{Neuromuscular control}

- Rationale: Neuromuscular control is a critical factor in dynamic knee stability during the activities of walking and ascending/descending stairs [38-41].

- Type of exercises: Patients are required to produce force in a controlled way through finely-tuned and coordinated muscle activity in lying, sitting or standing position. 


\section{Chapter 6}

\section{Core strength}

- Rationale: People with knee OA can have poor postural stability with decreased functional performance [42] and core strengthening can improve postural control [43].

- Type of exercises: Patients are required to strengthen their body in combination with balance and coordination tasks without compensation.

\section{Proprioception / balance}

- Rationale: People with knee OA demonstrate decreased proprioception [42, 44-46] and balance deficits $[42,47,48]$. Proprioceptive accuracy is essential in maintaining balance $[22,42,49]$ and reduced proprioceptive accuracy seems to be a risk factor for poor functional outcome [50].

- Type of exercises: Patients are required to step forward, backward and sideward, for example, on a stable or unstable surface to stimulate automatic feedback on body positions and movements.

\section{Functional limb alignment:}

- Rationale: Besides the quadriceps, other muscles in the lower extremity (such as the gastrocnemius, hamstrings and hip abductors) are also important for stabilizing the knee joint [12]. What is seen as medial-to-foot position in the clinic is the consequence of increased internal hip rotation and amenability to change with exercise [18].

- Type of exercises: Patients are required to maintain the knee in an aligned neutral position as they perform a movement with the other leg.

\section{Outcome Measures}

The outcome measures were self-reported pain, self-reported disability and in addition performance-based lower limb function. If a study reported more than one outcome for self-reported pain or disability, a list reported by Juhl et al. was used to decide which outcome to choose [51]. A hierarchy of performance-based lower limb function was pre-specified in the protocol as: (1) Chair Stand Test (CST), (2) Timed Up and Go (TUG), (3) others.

\section{Data Extraction}

A customized data extraction form was developed for each of the outcomes selfreported pain, self-reported disability and performance-based lower limb function. Two authors ( $\mathrm{EOH}$ and $\mathrm{HL}$ ) independently performed the data-extraction. The following information were mandatory: author, year of publication, number of patients allocated 
to the intervention and control groups, age, gender distribution, disability and pain at baseline, score of change. The FSE program characteristics extracted were the number of supervised sessions and duration of intervention in weeks.

\section{Risk of bias assessment}

Risk of bias in the individual studies was assessed in the domains: selection bias, performance bias, detection bias, attrition bias and reporting bias [52]. Two authors (EOH and $\mathrm{HL}$ ) independently assessed the following sources of bias: sequence generation, concealment of allocation, blinding, incomplete outcome data addressed, selective outcome reporting and other bias. Each of these sources was explicitly judged, using: adequate = low risk of bias; inadequate = high risk of bias; unclear = either lack of information or uncertainty over the potential for bias [52]. Sensitivity analyses were performed on different levels of risk of bias and small study bias was analyzed using Eggers test [53].

\section{Strategy for Data Synthesis}

The effect size (ES) was measured by the standardized mean difference (SMD), which allowed pooling of the various outcomes assessed in the individual trials. The SMD was calculated as the difference between the mean changes in the intervention groups and the control groups, divided by the pooled standard deviation (SD). When the SD was not available, it was estimated from the standard error (SE), the confidence interval $(\mathrm{CI})$, the p-value or other methods recommended by the Cochrane Handbook for Systematic Reviews [36]. The ES was clinically interpreted as proposed originally by Cohen [54]. An ES of 0.2 was considered small, an ES of $\sim 0.5$ was considered moderate (and would be recognized as clinically important) and an ES $>0.8$ was considered large [54]. A correction factor was used to convert the effect size to Hedges $g$.

A random effects model meta-analysis was applied using the DerSimonian \& Laird method [55]. Heterogeneity was calculated as the $1^{2}$ statistics [56] measuring the proportion of variation (i.e. inconsistency) in the combined estimates due to betweenstudy-variance [57]. An $I^{2}$ of $0 \%$ indicates that no inconsistency was seen between the results of individual trials and an $\mathrm{I}^{2}$ of $100 \%$ indicated maximal inconsistency. The level of heterogeneity was categorized as low (25\%), moderate (50\%) and high (75\%) [57]. A relevant study-level covariate was defined as one which was able to decrease inconsistency measured at the $\mathrm{I}^{2}$ (and thus the between-study variance $\left(\operatorname{Tau}^{2}\right)$ ) [58]. The analysis was made at the first measurement post-intervention defined in the individual studies.

Two subgroup analyses were performed. One analysis was on the number of supervised and unsupervised sessions performed to reduce pain and disability, as well as to improve performance-based lower limb function. The second analyzed the difference in 


\section{Chapter 6}

ES between functional stability exercise compared to no treatment, as well as versus functional stability exercise as an additional treatment to standard care.

Prediction intervals, encompassing the effect of a future study with 95\% certainty, were estimated in order to evaluate the quantitative impact of inconsistency using the between-study variance $\left(\mathrm{Tau}^{2}\right)$ and the SE, according to the method of Higgins et al. [52]. If the extremes of the prediction interval lead to different clinical recommendations, further research is needed.

\section{RESULTS}

\section{Study Selection}

1037 records were identified through electronic searches of five databases. After the removal of duplicates, 502 remained. Subsequent to the screening of titles and abstracts, 23 articles were found to be potentially eligible and were obtained in full text. Four additional studies [59-61] were identified from the reference lists and personal contact, resulting in a total of 27 full text assessments. Of these, 16 studies were excluded, leaving 11 articles included in the systematic review. The process of study selection is outlined in Figure 1.

\section{Study Characteristics}

The characteristics of the 11 studies are presented in Table 1. Ten trials were published between 2005 and 2012 [22, 59, 60, 62-68]. One study was at the stage of "submitted for publication" and has now been published [69]. Overall, 697 participants were included with 355 in the intervention groups and 342 in the control groups. All trials were reported in English. In 9 studies, outcomes were analyzed according to the intention-totreat principle, including all randomized individuals. Two studies analyzed only the data of those individuals who completed all assessments $[62,66]$.

Participants: The mean age of the participants in 10 of the included trials ranged from 59 to 71.2 years. One study reported only the age range (35-65) [62]. Nine studies recruited both genders (average \% of females ranged from 43.5 to 93.3 ) and two studies recruited only females $[63,65]$. 


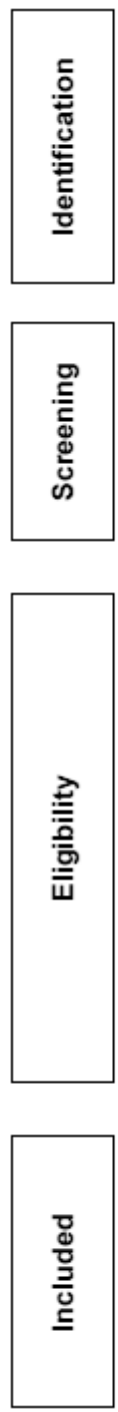

1037 records identified through database searching (181 in Medline, 281 in Embase

210 in Cochrane Database of registered trials, 59 in CINAHL, 306 in Web of Science)

502 records after removal of duplicates

512 records excluded due to inclusion/exclusion criteria

23 full-text articles assessed for eligibility

3 additional references from manual searches of the reference list,

1 additional reference from personal contact

Full-text articles excluded from final analysis $(n=16$ )

- 11 articles had no appropriate exercise group

- 3 articles did not focus on knee osteoarthritis

- 1 article was a secondary analysis of an included article

- 1 article was a sub-group analysis of an included article

Figure 1: Flowchart of the studies review process

Interventions: The intervention duration ranged from 5 - 12 weeks, the number of supervised and unsupervised sessions within this period ranged between $10-24$ and the duration of one session ranged from $20-60$ minutes. The exercise programs' intensities were not reported. Across the 11 trials, FSE were broadly similar, with all including the described four components "neuromuscular control", "core strength", "proprioception/balance" and "functional limb alignment". More specifically, the intervention consisted of a Tai Chi program in three studies $[59,65,68]$ and the NEMEX-TJR program in two studies $[67,69]$. Further details are shown in Table 2. 
Chapter 6

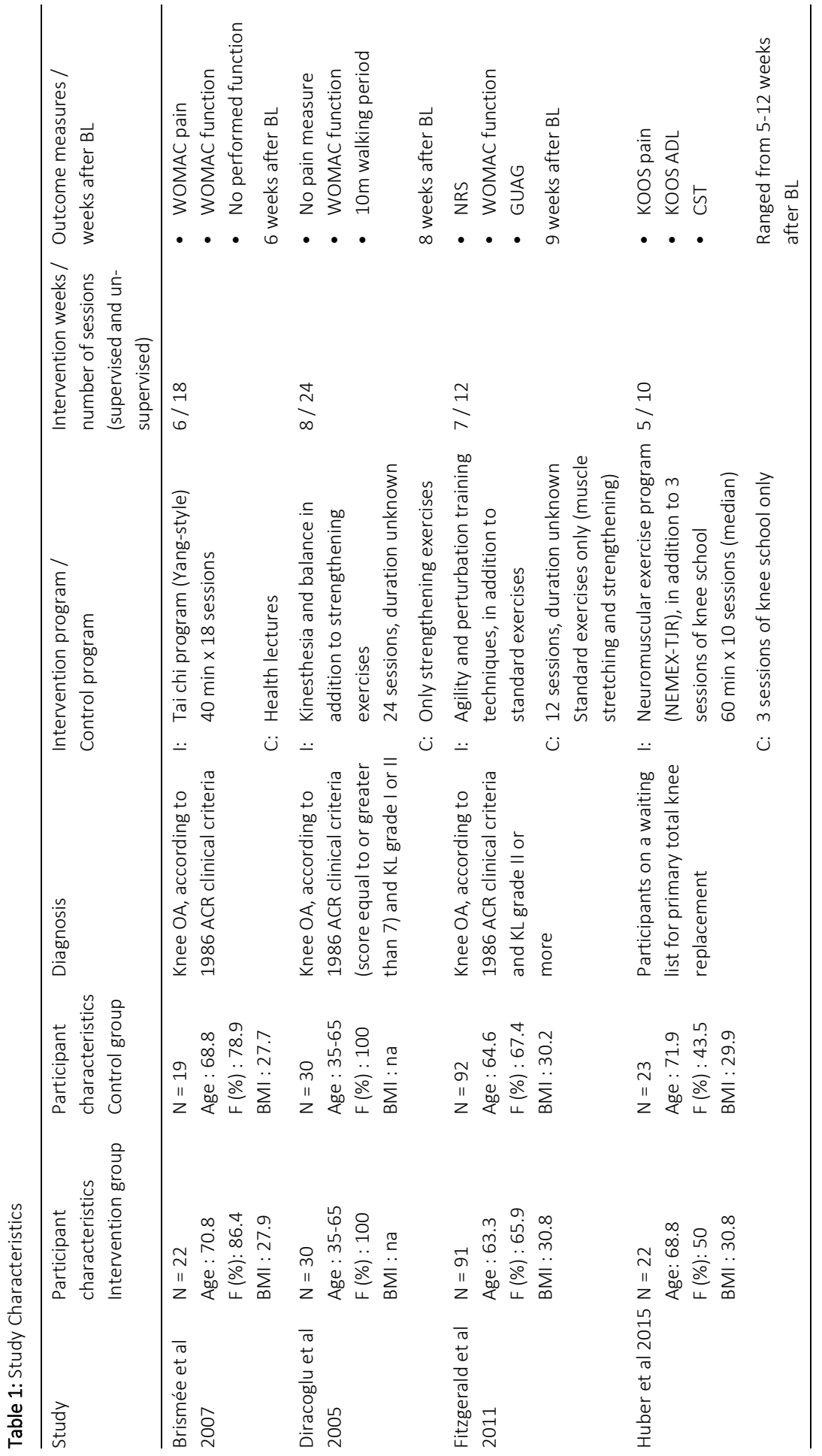


Effect of functional stability exercise programs: A meta-analysis

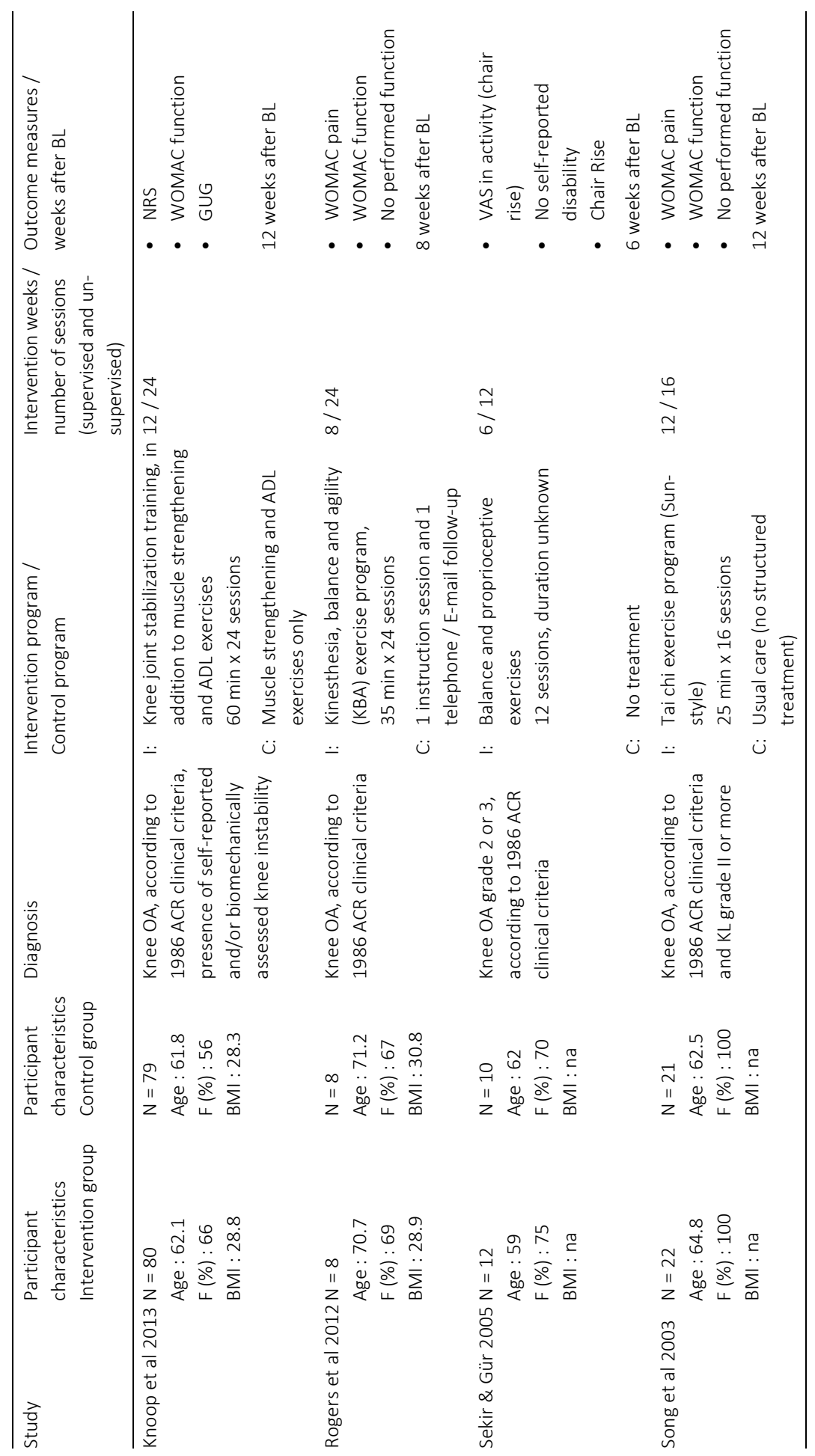




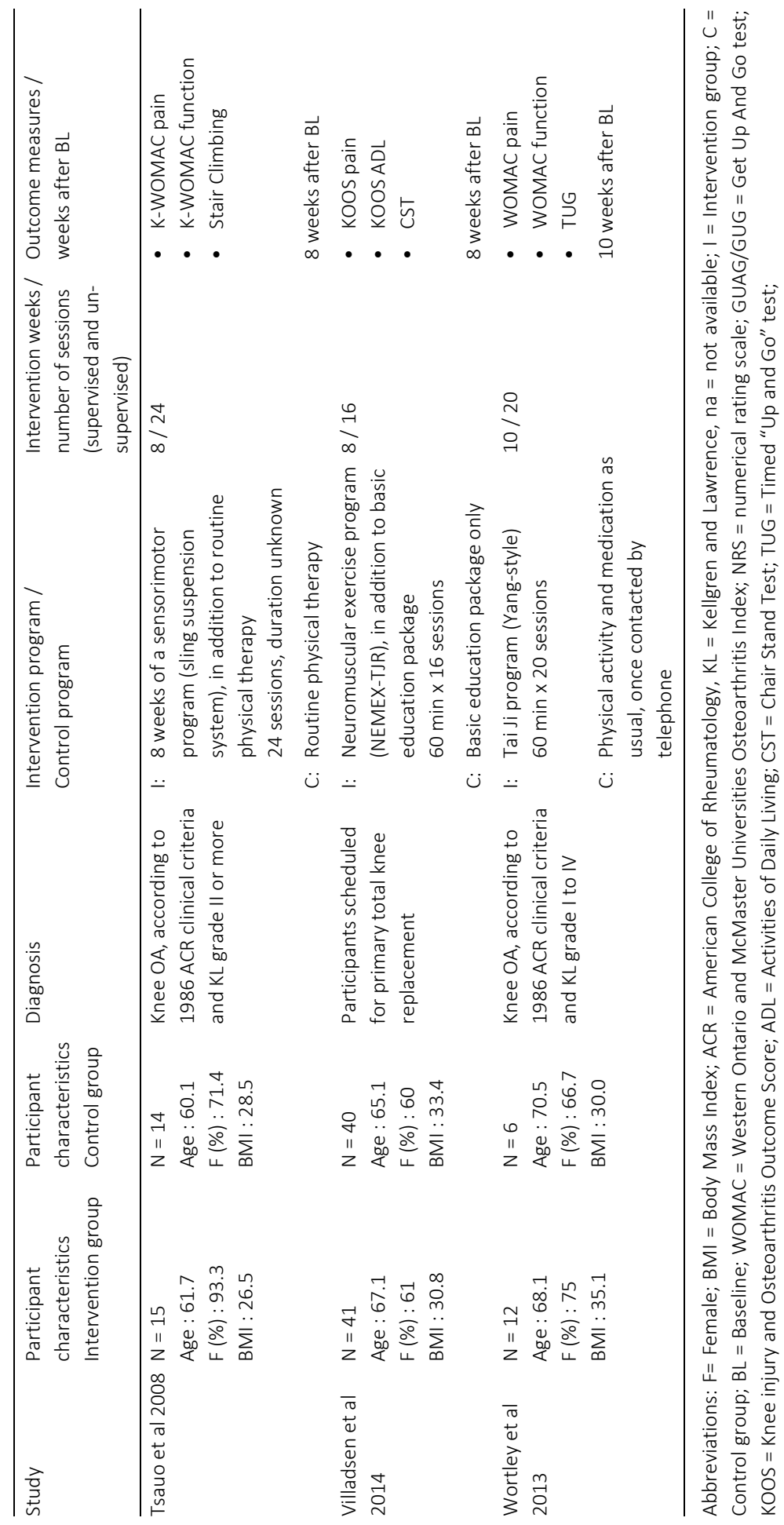




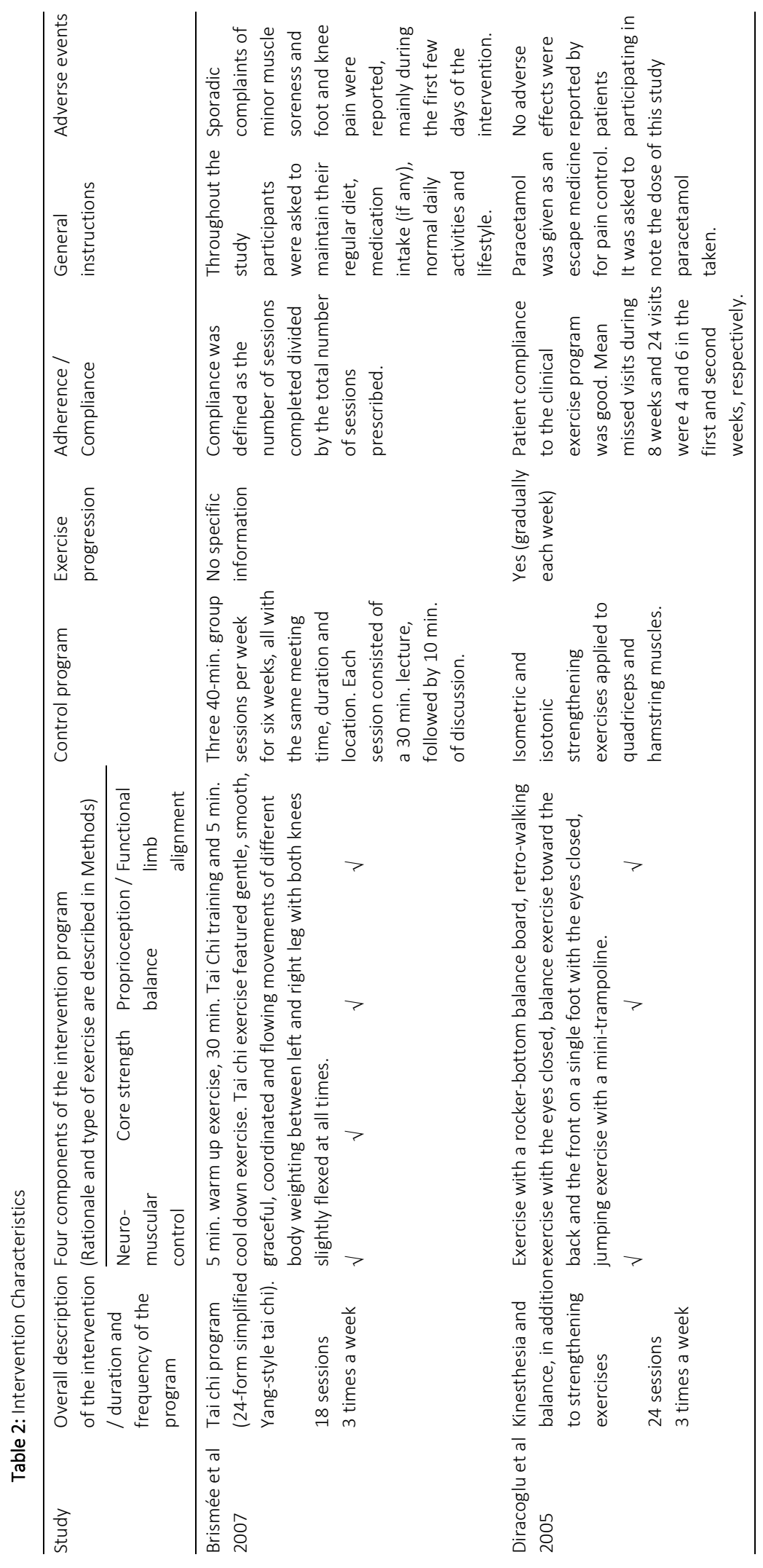

g 


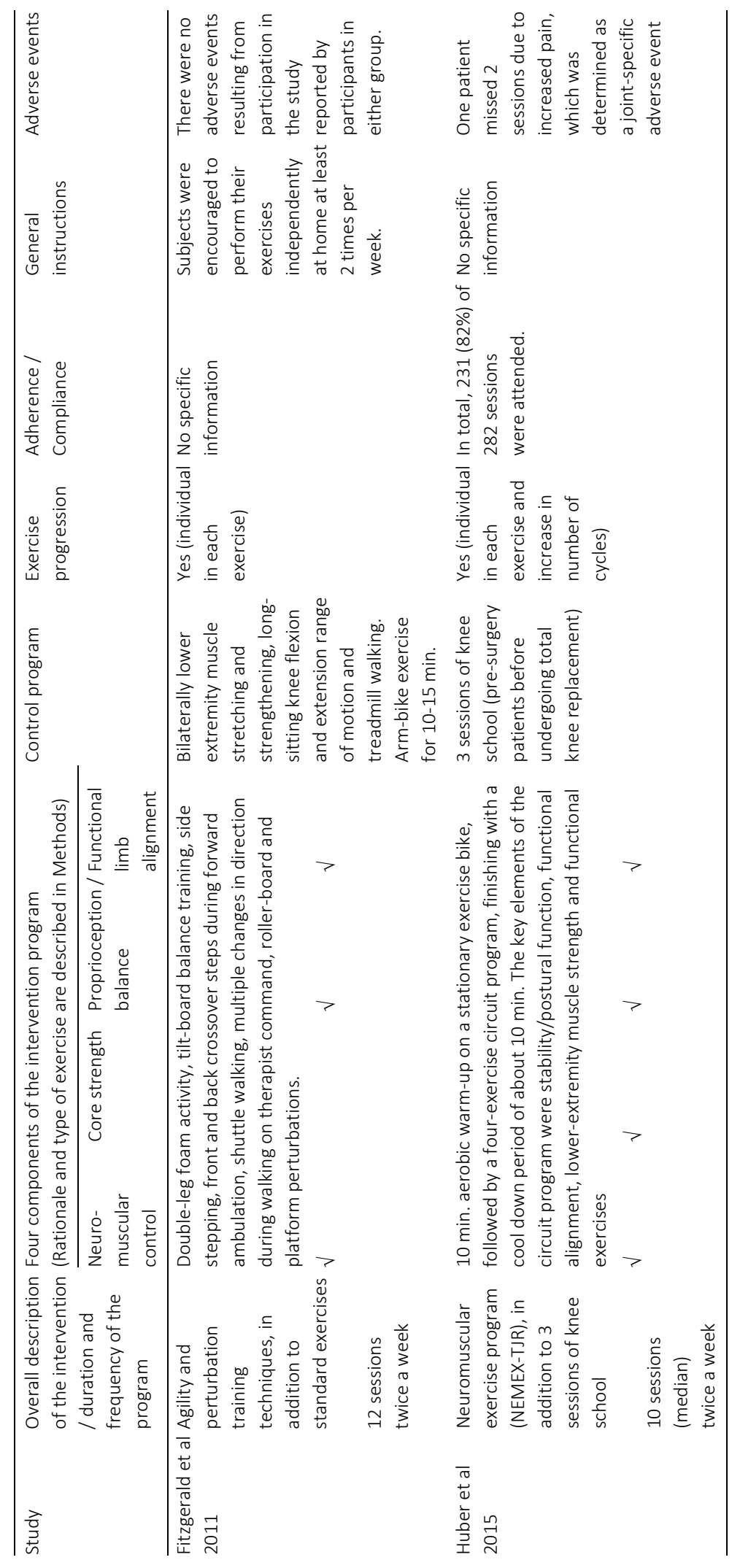




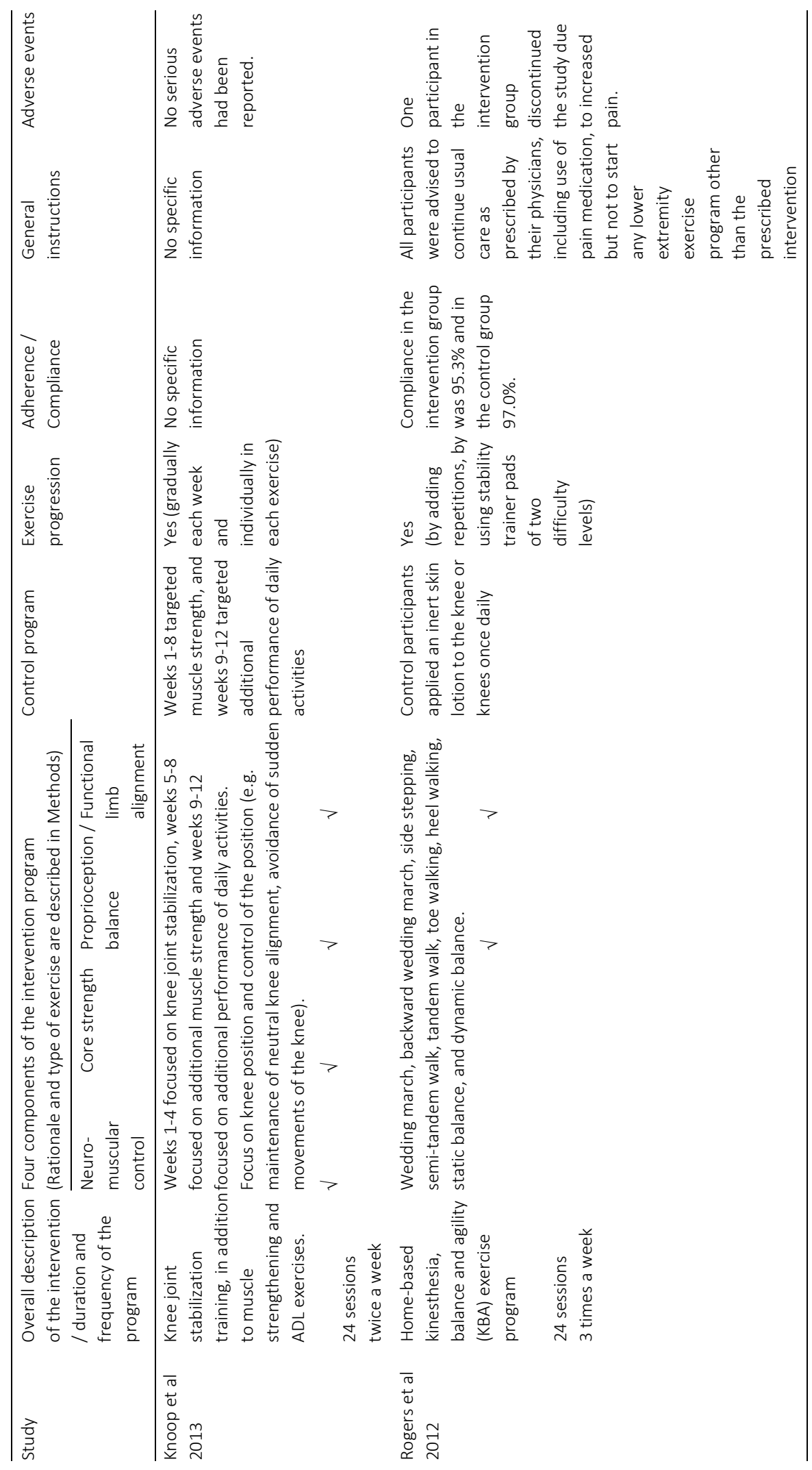




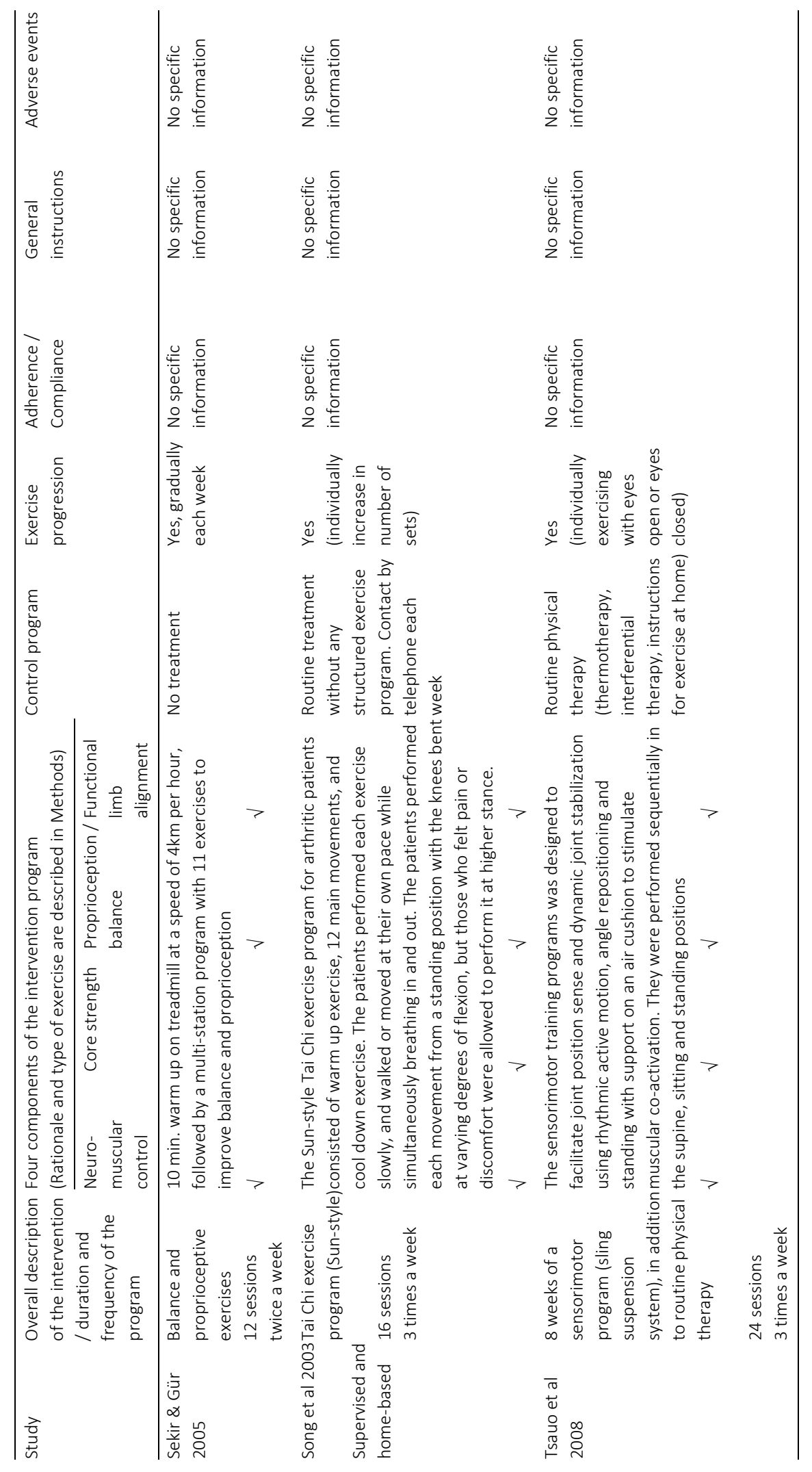




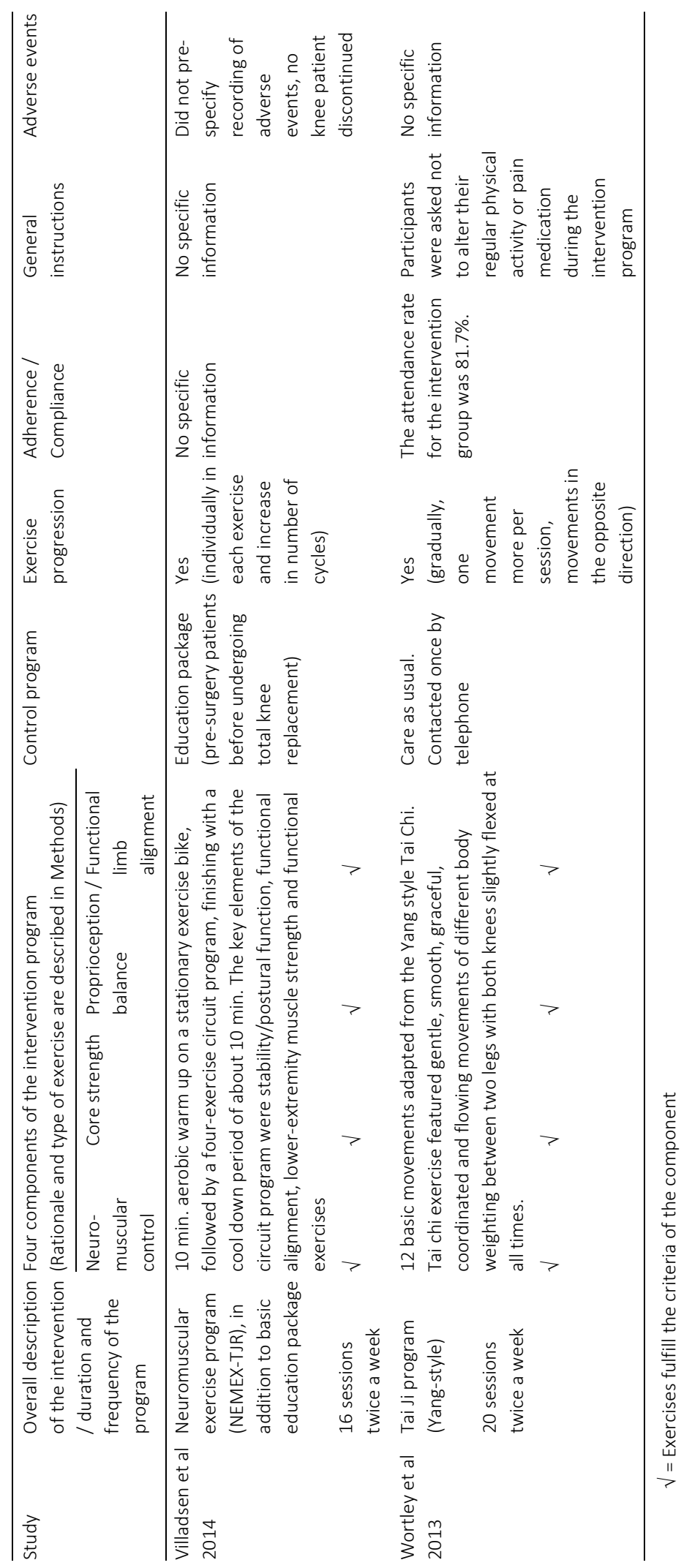




\section{Chapter 6}

Outcomes: Self-reported pain and disability were reported in 10 of the 11 trials. One trial did not report pain [62] and 1 trial did not report disability [60]. Performance-based lower limb function was reported in 8 trials. The time-period between the baseline and the first post-intervention assessment ranged from 6-12 weeks, whereas in one trial the time-period was not given in the design [69]. Further details are shown in Table 1.

\section{Assessment of Risk of Bias}

Three studies did not state, or it was unclear, as to whether they had performed a low risk sequence generation $[60,62,68]$. Six studies did not state, or it was unclear, whether they had performed an allocation concealment [22, 60, 62, 64-66]. Lack of blinding of participants and personnel were present in all studies except one [64]. In three studies, it was unclear whether the outcome assessor had been blinded [60,65, $68]$. Only two studies did not address incomplete data $[62,66]$, and one ran the risk of selective reporting [64]. The risk of bias assessment is shown in Table 3.

Table 3: Risk of Bias Assessment

\begin{tabular}{|c|c|c|c|c|c|c|c|}
\hline \multirow[t]{2}{*}{ Study } & \multicolumn{2}{|c|}{ Selection Bias } & \multirow{2}{*}{$\begin{array}{l}\text { Performance } \\
\text { Bias } \\
\text { Blinding of } \\
\text { t Participants } \\
\text { and Personnel }\end{array}$} & \multirow{2}{*}{$\begin{array}{l}\text { Detection Bias } \\
\text { Blinding of } \\
\text { Outcome } \\
\text { Assessor }\end{array}$} & \multirow{2}{*}{$\begin{array}{l}\text { Attrition Bias } \\
\text { Incomplete } \\
\text { Outcome Data } \\
\text { Addressed }\end{array}$} & \multirow{2}{*}{$\begin{array}{l}\text { Reporting } \\
\text { Bias } \\
\text { Selective } \\
\text { Outcome } \\
\text { Reporting }\end{array}$} & \multirow{2}{*}{$\begin{array}{l}\text { Other } \\
\text { Bias } \\
\text { Other } \\
\text { Source } \\
\text { of Bias }\end{array}$} \\
\hline & $\begin{array}{l}\text { Sequence } \\
\text { Generation }\end{array}$ & $\begin{array}{l}\text { Allocation } \\
\text { Concealment }\end{array}$ & & & & & \\
\hline $\begin{array}{l}\text { Brismée et } \\
\text { al, } 2007\end{array}$ & $\sqrt{ }$ & $\sqrt{ }$ & $x$ & $\sqrt{ }$ & $\sqrt{ }$ & $\sqrt{ }$ & $\sqrt{ }$ \\
\hline $\begin{array}{l}\text { Diracoglu et } \\
\text { al, } 2005\end{array}$ & $x$ & $?$ & $x$ & $\sqrt{ }$ & $x$ & $\sqrt{ }$ & $\sqrt{ }$ \\
\hline $\begin{array}{l}\text { Fitzgerald et } \\
\text { al, } 2014\end{array}$ & $\sqrt{ }$ & $\sqrt{ }$ & $x$ & $\sqrt{ }$ & $\sqrt{ }$ & $\sqrt{ }$ & $\sqrt{ }$ \\
\hline $\begin{array}{l}\text { Huber et al, } \\
\text { submitted }\end{array}$ & $\sqrt{ }$ & $\sqrt{ }$ & $x$ & $\sqrt{ }$ & $\sqrt{ }$ & $\sqrt{ }$ & $\sqrt{ }$ \\
\hline $\begin{array}{l}\text { Knoop et al, } \\
2013\end{array}$ & $\sqrt{ }$ & $?$ & $x$ & $\sqrt{ }$ & $\sqrt{ }$ & $\sqrt{ }$ & $\sqrt{ }$ \\
\hline $\begin{array}{l}\text { Rogers et al, } \\
2012\end{array}$ & $\sqrt{ }$ & $?$ & $\sqrt{ }$ & $\sqrt{ }$ & $\sqrt{ }$ & $x$ & $\sqrt{ }$ \\
\hline $\begin{array}{l}\text { Sekir \& Gür, } \\
2005\end{array}$ & $?$ & $?$ & $x$ & ? & $\sqrt{ }$ & $\sqrt{ }$ & $\sqrt{ }$ \\
\hline $\begin{array}{l}\text { Song et al, } \\
2012\end{array}$ & $\sqrt{ }$ & $?$ & $x$ & $?$ & $\sqrt{ }$ & $\sqrt{ }$ & $\sqrt{ }$ \\
\hline $\begin{array}{l}\text { Tsauo et al, } \\
2008\end{array}$ & $\sqrt{ }$ & $?$ & $x$ & $\sqrt{ }$ & $x$ & $\sqrt{ }$ & $\sqrt{ }$ \\
\hline $\begin{array}{l}\text { Villadsen et } \\
\text { al, } 2014\end{array}$ & $\sqrt{ }$ & $\sqrt{ }$ & $x$ & $\sqrt{ }$ & $\sqrt{ }$ & $\sqrt{ }$ & $\sqrt{ }$ \\
\hline $\begin{array}{l}\text { Wortley et } \\
\text { al, } 2013\end{array}$ & $x$ & $\sqrt{ }$ & $x$ & ? & $\sqrt{ }$ & $\sqrt{ }$ & $\sqrt{ }$ \\
\hline
\end{tabular}

Abbreviations: $\sqrt{ }$ = adequate; $?=$ unclear; $x$ = inadequate 


\section{Synthesis of Results}

All studies were included in the quantitative synthesis. The overall pooled SMD for pain reduction was $0.25(95 \% \mathrm{Cl} 0.09,0.41)$ in favor of exercise with no heterogeneity $\left(\mathrm{I}^{2}=\right.$ $0 \%)$. For self-reported disability and performance-based lower limb function, corresponding values were $0.27(95 \% \mathrm{Cl} 0.09,0.46)\left(\mathrm{I}^{2}=22 \%\right)$ and $0.21(95 \% \mathrm{Cl}-0.05,0.47)\left(\mathrm{I}^{2}\right.$ $=49.8 \%)$ respectively. All results are presented in Figure 3. Pre- and post-intervention results and the corresponding clinical message are presented in Table 4.

When the studies were stratified according to different aspects of study quality, no significant difference between groups were found, but a systematic greater effect in those trials judged unclear or high risk of bias was found. Stratified analysis of the impact of risk of bias on pain is presented in Figure 2.

\section{Number of sessions}

Subgroup analyses of the number of supervised and unsupervised sessions for reducing self-reported pain and disability, as well as for improving performance-based lower limb function, demonstrated no statistically significant differences. All results are presented in Figure 4.

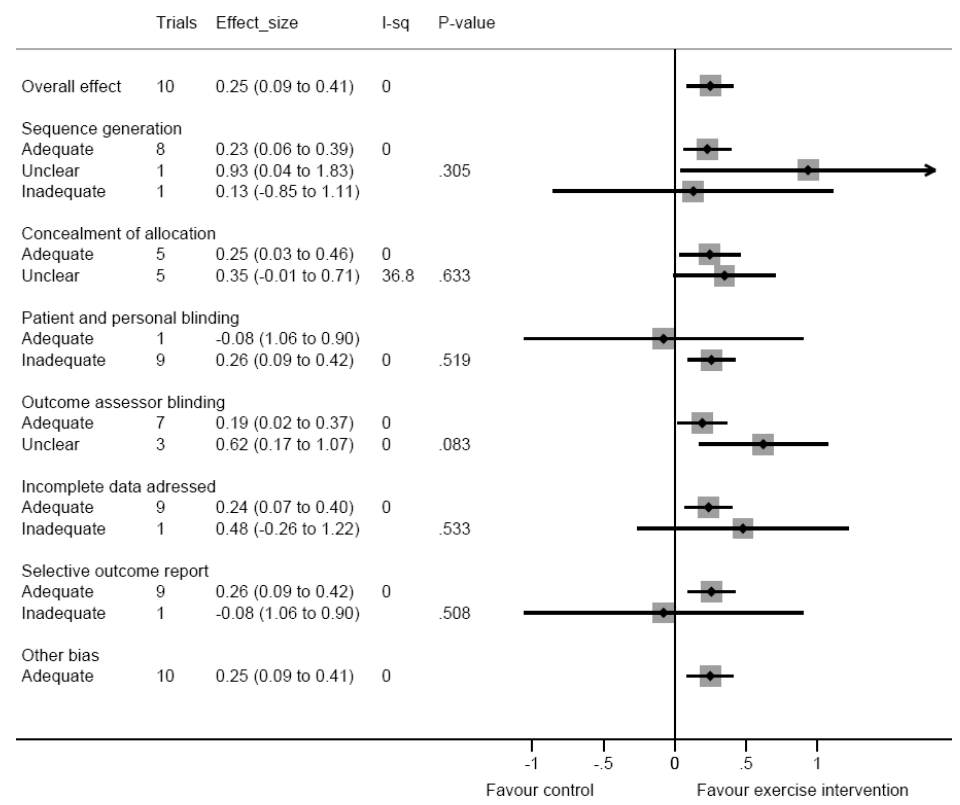

Figure 2: Analysis of the impact of risk of bias on the effect of functional stability exercises on pain. The effect size (ES) was measured as the standardized mean difference (SMD) as the difference between the mean changes in pain in the groups at the end of the exercise program, divided by the pooled standard deviation and adjusted to Hedges $g$. 


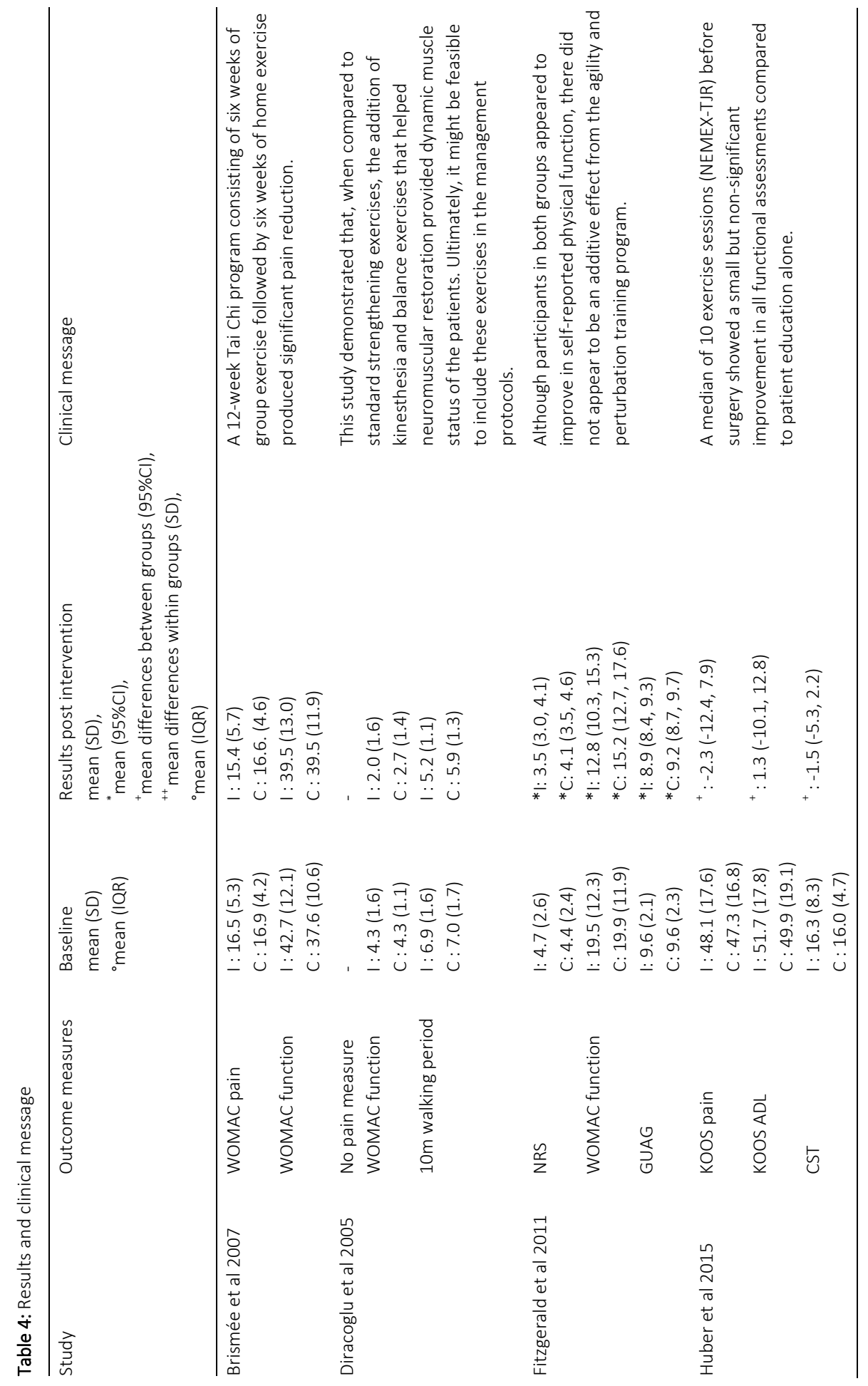




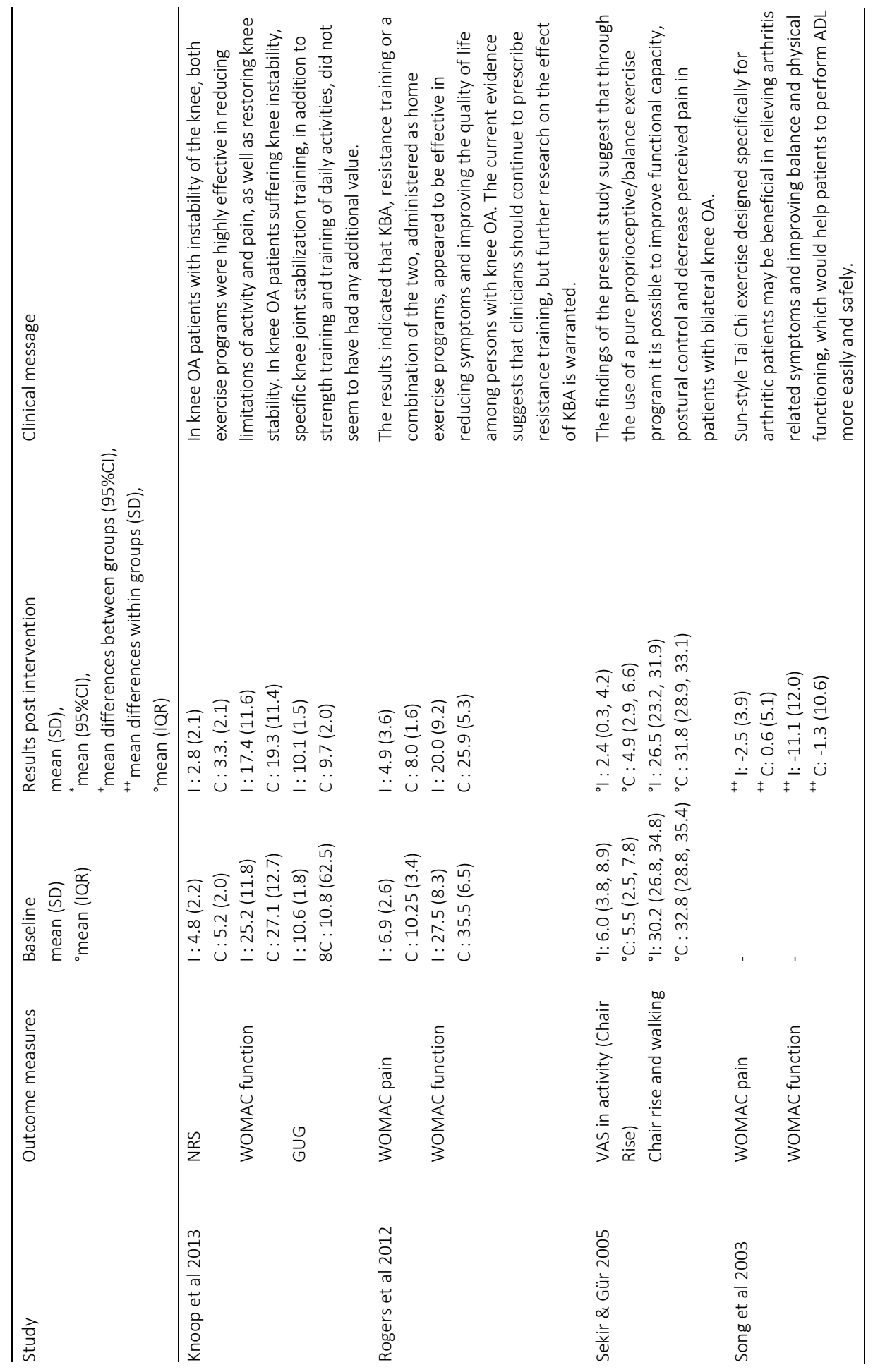




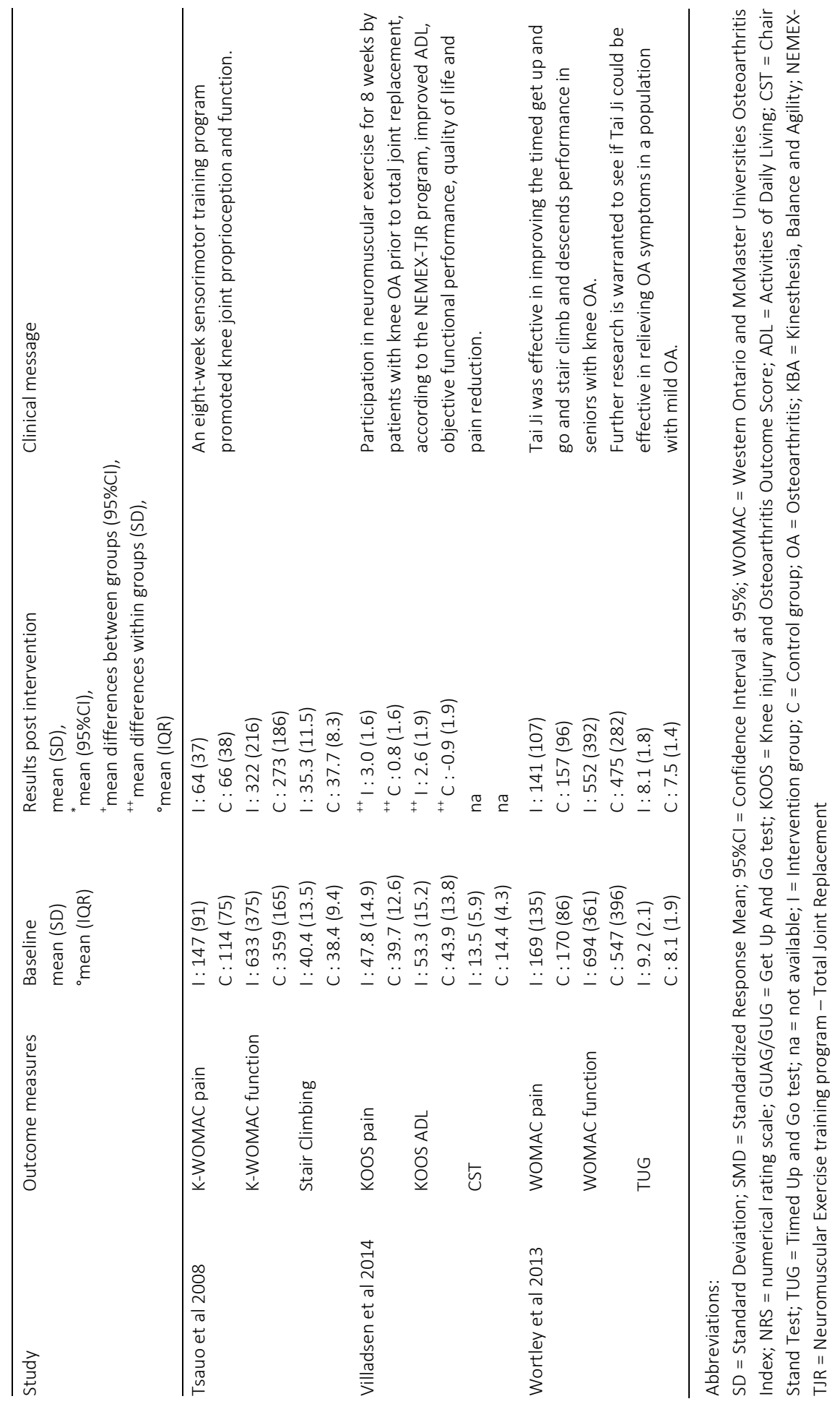


3a: Pain

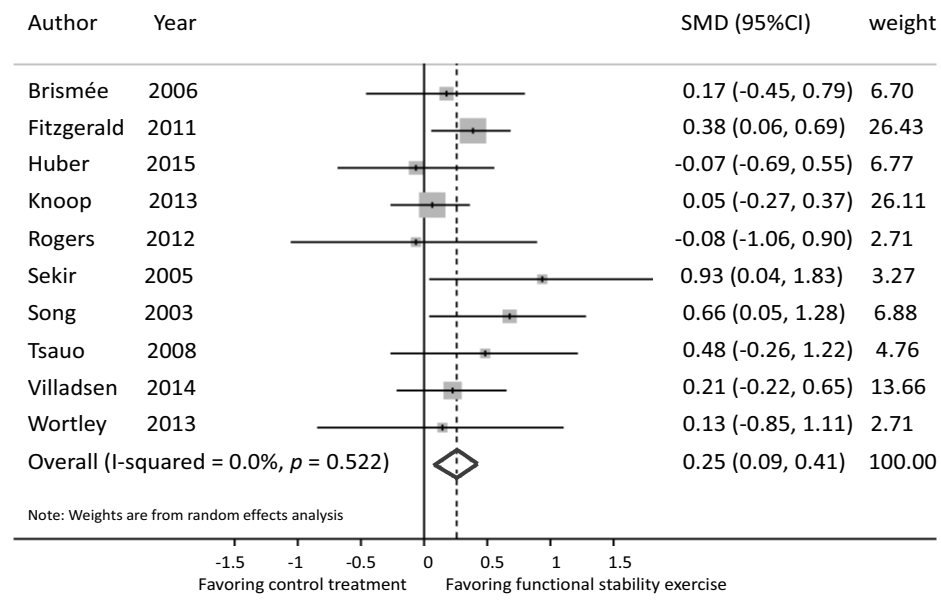

3b: Disability

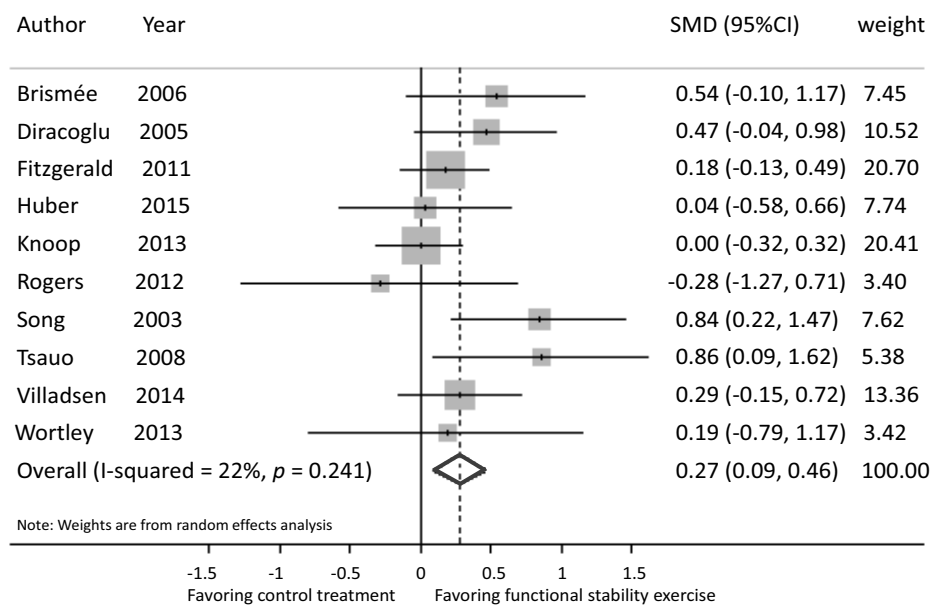




\section{Chapter 6}

3c: Performance-based lower limb function

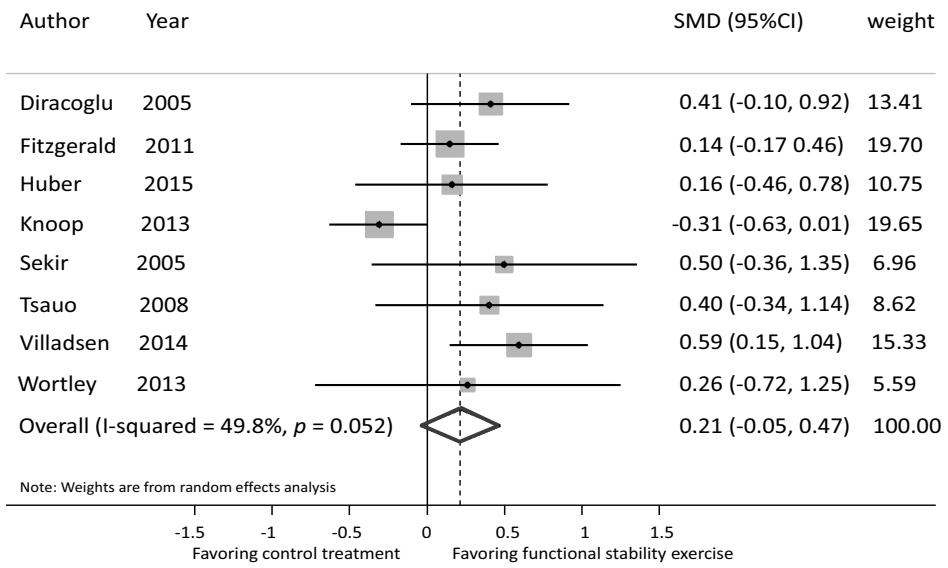

Figure 3: Forest plots on the effect of exercise on pain, disability and performance-based lower limb function. Weights are from a random effects analysis. Effects are shown with $95 \%$ confidence interval.

\section{4a: Pain}

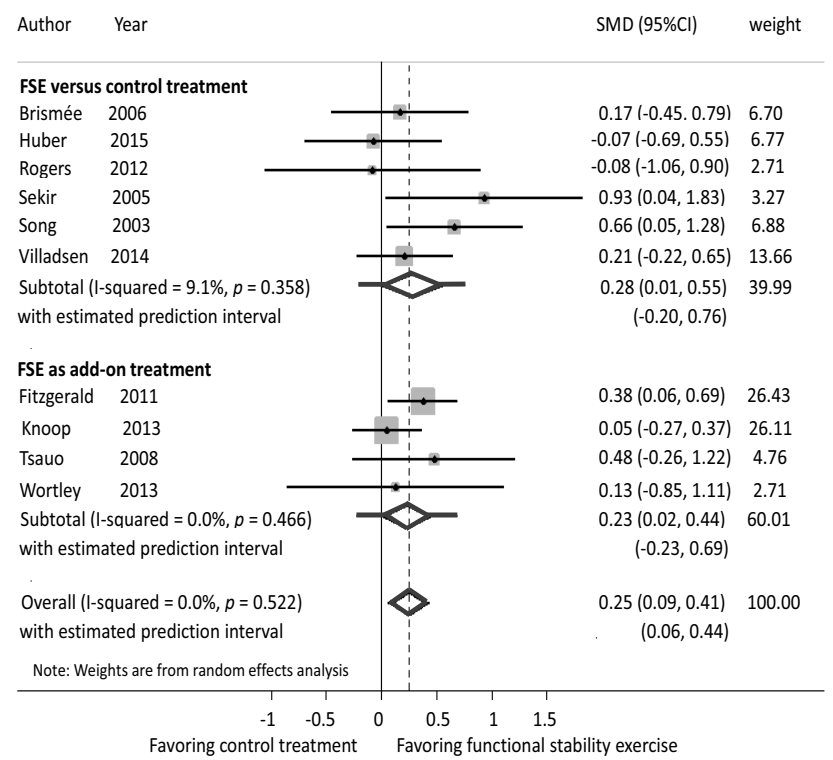


4b: Disability

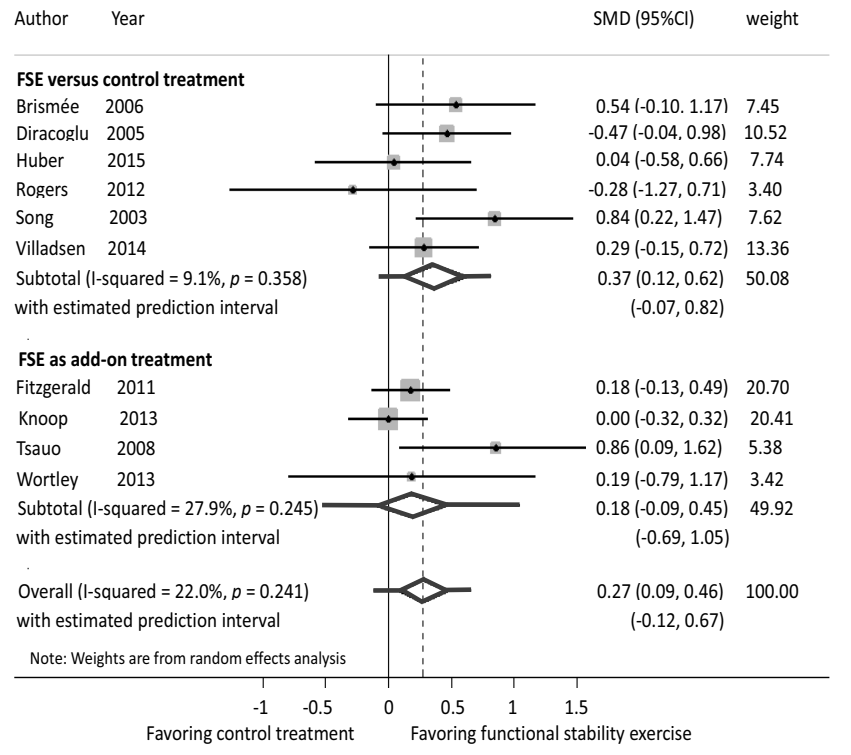

4c: Performance-based lower limb function

Author Year

$\operatorname{SMD}(95 \% \mathrm{Cl}) \quad$ weight

FSE versus control treatment

Diracoglu 2005

Huber 2015

Sekir 2005

Villadsen 2014

Subtotal (I-squared $=0.0 \%, p=0.740$ )

with estimated prediction interval

FSE as add-on treatment

Fitzgerald 2011

Knoop 2013

Tsauo 2008

Wortley 2013

Subtotal

(I-squared $=48.4 \%, p=0.121$ )

with estimated prediction interval

Overall (I-squared $=49.8 \%, p=0.052$ )

with estimated prediction interval

Note: Weights are from random effects analysis

Favoring control treatment

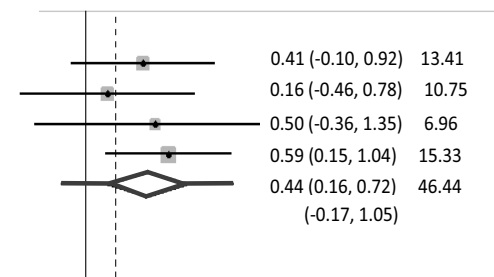

$0.14(-0.17,0.46) \quad 19.70$

$-0.31(-0.63,0.01) \quad 19.65$

$0.40(-0.34,1.14) \quad 8.62$

$0.26(-0.72,1.25) \quad 5.59$

$0.02(-0.31,0.36) \quad 53.56$

$(-1.21,1.26)$

$0.21(-0.05,0.47) \quad 100.00$

$(-0.48,0.91)$

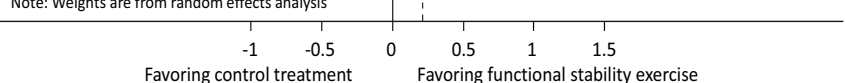

Figure 4: Forest plots on the effect of functional stability exercise as a stand-alone intervention compared to functional stability exercise as an add-on to control treatment with estimated predictive interval 


\section{Functional stability exercise as an add-on to standard exercise or as a stand-alone intervention}

Subgroup analyses of FSE as a stand-alone intervention compared to FSE as an add-on to control treatment showed a higher ES for pain (7 studies), disability (6 studies) and performance-based lower limb function (4 studies): $0.25(95 \% \mathrm{Cl} 0.09,0.41), 0.27$ $(95 \% \mathrm{Cl} 0.09,0.46), 0.21(95 \% \mathrm{Cl}-0.05,0.47)$. All results are presented in Figure 4. No small-study bias was seen for any of the three outcomes.

\section{DISCUSSION}

The main findings of our meta-analysis of 11 RCTs with a total of almost 700 patients showed a small effect of stability exercise (Figure 3). However, the results of the prediction intervals showed opposite conclusions from the two extremes of the prediction intervals for all three outcomes (Figure 4). The left extreme indicate that stabilizing exercise have no effect, while the right extreme indicate a high/moderate effect of stabilizing exercise for all three outcomes. Thus, further research is needed before a final conclusion can be made. The subgroup analyses comparing studies where FSE was add-on to a standard exercise program or not showed ambiguous results. The assumption that FSE can be tested either as a sole intervention or as an add-on was confirmed for pain but not for disability or performance-based function (Figure 4). Thus, further research should primarily focus on a design in which FSE is compared to a control or a placebo intervention.

In order to avoid the risk of making clinical decisions based upon only one or a few studies (single study bias), a systematic review including all studies evaluating the question needs to be performed. A key aspect of any systematic review is the definition of the method to be applied prior to performing the literature search and the subsequent meta-analysis [36]. The very reason for performing a systematic review is two-fold: firstly, to investigate whether we have a definite answer to the question under review or secondly, to ascertain whether further research is needed. The results from our present review clearly show that we do not have a definite answer to our question and that, further research is needed. As can be seen below under the Implications for further research, the analysis of the included studies, together with the results of the meta-analyses, make it possible to formulate specific recommendations for further RCTs to evaluate the effect of FSE on pain and disability for patients with knee OA [36].

An immediate argument for the lack of a clear result could be the heterogeneity of the interventions used in the eligible studies in this review. Even though different types of exercise were included, the statistical heterogeneity was very low or even absent. Earlier meta-analyses, including all kinds of exercise types, showed a high heterogeneity $[4,5]$, which could not be explained by type of exercise, patient characteristics or dis- 
ease-specific covariates [5]. The low heterogeneity may indicate that the different exercise programs have something in common, even though the program here denoted FSE, is not clearly defined.

In considering physical exercise as therapeutic intervention different aspects, such as muscle strength, range of motion, aerobic capacity, performance etc. could be involved. In order to focus on the ability of the knee OA patient to perform various daily activities, such as walking, running, stair climbing, stand up and sit down and such like, and taking into consideration that many patients with knee OA have difficulties in performing these activities (maybe due to impairments involving the control of the knee) FSE may be a possible approach. Even though the definition only demanded that one of four criteria be fulfilled, all 11 studies included the components "proprioception/balance" and "functional limb alignment", i.e. at least two of the four criteria was fulfilled. However, the types of exercise applied were still heterogeneous and subgroup analyses (e.g. perturbation, Tai Chi, NEMEX-TJR) were not possible due to the low number of available studies.

The comparators in our studies were heterogeneous. Five trials conducted active control treatment (some type of exercises, e.g. muscle stretching, strengthening), 2 trials conducted care as usual and only 4 trials offered no treatment or attention control (i.e. education sessions or telephone contact). Although a placebo-control is generally considered the ideal comparator group in drug trials, placebo interventions in rehabilitation trials are difficult to devise and implement [70]. Therefore, we took a pragmatic approach [70-72] and formulated inclusion criteria including RCTs with attention control as well. Besides the obvious effect of attention recruitment of participants could be limited if the control intervention are less desirable than the study intervention [73].

Subgroup analyses comparing studies where FSE was an add-on to a standard exercise program or a stand-alone intervention showed ambiguous results. The assumption that stabilizing exercise can be tested either as a sole intervention or as an add-on was confirmed for pain, but not for disability or performance-based lower limb function (Figure 4).

The number of sessions ranged from 10 to 24. Surprisingly, in our systematic review, a greater number of sessions did not show a larger ES. On the contrary, in pain and performance-based lower limb function, a smaller number of sessions even led to a higher ES. These findings are contradictory to other findings. In their systematic review, Juhl et al. found that the more supervised aerobic sessions performed the higher was the effect size [5].

Whether the exercise was or was not weight-bearing was not an influencing factor, confirming previous results by Jan et al., where weight-bearing exercises showed equally significant improvements in the WOMAC physical functional scale as non-weightbearing exercises [74]. But the results may be influenced by other factors, such as intensity and the progression of each single exercise in the programs. It was not possible 


\section{Chapter 6}

to control for these factors due to the huge variety of single exercises and insufficient descriptions in some of the studies.

Our study has several strengths. We performed a comprehensive search of several databases to identify eligible trials and included only randomized controlled trials. We reduced potential bias in the conduct of this review by having two reviewers, who independently screened titles and abstracts for study eligibility and assessed the methodology of each trial. In recent years exercises that target muscle timing and function rather than purely strength has received increased interest [12, 75]. To the author's knowledge, this is the first review that synthesizes the results of studies evaluating a FSE regimen in patients with knee $O A$.

The main limitations of the present meta-analysis were that the quality of the included trials was low or unclear in terms of selection and detection bias, and that the number of participants in each included study was low. These limitations could explain the lack of a clear final result.

Another potential problem is that the chosen performance-based outcome measures may not have been sufficiently sensitive to capture aspects of lower limb function that might be more influenced by functional stability exercise programs. Tests to assess performance-based function were variable and in the majority encompassed sit-to-stand activities as well as walking and ambulatory transition activities. For example: Fitzgerald et al.[63] presented a pre- to post-exercise between-group difference in the Get Up and Go Test (GUAG) of 0.3 seconds, which the authors did not consider as clinically meaningful. Knoop et al. [22] presented a pre- to post-exercise between-group difference in the Get Up and Go Test (GUG) of 0.6 seconds in favor of the control group. Tsauo et al. [66] presented a pre- to post-exercise between-group difference in Stair Climbing (a flight of 13 stairs) of 4.3 seconds. In summary, the reported pre- to postexercise between-group differences are to be interpreted with caution and are generally not considered as clinically meaningful. Therefore, assessments targeted more specifically at functional stability could be taken into account, which might provide additional information and contribute to a better understanding of the results.

In addition, we did not control for several potential confounders, e.g. mood or selfefficacy. Decreased depression symptoms influence self-perceived pain and disability [10]. Respectively, persons of the "depression phenotype" demonstrate the highest levels of pain and activity limitations [76]. Self-efficacy (one's belief in one's own ability to perform tasks) is associated with good adherence and better outcomes, resulting in an increasing impact of the benefits of exercise over time [77]. 


\section{CONCLUSION}

An analysis of the prediction intervals of all three outcomes indicates that further research is needed. Thus, no final conclusion can be made about the effect size of stabilizing exercise for patients with knee osteoarthritis.

\section{Implications for further research}

The explanations for the effect on pain and function following exercise for patients with knee OA need to be further evaluated. Two different studies have shown a great variety of explanations. $[9,10]$ A systematic review evaluating the evidence for the various suggested explanations could provide indicators of the most promising explanations. Thereby, a theoretical argument as to when strengthening exercise, aerobic capacity exercise or FSE is most appropriate could be found.

In addition, further clinical research should consist of randomized clinical trials involving participants of 50 years and older, both genders, and classified as mild, moderate or severe OA. Additional information about knee instability and knee mal-alignment is desired. The RCTs should be designed such that FSE is compared to a control or a placebo intervention. The effect of the main outcomes pain and disability should be measured immediately after intervention and after a sufficient follow-up time. Furthermore, the interventions need to be sufficiently described according to type of exercise and dose (intensity, progressions, frequency and duration), in order to be able to replicate the study and eventually implement the exercise in clinical practice.

\section{Implications for practice}

Our results do not indicate that FSE is harmful. Therefore, there is no reason why practitioners, who have good theoretical and clinical reasons for using FSE or a similar exercise program, should not continue to do so. Clinicians should be aware, however, that future studies might lead to a synthesized result showing that FSE is ineffective.

\section{KEY POINTS}

\section{Findings}

The main finding was a small effect in favor of functional stability exercise on selfreported pain, self-reported disability and performance-based lower limb function. However, large prediction intervals indicate that no final conclusion can be made and that further research is needed. 
Chapter 6

\section{Implications}

When clinicians have good theoretical and clinical argumentation functional stability exercise programs are feasible and safe and could be used for patients with knee OA, alone or in addition to other exercise programs.

\section{Cautions}

Prediction intervals indicate a need for further research before any final conclusion can be drawn on the effectiveness of functional stability exercises for patients with knee OA. 


\section{REFERENCES}

1. Woolf AD, Pfleger B: Burden of major musculoskeletal conditions. Bull World Health Organ 2003, 81(9):646-656.

2. Murphy L, Schwartz TA, Helmick CG, Renner JB, Tudor G, Koch G, Dragomir A, Kalsbeek WD, Luta G, Jordan JM: Lifetime risk of symptomatic knee osteoarthritis. Arthritis Rheum 2008, 59(9):1207-1213.

3. McAlindon TE, Bannuru RR, Sullivan MC, Arden NK, Berenbaum F, Bierma-Zeinstra SM, Hawker GA, Henrotin Y, Hunter DJ, Kawaguchi H et al: OARSI guidelines for the non-surgical management of knee osteoarthritis. Osteoarthritis Cartilage 2014, 22(3):363-388.

4. Fransen M, McConnell S, Harmer AR, Van der Esch M, Simic M, Bennell KL: Exercise for osteoarthritis of the knee. Cochrane Database Syst Rev 2015, 1:CD004376.

5. Juhl C, Christensen R, Roos EM, Zhang W, Lund H: Impact of exercise type and dose on pain and disability in knee osteoarthritis: a systematic review and meta-regression analysis of randomized controlled trials. Arthritis Rheumatol 2014, 66(3):622-636.

6. Iversen MD: Rehabilitation interventions for pain and disability in osteoarthritis: a review of interventions including exercise, manual techniques, and assistive devices. Orthop Nurs 2012, 31(2):103-108.

7. Bennell KL, Hinman RS: A review of the clinical evidence for exercise in osteoarthritis of the hip and knee. $J$ Sci Med Sport 2011, 14(1):4-9.

8. Escalante Y, Garcia-Hermoso A, Saavedra JM: Effects of exercise on functional aerobic capacity in lower limb osteoarthritis: a systematic review. J Sci Med Sport 2011, 14(3):190-198.

9. Runhaar J, Luijsterburg P, Dekker J, Bierma-Zeinstra SM: Identifying potential working mechanisms behind the positive effects of exercise therapy on pain and function in osteoarthritis; a systematic review. Osteoarthritis Cartilage 2015, 23(7):1071-1082.

10. Beckwée $D$, Vaes $P$, Cnudde $M$, Swinnen E, Bautmans I: Osteoarthritis of the knee: why does exercise work? A qualitative study of the literature. Ageing Res Rev 2013, 12(1):226-236.

11. Roos EM, Herzog W, Block JA, Bennell KL: Muscle weakness, afferent sensory dysfunction and exercise in knee osteoarthritis. Nat Rev Rheumatol 2011, 7(1):57-63.

12. Bennell KL, Wrigley TV, Hunt MA, Lim BW, Hinman RS: Update on the role of muscle in the genesis and management of knee osteoarthritis. Rheum Dis Clin North Am 2013, 39(1):145-176.

13. Fitzgerald GK, Piva SR, Irrgang JJ: Reports of joint instability in knee osteoarthritis: its prevalence and relationship to physical function. Arthritis Rheum 2004, 51(6):941-946.

14. Felson DT, Niu J, McClennan C, Sack B, Aliabadi P, Hunter DJ, Guermazi A, Englund M: Knee buckling: prevalence, risk factors, and associated limitations in function. Ann Intern Med 2007, 147(8):534-540.

15. Schmitt LC, Fitzgerald GK, Reisman AS, Rudolph KS: Instability, laxity, and physical function in patients with medial knee osteoarthritis. Phys Ther 2008, 88(12):1506-1516.

16. Ramsey DK, Briem K, Axe MJ, Snyder-Mackler L: A mechanical theory for the effectiveness of bracing for medial compartment osteoarthritis of the knee. J Bone Joint Surg Am 2007, 89(11):2398-2407.

17. Creaby MW, Wrigley TV, Lim BW, Hinman RS, Bryant AL, Bennell KL: Self-reported knee joint instability is related to passive mechanical stiffness in medial knee osteoarthritis. BMC Musculoskelet Disord 2013, 14:326.

18. Ageberg E, Link A, Roos EM: Feasibility of neuromuscular training in patients with severe hip or knee OA: The individualized goal-based NEMEX-TJR training program. Bmc Musculoskeletal Disorders 2010, 11:7.

19. Ageberg E, Roos EM: Neuromuscular exercise as treatment of degenerative knee disease. Exerc Sport Sci Rev 2015, 43(1):14-22.

20. Bennell KL, Kyriakides M, Metcalf B, Egerton T, Wrigley TV, Hodges PW, Hunt MA, Roos EM, Forbes A, Ageberg $\mathrm{E}$ et al: Neuromuscular versus quadriceps strengthening exercise in patients with medial knee osteoarthritis and varus malalignment: a randomized controlled trial. Arthritis Rheumatol 2014, 66(4):950959.

21. Bennell KL, Dobson F, Roos EM, Skou ST, Hodges P, Wrigley TV, Kyriakides M, Metcalf B, Hunt MA, Hinman RS: The influence of biomechanical characteristics on pain and function outcomes from exercise 
in medial knee osteoarthritis and varus malalignment: exploratory analyses from a randomised controlled trial. Arthritis Care Res (Hoboken) 2015.

22. Knoop J, Dekker J, van der Leeden M, van der Esch M, Thorstensson CA, Gerritsen M, Voorneman RE, Peter WF, de Rooij M, Romviel S et al: Knee joint stabilization therapy in patients with osteoarthritis of the knee: a randomized, controlled trial. Osteoarthritis Cartilage 2013, 21(8):1025-1034.

23. Brand E, Nyland J, Henzman C, McGinnis M: Arthritis self-efficacy scale scores in knee osteoarthritis: a systematic review and meta-analysis comparing arthritis self-management education with or without exercise. The Journal of orthopaedic and sports physical therapy 2013, 43(12):895-910.

24. de Oliveira Melo M, Aragao FA, Vaz MA: Neuromuscular electrical stimulation for muscle strengthening in elderly with knee osteoarthritis - a systematic review. Complement Ther Clin Pract 2013, 19(1):27-31.

25. Esser S, Bailey A: Effects of exercise and physical activity on knee osteoarthritis. Current pain and headache reports 2011, 15(6):423-430.

26. Golightly YM, Allen KD, Caine DJ: A comprehensive review of the effectiveness of different exercise programs for patients with osteoarthritis. Phys Sportsmed 2012, 40(4):52-65.

27. Hochberg MC, Altman RD, April KT, Benkhalti M, Guyatt G, McGowan J, Towheed T, Welch V, Wells G, Tugwell P: American College of Rheumatology 2012 recommendations for the use of nonpharmacologic and pharmacologic therapies in osteoarthritis of the hand, hip, and knee. Arthritis Care Res (Hoboken) 2012, 64(4):465-474.

28. Jansen MJ, Viechtbauer W, Lenssen AF, Hendriks EJ, de Bie RA: Strength training alone, exercise therapy alone, and exercise therapy with passive manual mobilisation each reduce pain and disability in people with knee osteoarthritis: a systematic review. J Physiother 2011, 57(1):11-20.

29. Kristensen J, Franklyn-Miller A: Resistance training in musculoskeletal rehabilitation: a systematic review. Br J Sports Med 2012, 46(10):719-726.

30. Loew L, Brosseau L, Wells GA, Tugwell P, Kenny GP, Reid R, Maetzel A, Huijbregts M, McCullough C, De Angelis $\mathrm{G}$ et al: Ottawa panel evidence-based clinical practice guidelines for aerobic walking programs in the management of osteoarthritis. Archives of physical medicine and rehabilitation 2012, 93(7):12691285.

31. Loyola-Sanchez A, Richardson J, Maclntyre NJ: Efficacy of ultrasound therapy for the management of knee osteoarthritis: a systematic review with meta-analysis. Osteoarthritis Cartilage 2010, 18(9):1117-1126.

32. Vincent KR, Vincent HK: Resistance exercise for knee osteoarthritis. PM \& $R$ : the journal of injury, function, and rehabilitation 2012, 4(5 Suppl):S45-52.

33. Wallis JA, Taylor NF: Pre-operative interventions (non-surgical and non-pharmacological) for patients with hip or knee osteoarthritis awaiting joint replacement surgery--a systematic review and meta-analysis. Osteoarthritis Cartilage 2011, 19(12):1381-1395.

34. Tanaka R, Ozawa J, Kito N, Moriyama H: Efficacy of strengthening or aerobic exercise on pain relief in people with knee osteoarthritis: a systematic review and meta-analysis of randomized controlled trials. Clin Rehabil 2013, 27(12):1059-1071.

35. Waller B, Ogonowska-Slodownik A, Vitor M, Lambeck J, Daly D, Kujala UM, Heinonen A: Effect of therapeutic aquatic exercise on symptoms and function associated with lower limb osteoarthritis: systematic review with meta-analysis. Phys Ther 2014, 94(10):1383-1395.

36. Higgins JP GSe: Cochrane Handbook for Systematic Reviews of Interventions 5.1.0 [updated March 2011] The Cochrane Collaboration, 20112011.

37. Altman R, Asch E, Bloch D, Bole G, Borenstein D, Brandt K, Christy W, Cooke TD, Greenwald R, Hochberg $M$ et al: Development of criteria for the classification and reporting of osteoarthritis. Classification of osteoarthritis of the knee. Diagnostic and Therapeutic Criteria Committee of the American Rheumatism Association. Arthritis Rheum 1986, 29(8):1039-1049.

38. Williams GN, Chmielewski T, Rudolph K, Buchanan TS, Snyder-Mackler L: Dynamic knee stability: current theory and implications for clinicians and scientists. J Orthop Sports Phys Ther 2001, 31(10):546-566.

39. Williams GN, Barrance PJ, Snyder-Mackler L, Axe MJ, Buchanan TS: Specificity of muscle action after anterior cruciate ligament injury. J Orthop Res 2003, 21(6):1131-1137. 
40. Hortobagyi T, Westerkamp L, Beam S, Moody J, Garry J, Holbert D, DeVita P: Altered hamstringquadriceps muscle balance in patients with knee osteoarthritis. Clin Biomech (Bristol, Avon) 2005, 20(1):97-104.

41. Mills K, Hunt MA, Leigh R, Ferber R: A systematic review and meta-analysis of lower limb neuromuscular alterations associated with knee osteoarthritis during level walking. Clin Biomech (Bristol, Avon) 2013, 28(7):713-724.

42. Hurley MV, Scott DL, Rees J, Newham DJ: Sensorimotor changes and functional performance in patients with knee osteoarthritis. Ann Rheum Dis 1997, 56(11):641-648.

43. Myer GD, Brunner HI, Melson PG, Paterno MV, Ford KR, Hewett TE: Specialized neuromuscular training to improve neuromuscular function and biomechanics in a patient with quiescent juvenile rheumatoid arthritis. Phys Ther 2005, 85(8):791-802.

44. Hortobagyi T, Garry J, Holbert D, Devita P: Aberrations in the control of quadriceps muscle force in patients with knee osteoarthritis. Arthritis Rheum 2004, 51(4):562-569.

45. Pai YC, Rymer WZ, Chang RW, Sharma L: Effect of age and osteoarthritis on knee proprioception. Arthritis Rheum 1997, 40(12):2260-2265.

46. Shakoor N, Agrawal A, Block JA: Reduced lower extremity vibratory perception in osteoarthritis of the knee. Arthritis Rheum 2008, 59(1):117-121.

47. Hassan BS, Mockett S, Doherty M: Static postural sway, proprioception, and maximal voluntary quadriceps contraction in patients with knee osteoarthritis and normal control subjects. Ann Rheum Dis 2001, 60(6):612-618.

48. Hinman RS, Bennell KL, Metcalf BR, Crossley KM: Balance impairments in individuals with symptomatic knee osteoarthritis: a comparison with matched controls using clinical tests. Rheumatology (Oxford) 2002, 41(12):1388-1394

49. Chaipinyo K, Karoonsupcharoen O: No difference between home-based strength training and home-based balance training on pain in patients with knee osteoarthritis: a randomised trial. Aust J Physiother 2009, 55(1):25-30.

50. Sharma L, Cahue S, Song J, Hayes K, Pai YC, Dunlop D: Physical functioning over three years in knee osteoarthritis: role of psychosocial, local mechanical, and neuromuscular factors. Arthritis Rheum 2003, 48(12):3359-3370.

51. Juhl C, Lund H Fau - Roos EM, Roos Em Fau - Zhang W, Zhang W Fau - Christensen R, Christensen R: A hierarchy of patient-reported outcomes for meta-analysis of knee osteoarthritis trials: empirical evidence from a survey of high impact journals. (2090-1992 (Electronic)).

52. Higgins JP, Thompson SG, Spiegelhalter DJ: A re-evaluation of random-effects meta-analysis. J R Stat SoC Ser A Stat Soc 2009, 172(1):137-159.

53. Egger M, Davey Smith G, Schneider M, Minder C: Bias in meta-analysis detected by a simple, graphical test. BMJ 1997, 315(7109):629-634.

54. Cohen J: Statistical Power Analysis for the Behavioral Sciences, Second Edition: Lawrence Erlbaum Assoc Inc; 1988.

55. DerSimonian R, Laird N: Meta-analysis in clinical trials. Control Clin Trials 1986, 7(3):177-188.

56. Higgins JP, Thompson SG: Quantifying heterogeneity in a meta-analysis. Stat Med 2002, 21(11):15391558.

57. Higgins JP, Thompson SG, Deeks JJ, Altman DG: Measuring inconsistency in meta-analyses. BMJ 2003, 327(7414):557-560.

58. Thompson SG, Higgins JP: Treating individuals 4: can meta-analysis help target interventions at individuals most likely to benefit? Lancet 2005, 365(9456):341-346.

59. Brismee JM, Paige RL, Chyu MC, Boatright JD, Hagar JM, McCaleb JA, Quintela MM, Feng D, Xu KT, Shen $\mathrm{CL}$ : Group and home-based tai chi in elderly subjects with knee osteoarthritis: a randomized controlled trial. Clin Rehabil 2007, 21(2):99-111.

60. Sekir U, Gur H: A multi-station proprioceptive exercise program in patients with bilateral knee osteoarthrosis: functional capacity, pain and sensoriomotor function. A randomized controlled trial. J Sports Sci Med 2005, 4(4):590-603. 
61. Thomas KS, Muir KR, Doherty M, Jones AC, O'Reilly SC, Bassey EJ: Home based exercise programme for knee pain and knee osteoarthritis: randomised controlled trial. BMJ 2002, 325(7367):752.

62. Diracoglu D, Aydin R, Baskent A, Celik A: Effects of kinesthesia and balance exercises in knee osteoarthritis. J Clin Rheumatol 2005, 11(6):303-310.

63. Fitzgerald GK, Piva SR, Gil AB, Wisniewski SR, Oddis CV, Irrgang JJ: Agility and perturbation training techniques in exercise therapy for reducing pain and improving function in people with knee osteoarthritis: a randomized clinical trial. Phys Ther 2011, 91(4):452-469.

64. Rogers MW, Tamulevicius N, Semple SJ, Krkeljas Z: Efficacy of home-based kinesthesia, balance \& agility exercise training among persons with symptomatic knee osteoarthritis. J Sports Sci Med 2012, 11(4):751758.

65. Song R, Lee EO, Lam P, Bae SC: Effects of tai chi exercise on pain, balance, muscle strength, and perceived difficulties in physical functioning in older women with osteoarthritis: a randomized clinical trial. J Rheumatol 2003, 30(9):2039-2044.

66. Tsauo JY, Cheng PF, Yang RS: The effects of sensorimotor training on knee proprioception and function for patients with knee osteoarthritis: a preliminary report. Clin Rehabil 2008, 22(5):448-457.

67. Villadsen A, Overgaard S, Holsgaard-Larsen A, Christensen R, Roos EM: Immediate efficacy of neuromuscular exercise in patients with severe osteoarthritis of the hip or knee: a secondary analysis from a randomized controlled trial. J Rheumatol 2014, 41(7):1385-1394.

68. Wortley M, Zhang SN, Paquette M, Byrd E, Baumgartner L, Klipple G, Krusenklaus J, Brown L: Effects of resistance and Tai Ji training on mobility and symptoms in knee osteoarthritis patients. Journal of Sport and Health Science 2013, 2(4):209-214.

69. Huber EO, Roos EM, Meichtry A, de Bie RA, Bischoff-Ferrari HA: Effect of preoperative neuromuscular training (NEMEX-TJR) on functional outcome after total knee replacement: an assessor-blinded randomized controlled trial. BMC Musculoskelet Disord 2015, 16:101.

70. Fitzgerald GK, Hinman RS, Zeni J, Jr., Risberg MA, Snyder-Mackler L, Bennell KL: OARSI Clinical Trials Recommendations: Design and conduct of clinical trials of rehabilitation interventions for osteoarthritis. Osteoarthritis Cartilage 2015, 23(5):803-814.

71. Moher D, Hopewell S, Schulz KF, Montori V, Gotzsche PC, Devereaux PJ, Elbourne D, Egger M, Altman DG: CONSORT 2010 Explanation and Elaboration: Updated guidelines for reporting parallel group randomised trials. J Clin Epidemiol 2010, 63(8):e1-37.

72. Zwarenstein M, Treweek S, Gagnier JJ, Altman DG, Tunis S, Haynes B, Oxman AD, Moher D: Improving the reporting of pragmatic trials: an extension of the CONSORT statement. BMJ 2008, 337:a2390.

73. Ross S, Grant A, Counsell C, Gillespie W, Russell I, Prescott R: Barriers to participation in randomised controlled trials: a systematic review. J Clin Epidemiol 1999, 52(12):1143-1156.

74. Jan $\mathrm{MH}$, Lin CH, Lin YF, Lin JJ, Lin DH: Effects of weight-bearing versus nonweight-bearing exercise on function, walking speed, and position sense in participants with knee osteoarthritis: a randomized controlled trial. Arch Phys Med Rehabil 2009, 90(6):897-904.

75. Anwer S, Alghadir A, Brismee JM: Effect of Home Exercise Program in Patients With Knee Osteoarthritis: A Systematic Review and Meta-analysis. J Geriatr Phys Ther 2015.

76. Knoop J, van der Leeden M, Thorstensson CA, Roorda LD, Lems WF, Knol DL, Steultjens MP, Dekker J: Identification of phenotypes with different clinical outcomes in knee osteoarthritis: data from the Osteoarthritis Initiative. Arthritis Care Res (Hoboken) 2011, 63(11):1535-1542.

77. Marks R, Allegrante JP: Chronic osteoarthritis and adherence to exercise: a review of the literature. J Aging Phys Act 2005, 13(4):434-460. 


\section{CHAPTER 7}

Construct validity of change scores of the Chair Stand Test versus Timed Up and Go test, KOOS questionnaire and the isometric muscle strength test in patients with severe knee osteoarthritis undergoing total knee replacement

Huber EO Meichtry A de Bie RA Bastiaenen CHG

Manual Therapy (2015), http://dx.doi.org/10.1016/j.math.2015.09.012 


\section{Chapter 7}

\section{ABSTRACT}

\section{Introduction}

The Chair Stand Test (CST) is a frequently used performance-based test in clinical studies involving individuals with knee osteoarthritis and demonstrates good reliability.

\section{Aim}

To assess the construct validity of change scores of the CST compared to three other measures in patients before and after total knee replacement surgery.

\section{Methods}

The construct validity of change scores of the CST compared to the Timed Up and Go (TUG) test, the Knee Injury and Osteoarthritis Outcome Score questionnaire (KOOS, subscale $A D L$ ) and the isometric muscle strength test of the knee extensors (IMS sum) was measured 1-2 week before and 3 months after surgery.

\section{Results}

Change $(\%) \mathrm{CST}=-4.45, \mathrm{TUG}=-2.08, \mathrm{KOOS} \mathrm{ADL}=43.90, \mathrm{IMS}$ sum $=-13.24$. Correlations CST-TUG $=0.56$ (95\% confidence interval $(\mathrm{Cl}) 0.29,0.74)$, CST-KOOS $=-0.31(95 \% \mathrm{Cl}-$ $0.57,0.01)$, CST-IMS $=-0.11(95 \% \mathrm{Cl}-0.42,0.22)$. Comparison of pairwise correlations: CST-KOOS versus CST-TUG $(p<0.0004)$, CST-TUG versus CST-IMS sum $(p<0.0068)$, CSTKOOS versus CST-IMS sum $(p<0.3100)$.

\section{Conclusion}

For patients undergoing TKR, the CST might not be an ideal measure to assess change between pre-surgery and 3 months post-surgery. Construct validity of change scores was close to zero but the result might have been influenced by the relatively small homogenous sample size and the chosen timespan of measurement. We ordered pairwise correlations based on the strength of correlation between the different instruments, which to our knowledge has never been done before.

\section{Keywords}

Responsiveness, Longitudinal Validity, Chair Stand Test, Knee Osteoarthritis, Total Knee Replacement 


\section{INTRODUCTION}

Responsiveness is defined as "the ability to detect change over time in the construct being measured" [1] and should be considered as an aspect of validity in a longitudinal setting [2], referring to the validity of a change score. TKR is recognized as a highly beneficial and cost-effective treatment. Consequently, knowledge of the expected rate of change in functional status following surgery is a measure of significant interest to researchers, clinicians and patients [3].

Constructs behind the chosen measures can be characterized within the framework of the International Classification of Functioning, Disability and Health (ICF) [4], in which human functioning is seen as an umbrella term encompassing "body functions and structures", "activities", and "participation". Our focus lies on physical function, related to the ability to move around [5] and to perform daily activities [6] and can be classified within the "activities" and "participation" components. Physical function can be measured either by self-reporting or by systematic observation by a clinician. Clinical observation, or performance-based measures, assess what an individual is actually able to perform by measuring the functional activities [6]. Patient-reported outcome (PRO) instruments are completed by patients themselves [7]. They mainly correspond to the ICF components "activities" and "participation" [8]. Several authors indicate that selfreported measures of function provide different information to performance-based measures in people with osteoarthritis (OA) or joint replacement [9-12]. Self-reported measures comment more on a patient's experience of moving around whereas performance-based measures may better represent their ability to move around [13].

The ability to move from a sitting to a standing position is an important activity that is often restricted in people awaiting joint replacement surgery of the hip or knee [14]. The Chair Stand Test (CST) is a frequently used performance test in clinical studies involving individuals with OA, as well as individuals before and after TKR surgery [15-18]. However, construct validity of change scores has yet to be investigated.

This study focuses on the construct validity of change scores of the CST compared to other instruments in a population of patients with severe knee OA, both before and after surgery. Severe knee osteoarthritis $(O A)$ was determined by the patient being on a waiting list for primary total knee replacement (TKR). The study makes a comparison between the CST and the Timed Up and Go (TUG) test, which fall within the same ICF component and are therefore assumed to measure almost the same construct. Comparisons with the Knee Injury and Osteoarthritis Outcome Score (KOOS) questionnaire and isometric muscle strength (IMS) test of the lower extremities, measuring a different construct, are also made. All measures are used in clinical practice to measure change over time in this patient group or in elderly people.

The aim of this study is to assess the construct validity of change scores of the CST in a population of patients with severe knee OA undergoing TKR surgery, compared to the TUG, the KOOS (subscale activities of daily living (ADL)) and the IMS sum. We hypothe- 
size that the strength of the correlations between CST and TUG compared to CST and KOOS and compared to CST and IMS sum will decrease.

\section{METHODS}

\section{Study design}

This study is a secondary analysis of a previous randomized controlled trial (RCT) [19]. Because no significant difference was found between the two groups in the RCT, the whole study population can be considered as one group for this study. Longitudinal data used in this study (besides the demographic variables of age, gender and Body Mass Index) were collected in the follow-up period after the end of the experimental and control intervention of the RCT. The interventions of the RCT can be characterized as "education and exercise" versus "education alone" prior to surgery. Follow-up measures were scheduled 2 weeks before and 3 months after surgery. Two authors have provided recovery curves for different outcomes after TKR with the greatest improvement occurring in the first 12 weeks after surgery $[3,20]$. Test measures included quadriceps strength, knee range of motion (ROM), TUG, timed stair-climbing, bodily pain and general health and knee function questionnaires [23] and lower extremity functional scale and six minute walk test [6]. Therefore, it was theorized that a patient's lower extremity functional status would improve over the interval 1 - 2 weeks before and 3 months after surgery.

The conditions and methods of the study were approved by the Ethics Committee of the Cantons Aargau and Solothurn, approval number 2009/12 and the trial is registered with ClinicalTrials.gov, identifier: NCT00913575.

\section{Patients}

Patients with severe OA who were on a waiting list for primary TKR at the Cantonal Hospital Olten or the Cantonal Hospital Aarau were recruited. Exclusion criteria were revision surgery, history of inflammatory arthritis, cognitive impairments, absence before or after surgery and inability to walk at least 3 meters with or without walking aid. All Patients had a Mini-Mental State Examination score greater than 24/30 [21]. Informed written consent was obtained on the first assessment day.

\section{MEASUREMENTS}

The primary measure of interest in this study is the CST. Three other measures are included for comparison: the TUG, the KOOS ADL and the IMS. All patients were assessed 1-2 weeks before surgery and 3 months after surgery at the Cantonal Hospitals Olten 
and Aarau by an experienced physical therapist with especial training to carry out these assessments.

\section{Measures}

A detailed description of the outcome measures and the allocation to the ICF components is shown in Table 1.

1. The CST is a performance-based test [22], also known as the five-times-sit-to-stand test. The test is commonly used as a measure of lower extremity strength and balance [17, 23-26]. In a previous study, the mean time required for the test in healthy subjects (mean age 69 years) was 10.08 seconds and for subjects with knee OA (mean age 69 years) 14.3 seconds [18]. The CST is easy to perform in clinical practice and has shown excellent intra- and inter-rater reliability (ICC, 0.89) in patients with severe hip or knee OA [17].

2. The TUG is a performance-based measure [27] and its construct refers to the ICF domain activities. The mean time required for the test in healthy subjects (aged between 60 and 79) was 8.1 - 9.2 seconds [28] and for subjects with knee OA (mean age 69 years) 9.8 seconds [29]. The TUG has demonstrated good reliability in patients awaiting TKR (ICC, 0.75; MDC $90,2.49$ seconds) [29].

3. The KOOS [30] is a commonly used patient-reported outcome measure with overall acceptable psychometric properties [31-34] to evaluate patients with knee injury and knee OA [34], including those undergoing TKR [35]. In this study we used the KOOS ADL subscale for comparison. The KOOS ADL has shown adequate internal consistency (Cronbach's Alpha $=0.78-0.97$ ) and test-retest reliability (ICC, 0.84-0.94) in knee OA [34]. The German version of the KOOS was used [36].

4. The IMS test used in our study is a performance-based measure with a method described and depicted in detail [37-39]. In healthy subjects (mean age 48 years), the IMS sum (added values of both legs) measured for men and women was 1043.78 and 646.48 Newton, respectively [37]. To our knowledge no values are available for the IMS in OA patients. The test has shown very good inter-observerreliability in healthy subjects (ICC, knee extension in the left and right leg, 0.83). Because we compared the IMS with the CST, which is a two-legged test, we decided to take measures of both legs and build a sum of the values. The measure is therefore called "IMS sum" (Table 1). 
Table 1: Description of the outcome measures and allocation to the ICF components

\begin{tabular}{|c|c|c|}
\hline Measure & Description & ICF component \\
\hline \multicolumn{3}{|l|}{ Performance-based } \\
\hline Chair Stand Test & $\begin{array}{l}\text { The CST was performed according to the OsteoArthritis Initiative } \\
\text { manual including detailed standardization and instructions (available } \\
\text { from: http//:oai.epi-ucsf.org). Patients sat on a standard chair } \\
\text { without armrests. Feet were placed comfortably on the floor with } \\
\text { knees flexed slightly greater than } 90 \text { degrees. Patients were asked to } \\
\text { stand up to a fully erect standing position five times as quickly as } \\
\text { possible without using their hands. Timing with a stopwatch started } \\
\text { on "Go" after a countdown from } 3 \text { and ended on the fifth stand. } \\
\text { After an exercise phase the test was performed once. }\end{array}$ & Activities \\
\hline Timed Up and Go & $\begin{array}{l}\text { It documents the time in seconds which requires a person to rise } \\
\text { from a standard stair, walk to a line that is } 3 \text { meters away, turn } 180 \\
\text { degrees, return to the chair and sit down. The patient began seated } \\
\text { with his or her feet on the floor and began the test upon the } \\
\text { assessor's command. Subjects were permitted to use the arms of the } \\
\text { chair for support during rising and sitting if needed. The average of } \\
\text { two trials was taken. }\end{array}$ & Activities \\
\hline $\begin{array}{l}\text { Isometric Muscle } \\
\text { Strength of the } \\
\text { Knee Extensors }\end{array}$ & $\begin{array}{l}\text { Fifty one functional muscle groups were measured, where as a } \\
\text { functional muscle group was defined as the sum of all muscles } \\
\text { contributing to an activity (e.g. knee extension) under predefined } \\
\text { conditions (e.g. in sitting position in } 90 \text { degrees of knee flexion). For } \\
\text { the measurement, a hand-held pull gauge was used. }\end{array}$ & Body function \\
\hline \multicolumn{3}{|l|}{ Self-reported } \\
\hline KOOS & $\begin{array}{l}\text { KOOS contains } 5 \text { subscales with a total of } 42 \text { items: } 1 \text { ) pain, } 2 \text { ) other } \\
\text { symptoms, 3) function in daily living (ADL), 4) function in sport and } \\
\text { recreation and } 5 \text { ) knee-related quality of life. Each question receives } \\
\text { a score from } 0 \text { to } 4 \text { and the scores are transformed to a } 0 \text { to } 100 \\
\text { score ( } 0 \text { = extreme symptoms, } 100 \text { = no symptoms). The User's } \\
\text { Guide, including scoring instructions, are available from } \\
\text { http://www.koos.nu. }\end{array}$ & $\begin{array}{l}\text { 1-2) Body function } \\
\text { and structure } \\
\text { 3-5) Activities and } \\
\text { participation }\end{array}$ \\
\hline
\end{tabular}

\section{Comparisons of change scores}

The method of this study follows the Consensus-based Standards for the selection of health Measurements Instruments (COSMIN) taxonomy of relationships of measurement properties, designed to detect change over time using the construct approach and to test a priori hypotheses.

\section{Hypothesis 1}

Change in the mean scores between the two measurements of the CST will be better than -2.7 seconds in a positive direction (less time needed). 
In patients with severe hip or knee osteoarthritis, the CST demonstrated moderate agreement $\left(C V_{W s}=13.9 \%\right)$, excellent reliability $(I C C=0.89)$ and a minimal detectable change $\left(\mathrm{MDC}_{90}\right)$ of $2.7 \mathrm{~s}$ in previous research [17].

\section{Hypotheses $2 a-c$}

We hypothesize that the two performance measures CST and TUG are indicators of nearly the same construct (lower extremity strength and balance referring to the ICF component "activities") and, therefore, a high correlation between these tests is expected. As reported in the literature, differences between perceived and observed measures may occur and, therefore, we hypothesize a lower and moderate correlation between the CST and KOOS ADL. Finally, we compare the CST with the IMS sum, i.e. to the ICF component "body function". With the sit-to-stand task of the CST in mind, a moderate correlation is expected, even though the constructs are different. Because it is reported that muscle strength might not yet be optimally recovered at 3 months after surgery [33], thus, we hypothesize the lowest correlation between the CST and IMS sum.

\section{Hypothesis 2d}

The expectation of the order of the pairwise correlations between the different instruments is postulated as follows:

Changes in lower extremity strength and balance over a period of $13-15$ weeks (presurgery versus post-surgery), as estimated by the CST

a) will correlate highly with changes measured with the TUG

b) will correlate less with changes measured with the KOOS ADL

c) will correlate least with changes measured with the IMS sum

\section{Statistical analysis}

Demographic variables, the scores of the instruments at the two time points and the respective change scores were examined using descriptive statistics. To quantify construct validity of change scores, the linear relationship between changes on different instruments was estimated using Pearson-moment correlations.

To test our hypotheses on the order of the pairwise correlations between the different instruments, we performed tests of significance of the difference between two dependent correlations sharing one variable (William's test) [40]. These tests, for sample size $n$, and observed correlations $r_{12}, r_{13}$ and $r_{23}$, test for the difference of two dependent correlations ( $r_{12}$ versus $r_{13}$ ) $[40,41]$. The level for statistical significance was set at 0.05 .

All analyses were conducted with $R$ version 2.14 .1 software $[42,43]$. 


\section{Chapter 7}

\section{RESULTS}

A total of 44 patients from a waiting list for TKR were recruited and assessed between May 2009 and June 2012. Mean age was 70.61 (Standard Deviation (SD) 8.1), Body Mass Index was 30.3 (5.2) and 45.5\% were female (20).

\section{Mean scores, mean change and change in percentage}

The mean changes of the CST and the TUG were 1.28 (6.5) and 0.44 (2.2) seconds, respectively, in a negative direction (more time needed). The mean change of the KOOS ADL was 22.82 (17.5) points and of the ISM sum was -76.55 (158.44) Newton. The changes in percentage terms for CST, TUG, KOOS ADL and IMS sum were $-4.45 \%$, 2.08\%, 43.90\% and $-13.24 \%$, respectively. All results are presented in Table 2.

Table 2: Mean (SD) at 1-2 weeks before and 3 months after surgery and mean change (SD)

\begin{tabular}{|c|c|c|c|c|c|c|}
\hline & $\begin{array}{l}\text { Number } \\
\text { of patients }\end{array}$ & $\begin{array}{l}\text { Mean (SD) } \\
1-2 \text { weeks } \\
\text { before surgery }\end{array}$ & $\begin{array}{l}\text { Number } \\
\text { of patients }\end{array}$ & $\begin{array}{l}\text { Mean (SD) } \\
3 \text { months } \\
\text { after surgery }\end{array}$ & $\begin{array}{l}\text { Mean change } \\
\text { (SD) }\end{array}$ & $\begin{array}{l}\text { Change } \\
(\%)\end{array}$ \\
\hline \multicolumn{7}{|c|}{ Functional performance measures (seconds) } \\
\hline Chair Stand Test & 41 & $14.83(5.8)$ & 40 & $15.49(6.5)$ & $1.28(6.5)$ & -4.45 \\
\hline Timed up and go & 41 & $10.08(4.1)$ & 41 & $10.29(3.5)$ & $0.44(2.2)$ & -2.08 \\
\hline \multicolumn{7}{|c|}{ Self-administered outcome measure (score 0-100) } \\
\hline KOOS ADL & 41 & $53.61(19.1)$ & 41 & $77.15(16.6)$ & $22.82(17.5)$ & 43.90 \\
\hline \multicolumn{7}{|c|}{ Capacity test Isometric Muscle strength (Newton) } \\
\hline Sum (op + contra) & 41 & $554.58(189.0)$ & 40 & $481.17(157.6)$ & $-76.55(158.44)$ & -13.24 \\
\hline
\end{tabular}

\section{Hypotheses}

Two out of seven hypotheses were rejected. The correlation between the measures and the difference between two dependent correlations are presented in Table 3. 
Table 3: Hypotheses testing

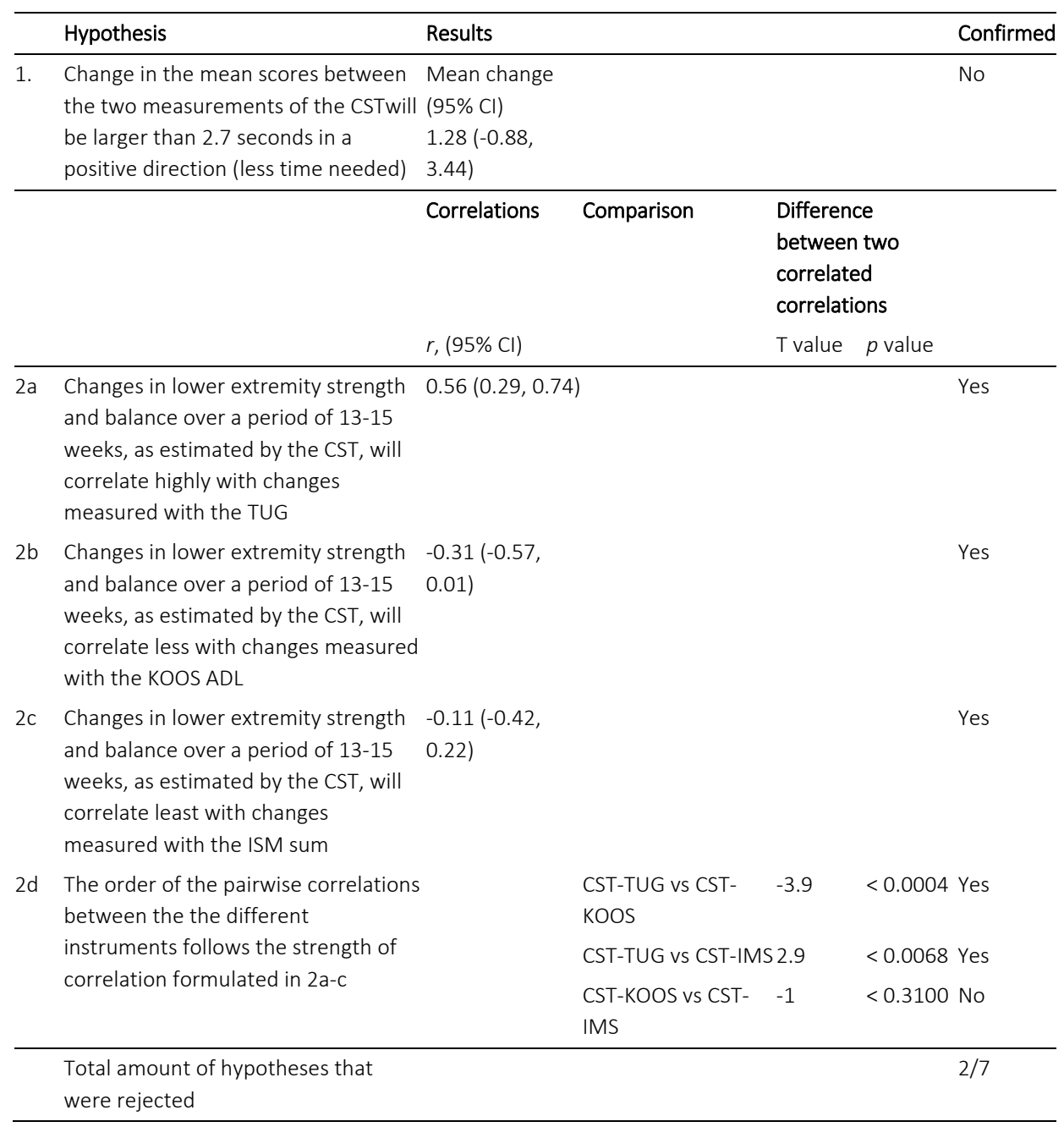

CST, Chair Stand Test; TUG, Timed Up and Go test; KOOS, Knee Injury and Osteoarthritis Score; ADL, subscale Activity of Daily Living; IMS sum, Isometric Muscle Strength test sum $r$ = Pearson's correlation coefficient; $\mathrm{Cl}=$ Confidence Interval

\section{DISCUSSION}

Change scores of the CST and the TUG were close to zero. The scores of the KOOS ADL (and other subscales, such as pain) did change and the IMS sum showed a slight deterioration. At the beginning of the study, because it is a proven positive intervention, we 
assumed that patients improved in all components of the ICF after TKR. However, this assumption seems unrealistic for all components.

\section{Hypothesis 1}

We expected a mean change score between the two measurements of the CST of more than 2.7 seconds in a positive direction. Other trials reported similar mean change scores in patients with knee OA, indicating positive 2.38 seconds [18] and 2.2 seconds [44]. Given that there was a change in the assessed population between the two timepoints, some reflection on the sit-to-stand movement in combination with TKR surgery might help to understand the unexpected result. Immediate pain relief can be expected following surgery, but some functional impairment is still present for up to 3 months. During this period, subjects with unilateral TKR will still demonstrate side-to-side differences during sit-to-stand in terms of altered movement patterns $[45,46]$ and weightbearing asymmetry [47]. It appears that, due to pain and muscle weakness, many patients persist in the pre-surgical adopted pattern of avoiding the use of the affected leg during the sit-to-stand task and compensate using different neuromuscular strategies. This is in line with another trial which investigated a sit-to-stand task in TKR patients by evaluating ground reaction forces, time to complete a five-time-sit-to-stand (FTSTS) task and quadriceps and hamstring muscle activation [48]. Specifically, patients unloaded their surgical limb, were slower to complete the task and demonstrated higher quadriceps/hamstrings coactivation with increased distribution of the quadriceps activation when lowering to seated position.

\section{Hypothesis $2 a$}

We assumed CST and TUG to measure almost the same construct and therefore expected a high correlation. However, our patients showed a deterioration of $-4.45 \%$ in the CST and $-2.08 \%$ in the TUG, resulting in only a moderate correlation. There might be a difference between the demands of the CST and TUG tasks, indicating that potentially they are not measuring the same construct. The CST appeared to be a more physically demanding activity than the TUG, requiring, while rising up and down from a chair, a quick change from concentric to eccentric muscle activation, which might still have been partly inhibited. This is supported by literature showing that locomotor deficits, e.g. reduced activation in proximal (vastus lateralis, medial hamstrings) and distal muscles (medial gastrocnemius and tibialis anterior), could still be present at 3 months postoperative [49]. Muscle fatigue is another important aspect because of the significant role of quadriceps muscle endurance in walking and climbing stairs. Because the quadriceps muscle of the involved leg is weaker than that of the contralateral leg, muscle fatigue is greater in the contralateral leg [50]. We did not find any literature comparing CST and TUG in a similar target population and, therefore, comparisons are limited. 


\section{Hypothesis $2 b$}

We expected a good correlation and our patients improved $43.9 \%$ on the outcome of the KOOS ADL, resulting in a poor correlation with the CST. Our results are in line with several other authors. One author evaluated how KOOS outcomes in patients after TKR related to performance measures. The study showed that 3 months after TKR selfreported outcomes far exceeded preoperative values, whereas performance measures recovered to only slightly better than preoperative values [33]. At 3 months postoperative they presented a very low correlation (Pearson's $r=0.021$ ) between KOOS ADL and the 6 minute walk test. Other authors suggested that self-reported mobility improved before the subjects were actually doing more [12, 20, 51]. In summary, it seems that only low to moderate correlations can be expected between self-reported and performance-based measures. Patients appear to perceive an improvement in function compared to pre-surgery, although their capacity to perform a task has in reality not increased. KOOS ADL best reflects the improvement of the TKR three months after surgery.

\section{Hypothesis 2c}

We expected moderate negative correlation between CST and IMS sum, but only poor correlation was found. Our patients showed a deterioration of $-13.24 \%$ in muscle strength post-surgery compared to pre-surgery. This is in agreement with a study which showed that leg extensor muscle strength was still deteriorated 3 months post-surgery compared to pre-surgery. The preoperative level was achieved only half a year after TKR (difference was 3\%) and the operated leg continued to be weaker than the nonoperated leg (38\%) [52]. Another longitudinal design trial showed 3 months postoperative a fair-to-high negative correlation between isometric muscle strength of the involved leg and the stair climbing test (Pearson's $r=-0.39$ to -0.63 ) [20]. Their results revealed quadriceps force-producing ability impairment one month after surgery and continued impairment three months after surgery. Another trial showed moderate-togood negative correlations between stair climbing tests and TUG to normalized voluntary isometric contractions (Pearson's $r=0.64$ and 0.58 , respectively) [53]. In summary, three months after surgery muscle strength might not have recovered to the level before surgery and, therefore, only poor-to-moderate correlations with performancebased measures can be expected.

\section{Hypothesis 2d}

To test our hypotheses about the order of the pairwise correlations between the different instruments, we performed tests of significance of the difference between two dependent correlations sharing one variable, the CST. The order of the pairwise correlations between the different instruments followed the strength of correlations formulat- 


\section{Chapter 7}

ed in 2a-c. The only positive correlation was between CST and TUG, the other two showed negative correlations. In the pairwise comparison of the CST-KOOS versus CSTIMS sum both correlations were in the same (negative) direction and, therefore, it was the only one that did not reach significance in difference. In summary, the order of our hypotheses was correct.

\section{Limitations}

Some limitations to this investigation should be considered. Firstly, the study was not primary designed to investigate clinimetric properties but as an intervention study, and, due to its explicit inclusion- and exclusion criteria, the study population was rather homogeneous. Secondly, our sample size was relatively small. Finally, the timing of assessments post-surgery is quite important. These were chosen within the context of the trial design to be long enough for improvement to occur.

\section{Summary and Conclusion}

In summary, in patients undergoing TKR surgery, the CST is not an ideal measure to assess change between pre-surgery and 3 months post-surgery performance. Because change scores were close to zero, construct validity of change scores of the CST could be close to zero if patients actually changed within the construct of measurement. The results of the TUG were more or less in line with the CST. Outcomes of the KOOS reported positive changes over time in all subscales, including the subscale ADL. It seems that the CST is measuring a different construct (activity performance) compared to the KOOS ADL (activities and participation) and is somewhat more related to the construct of the TUG (also activity performance related, but less demanding). Compared to the IMS sum (component body function), the correlation is in line with expectation. However, the IMS sum change scores, like the CST and TUG change scores were not as expected. None of the instruments reported improvement. In the last step we investigated our concept of ordering the strength of correlations between different instruments, which, to our knowledge, has never been done before.

Finally, we must conclude that the construct validity of change scores of the CST in a pre-post setting 3 months after TKR surgery in patients with severe knee OA seems close to zero. However, there are two factors that could have influenced our results. The homogeneous and small study population, with only patients who did not improve on the construct being measured, and the given time span of measurement. Three months is possibly too short a period to expect improvement over time on the construct of the CST in this particular patient group. 


\section{REFERENCES}

1. Mokkink LB, Terwee CB, Patrick DL, Alonso J, Stratford PW, Knol DL, Bouter LM, de Vet HC: The COSMIN study reached international consensus on taxonomy, terminology, and definitions of measurement properties for health-related patient-reported outcomes. Journal of clinical epidemiology 2010, 63(7):737-745.

2. Terwee CB, Dekker FW, Wiersinga WM, Prummel MF, Bossuyt PM: On assessing responsiveness of health-related quality of life instruments: guidelines for instrument evaluation. Quality of life research : an international journal of quality of life aspects of treatment, care and rehabilitation 2003, 12(4):349-362.

3. Kennedy DM, Stratford PW, Riddle DL, Hanna SE, Gollish JD: Assessing recovery and establishing prognosis following total knee arthroplasty. Physical therapy 2008, 88(1):22-32.

4. WHO: World Health Organization. International Classification of Functioning, Disability and Health. Geneva, Switzerland: World Health Organization 2001.

5. Bellamy N, Kirwan J, Boers M, Brooks P, Strand V, Tugwell P, Altman R, Brandt K, Dougados M, Lequesne $M$ : Recommendations for a core set of outcome measures for future phase III clinical trials in knee, hip, and hand osteoarthritis. Consensus development at OMERACT III. The Journal of rheumatology 1997, 24(4):799-802.

6. Terwee CB, Mokkink LB, Steultjens MP, Dekker J: Performance-based methods for measuring the physical function of patients with osteoarthritis of the hip or knee: a systematic review of measurement properties. Rheumatology (Oxford, England) 2006, 45(7):890-902.

7. Patrick DL, Burke LB, Powers JH, Scott JA, Rock EP, Dawisha S, O'Neill R, Kennedy DL: Patient-reported outcomes to support medical product labeling claims: FDA perspective. Value in health : the journal of the International Society for Pharmacoeconomics and Outcomes Research 2007, 10 Suppl 2:S125-137.

8. World Health Organisation. International Classification of Functioning, Disability and Health. Geneva: World Health Organization. 2001.

9. Maly MR, Costigan PA, Olney SJ: Determinants of self-report outcome measures in people with knee osteoarthritis. Archives of physical medicine and rehabilitation 2006, 87(1):96-104.

10. Stratford PW, Kennedy DM: Performance measures were necessary to obtain a complete picture of osteoarthritic patients. Journal of clinical epidemiology 2006, 59(2):160-167.

11. Stratford PW, Kennedy DM, Woodhouse LJ: Performance measures provide assessments of pain and function in people with advanced osteoarthritis of the hip or knee. Physical therapy 2006, 86(11):14891496.

12. Parent $\mathrm{E}$, Moffet $\mathrm{H}$ : Comparative responsiveness of locomotor tests and questionnaires used to follow early recovery after total knee arthroplasty. Archives of physical medicine and rehabilitation 2002, 83(1):70-80.

13. Kennedy DM, Stratford PW, Hanna SE, Wessel J, Gollish JD: Modeling early recovery of physical function following hip and knee arthroplasty. BMC musculoskeletal disorders 2006, 7:100.

14. Kennedy D, Stratford PW, Pagura SM, Walsh M, Woodhouse LJ: Comparison of gender and group differences in self-report and physical performance measures in total hip and knee arthroplasty candidates. The Journal of arthroplasty 2002, 17(1):70-77.

15. Sharma L, Cahue S, Song J, Hayes K, Pai YC, Dunlop D: Physical functioning over three years in knee osteoarthritis: role of psychosocial, local mechanical, and neuromuscular factors. Arthritis and rheumatism 2003, 48(12):3359-3370.

16. Villadsen A, Overgaard S, Holsgaard-Larsen A, Christensen R, Roos EM: Postoperative effects of neuromuscular exercise prior to hip or knee arthroplasty: a randomised controlled trial. Annals of the rheumatic diseases 2014, 73(6):1130-1137.

17. Villadsen A, Roos EM, Overgaard S, Holsgaard-Larsen A: Agreement and reliability of functional performance and muscle power in patients with advanced osteoarthritis of the hip or knee. American journal of physical medicine \& rehabilitation / Association of Academic Physiatrists 2012, 91(5):401-410. 
18. Ageberg E, Nilsdotter A, Kosek E, Roos EM: Effects of neuromuscular training (NEMEX-TJR) on patientreported outcomes and physical function in severe primary hip or knee osteoarthritis: a controlled beforeand-after study. BMC musculoskeletal disorders 2013, 14(1):232.

19. Huber EO, de Bie RA, Roos EM, Bischoff-Ferrari HA: Effect of pre-operative neuromuscular training on functional outcome after total knee replacement: a randomized-controlled trial. BMC musculoskeletal disorders 2013, 14:157.

20. Mizner RL, Petterson SC, Snyder-Mackler L: Quadriceps strength and the time course of functional recovery after total knee arthroplasty. The Journal of orthopaedic and sports physical therapy 2005, 35(7):424436.

21. Folstein M, Anthony JC, Parhad I, Duffy B, Gruenberg EM: The meaning of cognitive impairment in the elderly. Journal of the American Geriatrics Society 1985, 33(4):228-235.

22. Guralnik JM, Simonsick EM, Ferrucci L, Glynn RJ, Berkman LF, Blazer DG, Scherr PA, Wallace RB: A short physical performance battery assessing lower extremity function: association with self-reported disability and prediction of mortality and nursing home admission. Journal of gerontology 1994, 49(2):M85-94.

23. Bohannon RW: Alternatives for measuring knee extension strength of the elderly at home. Clin Rehabil 1998, 12(5):434-440.

24. Bohannon RW: Sit-to-stand test for measuring performance of lower extremity muscles. Percept Mot Skills 1995, 80(1):163-166.

25. Lord SR, Murray SM, Chapman K, Munro B, Tiedemann A: Sit-to-stand performance depends on sensation, speed, balance, and psychological status in addition to strength in older people. J Gerontol A Biol Sci Med Sci 2002, 57(8):M539-543.

26. Whitney SL, Wrisley DM, Marchetti GF, Gee MA, Redfern MS, Furman JM: Clinical measurement of sit-tostand performance in people with balance disorders: validity of data for the Five-Times-Sit-to-Stand Test. Physical therapy 2005, 85(10):1034-1045

27. Podsiadlo D, Richardson S: The timed "Up \& Go": a test of basic functional mobility for frail elderly persons. Journal of the American Geriatrics Society 1991, 39(2):142-148.

28. Bohannon RW: Reference values for the timed up and go test: a descriptive meta-analysis. Journal of geriatric physical therapy (2001) 2006, 29(2):64-68.

29. Kennedy DM, Stratford PW, Wessel J, Gollish JD, Penney D: Assessing stability and change of four performance measures: a longitudinal study evaluating outcome following total hip and knee arthroplasty. BMC musculoskeletal disorders 2005, 6:3.

30. Roos EM, Roos HP, Lohmander LS, Ekdahl C, Beynnon BD: Knee Injury and Osteoarthritis Outcome Score (KOOS)--development of a self-administered outcome measure. The Journal of orthopaedic and sports physical therapy 1998, 28(2):88-96.

31. Monticone M, Ferrante S, Salvaderi S, Motta L, Cerri C: Responsiveness and minimal important changes for the Knee Injury and Osteoarthritis Outcome Score in subjects undergoing rehabilitation after total knee arthroplasty. American journal of physical medicine \& rehabilitation / Association of Academic Physiatrists 2013, 92(10):864-870.

32. Peer MA, Lane J: The Knee Injury and Osteoarthritis Outcome Score (KOOS): a review of its psychometric properties in people undergoing total knee arthroplasty. The Journal of orthopaedic and sports physical therapy 2013, 43(1):20-28.

33. Stevens-Lapsley JE, Schenkman ML, Dayton MR: Comparison of self-reported knee injury and osteoarthritis outcome score to performance measures in patients after total knee arthroplasty. $P M \& R$ : the journal of injury, function, and rehabilitation 2011, 3(6):541-549; quiz 549.

34. Collins NJ, Misra D, Felson DT, Crossley KM, Roos EM: Measures of knee function: International Knee Documentation Committee (IKDC) Subjective Knee Evaluation Form, Knee Injury and Osteoarthritis Outcome Score (KOOS), Knee Injury and Osteoarthritis Outcome Score Physical Function Short Form (KOOSPS), Knee Outcome Survey Activities of Daily Living Scale (KOS-ADL), Lysholm Knee Scoring Scale, Oxford Knee Score (OKS), Western Ontario and McMaster Universities Osteoarthritis Index (WOMAC), Activity Rating Scale (ARS), and Tegner Activity Score (TAS). Arthritis care \& research 2011, 63 Suppl 11:S208-228. 
35. Roos EM: Effectiveness and practice variation of rehabilitation after joint replacement. Curr Opin Rheumatol 2003, 15(2):160-162.

36. Kessler S, Lang S, Puhl W, Stove J: [The Knee Injury and Osteoarthritis Outcome Score--a multifunctional questionnaire to measure outcome in knee arthroplasty]. Z Orthop Ihre Grenzgeb 2003, 141(3):277-282.

37. Stoll T, Huber E, Seifert B, Michel BA, Stucki G: Maximal isometric muscle strength: normative values and gender-specific relation to age. Clin Rheumatol 2000, 19(2):105-113.

38. Huber EO: Zuverlässigkeit und Normperzentilen einer neuen isometrischen Muskelkraftmessmethode. Physiotherapie 1997.

39. Stucki G, Schonbachler J, Bruhlmann P, Mariacher S, Stoll T, Michel BA: Does a muscle strength index provide complementary information to traditional disease activity variables in patients with rheumatoid arthritis? The Journal of rheumatology 1994, 21(12):2200-2205.

40. Williams EJ: Regression Analysis: John Wiley and Sons; 1959.

41. Steiger JH: Tests for Comparing Elements of a Correlation Matrix. Psychological Bulletin 1980, 87(2):245251.

42. R Core Team. R: A language and environment for statistical computing [http://www.R-project.org/.]

43. Revelle W: psych: Procedures for Personality and Psychological Research. Nortwestern University, Evanston, Illinois, USA [http://CRAN.R-project.org/package=psych] Version = 1.5.1.

44. French HP, Fitzpatrick M, FitzGerald O: Responsiveness of physical function outcomes following physiotherapy intervention for osteoarthritis of the knee: an outcome comparison study. Physiotherapy 2011, 97(4):302-308.

45. Mizner RL, Snyder-Mackler L: Altered loading during walking and sit-to-stand is affected by quadriceps weakness after total knee arthroplasty. Journal of orthopaedic research : official publication of the Orthopaedic Research Society 2005, 23(5):1083-1090.

46. Farquhar SJ, Reisman DS, Snyder-Mackler L: Persistence of altered movement patterns during a sit-tostand task 1 year following unilateral total knee arthroplasty. Physical therapy 2008, 88(5):567-579.

47. Christiansen CL, Bade MJ, Judd DL, Stevens-Lapsley JE: Weight-bearing asymmetry during sit-stand transitions related to impairment and functional mobility after total knee arthroplasty. Archives of physical medicine and rehabilitation 2011, 92(10):1624-1629.

48. Davidson BS, Judd DL, Thomas AC, Mizner RL, Eckhoff DG, Stevens-Lapsley JE: Muscle activation and coactivation during five-time-sit-to-stand movement in patients undergoing total knee arthroplasty. Journal of electromyography and kinesiology : official journal of the International Society of Electrophysiological Kinesiology 2013, 23(6):1485-1493.

49. Ouellet $\mathrm{D}$, Moffet $\mathrm{H}$ : Locomotor deficits before and two months after knee arthroplasty. Arthritis and rheumatism 2002, 47(5):484-493.

50. Elboim-Gabyzon M, Rozen N, Laufer Y: Quadriceps femoris muscle fatigue in patients with knee osteoarthritis. Clinical interventions in aging 2013, 8:1071-1077.

51. Aarons H, Hall G, Hughes S, Salmon P: Short-term recovery from hip and knee arthroplasty. The Journal of bone and joint surgery British volume 1996, 78(4):555-558.

52. Vahtrik D, Gapeyeva H, Ereline J, Paasuke M: Relationship between leg extensor muscle strength and knee joint loading during gait before and after total knee arthroplasty. The Knee 2014, 21(1):216-220.

53. Marmon AR, Milcarek BI, Snyder-Mackler L: Associations between knee extensor power and functional performance in patients after total knee arthroplasty and normal controls without knee pain. International journal of sports physical therapy 2014, 9(2):168-178. 



\section{CHAPTER 8}

\section{General discussion}
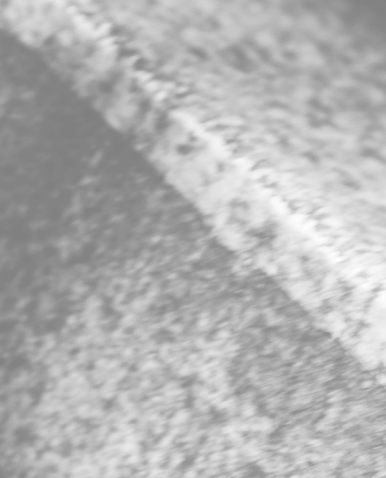

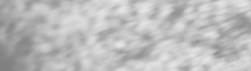

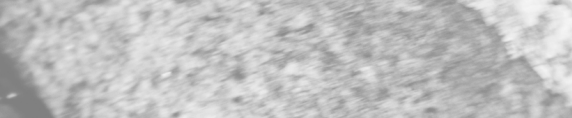

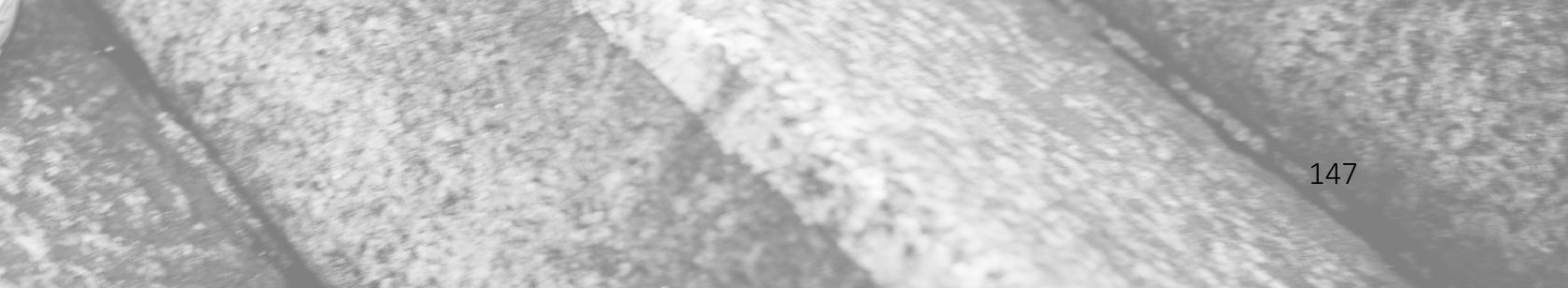




\section{MAIN FINDINGS}

\section{Effect of preoperative neuromuscular training on functional outcome}

The effect of preoperative neuromuscular training (NEMEX-TJR) on functional outcomes after total knee replacement (TKR) has been investigated in an assessor-blinded randomized controlled trial (CHAPTERS 3 and 4) [1, 2]. At 3 months after surgery, we observed a small improvement in the primary endpoint Chair Stand Test (CST) in the control group and a significant improvement in the secondary endpoints of the Knee Injury and Osteoarthritis Outcome Score (KOOS subscales ADL and pain) in both the exercise and control groups, which did not differ significantly between groups. Therefore, we had to reject our hypothesis that patients undergoing the NEMEX-TJR would improve in functional outcome at 3 months after surgery.

The performance level of our study population with respect to the primary endpoint CST was similar to other studies with the same patient group at baseline. It was unexpected that CST performance did not improve significantly in the exercise group at 3 months postoperative compared to baseline.

A considerable limitation to our trial was the relatively small sample size of 45 patients instead of the planned 80. Additionally, our assumptions for calculating the sample size for the CST were, in retrospect, too optimistic and we assume that our trial could have resulted in imprecise estimates. On the other hand, we identified statistically significant differences of 3-6 points between groups, in favor of the exercise group, for the secondary endpoints KOOS subscales ADL and pain. These between-group differences are greater than the smallest detectable differences reported at group level, indicating that the study is most probably sufficiently powered to detect between-group differences significantly different from zero.

In conclusion, our results do not give a conclusive answer to the question of whether additional preoperative neuromuscular exercise has a beneficial effect on postoperative functional outcomes.

\section{Explanations from a broader perspective}

The results of the RCT generated new questions and aspects from a broader perspective that might have influenced the obtained results.

\section{Influence of the contralateral knee on functional outcome of the operated knee}

We hypothesized that pain and function of the contralateral nonoperated knee might have influenced the results postoperatively. We investigated the association of pain and function of the contralateral knee preoperatively and on the operated knee postoperatively (CHAPTER 5) [3]. Early outcome in the operated knee was influenced to a small, but significant, extent by the preoperative pain and function of the contralateral knee. 
These effects were independent of baseline function/pain in the operated knee, and of gender, BMI, or age. Several explanations for this finding can be given. Firstly, in the acute and post-acute rehabilitation phases, the contralateral leg of the patient is also included in therapeutic exercise and physical activity. Thus, surgery could have served as a mechanism for patients to receive needed physical therapy treatment on their affected contralateral joint. Secondly, the contralateral joint could be rested as a consequence of the surgery, in the sense that injurious and painful demands are restricted. Walking with canes, distinctly reduced physical activity in the acute and post-acute phase after surgery, invalidate the argument that the contralateral limb has to compensate for the operated limb. Thirdly, treatment of one knee can have bilateral effects through the central nervous system connections. Creamer et al. [4] demonstrated that the injection of local anesthetic in one knee did not only reduce pain in the injected knee but was also followed by pain relief in the contralateral non-injected knee. These findings are also supported by other studies $[5,6]$.

Unfortunately, in our RCT the contralateral knee was not assessed and so we are not aware of how many patients had pain and impaired function of the contralateral knee preoperatively. We can only suppose that, theoretically, functional outcome in our RCT could have been influenced by the contralateral knee.

In conclusion, pre-surgery pain and function of the contralateral knee had a small but significant effect on the outcome of the operated knee.

\section{Effectiveness of the applied intervention (NEMEX-TJR)}

We hypothesized that the NEMEX-TJR might not have been effective in patients with severe knee osteoarthritis (OA) and, as a result, conducted a systematic review and meta-analysis to provide an overview of the currently available evidence on pain, disability and performance-based function of functional stability exercise (FSE) programs for the lower limb in people with knee OA (CHAPTER 6) [7]. The main findings of our metaanalysis of 11 RCTs with a total of almost 700 patients showed a small effect of stability exercise. However, the results of the prediction intervals showed opposite conclusions from the two extremes of the prediction intervals for all three outcomes. Thus, further research is needed before a final conclusion can be made.

The subgroup analyses comparing studies where FSE was add-on to a standard exercise program or not showed ambiguous results. The assumption that FSE can be tested either a sole intervention or as an add-on was confirmed for pain but not for disability or performance-based function. We offered a non-active attention control treatment in our RCT, assuming that the effect size was not lowered by the control treatment. However, we did not ask our patients in the control group to maintain the existing level of their physical activity during the study period. Therefore, we do not know whether the patient education intervention might have influenced their physical activity habits in a positive direction. 
A subgroup analysis was performed on the number of sessions, which ranged from 10-24; a greater number of sessions did not show a larger effect size. On the contrary, a smaller number of sessions resulted in larger effect sizes on pain and performancebased lower limb function. These findings do not support the assumption that the relatively low number of treatment sessions in our RCT (median number of 10 attended sessions) might not have been an effective dose. However, other authors have shown that an increased number of supervised aerobic sessions led to higher effect sizes [8].

In conclusion, the main finding was a small effect in favor of FSE on self-reported pain, self-reported disability and performance-based lower limb function. However, large prediction intervals indicate that no final conclusion can be made and further research is needed.

\section{Chair Stand Test (CST) as primary endpoint measure}

We hypothesized that the CST might not be the ideal measure to demonstrate change scores before and after surgery. We assessed the construct validity of change scores of the CST compared to three other measures in patients before and after TKR surgery (CHAPTER 7) [9]. The change scores in our study were close to zero. This could mean either that our patients did not change on the construct of the CST, or that the CST is not able to identify a change.

It has been shown that individuals with knee OA display different movement strategies when performing a sit-to-stand (STS) task than asymptomatic individuals [10-12]. In particular, they perform it at a slower speed [13] and with greater muscle cocontraction [14]. These strategies and factors may lead to altered coordination and movement patterns. Immediate pain relief can be expected following TKR surgery, but subjects will still demonstrate side-to-side differences during STS [15, 16] and weightbearing asymmetry [17]. Patients continue to have locomotor deficits for 2 months after TKR, e.g. cadence (steps/minute) during stair ascent [18]. It appears that many patients persist in their pre-surgical adopted pattern and compensate using different neuromuscular strategies. Patients who unload their operated limb are slower to complete the task and demonstrate higher quadriceps/hamstrings co-activation [19].

Another interesting option could be that patients have not (yet) actually changed within the construct during the investigated time span. It has been shown that locomotor capacity is still far below the preoperative level of function that justified the TKR surgery for 2 months after TKR [18]. This aspect is supported by the fact that the Timed Up and Go (TUG) test, our second performance-based measure, also demonstrated change scores close to zero.

However, outcomes of the KOOS reported positive changes over time in all other subscales, as well as the subscale ADL. It seems that the CST is measuring a different construct (activity performance) compared to the KOOS ADL (activities and participa- 
tion), as expressed in the terminology of the International Classification of Functioning, Disability and Health (ICF) [20].

There is an ongoing debate about the use of self-reported measures and/or performance-based measures. Several authors indicate that self-reported measures of function provide different information to performance-based measures in people with OA or joint replacement [21-23]. Nowadays, a combination of both types of measures is suggested to obtain a complete picture of function, but it might be advisable to choose a self-reported outcome measure as primary endpoint measure for a functional research question, such as the one on which we were focusing. As a consequence, patientreported outcomes on the level of functioning and participation are of great importance for a rehabilitation trial.

In conclusion, the CST might not be an ideal measure to assess change between presurgery and 3 months post-surgery for patients undergoing TKR.

\section{Development of a measurement instrument}

The benefit of preoperative education on postoperative outcomes was recently evaluated in a review by the Cochrane collaboration [24]. The authors were uncertain as to whether it offers benefits over usual care in terms of reducing anxiety, or to surgical outcomes, such as pain, function and adverse events. In all studies, the content of the educational intervention itself was not evaluated and patients were not asked whether the content of the education program actually suited their needs. While offering patient education as the control intervention in our RCT, we developed a generic instrument for the use of patients, named the "Knee Osteoarthritis Patient Education Questionnaire" (KOPEQ), to assess the validity of a preoperative educational intervention and we preliminarily tested its psychometric properties (CHAPTER 2) [25]. The KOPEQ had strong internal consistency and a four-factor model was able to explain $61 \%$ of the variance. The relatively small convenience sample of patients $(n=35)$ may be responsible for the limited generalizability of the results.

Interviews with patients generated important information. Firstly, patients are focused on walking with canes and climbing stairs, understandably since these are often functional discharge criteria [26]. Secondly, patients expect practical advice, e.g. on the distance they are recommended to walk after discharge, and they expect motivational support for home exercises. Both expectations are not covered by outcome measures typically used in knee OA. Thirdly, none of the patients expressed higher expectations as a consequence, as some authors have reported [27-29]. One patient mentioned explicitly that the imparted knowledge helped her to modify her expectations regarding recovery and become more patient.

In conclusion, the KOPEQ can help to provide health professionals with valid feedback on how patients assessed the applied patient education intervention. 


\section{Methodological reflections}

Several issues that could have influenced the validity of the results in this thesis are discussed.

\section{Randomized Controlled Trial}

The RCT is the study design most likely to produce unbiased conclusions about the causal relationship between intervention and outcome, i.e. about the effectiveness of a therapy [30, 31]. We used a randomized controlled trial (RCT) to assess the effect of the preoperative neuromuscular training on postoperative functional outcomes at 3 months after surgery [2].

\section{Allocation}

Trials with inadequate allocation concealment have been associated with larger treatment effects compared with trials in which authors reported adequate allocation concealment $[32,33]$. It is important that participants and personnel cannot influence allocation, which would be the case when, e.g. allocation were based on the day of admission or on a case record number. In our study, we took advantage of an independent randomization center, where allocation was conducted and concealed by a center study nurse after baseline assessment. Participants were randomized using block allocation, with a block size of four from a computer generated list.

\section{Blinding}

Various types of people can be blinded in a clinical trial [34]. In describing the blinding, the most common terms used are single-blind and double-blind. These terms do not give information as to who is blinded. It is therefore helpful to state precisely and concretely who is blinded. In our study, because of the nature of the intervention, participants and personnel were not blinded after the concealed allocation procedure. Patients were informed for ethical reasons that the main focus of the study was to investigate lower limb function. The personnel were also globally informed of the study aim. Since patients and personnel were not blinded, this might have resulted in biased effect estimates.

On the other hand, the outcome assessor was blinded to the allocation of the participants and the latter were advised not to mention their allocation. Additionally, the outcome assessor was not a member of the physical therapy team applying the interventions. There was no other contact between the outcome assessor and the physical therapy team. In summary, our study was an assessor-blinded RCT, which is the most feasible in rehabilitation research. 


\section{Control intervention}

The choice of control intervention has important implications for trial ethics, recruitment, results and interpretation. In an explanatory trial, a sham exercise (placebo) would be the expected option for control intervention. Pengel et al. [35] applied a sham exercise as the control intervention in their trial. The exercise program included an individualized, progressive, submaximal program of different exercises, while the sham exercise intervention consisted of sham shortwave diathermy and sham pulsed ultrasound. The sham exercise is quite different compared to the therapeutic exercise and there is a risk that participants recognize the sham exercise as such. Lange et al. [36] conducted a strengthening program on machines as the therapeutic exercise program. Participants randomized to the sham-exercise group trained on the same equipment but with less exercises, minimal resistance and no progression, resulting in a sham exercise quite similar to the intervention exercise. We discussed the option of a sham exercise very carefully and finally decided against it because, in our opinion, the danger of a sham exercise being too similar to the therapeutic exercise in neuromuscular training, and therefore influencing the lower limb function, was too high.

Instead we decided on a pragmatic approach by offering patients in the control group a beneficial intervention as well, bearing in mind that a potential barrier to trial participation is the possibility of being allocated to the control intervention that is perceived as less desirable than the study intervention [37]. We chose an attention control intervention in the form of patient education. The decision was also made to offer the control intervention to the participants in the intervention group. In practice, both groups received the attention control intervention, while the intervention group received the neuromuscular training as an additional element. There is a continuum rather than a dichotomy between explanatory and pragmatic trials, especially in rehabilitation trials, as referenced by the existing CONSORT statement, as well as to its extension $[30,31]$.

\section{Recruitment phase}

The size of our study was hampered by severe recruiting problems. A reduction in preoperative waiting-time occurred during the recruitment phase, due to a change in the reimbursement system at the acute care hospitals. Although altogether around 800 TKR surgeries took place during this time in both recruiting sites, only 74 of these patients were eligible for our study. The consequences of these described recruitment problems were lower precision in the estimates and, possibly, biased estimates. Since recruiting problems occur frequently in RCTs, the question arises as to whether the RCT design should be continued or an alternative design chosen, such as the single case [38]. The latter is a controlled experimental method for testing the effectiveness of a treatment on a single subject. A major advantage of this design type is that only a relatively small sample of participants is generally needed, because correlated multiple repeated meas- 


\section{Chapter 8}

urements on the same subject increases the power to detect within-subject effects. The reason for this is that there is the possibility to split the variance into between-subject and within-subject variances in longitudinal studies. Moreover, because the treatment is assessed repeatedly, it allows the researcher to see how consistently the treatment changes over time. However, it is important to choose an optimal single moment in time for the evaluation and to determine the success of the trial at this point. Multiple time points require more correction for measurement and lower the alpha. A disadvantage, however, is the performance of a large number of assessments on one individual, which can be tiresome for the participants [39]. In addition, this design does not provide information on recruitment or drop-out rate and also has the problem of generalizability.

\section{Intention-to-treat}

Statistical analyses were based on the intention-to-treat (ITT) principle. ITT analyses compare patients in the groups to which they were originally randomly assigned [40]. Patients in our study did not change groups during the treatment or follow-up phase. Full application of ITT analysis can only be performed with complete response data for all randomized subjects. To handle missing data, we therefore fitted a linear mixed model with time, group and group-time interaction as fixed effects and subject as a random intercept [41]. In contrast to classical repeated-measures ANOVA, random intercept models can deal naturally with missing observations, whilst still retaining power.

\section{Systematic review and meta-analysis}

The results of a systematic review and meta-analysis, synthesizing the effect of FSE programs designed to improve pain and lower limb disability in people with knee osteoarthritis, are reported in this thesis. The study followed a standard methodology, as suggested by the PRISMA statement [42]. It included a comprehensive search strategy and an explicit method to appraise and synthesize the available evidence from individual studies. However, these results are always dependent on the quality of the original trials. The overall methodological quality of the 11 studies included in our review was low to moderate. The studies were stratified according to different aspects of study quality and no significant differences between groups were found, but, in those judged unclear or high risk of bias, a systematic greater effect was found.

\section{Meta-analysis}

Our study focus was on RCT trials. The included trials were investigated in both the qualitative synthesis and the quantitative synthesis. The results showed a small effect in favor of stability exercises, with no or low heterogeneity for pain and self-reported 
disability, respectively, and moderate heterogeneity for performance-based lower limb function. This indicates that the results of the various included studies were not very different, indicating that studies were identified relevant to its purpose. A random effects model was fitted to the study data and to the evaluated heterogeneity. However, solely reporting the summary estimate and its 95\% confidence interval might have masked the potential effects of heterogeneity. A 95\% prediction interval, which takes into account the total uncertainty surrounding the summary estimate, describes the whole distribution of effects in a random effects model, the degree of between-study heterogeneity and, conveniently, provides a range for which we are 95\% sure that the treatment effect lies within in a new study [43]. To allow an optimal interpretation of the estimated heterogeneity, an analysis of the prediction intervals was performed for all three outcomes. This analysis indicated that further research is needed before final conclusions can be drawn.

\section{Comparators}

The comparators in our study were heterogeneous. Five trials conducted active control treatment (some type of exercises, e.g. muscle stretching, strengthening), 2 trials conducted care as usual and only 4 trials offered no treatment or attention control (i.e. education sessions or telephone contact). Other systematic reviews comparing exercise interventions alone to non-exercise control groups revealed higher effect sizes than our study $[8,44]$. Although a placebo-control is generally considered the ideal comparator group in drug trials, placebo interventions in rehabilitation trials are difficult to devise and implement. Our recommendation, therefore, is that future RCTs should be designed to compare FSE with a control intervention. In our field, when heterogeneity between-study is too high, using best evidence synthesis instead of pooling could also be considered, as described by van Tulder et al. [45].

\section{Psychometric aspects of measures}

Two studies in this thesis deal with psychometric aspects of measures.

\section{Development of the knee osteoarthritis patient education questionnaire (KOPEQ)}

Patient education is seen as an intervention with the aim of improving outcomes, mostly anxiety, pain and function [24]. The format of education ranges from one-to-one verbal communication, patient group sessions, to video or booklet with no verbal communication. Information on the validity of these interventions is not available. The term patient education is often used for patient information. However, information is only a small part of patient education [46]. It is important to embed discussion and exchange of experience in a patient education intervention. 
To our knowledge, the development of a measurement instrument to evaluate the content of a patient education intervention is quite new. The study followed the methodological recommendations of de Vet et al. [47]. The conceptual framework of Wilson and Cleary was used as a methodological guide during the development of the items $[48,49]$, which helped us to structure the items in a logical way. During a brainstorming conference, a team of experts identified the four dimensions as being important for the formative model and formulated two to six items for each dimension. Three dimensions were identified as being important for the reflective model and, in order to leave as much openness for patients to answer the questions, only one item per dimension was formulated. A five-point Likert scale, ranging from 1 to 5, was chosen for the scoring. Targeted patients answered questions on the understandability, the response options and the length of the questionnaire. Patients were also asked to formulate the benefits they expected to receive from the patient education intervention in their own words, using a think-aloud methodology [50]. For clinical practice and for research purposes, the items were linked to the ICF by an experienced ICF-linking expert [51]. Preliminary psychometric testing showed strong internal consistency and factor analysis revealed new insights into how patients linked aspects of the intervention with clinical outcomes. This first phase of development forms a solid base for the next step of further validation using a larger sample of patients, followed by translation into other languages from the original German and a corresponding cross-cultural adaption.

The KOPEQ was specially designed for the evaluation of the patient education intervention applied in this RCT. Therefore, one could argue that its generalizability is limited. However, because all the important aspects of patient education are included, the principles in this patient education intervention could also be applied to other patient education interventions.

\section{Construct validity of change scores of outcome measures}

Our primary endpoint in the RCT was the CST. We were interested in its construct validity of change scores compared to three other instruments. Construct validity of change scores can be seen as the external responsiveness of a measure, according to some authors [52]. According to de Vet et al [47], the external responsiveness is the real responsiveness. Following the construct approach, we formulated a priori hypotheses, postulating different pairwise correlations strengths between CST and the other instruments.

Additionally, we hypothesized that the order of these pairwise correlations follows the strength of the preceded hypotheses $[53,54]$, which to our knowledge has not yet been done. Tests for dependent correlations sharing CST were performed, showing that the order of our hypotheses was only partially correct.

A limitation to our study was its homogeneous population. Ideally, in a study with a heterogeneous population, all different type of scores would occur. In our homogene- 
ous group, the problems of the participants had an impact on the scores. We have seen that the CST is not an ideal measure to assess change between pre-surgery and 3 months post-surgery, whereas the KOOS reported positive changes. Therefore, we would choose a different measure as primary endpoint in a future study.

\section{Recommendations for clinical practice}

The following recommendations for clinical practice can be made based on the findings of this thesis.

\section{Inconclusive results on the effect of preoperative exercise on postoperative functional outcome}

Preoperative functioning is strongly associated with postoperative functioning $[29,55-$ 60]. However, at 3 months after surgery, our RCT was unable to show a beneficial effect of additional preoperative neuromuscular exercise on postoperative functional outcome. Whether such an intervention is opportune needs additional research, as confirmed by two recent systematic reviews [61, 62].

\section{Improve sensorimotor control and functional stability in (end-stage) knee OA}

Exercise is a key component in the management of OA symptoms in the non-surgical treatment of (end-stage) knee $\mathrm{OA}$ and has been shown to be beneficial for individuals with OA disease of all severities [63]. Neuromuscular exercise, NEMEX-TJR, FSE or other denotations, has been used and has been argued for [64-69]. Our meta-analysis showed that when clinicians have good theoretical and clinical argumentation FSE are feasible and safe and could be used for patients with knee OA, alone or in addition to other exercise programs.

\section{Evaluate the validity of the patient education intervention}

Educating and informing people preoperatively has become an essential part of patient care and can be seen as integral to the consent process [24]. In a recent review and meta-analysis on preoperative exercise on functional recovery after joint replacement, the authors concluded that "poor therapeutic validity of the therapeutic exercise programs may have hampered potentially beneficial effects" [70]. This is also relevant to patient education interventions. Although the content of preoperative education varies between settings, it is frequently comprised of discussion of pre-surgical procedures, the actual steps in the surgical procedure, postoperative care, potential stressful scenarios associated with surgery, potential surgical and non-surgical complications, postoperative pain management and post-surgery movements to avoid. Education is usually provided by physiotherapists, nurses or members of multidisciplinary teams, including psychologists. The format of education ranges from one-to-one verbal communication, 


\section{Chapter 8}

patient group sessions, or video or booklet with no verbal communication [24]. It is therefore important to evaluate not only the outcome of a patient education intervention, but also its validity. Patients' perception of the complexity of patient education materials influences their ability to effectively learn from those materials [71]. The Knee Osteoarthritis Patient Education Questionnaire (KOPEQ) can help to provide health professionals with reliable feedback on how patients assessed the applied patient education intervention.

\section{Address the contralateral knee}

Many daily activities such as rising from a chair, walking and stair climbing require bilateral limb movement. Several authors reported on the association between pain at the contralateral knee and post-surgery outcomes [5, 6, 72]. Pre-surgery function and pain of the contralateral knee had a small, but significant, effect on the outcome of the operated knee and was a significant predictor of function at 6 to 10 weeks following knee replacement in the operated knee. Addressing the contralateral knee in preoperative assessment and treatment might be advantageous to health professionals and patients' postoperative outcomes.

\section{Recommendations for further research}

The following recommendations for further research can be made based on the findings of this thesis:

- The identification of individuals with low preoperative status would be valuable [73].

- Self-reported and performance-based measures are both used when evaluating functional outcomes in individuals with knee OA [74, 75]. There is a need for more insight into the content of the outcome assessments. Selecting an outcome measure requires information on the specific content at the item level. The International Classification of Functioning, Disability and Health (ICF) [20], provides an instrument to evaluate the content of a measure in a systematic way.

- Further studies are needed investigating psychometric properties of performancebased outcome measures; especially construct validity of change scores [76]. Additionally, future research should explore the bases for differences in self-reported and performance-based measures [77].

- The therapeutic validity of patient education interventions should be assessed.

- Further research should focus on potential working mechanisms behind the positive effects of exercise [78], and which type of exercise is most effective for which subgroup (phenotype) of knee OA [79-81].

- Future research should assess both the knee scheduled for operation and the contralateral knee. 


\section{Final conclusions}

The research presented in this dissertation has added to the bank of knowledge in the field of preoperative exercise in patients with severe knee OA before TKR surgery. We have shown that our results do not give a conclusive answer to the question of whether additional preoperative exercise has a beneficial effect on postoperative functional outcomes. We have hypothesized that broader aspects might have influenced these results. We have demonstrated that preoperative pain and impaired function in the contralateral knee influences early functional outcome after TKR surgery to a small extent. FSE programs designed to reduce pain and improve lower limb function, such as the NEMEX-TJR, are safe and ca be used in clinical practice. But there is need for further research before any final conclusion can be drawn on the effect of FSE for patients with knee OA. The combination of self-reported and performance-based measures was shown to be valuable in the assessment of lower limb function, and it has to be noticed that they are only moderately correlated. The CST might not have been an ideal measure to assess change between pre-surgery and 3 months post-surgery and it might be advisable to choose a self-reported outcome measure as the primary endpoint measure. In addition, we have developed a generic instrument, called the "Knee Osteoarthritis Patient Education Questionnaire" (KOPEQ), to assess the validity of a preoperative educational intervention and preliminarily tested its psychometric properties. The KOPEQ can help to provide health professionals with reliable feedback on how patients assessed the applied patient education intervention. 


\section{REFERENCES}

1. Huber EO, de Bie RA, Roos EM, Bischoff-Ferrari HA: Effect of pre-operative neuromuscular training on functional outcome after total knee replacement: a randomized-controlled trial. BMC Musculoskelet Disord 2013, 14:157.

2. Huber EO, Roos EM, Meichtry A, de Bie RA, Bischoff-Ferrari HA: Effect of preoperative neuromuscular training (NEMEX-TJR) on functional outcome after total knee replacement: an assessor-blinded randomized controlled trial. BMC Musculoskelet Disord 2015, 16:101.

3. Huber EO, Meyer U, Felson D, Egli A, Schietzel S, Degen T, Meyer O, Wanner G, Guggi T, Theiler R et al: Early outcomes following unilateral total or partial knee replacement (TKR/PKR) due to severe unilateral knee OA: change in function and pain at the contralateral knee. Submitted 2015.

4. Creamer $P$, Hunt $M$, Dieppe P: Pain mechanisms in osteoarthritis of the knee: effect of intraarticular anesthetic. The Journal of rheumatology 1996, 23(6):1031-1036.

5. Desmeules F, Dionne CE, Belzile EL, Bourbonnais R, Champagne F, Fremont P: Determinants of pain, functional limitations and health-related quality of life six months after total knee arthroplasty: results from a prospective cohort study. BMC sports science, medicine and rehabilitation 2013, 5:2.

6. Kahn TL, Soheili AC, Schwarzkopf R: Poor WOMAC Scores in Contralateral Knee Negatively Impact TKA Outcomes: Data From the Osteoarthritis Initiative. The Journal of arthroplasty 2014, 29(8):1580-1585.

7. Huber EO, Juhl CB, Roos EM, Lund H: Effect of Functional Stability Exercise Programs designed to improve Pain and Lower Limb Disability in people with Knee Osteoarthritis: a Systematic Review and Meta-analysis of Randomized Controlled Trials. Submitted 2015.

8. Juhl C, Christensen R, Roos EM, Zhang W, Lund H: Impact of exercise type and dose on pain and disability in knee osteoarthritis: a systematic review and meta-regression analysis of randomized controlled trials. Arthritis \& rheumatology (Hoboken, NJ) 2014, 66(3):622-636.

9. Huber EO, Meichtry A, De Bie RA, Bastiaenen $\mathrm{CH}$ : Construct validity of change scores of the Chair Stand Test versus Timed Up and Go test, KOOS questionnaire and the isometric muscle strength test in patients with severe knee osteoarthritis undergoing total knee replacement Manual Therapy (2015), doi: 10.1016/j.math.2015.09.012.

10. Pai YC, Chang HJ, Chang RW, Sinacore JM, Lewis JL: Alteration in multijoint dynamics in patients with bilateral knee osteoarthritis. Arthritis and rheumatism 1994, 37(9):1297-1304.

11. Segal NA, Boyer ER, Wallace R, Torner JC, Yack HJ: Association between chair stand strategy and mobility limitations in older adults with symptomatic knee osteoarthritis. Archives of physical medicine and rehabilitation 2013, 94(2):375-383.

12. Turcot K, Armand S, Fritschy D, Hoffmeyer P, Suva D: Sit-to-stand alterations in advanced knee osteoarthritis. Gait Posture 2012, 36(1):68-72.

13. Patsika G, Kellis E, Amiridis IG: Neuromuscular efficiency during sit to stand movement in women with knee osteoarthritis. Journal of electromyography and kinesiology : official journal of the International Society of Electrophysiological Kinesiology 2011, 21(5):689-694.

14. Bouchouras G, Patsika G, Hatzitaki V, Kellis E: Kinematics and knee muscle activation during sit-to-stand movement in women with knee osteoarthritis. Clinical biomechanics (Bristol, Avon) 2015.

15. Mizner RL, Snyder-Mackler L: Altered loading during walking and sit-to-stand is affected by quadriceps weakness after total knee arthroplasty. Journal of orthopaedic research : official publication of the Orthopaedic Research Society 2005, 23(5):1083-1090.

16. Farquhar SJ, Reisman DS, Snyder-Mackler L: Persistence of altered movement patterns during a sit-tostand task 1 year following unilateral total knee arthroplasty. Physical therapy 2008, 88(5):567-579.

17. Christiansen CL, Bade MJ, Judd DL, Stevens-Lapsley JE: Weight-bearing asymmetry during sit-stand transitions related to impairment and functional mobility after total knee arthroplasty. Archives of physical medicine and rehabilitation 2011, 92(10):1624-1629.

18. Ouellet $\mathrm{D}$, Moffet $\mathrm{H}$ : Locomotor deficits before and two months after knee arthroplasty. Arthritis and rheumatism 2002, 47(5):484-493. 
19. Davidson BS, Judd DL, Thomas AC, Mizner RL, Eckhoff DG, Stevens-Lapsley JE: Muscle activation and coactivation during five-time-sit-to-stand movement in patients undergoing total knee arthroplasty. Journal of electromyography and kinesiology : official journal of the International Society of Electrophysiological Kinesiology 2013, 23(6):1485-1493.

20. World Health Organization. International Classification of Functioning, Disability and Health. Geneva, Switzerland

21. Maly MR, Costigan PA, Olney SJ: Determinants of self-report outcome measures in people with knee osteoarthritis. Archives of physical medicine and rehabilitation 2006, 87(1):96-104.

22. Stratford PW, Kennedy DM: Performance measures were necessary to obtain a complete picture of osteoarthritic patients. Journal of clinical epidemiology 2006, 59(2):160-167.

23. Parent $\mathrm{E}$, Moffet $\mathrm{H}$ : Comparative responsiveness of locomotor tests and questionnaires used to follow early recovery after total knee arthroplasty. Archives of physical medicine and rehabilitation 2002, 83(1):70-80.

24. McDonald S, Page MJ, Beringer K, Wasiak J, Sprowson A: Preoperative education for hip or knee replacement. The Cochrane database of systematic reviews 2014, 5:CD003526.

25. Huber EO, Bastiaenen CH, Bischoff-Ferrari HA, Meichtry A, De Bie RA: Development of the knee osteoarthritis patient education questionnaire (KOPEQ): A new measure for evaluating preoperative patient education programs for patients undergoing total knee replacement. Accepted for publication in Swiss Medical Weekly 2015.

26. Jones S, Alnaib M, Kokkinakis M, Wilkinson M, St Clair Gibson A, Kader D: Pre-operative patient education reduces length of stay after knee joint arthroplasty. Annals of the Royal College of Surgeons of England 2011, 93(1):71-75.

27. Marcinkowski K, Wong VG, Dignam D: Getting back to the future: a grounded theory study of the patient perspective of total knee joint arthroplasty. Orthopaedic nursing / National Association of Orthopaedic Nurses 2005, 24(3):202-209.

28. Hawker GA: Who, when, and why total joint replacement surgery? The patient's perspective. Current opinion in rheumatology 2006, 18(5):526-530.

29. Mahomed NN, Liang MH, Cook EF, Daltroy LH, Fortin PR, Fossel AH, Katz JN: The importance of patient expectations in predicting functional outcomes after total joint arthroplasty. The Journal of rheumatology 2002, 29(6):1273-1279.

30. Moher D, Hopewell S, Schulz KF, Montori V, Gotzsche PC, Devereaux PJ, Elbourne D, Egger M, Altman DG: CONSORT 2010 Explanation and Elaboration: Updated guidelines for reporting parallel group randomised trials. Journal of clinical epidemiology 2010, 63(8):e1-37.

31. Zwarenstein M, Treweek S, Gagnier JJ, Altman DG, Tunis S, Haynes B, Oxman AD, Moher D: Improving the reporting of pragmatic trials: an extension of the CONSORT statement. BMJ (Clinical research ed) 2008, 337:a2390.

32. Schulz KF: Subverting randomization in controlled trials. Jama 1995, 274(18):1456-1458.

33. Schulz KF, Chalmers I, Altman DG, Grimes DA, Dore CJ: The methodologic quality of randomization as assessed from reports of trials in specialist and general medical journals. The Online journal of current clinical trials 1995, Doc No 197:[81 paragraphs].

34. Haahr MT, Hrobjartsson A: Who is blinded in randomized clinical trials? A study of 200 trials and a survey of authors. Clinical trials (London, England) 2006, 3(4):360-365.

35. Pengel LH, Refshauge KM, Maher CG, Nicholas MK, Herbert RD, McNair P: Physiotherapist-directed exercise, advice, or both for subacute low back pain: a randomized trial. Annals of internal medicine 2007, 146(11):787-796.

36. Lange AK, Vanwanseele B, Foroughi N, Baker MK, Shnier R, Smith RM, Singh MA: Resistive Exercise for Arthritic Cartilage Health (REACH): a randomized double-blind, sham-exercise controlled trial. BMC geriatrics 2009, 9:1.

37. Ross S, Grant A, Counsell C, Gillespie W, Russell I, Prescott R: Barriers to participation in randomised controlled trials: a systematic review. Journal of clinical epidemiology 1999, 52(12):1143-1156. 
38. Onghena $\mathrm{P}$, Edgington ES: Customization of pain treatments: single-case design and analysis. The Clinical journal of pain 2005, 21(1):56-68; discussion 69-72.

39. Hoogeboom TJ, Kwakkenbos L, Rietveld L, den Broeder AA, de Bie RA, van den Ende CH: Feasibility and potential effectiveness of a non-pharmacological multidisciplinary care programme for persons with generalised osteoarthritis: a randomised, multiple-baseline single-case study. BMJ open 2012, 2(4).

40. Hollis $S$, Campbell F: What is meant by intention to treat analysis? Survey of published randomised controlled trials. BMJ (Clinical research ed) 1999, 319(7211):670-674.

41. Laird NM, Ware JH: Random-effects models for longitudinal data. Biometrics 1982, 38(4):963-974.

42. Liberati A, Altman DG, Tetzlaff J, Mulrow C, Gøtzsche PC, loannidis JPA, Clarke M, Devereaux PJ, Kleijnen J, Moher D: The PRISMA Statement for Reporting Systematic Reviews and Meta-Analyses of Studies That Evaluate Health Care Interventions: Explanation and Elaboration. PLoS Medicine 2009, 6(7):e1000100.

43. Higgins JP, Thompson SG, Spiegelhalter DJ: A re-evaluation of random-effects meta-analysis. Journal of the Royal Statistical Society Series A, (Statistics in Society) 2009, 172(1):137-159.

44. Jansen MJ, Viechtbauer W, Lenssen AF, Hendriks EJ, de Bie RA: Strength training alone, exercise therapy alone, and exercise therapy with passive manual mobilisation each reduce pain and disability in people with knee osteoarthritis: a systematic review. Journal of physiotherapy 2011, 57(1):11-20.

45. van Tulder M, Furlan A, Bombardier C, Bouter L: Updated method guidelines for systematic reviews in the cochrane collaboration back review group. Spine 2003, 28(12):1290-1299.

46. Newman S, Mulligan K, Steed L: What is meant by self-management and how can its efficacy be established? Rheumatology (Oxford, England) 2001, 40(1):1-4

47. de Vet HCW, Terwee CB, Mokkink LB, Knol DL: Measurement in Medicine: A Practical Guide: Cambridge University Press; 2011.

48. Wilson IB, Cleary PD: Linking clinical variables with health-related quality of life. A conceptual model of patient outcomes. Jama 1995, 273(1):59-65.

49. Wilson IB, Kaplan S: Clinical practice and patients' health status: how are the two related? Med Care 1995, 33(4 Suppl):AS209-214

50. Using the think aloud method (cognitive labs) to evaluate test design for students with disabilities and English language learners (Technical Report 44). Available from: [http//education.umn.edu/ NCEO/OnlinePubs/Tech44/. 26 July 2014]

51. Alviar MJ, Olver J, Brand C, Hale T, Khan F: Do patient-reported outcome measures used in assessing outcomes in rehabilitation after hip and knee arthroplasty capture issues relevant to patients? Results of a systematic review and ICF linking process. Journal of rehabilitation medicine 2011, 43(5):374-381.

52. Husted JA, Cook RJ, Farewell VT, Gladman DD: Methods for assessing responsiveness: a critical review and recommendations. Journal of clinical epidemiology 2000, 53(5):459-468.

53. Williams EJ: Regression Analysis: John Wiley and Sons; 1959.

54. Steiger JH: Tests for Comparing Elements of a Correlation Matrix. Psychological bulletin 1980, 87(2):245251.

55. Bade MJ, Kittelson JM, Kohrt WM, Stevens-Lapsley JE: Predicting functional performance and range of motion outcomes after total knee arthroplasty. American journal of physical medicine \& rehabilitation / Association of Academic Physiatrists 2014, 93(7):579-585.

56. Kennedy LG, Newman JH, Ackroyd CE, Dieppe PA: When should we do knee replacements? Knee 2003, 10(2):161-166.

57. Zeni JA, Jr., Snyder-Mackler L: Preoperative predictors of persistent impairments during stair ascent and descent after total knee arthroplasty. The Journal of bone and joint surgery American volume 2010, 92(5):1130-1136.

58. Escobar A, Quintana JM, Bilbao A, Azkarate J, Guenaga JI, Arenaza JC, Gutierrez LF: Effect of patient characteristics on reported outcomes after total knee replacement. Rheumatology (Oxford, England) 2007, 46(1):112-119.

59. Fitzgerald JD, Orav EJ, Lee TH, Marcantonio ER, Poss R, Goldman L, Mangione CM: Patient quality of life during the 12 months following joint replacement surgery. Arthritis and rheumatism 2004, 51(1):100-109. 
60. Lingard EA, Katz JN, Wright EA, Sledge CB: Predicting the outcome of total knee arthroplasty. The Journal of bone and joint surgery American volume 2004, 86-A(10):2179-2186.

61. Simmons L, Smith T: Effectiveness of pre-operative physiotherapy-based programmes on outcomes following total knee arthroplasty: a systematic review and meta-analysis. Physical Therapy Reviews 2013, 18(1):1-10.

62. Shoemaker M, Gibson C, Saagman S: Preoperative exercise in indvidiuals undergoing total knee arthroplasty: state of the evidence. Topics in Geriatric Rehabilitation 2013, 29(1):2-16.

63. Bennell KL, Hinman RS: A review of the clinical evidence for exercise in osteoarthritis of the hip and knee. Journal of science and medicine in sport / Sports Medicine Australia 2011, 14(1):4-9.

64. Ageberg E, Link A, Roos EM: Feasibility of neuromuscular training in patients with severe hip or knee OA: The individualized goal-based NEMEX-TJR training program. BMC Musculoskelet Disord 2010, 11:7.

65. Ageberg E, Roos EM: Neuromuscular exercise as treatment of degenerative knee disease. Exercise and sport sciences reviews 2015, 43(1):14-22.

66. Ericsson YB, Dahlberg LE, Roos EM: Effects of functional exercise training on performance and muscle strength after meniscectomy: a randomized trial. Scandinavian journal of medicine \& science in sports 2009, 19(2):156-165.

67. Knoop J, Dekker J, van der Leeden M, van der Esch M, Thorstensson CA, Gerritsen M, Voorneman RE, Peter WF, de Rooij M, Romviel S et al: Knee joint stabilization therapy in patients with osteoarthritis of the knee: a randomized, controlled trial. Osteoarthritis and cartilage / OARS, Osteoarthritis Research Society 2013, 21(8):1025-1034.

68. Smith TO, King JJ, Hing CB: The effectiveness of proprioceptive-based exercise for osteoarthritis of the knee: a systematic review and meta-analysis. Rheumatology international 2012, 32(11):3339-3351.

69. Bennell KL, Wrigley TV, Hunt MA, Lim BW, Hinman RS: Update on the role of muscle in the genesis and management of knee osteoarthritis. Rheumatic diseases clinics of North America 2013, 39(1):145-176.

70. Hoogeboom TJ, Oosting E, Vriezekolk JE, Veenhof C, Siemonsma PC, de Bie RA, van den Ende CH, van Meeteren NL: Therapeutic validity and effectiveness of preoperative exercise on functional recovery after joint replacement: a systematic review and meta-analysis. PloS one 2012, 7(5):e38031.

71. Farnsworth $\mathrm{M}$ : Differences in perceived difficulty in print and online patient education materials. The Permanente journal 2014, 18(4):45-50.

72. Maxwell J, Niu J, Singh JA, Nevitt MC, Law LF, Felson D: The influence of the contralateral knee prior to knee arthroplasty on post-arthroplasty function: the multicenter osteoarthritis study. The Journal of bone and joint surgery American volume 2013, 95(11):989-993.

73. Judge A, Javaid MK, Arden NK, Cushnaghan J, Reading I, Croft P, Dieppe PA, Cooper C: Clinical tool to identify patients who are most likely to achieve long-term improvement in physical function after total hip arthroplasty. Arthritis care \& research 2012, 64(6):881-889.

74. Wright AA, Hegedus EJ, Baxter GD, Abbott JH: Measurement of function in hip osteoarthritis: developing a standardized approach for physical performance measures. Physiotherapy theory and practice 2011, 27(4):253-262.

75. Jordan KP, Wilkie R, Muller S, Myers H, Nicholls E: Measurement of change in function and disability in osteoarthritis: current approaches and future challenges. Curr Opin Rheumatol 2009, 21(5):525-530.

76. Dobson F, Hinman RS, Hall M, Terwee CB, Roos EM, Bennell KL: Measurement properties of performance-based measures to assess physical function in hip and knee osteoarthritis: a systematic review. Osteoarthritis and cartilage / OARS, Osteoarthritis Research Society 2012, 20(12):1548-1562.

77. Riddle DL, Stratford PW: Unilateral vs bilateral symptomatic knee osteoarthritis: associations between pain intensity and function. Rheumatology (Oxford, England) 2013, 52(12):2229-2237.

78. Runhaar J, Luijsterburg P, Dekker J, Bierma-Zeinstra SM: Identifying potential working mechanisms behind the positive effects of exercise therapy on pain and function in osteoarthritis; a systematic review. Osteoarthritis and cartilage / OARS, Osteoarthritis Research Society 2015, 23(7):1071-1082.

79. Iversen MD: Rehabilitation interventions for pain and disability in osteoarthritis: a review of interventions including exercise, manual techniques, and assistive devices. Orthopedic nursing 2012, 31(2):103-108. 
80. Knoop J, van der Leeden M, Thorstensson CA, Roorda LD, Lems WF, Knol DL, Steultjens MP, Dekker J: Identification of phenotypes with different clinical outcomes in knee osteoarthritis: data from the Osteoarthritis Initiative. Arthritis care \& research 2011, 63(11):1535-1542.

81. lijima H, Fukutani N, Aoyama T, Fukumoto T, Uritani D, Kaneda E, Ota K, Kuroki H, Matsuda S: Clinical Phenotype Classifications Based on Static Varus Alignment and Varus Thrust in Japanese Patients With Medial Knee Osteoarthritis. Arthritis \& rheumatology (Hoboken, NJ) 2015, 67(9):2354-2362. 


\section{Summary / Zusammenfassung}

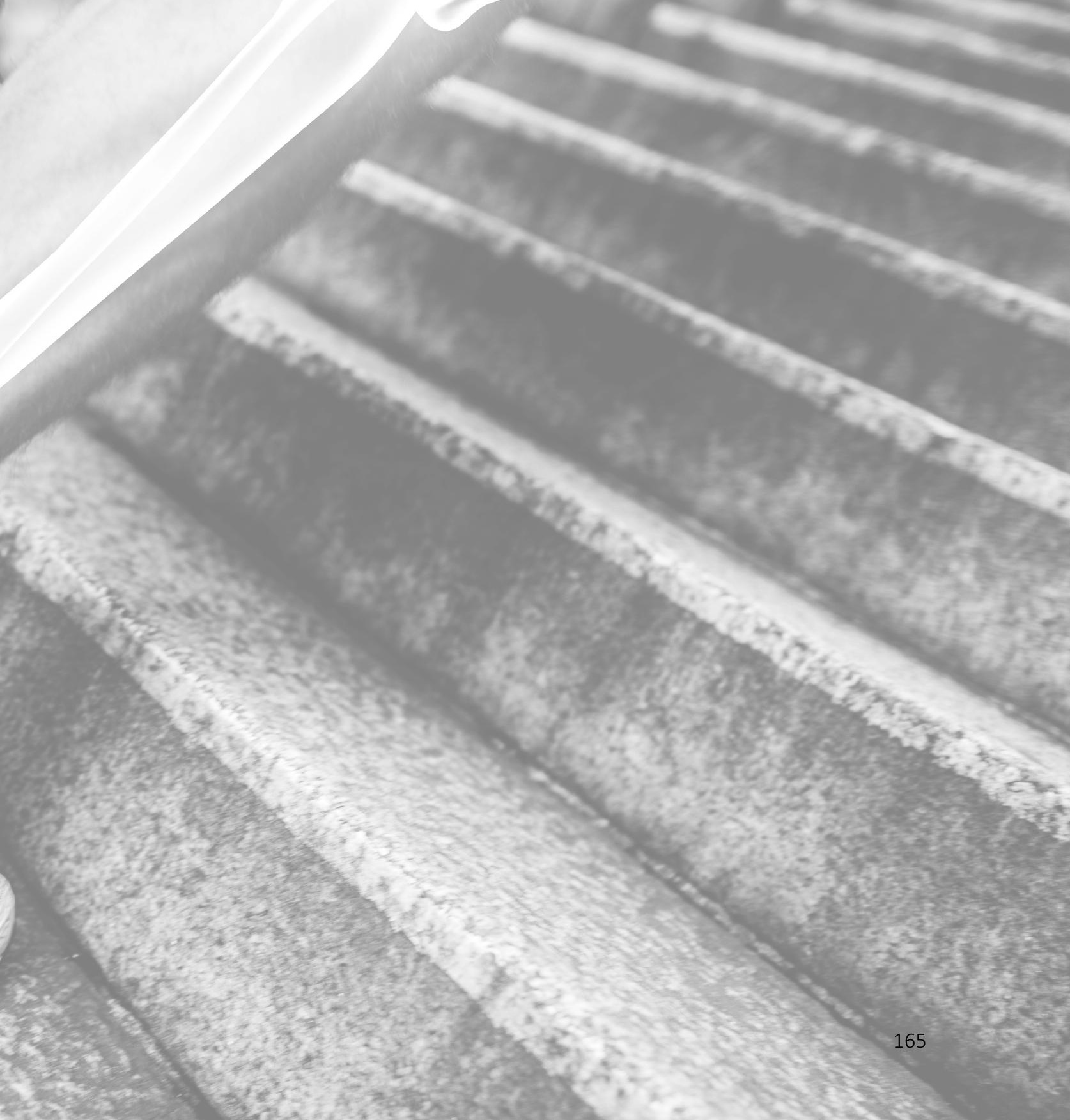





\section{Summary}

This dissertation addresses preoperative interventions in patients with severe knee osteoarthritis (OA) and planned total knee replacement (TKR). The topics covered include neuromuscular training and patient education.

Chapter 1 provides a background on knee OA and therapeutic exercise, an overview of the current evidence of preoperative exercise, as well as the objectives and outline of the thesis.

Knee OA is a major public health issue causing (chronic) pain, reduced physical function and diminished quality of life. Patients with knee OA are less physically active when compared to the same age group in a general population. Most research to date has focused on quadriceps strengthening programs. Investigation into the role of exercises that target muscle timing and function, rather than purely strength, (denoted functional stability exercise / neuromuscular exercise) has received increased interest in recent years. The individualized goal-based neuromuscular exercise program-total joint replacement (NEMEX-TJR) is a well-described and feasible exercise program, addressing sensorimotor control and functional stability in patients with knee OA.

TKR is an effective intervention for people with severe knee OA who are unresponsive to conservative therapy. Patients often have to wait for many weeks or months for their surgery and preoperative interventions, such as therapeutic exercise and education for patients awaiting knee replacement surgery, are performed in the expectation that these programs may improve preoperative outcomes as well as improving functional outcome post-surgery. The results of two previous reviews have concluded that preoperative exercise programs were not effective in improving outcomes. Limitations of these reviews were the relatively small number of patients studied, the heterogeneous and not always well-described interventions, and comparators and outcome measures which were not related to the interventions used. Given these limitations, taken together with a positive trend in a recent trial, indications were that there was still a need for future research in this field. 


\section{Summary}

Chapter 2 comprises a study in which the development of a measurement instrument is described. This generic instrument for the use of patients, named the "Knee Osteoarthritis Patient Education Questionnaire" (KOPEQ), was designed to assess the validity of a preoperative educational intervention. Its psychometric properties were preliminarily tested. The design of the instrument followed the conceptual framework of Wilson and Cleary as a methodological guide.

The results showed that targeted patients confirmed in interviews that all questions were highly understandable and that the length of the questionnaire was feasible and acceptable. The internal consistency of the KOPEQ was good and four factors were identified to explain $61 \%$ of the variance. These factors were named "didactics", "addressability", "empowerment" and "theory".

Chapter 3 defines a study protocol and presents the rationale for a randomized controlled trial (RCT) to assess the effect on lower extremity function and pain in individuals on a waiting list for TKR due to severe knee OA of preoperative neuromuscular training plus knee OA patient education intervention compared to knee OA patient education intervention alone. The neuromuscular training of the experimental group is described in detail. The sit-to-stand ability is measured using a performance-based measure (primary endpoint) and activities of daily living and pain are measured using self-reported outcome measures (secondary endpoints).

Chapter 4 contains the findings of the RCT described in CHAPTER 3. Results indicated that at 3 months post-surgery there was no improvement in the primary endpoint and significant improvements in the secondary endpoints in both the exercise and control groups, with no significant difference between groups. Noticeably, after the training intervention but before surgery, we observed a small improvement in all primary and secondary endpoints in both the exercise and control groups, which also did not differ significantly between groups. The median number of attended sessions was 10 , which was determined by the length of the waiting time for surgery. The neuromuscular program was found to be well-tolerated with only one patient missing 2 sessions due to a joint-specific adverse event (increased pain), and the adherence to the program was high (82\%).

The conclusion of this study is that no conclusive answer is provided to the question of whether additional preoperative exercise is beneficial to postoperative functional outcome. The small size of this trial is a considerable limitation that may have prevented the documentation of small and sustained benefits.

Chapter 5 presents the change in function and pain in the contralateral knee from 1-2 weeks prior to surgery to 6-10 weeks post-surgery, as well as the influence of function and pain in the contralateral knee prior to surgery on early outcome of the knee undergoing unilateral total or partial knee replacement. The results showed that following 
surgery both knees improved significantly and remained weakly correlated for pain and function. Several explanations could be considered: in the acute and post-acute rehabilitation phase the contralateral leg of the patient is also included in therapeutic exercises; the contralateral joint is rested as a consequence of surgery and injurious painful demands are avoided; treatment of one knee can have bilateral effects though the central nervous system connections. Our recommendation as a result of this study is that surgeons delay total or partial knee replacement surgery of the second knee for at least 3 months after first surgery.

The study also revealed that impaired functional status and pain in the contralateral knee had a small but significant independent negative influence on early outcome after unilateral total or partial knee replacement. This might be one explanation as to why function and pain in patients might improve less than expected in the early postoperative phase. We therefore recommend that measures prior to surgery should include not only the scheduled knee but also the contralateral knee.

Chapter 6 incorporates a systematic review and meta-analysis synthesizing the current state of knowledge of the effects of functional stability exercise (FSE) programs designed to improve pain and lower limb disability in people with knee OA. The main findings showed a small effect of FSE, but the results of the prediction intervals showed opposite conclusions from the two extremes of the prediction intervals for all three outcomes. Thus, further research is needed before a final conclusion can be reached. The lack of a clear final result could perhaps be explained by the low quality of the included trials which were unclear in terms of selection and detection bias, as well as the low number of participants in each included study.

Although the FSE program is not clearly defined and even though different types of interventions were included, the statistical heterogeneity was very low or even absent, indicating that the different exercise programs have something in common. The explanations for the effect on pain and function following exercise in patients with knee OA need to be further evaluated. A theoretical argument as to when to apply strengthening exercise, aerobic capacity exercise or FSE most appropriately would be of interest to clinicians.

Chapter 7 investigates the construct validity of change scores of the Chair Stand Test (CST) versus Timed Up and Go (TUG) test, KOOS questionnaire and the isometric muscle strength test (IMS) in patients with severe knee osteoarthritis undergoing total knee replacement. Results showed that the CST might not be an ideal measure to assess change between pre-surgery and 3 months post-surgery in the target group. Some reflections on the sit-to-stand movement in combination with TKR surgery might help to understand the unexpected result. In the immediate postoperative phase subjects with unilateral TKR will still demonstrate side-to-side differences during sit-to-stand and it appears that, due to pain and muscle weakness, many patients persist in the pre- 


\section{Summary}

surgical adopted pattern of avoiding the use of the affected leg during the sit-to-stand task and compensate using different neuromuscular strategies.

The comparison of the CST with the other measures showed that only the KOOS reported positive changes over time in all subscales, including the subscale activities of daily living (ADL). Patients appear to perceive an improvement in function compared to pre-surgery, although their capacity to perform a task has not increased in reality. KOOS $A D L$ best reflects the improvement of the TKR 3 months after surgery.

Chapter 8 discusses the results, presents methodological reflections and provides recommendations for clinical practice and further research. Our results do not provide a conclusive answer to the question of whether additional preoperative neuromuscular exercise has a beneficial effect on postoperative functional outcomes. An investigation of the association of pain and function of the contralateral knee preoperatively on the operated knee postoperatively showed that early outcome in the operated knee was influenced to a small but significant extent by the preoperative pain and function in the contralateral knee. Whether the applied intervention (FSE / neuromuscular exercise) is effective in improving pain and function in patients with severe knee OA is inconclusive and further research is required. The CST might not be an ideal measure to assess change between pre-surgery and 3 months post-surgery for patients undergoing TKR. Finally, a generic instrument was developed for the use of patients to assess the validity of a preoperative educational intervention and its psychometric properties were preliminary tested, showing strong internal consistency.

Future research should assess both the knee scheduled for operation and the contralateral knee. Further studies are needed to investigate the psychometric properties of performance-based outcome measures; especially construct validity of change scores. The therapeutic validity of patient education interventions should be assessed. Further research should focus on the potential working mechanisms behind the positive effects of exercise and on which type of exercise is most effective for particular subgroups (phenotype) of knee OA.

To date, we are unable to recommend the implementation of preoperative exercise in clinical practice. FSE, including neuromuscular exercise, is feasible and safe and could be used for patients with knee OA, alone or in addition to other exercise programs. When applying a preoperative patient education intervention, the KOPEQ can help to provide clinicians with reliable feedback on how patients assessed the intervention. 


\section{Zusammenfassung}

Diese Doktorarbeit befasst sich mit präoperativen Interventionen bei Patienten und Patientinnen mit schwerer Kniearthrose. Spezifische Themen waren ein neuromuskuläres Training und eine Patientenedukation.

Kapitel 1 gibt Hintergrundinformationen zu Kniearthrose und therapeutischen Übungen, einen Überblick über die aktuelle Evidenzlage von therapeutischen Übungen sowie die Ziele und die Gliederung der These.

Kniearthrose ist ein relevantes Gesundheitsthema und führt zu (chronischen) Schmerzen, reduzierter körperlicher Aktivität und verminderter Lebensqualität. Patienten und Patientinnen mit Kniearthrose sind körperlich weniger aktiv als Menschen einer gleichen Altersgruppe ohne Kniearthrose. Die Forschung hat bis heute mehrheitlich auf Kräftigungsprogramme für die vordere Oberschenkelmuskulatur fokussiert. Untersuchungen über die Rolle von Übungen, die sich mehr der Muskelsteuerung und der Muskelfunktion (auch funktionelle Stabilisierungs- oder neuromuskuläre Übungen genannt) widmen, als nur der reinen Muskelkräftigung, erfahren zunehmend ein grösseres Interesse.

Das individualisierte, zielorientierte neuromuskuläre Übungsprogramm bei totalem Gelenksersatz (NEMEX-TJR) ist ein gut beschriebenes und leicht durchführbares Programm, welches bei Patienten und Patientinnen mit Kniearthrose die sensomotorische Kontrolle und funktionelle Stabilität verbessern soll.

Der totale Kniegelenksersatz ist eine wirksame Intervention für Menschen mit schwerer Kniearthrose, die nicht auf konservative Therapien ansprechen. Patienten und Patientinnen müssen allerdings oft Wochen und Monate auf ihre Operation warten. Schon heute werden präoperative Interventionen (wie beispielsweise therapeutische Übungen und Patientenedukation) für Patienten und Patientinnen auf der Warteliste für eine Knieprothese durchgeführt mit der Erwartung, dass diese Programme sowohl präoperativ als auch postoperativ die Funktionsfähigkeit verbessern könnten. Zwei systematische Literatursuchen haben ergeben, dass präoperative Übungsprogramme das funktionelle Ergebnis nicht wirksam verbessert haben. Einschränkend kann festgehalten werden, dass die untersuchten Studien relativ geringe Fallzahlen aufwiesen, die 
Interventionen unterschiedlich und nicht immer gut beschrieben waren und die Vergleichsgruppen und Ergebnismessungen nicht mit den Interventionen in Bezug standen. Unter Berücksichtigung dieser Einschränkungen und einem positiven Trend in einer kürzlich erschienen Studie ist der Hinweis gegeben, dass immer noch ein Forschungsbedarf in diesem Feld besteht.

Kapitel 2 beinhaltet eine Studie, die die Entwicklung eines Messinstrumentes beschreibt. Dieses allgemeine Instrument für Patienten und Patientinnen, genannt Kniearthrose-Patientenedukations-Fragebogen (KOPEQ), wurde konzipiert, um die Gültigkeit einer präoperativen Patientenedukation zu untersuchen. Seine psychometrischen Eigenschaften wurden vorläufig getestet. Die Ausgestaltung des Fragebogens basierte auf dem konzeptionellen Bezugssystem von Wilson und Cleary, welches als methodologischer Leitfaden diente.

Die Resultate zeigten, dass die angesprochen Patienten und Patientinnen bestätigten, dass alle Fragen sehr verständlich formuliert sind und dass die Länge des Fragebogens machbar und akzeptierbar ist. Die interne Konsistenz des KOPEQ war gut und es konnten vier Faktoren identifiziert werden, die 61\% der Varianz erklärten. Diese vier Faktoren wurden „Didaktik“, „Ansprechbarkeit“, „Ermächtigung“ und „Theorie“ genannt.

Kapitel 3 umschreibt ein Studienprotokoll und präsentiert die Argumentation für eine klinische randomisierte Studie (RCT), die den Effekt eines präoperativen Trainings plus Knieschule für Kniearthrose verglichen mit Knieschule für Kniearthrose alleine auf die Funktionsfähigkeit der unteren Extremitäten bei Patienten und Patientinnen auf einer Warteliste für eine Knieprothese aufgrund schwerer Kniearthrose untersucht. Das neuromuskuläre Training in der untersuchten Gruppe ist detailliert beschrieben. Die Aktivität des Aufstehens von einem Stuhl wird mit einem klinischen Test gemessen (primärer Endpunkt), und die Aktivitäten des täglichen Lebens und der Schmerz werden mit einem Fragebogen erhoben (sekundäre Endpunkte).

Kapitel 4 beinhaltet die Resultate des im Kapitel 3 beschriebenen RCTs. Die Resultate zeigten, dass 3 Monate nach der Operation keine Verbesserung im primären Endpunkt stattfand und signifikante Verbesserungen in den sekundären Endpunkten in beiden Gruppen stattfanden, jedoch ohne signifikante Verbesserungen im Zwischengruppenvergleich. Unmittelbar nach dem Training (aber noch vor der Operation) konnten wir eine kleine Verbesserung in allen primären und sekundären Endpunkten in beiden Gruppen feststellen, die allerdings im Zwischengruppenvergleich nicht signifikant war. Im Mittel wurden 10 Trainingseinheiten besucht. Dieser Wert wurde von der Länge der Wartezeit vor der Operation bestimmt. Das neuromuskuläre Training wurde von den Patienten und Patientinnen gut toleriert. Lediglich ein Patient musste aufgrund 
verstärkter Schmerzen 2 Trainingseinheiten ausfallen lassen. 82\% der geplanten Trainingseinheiten wurden absolviert.

Zusammenfassend kann gesagt werden, dass es keine abschliessende Antwort auf die Frage gibt, ob ein zusätzliches präoperatives Training einen positiven Effekt auf die postoperative Funktionsfähigkeit hat. Die kleine Fallzahl in unserer Studie ist eine erhebliche Einschränkung und könnte die Dokumentation eines kleinen und anhaltenden Nutzens verhindert haben.

Kapitel 5 präsentiert die Veränderung von Funktion und Schmerz von 1-2 Wochen vor der Operation zu 6-10 Wochen nach der Operation im gegenüberliegenden Knie sowie den Einfluss von Funktion und Schmerz im gegenüberliegenden Knie vor der Operation auf die Funktionsfähigkeit des operierten Knies (totale oder partielle Knieprothese). Die Resultate zeigten nach der Operation eine signifikante Verbesserung in Funktion und Schmerz bei beiden Knien, die auch schwach miteinander korrelierten. Verschiedene Erklärungen sind denkbar: In der akuten und subakuten Rehabilitationsphase wird das gegenüberliegende Knie in die physiotherapeutische Behandlung miteinbezogen; es ist aufgrund der Operation des anderen Knies zur Ruhe gezwungen und schädliche und schmerzhafte Aufgaben werden vermieden; die Behandlung des operierten Knies kann über zentralnervöse Verbindungen einen bilateralen Effekt haben. Wir empfehlen Orthopäden und Orthopädinnen die Operation des gegenüberliegenden Knies frühestens 3 Monate nach der ersten Operation planen.

Die Studie zeigte auch, dass Beeinträchtigungen in Funktion und Schmerz im gegenüberliegenden Knie einen kleinen, aber signifikanten und unabhängigen Einfluss auf die Funktionsfähigkeit des operierten Knies nach der Operation hatten. Das könnte ein Grund dafür sein, warum sich Funktion und Schmerz bei Patienten und Patientinnen in der frühen postoperativen Phase weniger stark verbessern als erwartet. Darum empfehlen wir, dass vor der Operation neben dem operierten Knie auch das gegenüberliegende Knie untersucht wird.

Kapitel 6 beinhaltet eine systematische Literatursuche und Meta-Analyse, die den aktuellen Wissensstand über den Effekt von funktionellen Stabilisationsübungen (FSE) zur Verbesserung von Schmerz und Funktionsfähigkeit in den unteren Extremitäten bei Patienten und Patientinnen mit Kniearthrose zusammenfasst. Es konnte ein kleiner Effekt zu Gunsten FSE ermittelt werden, aber die Resultate von Prognoseintervallen führten zu entgegengesetzten Rückschlüssen für alle 3 Outcomes. Deshalb ist weitere Forschung nötig, bevor eine endgültige Folgerung gezogen werden kann. Das Fehlen eines klaren, abschliessenden Ergebnisses kann vielleicht mit der niedrigen Qualität der eingeschlossenen Studien erklärt werden, welche sowohl Verzerrungen als auch tiefe Fallzahlen beinhaltet.

Obwohl das FSE Programm nicht klar umschrieben ist und obwohl verschiedene Arten von Interventionen eingeschlossen worden sind, war die statistische Heterogeni- 
tät sehr gering oder abwesend. Dies zeigt, dass diese verschiedenen Programme sehr wohl Gemeinsamkeiten haben. Eine theoretische Argumentation, wann Kräftigungsprogramme, wann Herz-Kreislaufprogramme und wann FSE-Programme angebracht sind, wäre für Praktiker und Praktikerinnen sehr interessant.

Kapitel 7 untersucht die Konstruktvalidität von Veränderungswerten des Chair Stand Tests (CST) im Vergleich zum Timed Up and Go (TUG) Test, dem KOOS Fragebogen sowie der isometrischen Muskelkraftmessung (IMS) bei Patienten und Patientinnen mit schwerer Kniearthrose und erhaltener Knieprothese. Die Resultate zeigten, dass der CST möglicherweise kein geeignetes Messinstrument ist, um Veränderungen zwischen unmittelbar vor der Operation und 3 Monate nach der Operation zu messen. Es braucht deshalb eine Reflexion über die Aktivität des Aufstehens in Kombination mit einem Kniegelenksersatz. Die Patienten und Patientinnen zeigten im gemessenen Zeitraum während dieser Aktivität noch immer Seitenunterschiede im Sinne von veränderten Bewegungsmustern und asymmetrischer Gewichtsverteilung. Es scheint, dass viele Patienten und Patientinnen auch 3 Monate nach der Operation aufgrund von Schmerzen und Muskelschwäche in antrainierten präoperativen Bewegungsmustern verharren.

Der Vergleich des CST mit den anderen Messinstrumenten zeigte, dass lediglich der KOOS ADL (Aktivitäten des täglichen Lebens) positive Veränderungen über die Zeit in allen Subskalen zeigte. Patienten und Patientinnen scheinen postoperativ im Vergleich zu präoperativ eine Funktionsverbesserung wahrzunehmen, obwohl ihre Fähigkeit, diese Verbesserung in einem klinischen Test zu zeigen, in Realität nicht zugenommen hat. KOOS ADL reflektiert die Funktionsverbesserung 3 Monate nach der Operation am besten.

Kapitel 8 diskutiert die Resulate, präsentiert methodologische Reflexionen und gibt Empfehlungen für die Praxis und weiterführende Forschung ab. Unsere Resultate geben keine abschliessende Antwort auf die Frage, ob ein zusätzliches präoperatives neuromuskuläres Trainingsprogramm einen positiven Effekt auf die postoperative Funktionsfähigkeit hat. Eine Untersuchung zeigte, dass Funktion und Schmerz des operierten Knies in der frühen postoperativen Phase in einem kleinen, aber signifikanten Mass vom präoperativen Funktionszustand des gegenüberliegenden Knies beeinflusst ist. Ob die angewendete Intervention (FSE / neuromuskuläres Training) zur Verbesserung der postoperativen Funktionsfähigkeit effektiv ist, ist unschlüssig und benötigt weitere Forschung. Der CST könnte für Patienten und Patientinnen mit schwerer Kniearthrose keine ideale Messung sein, um Veränderungen zwischen unmittelbar vor und 3 Monate nach Kniegelenksersatz aufzuzeigen.

Letztendlich wurde zur Untersuchung der Gültigkeit einer Pateintenedukaton ein Fragebogen für Patienten und Patientinnen entwickelt. Seine psychometrischen Eigen- 
schaften wurden vorläufig getestet, und es konnte eine starke interne Konsistenz aufgezeigt werden.

Zukünftige Forschung sollte sowohl das operierte als auch das gegenüberliegende Knie umfassen. Weitere Studien, die die psychometrischen Eigenschaften (speziell Konstruktvalidität von Veränderungswerten) von klinischen Funktionstests untersuchen, sind nötig. Es empfiehlt sich, die therapeutische Gültigkeit von Patientendukationen zu untersuchen. Zukünftige Forschung sollte auf die dem positiven Effekt von Übungen zugrunde liegenden potentiellen Mechanismen fokussieren und darauf, welche Art von Übungsprogrammen für welche spezifische Subgruppe mit Kniearthrose am effektivsten ist.

Mit heutigem Kenntnisstand kann der Einsatz von präoperativen therapeutischen Übungen in der Praxis nicht empfohlen werden. FSE, inklusive neuromuskuläres Training, ist durchführbar und sicher und kann bei Patienten und Patientinnen mit Kniearthrose eingesetzt werden, sei es alleine oder in Verbindung mit anderen Übungsprogrammen. Bei der Anwendung einer präoperativen Patientenedukation kann der KOPEQ helfen, den Praktikern und Praktikerinnen ein zuverlässiges Feedback darüber zu geben, wie die Patienten und Patientinnen diese Patientenedukation beurteilt haben. 



\section{Valorisation}

This dissertation generated new knowledge in the field of preoperative interventions in patients with severe knee osteoarthritis and planned total knee replacement. In addition to the scientific value of this thesis, described in Chapters 2-7, this section presents and explains the innovative aspects of the thesis, discusses the findings in the social and economic contexts, reveals the potential for further target groups, and proposes approaches for the transfer into clinical practice.

\section{INNOVATION}

Approximately $30 \%$ of patients are dissatisfied with regard to pain relief and function following TKR [1-5]. Preoperative education has been proposed as a modality to improve outcomes postoperatively $[6,7]$. This intervention offers the opportunity to provide patients with relevant information and to address the realistic expectation of outcomes, since patient expectation is known to have an impact both on functional outcome and quality of life after joint replacement. The authors of a recent review concluded that current evidence is insufficient to recommend preoperative education in routine clinical practice and that further research is required to assess the cost effectiveness and long term patient-reported benefits associated with such intervention [8]. However, in all of the included studies the content of the educational intervention was not evaluated and patients were not asked to comment on whether the content actually met their needs. We have developed and carried out preliminary psychometrical testing on the Knee Osteoarthritis Patient Education Questionnaire (KOPEQ), a new instrument to assess the validity of preoperative patient education interventions, such as the Knee Osteoarthritis Patient Education Intervention (KOPEI) [9]. In our opinion, it is important to embed discussion and exchange of experience in patient education interventions in order to increase understanding and motivation. There is increasing interest in the validation of aspects of patient education interventions but, until now, the focus has been largely on patient information, such as print or audiovisual material $[10,11]$. Therefore, the findings presented in this thesis are innovative. 
It is conceivable that this new instrument could also be transferrable to patients of other education interventions, e.g. to patients prior to total hip replacement.

\section{SOCIAL AND ECONOMIC RELEVANCE}

Between 2002 and 2012 the total number of knee replacements in Switzerland increased by 50\%. In 2012, 16'696 persons received a knee replacement, with median hospital charges of around $18^{\prime} 000$ Swiss Francs per person [12, 13]. This increase demonstrates the relevance of the topic to society. Prolonged hospitalization, due to decreased physical fitness during the pre-intervention period (as in the case of patients awaiting TKR), increases the economic burden on society. Our findings, however, do not provide a conclusive answer as to whether preoperative exercise has a beneficial impact on postoperative functional outcome [14]. The results were influenced by several limitations, including the relatively small recruited sample size. In addition, due to a change in the reimbursement system in acute care hospitals, a reduction in preoperative waiting-time occurred during the recruitment phase. As a result of our inconclusive evidence on the beneficial effects of preoperative exercise, we are unable to recommend the implementation of preoperative exercise into clinical practice.

Our data are, however, encouraging for the many patients scheduled for unilateral knee replacement who also report pain and functional impairment in the contralateral knee, suggesting that not only the operated knee but also the contralateral knee improves after the intervention. Surgeons should inform patients with bilateral knee OA on the likelihood of recovery of the contralateral knee and also recommend a delay in further surgery on the second knee of at least 3 months after the first surgery. This recommendation is in line with a recent consensus statement from the consensus conference on bilateral total knee arthroplasty group [15].

This thesis did not show a direct impact on the social and economic burden, but it revealed new insights and can be taken as a point of departure for further exploration and assessment in this field of research.

\section{TARGET GROUP}

The results reported in this dissertation are of importance to people suffering from severe knee OA prior to replacement surgery. As recommended by clinical guidelines $[16,17]$, exercise is a core component of knee OA management and different types of exercise (such as strengthening, aerobic and neuromuscular / functional stability training) are recommended. The relatively modest benefits of exercise found to date may be explained by the one-size-fits-all approach to exercise prescription, without taking into account individual characteristics, which is likely to attenuate treatment effects [18]. 
The neuromuscular intervention used in our RCT (NEMEX-TJR) is feasible and safe and it is likely that people with greater varus malalignment during walking respond best to this neuromuscular program that addresses frontal plane control, functional stability and alignment of the knee in functional upright tasks. This assumption has recently been supported by preliminary findings [19], but further research is needed to confirm whether targeted exercise treatment based on individual characteristics can optimize outcomes in knee OA.

\section{TRANSFER OF KNOWLEDGE}

Since exercise is a recommended treatment for people with knee OA [17], we suggest that functional stability exercise, including neuromuscular exercise, is a well-tolerated intervention and that practitioners who already apply this type of exercise should continue to do so. They should be aware, however, that future studies might lead to different results.

Many results (including ours) do not give a conclusive answer to the question of whether additional preoperative exercise has a beneficial effect on postoperative functional outcomes [14, 22, 23]. We therefore cannot recommend preoperative exercise as standard treatment before TKR surgery.

Our results have revealed new and important insights into how education and training services and functioning domains might be linked together by patients [9]. Our results could lead to further research activities, including further validation, translation into other languages and corresponding cross-cultural adaption. Therapeutic validity is not only an issue in therapeutic exercise interventions [24] but also in patient education interventions. Our research contributed to this issue by developing and psychometrically testing a new measure to assess the validity of a preoperative education intervention.

Physical function can be measured either through self-reporting or by systematic observation by clinicians. It seems that only low to moderate correlations can be expected between self-reported and performance-based measures. Patients appear to perceive an improvement in function compared to pre-surgery, even though their capacity to perform a task has not increased in reality. Self-reported measures, such as KOOS and WOMAC, probably best reflect the benefit of TKR three months after surgery.

\section{CONCLUSION}

Based on the work in this thesis, we are unable to recommend the implementation of preoperative exercise as a standard treatment in clinical practice. Alongside strengthening and aerobic exercise, functional stability exercise could be applied as a stand-alone intervention or in addition to the other types of exercise, but further research should 
explore what types of exercise, at what frequency, intensity and duration is best to help patients with knee OA, targeting the specific individual biomechanical characteristics.

Patient education interventions are recommended [25] and it is hoped that these interventions would include more than just patient information. Their therapeutic validity as well as the outcomes should be equally evaluated. 


\section{REFERENCES}

1. Beswick AD, Wylde V, Gooberman-Hill R, Blom A, Dieppe P: What proportion of patients report long-term pain after total hip or knee replacement for osteoarthritis? A systematic review of prospective studies in unselected patients. BMJ open 2012, 2(1):e000435.

2. Alzahrani K, Gandhi R, Debeer J, Petruccelli D, Mahomed N: Prevalence of clinically significant improvement following total knee replacement. The Journal of rheumatology 2011, 38(4):753-759.

3. Judge A, Welton NJ, Sandhu J, Ben-Shlomo Y: Equity in access to total joint replacement of the hip and knee in England: cross sectional study. BMJ (Clinical research ed) 2010, 341:c4092.

4. Singh JA, O'Byrne MM, Harmsen WS, Lewallen DG: Predictors of moderate-severe functional limitation 2 and 5 years after revision total knee arthroplasty. The Journal of arthroplasty 2010, 25(7):1091-1095, 1095 e1091-1094.

5. Scott CE, Howie CR, MacDonald D, Biant LC: Predicting dissatisfaction following total knee replacement: a prospective study of 1217 patients. The Journal of bone and joint surgery British volume 2010, 92(9):1253-1258.

6. Jones S, Alnaib M, Kokkinakis M, Wilkinson M, St Clair Gibson A, Kader D: Pre-operative patient education reduces length of stay after knee joint arthroplasty. Annals of the Royal College of Surgeons of England 2011, 93(1):71-75.

7. Yoon RS, Nellans KW, Geller JA, Kim AD, Jacobs MR, Macaulay W: Patient education before hip or knee arthroplasty lowers length of stay. The Journal of arthroplasty 2010, 25(4):547-551.

8. Jordan RW, Smith NA, Chahal GS, Casson C, Reed MR, Sprowson AP: Enhanced education and physiotherapy before knee replacement; is it worth it? A systematic review. Physiotherapy 2014.

9. Huber EO, Bastiaenen CH, Bischoff-Ferrari HA, Meichtry A, De Bie RA: Development of the knee osteoarthritis patient education questionnaire (KOPEQ): A new measure for evaluating preoperative patient education programs for patients undergoing total knee replacement. Accepted for publication in Swiss Medical Weekly 2015.

10. Shoemaker SJ, Wolf MS, Brach C: Development of the Patient Education Materials Assessment Tool (PEMAT): a new measure of understandability and actionability for print and audiovisual patient information. Patient education and counseling 2014, 96(3):395-403.

11. Eschalier B, Descamps S, Boisgard S, Pereira B, Lefevre-Colau MM, Claus D, Coudeyre E: Validation of an educational booklet targeted to patients candidate for total knee arthroplasty. Orthopaedics \& traumatology, surgery \& research : OTSR 2013, 99(3):313-319.

12. Federal Department of Home Affairs. Bundesamt für Statistik. Medizinische Statistik der Krankenhäuser 2012.Berne, Switzerland [http://www.bfs.admin.ch/bfs/portal/de/index/themen/14/04/ 01/data/01/05.html]

13. Gesundheitsstatistik 2014. In. Edited by Statistik Bf. Neuchatel, Switzerland: Federal Department of Home Affairs; 2014.

14. Huber EO, Roos EM, Meichtry A, de Bie RA, Bischoff-Ferrari HA: Effect of preoperative neuromuscular training (NEMEX-TJR) on functional outcome after total knee replacement: an assessor-blinded randomized controlled trial. BMC Musculoskelet Disord 2015, 16:101.

15. Memtsoudis SG, Hargett M, Russell LA, Parvizi J, Cats-Baril WL, Stundner O, Sculco TP: Consensus statement from the consensus conference on bilateral total knee arthroplasty group. Clinical orthopaedics and related research 2013, 471(8):2649-2657.

16. Nelson AE, Allen KD, Golightly YM, Goode AP, Jordan JM: A systematic review of recommendations and guidelines for the management of osteoarthritis: The chronic osteoarthritis management initiative of the U.S. bone and joint initiative. Seminars in arthritis and rheumatism 2014, 43(6):701-712.

17. Fransen M, McConnell S, Harmer AR, Van der Esch M, Simic M, Bennell KL: Exercise for osteoarthritis of the knee. The Cochrane database of systematic reviews 2015, 1:CD004376.

18. Felson DT: Identifying different osteoarthritis phenotypes through epidemiology. Osteoarthritis and cartilage / OARS, Osteoarthritis Research Society 2010, 18(5):601-604. 


\section{Valorisation}

19. Bennell KL, Dobson F, Roos EM, Skou ST, Hodges P, Wrigley TV, Kyriakides M, Metcalf B, Hunt MA, Hinman RS: The influence of biomechanical characteristics on pain and function outcomes from exercise in medial knee osteoarthritis and varus malalignment: exploratory analyses from a randomised controlled trial. Arthritis care \& research 2015.

20. Huber EO, Meichtry A, De Bie RA, Bastiaenen $\mathrm{CH}$ : Construct validity of change scores of the Chair Stand Test versus Timed Up and Go test, KOOS questionnaire and the isometric muscle strength test in patients with severe knee osteoarthritis undergoing total knee replacement Manual Therapy (2015), doi: 10.1016/j.math.2015.09.012.

21. Villadsen A, Roos EM, Overgaard S, Holsgaard-Larsen A: Agreement and reliability of functional performance and muscle power in patients with advanced osteoarthritis of the hip or knee. American journal of physical medicine \& rehabilitation / Association of Academic Physiatrists 2012, 91(5):401-410.

22. Simmons L, Smith T: Effectiveness of pre-operative physiotherapy-based programmes on outcomes following total knee arthroplasty: a systematic review and meta-analysis. Physical Therapy Reviews 2013, 18(1):1-10.

23. Shoemaker M, Gibson C, Saagman S: Preoperative exercise in indvidiuals undergoing total knee arthroplasty: state of the evidence. Topics in Geriatric Rehabilitation 2013, 29(1):2-16.

24. Hoogeboom TJ, Oosting E, Vriezekolk JE, Veenhof C, Siemonsma PC, de Bie RA, van den Ende CH, van Meeteren NL: Therapeutic validity and effectiveness of preoperative exercise on functional recovery after joint replacement: a systematic review and meta-analysis. PloS one 2012, 7(5):e38031.

25. McDonald S, Page MJ, Beringer K, Wasiak J, Sprowson A: Preoperative education for hip or knee replacement. The Cochrane database of systematic reviews 2014, 5:CD003526. 


\section{Acknowledgment}

Research is not possible without a network of colleagues, friends and supporters and this $\mathrm{PhD}$ thesis would not have been possible without the help of so many people.

First of all I would like to thank my promoter, Prof. Dr. Rob A. de Bie, who has guided and encouraged me over the years. We met several times in Switzerland and in the Netherlands to discuss ideas and he helped me to take the next step along the way. He has the capability of capturing the core issues of a study or an idea very quickly and can simplify complex problems into practical tasks. His ability to ask searching questions and his sense of humor make him a perfect teacher. Rob, I thank you very much for your constructive and motivating feedback. I would also like to thank you for giving me the opportunity to spend such an instructive time at the Department of Epidemiology, School of Public Health and Primary Care (CAPHRI) at Maastricht University. Special thanks go to Conny de Zwart who supported me in all administrative and formal issues.

Prof. Dr. Heike Bischoff-Ferrari - my local promoter - was a mentor from the very beginning of my PhD project. She encouraged me to take Summer School courses at the Harvard School of Public Health in Boston, U.S.A. These courses provided me with a solid grounding in Epidemiology and Biostatistics. Heike, I especially thank you for inviting me to work in your team at the Center of Aging and Mobility at the University Hospital and the University of Zurich, for your crucial support during the execution of my RCT, as well as in the discussion of results and preparation of manuscripts. My thanks go to the whole team of ZAM for their valuable support, particularly Dr. Andreas Egli, Mona Leuenberger, Steffi Brunold, Dr. Ursina Meyer and Daniela Durisch, with a special thank you also to the computer scientist Stephen Ferrari, who helped to reduce my logistical work. Ursina, I thank you for having participated in the writing of one of my articles.

Prof. Dr. Ewa M. Roos - my third promoter - was also a mentor from the very beginning of my PhD project. Her profound knowledge in the field of osteoarthritis and her experience of the role of therapeutic exercise and physical therapy were particularly helpful. 
She gave me crucial advice when designing the RCT and I could benefit from her research, e.g. where the exercise intervention (neuromuscular exercise (NEMEX-TJR)) had already been tested in an uncontrolled trial. The physical therapists conducting the exercise intervention in my RCT and I had a fruitful and enjoyable time in Lund, where Ewa and her team members Dr. Eva Ageberg and Anne Link introduced us to the NEMEX-TJR program in detail. Ewa I thank you very much for your constructive feedback which was always a motivation for me. I also very much appreciate the opportunity you gave me to spend such an informative time at the Institute of Sports Science and Clinical Biomechanics, University of Southern Denmark. Many thanks to Dr. Hans Lund und Dr. Carsten Juhl from whom I also learnt a great deal. Thank you for having participated in the writing of one of my articles.

I met Dr. Carolien Bastiaenen when she acted as a supervisor of the PhD candidates group in Switzerland. I was so impressed by her profound expertise in clinical and methodological issues that, at a meeting in March 2013, I asked her whether she would like to write methodological manuscripts with me and I am very grateful that she accepted. During the PhD process many ups and downs occur. Carolien, you were the light in the dark and I thank you very much for the many interesting and valuable discussions during the writing process and your constructive, motivating and supportive feedback.

An essential part of this study was the recruitment of patients with severe knee osteoarthritis scheduled for total knee replacement. Many people were involved in this process, but I would like to thank in particular Dr. Christoph Schwaller, Ursula Nauer, Hanspeter Studer, Evelyn Kurmann, Samuel Gerber, Mirjam Hafner, Andrea Blaser and André Steiger, Kantonsspital Olten, Dr. Marc Zumstein, Ilona Märki-Wettstein, Lorenz Moser, Manuela Huber and Ruth Winkler, as well as the independent assessors Manuela Lüthi-Tuor and Madeleine Salathe.

Prof. Dr. Beat Michel and Barbara Gubler-Gut, thank you both for allowing me to start my PhD project while I was still employed at the University Hospital of Zurich.

Prof. Dr. Astrid Schämann, grateful thanks to you for providing the opportunity to continue and complete my PhD project while working in your team at the Institute of Physiotherapy, School of Health Professions at the Zurich University of Applied Sciences (ZHAW).

Special thanks to André Meichtry for his statistical support and for all the analyses that he made during this project. It was a great pleasure to work with you.

I want to express many thanks to my proof reader Karen Linwood. You corrected the English in all my articles and in my thesis. You are wonderful. 
Thanks must also go to the Albert Böni Stiftung in Zurich, Switzerland, a foundation for research in Rheumatology and Physical Medicine, who supported one study.

My great appreciation goes to my team at the Institute of Physiotherapy. You gave me emotional support, managed daily business in an excellent manner and accepted without complaint that I was sometimes so mentally absorbed that I was not as patient as perhaps I should have been.

I would like to thank the members of my PhD thesis assessment committee and the corona for their time and interest in my work: Prof dr. Annelies Boonen, Prof. dr. Sita M.A. Bierma-Zeinstra, Prof. dr. Maura D. Iversen, Prof. dr. Nico van Meeteren, and Prof. dr. Lodewijk W. van Rhijn.

There are other friends and colleagues who also supported me in some way during the process to reach this step. Prof. Dr. Gerold Stucki was my mentor in earlier times, after I met him in 1995 when he became the Director of the Institute of Physical Medicine at the University Hospital Zurich. I had the chance to participate in his research projects in the field of the International Classification of Functioning, Disability and Health. He encouraged me from the beginning to consider doing a PhD on my own. Now, 20 years later, one can say it is never too late. Prof. Dr. Karin Niedermann and I established the program "Physiotherapy Sciences" together, a collaboration project together with the University of Maastricht. Karin, I thank you for the fruitful and inspiring collaboration in this formative period.

Work and being involved in research reflects only one aspect of my life. I would very much like to thank my parents and my partner for their endless support and encouragement. Mami und Päps, ihr seid wunderbare Eltern. Was ich in meinem Leben erreicht habe und vor allem die Lebensqualität, die ich neben der Arbeit geniessen darf wäre ohne eure grosse Liebe und uneingeschränkte Unterstützung nie möglich gewesen. Aki, I spent many weeks abroad, I spent many week-ends in front of the computer, I was often mentally absorbed and my thoughts were somewhere else. We have had very few days and moments together in the last three years. I express my deepest thanks for your support, comprehension and patience. Your love means everything to me.

So many people have been involved in this $\mathrm{PhD}$ project or gave me their sympathy. I hope that I have not forgotten to acknowledge anybody. In the case that I have, I also thank you very much. 



\section{About the author}

\section{CURRICULUM VITAE}

Erika (Omega) Huber was born in 1957 in Niederglatt, Switzerland. She completed her training as a physical therapist at the University Hospital Zurich in 1982. In 1999 she gained a Master of Advanced Studies in Health Service Management at the University of Applied Sciences in St. Gallen, Switzerland. In 2008 she completed a program in Clinical Effectiveness at Harvard Medical School \& Harvard School of Public Health. In 2012 she received a certificate in Didactics at the Zurich University of Teacher Education.

Omega is the appointed Head of the Continuing Professional Development at the Institute of Physiotherapy, School of Health Professions at the Zurich University of Applied Sciences in Winterthur.

In 2002 Omega co-founded the Foundation Physiotherapy Sciences and is actually the current president of the foundation. 


\section{MEMBERSHIPS}

Physioswiss Swiss Physiotherapy Association (honorary member)

HPR Health Professionals in Rheumatology

FH Schweiz Dachverband der Absolventinnen und Absolventen der Fachhochschulen

\section{PUBLICATIONS}

\section{Journal articles}

Huber EO, Bastiaenen CH, Bischoff-Ferrari HA, Meichtry A, de Bie RA. Development of the knee osteoarthritis patient education questionnaire (KOPEQ): A new measure for evaluating preoperative patient education programs for patients undergoing total knee replacement. Accepted for publication in Swiss Medical Weekly 2015.

Huber EO, Meichtry A, de Bie RA, Bastiaenen $\mathrm{CH}$. Construct validity of change scores of the Chair Stand Test versus Timed Up and Go test, KOOS questionnaire and the isometric muscle strength test in patients with severe knee osteoarthritis undergoing total knee replacement. Manual Therapy (2015), doi: 10.1016/j.math.2015.09.012.

Huber EO, Roos EM, Meichtry A, de Bie RA, Bischoff-Ferrari HA. Effect of preoperative neuromuscular training (NEMEX-TJR) on functional outcome after total knee replacement: an assessor-blinded randomized controlled trial. BMC Musculoskelet Disord. 2015 Apr 25;16:101. doi: 10.1186/s12891-015-0556-8.

Huber EO, de Bie RA, Roos EM, Bischoff-Ferrari HA. Effect of pre-operative neuromuscular training on functional outcome after total knee replacement: a randomizedcontrolled trial. BMC Musculoskelet Disord. 2013 May 3;14:157. doi: 10.1186/14712474-14-157.

Lohmann S, Strobl R, Mueller M, Huber EO, Grill E. Psychosocial factors associated with the effects of physiotherapy in the acute hospital. Disabil Rehabil. 2011;33(23-24):231121. doi: 10.3109/09638288.2011.570410. Epub 2011 Apr 12.

Grill E, Gloor-Juzi T, Huber EO, Stucki G. Assessment of functioning in the acute hospital: operationalisation and reliability testing of ICF categories relevant for physical therapists interventions. J Rehabil Med. 2011 Jan;43(2):162-73. Doi: 10.2340/16501977-0642.

Grill E, Huber EO, Gloor-Juzi T, Stucki G. Intervention goals determine physical therapists' workload in the acute care setting. Phys Ther. 2010 Oct;90(10):1468-78. doi: 10.2522/ptj.20090390. Epub 2010 Aug 5.

Bürge E, Cieza A, Allet L, Finger ME, Stucki G, Huber EO. Intervention categories for physiotherapists treating patients with internal medicine conditions on the basis of the 
International Classification of Functioning, Disability and Health. Int J Rehabil Res. 2008 Mar;31(1):43-50. doi: 10.1097/MRR.0b013e3282f4525c.

Gloor-Juzi, Huber EO, Grill E. Operationalisierung von ICF-Kategorien für physiotherapeutische Interventionen im Akutkrankenhaus. physioscience 2008; 4:7-16.

Grill E, Huber EO, Stucki G. Standardisierung der Ziele physiotherapeutischer Interventionen im Akutkrankenhaus mithilfe der ICF. physioscience 2008; 4:17-24.

Grill E, Huber EO, Stucki G. Physiotherapeutischer Ressourcenaufwand im Akutkrankenhaus. physioscience 2008; 4:25-29.

Allet L, Cieza A, Bürge E, Finger M, Stucki G, Huber EO. Intervention categories for physiotherapists treating patients with musculoskeletal conditions on the basis of the International Classification of Functioning, Disability and Health. Int J Rehabil Res. 2007 Dec;30(4):273-80.

Huber EO, Cieza A. Umsetzung der ICF in den klinischen Alltag der Physiotherapie. physioscience 2007; 3:48-53.

Allet L, Cieza A, Bürge E, Finger ME, Stucki G, Affolter J, Tal-Akabi A, Huber EO. ICFInterventionskategorien für die Physiotherapie bei muskuloskelettalen Gesundheitsstörungen. physioscience 2007;3:54-62.

Finger ME, Cieza A, Allet L, Bürge E, Baumann Y, Albert S, Stucki G, Huber EO. ICF Interventionskategorien für die Physiotherapie bei neurologischen Gesundheitsstörungen. Physioscience 2007; 3:63-71.

Bürge E, Cieza A, Allet L, Finger ME, Stucki G, Kramer E, Wiggers-Müller B, Huber EO. ICF-Interventionskategorien für die Physiotherapie bei internistischen Gesundheitsstörungen. physioscience 2007; 3:72-79.

Allet L, Cieza A, Bürge E, Finger M, Stucki G, Huber EO. Intervention categories for physiotherapists treating patients with musculoskeletal conditions on the basis of the International Classification of Functioning, Disability and Health. Int J Rehabil Res 2007; 30:273-80.

Finger ME, Cieza A, Stoll J, Stucki G, Huber E=. Identification of intervention categories for physical therapy, based on the international classification of functioning, disability and health: a Delphi exercise. Phys Ther. 2006 Sep;86(9):1203-20.

Grill E, Huber EO, Stucki G, Herceg M, Fialka-Moser V, Quittan M. Identification of relevant ICF categories by patients in the acute hospital. Disabil Rehabil. 2005 Apr 8$22 ; 27(7-8): 447-58$. 
Grill E, Quittan M, Huber EO, Boldt C, Stucki G. Identification of relevant ICF categories by health professionals in the acute hospital. Disabil Rehabil. 2005 Apr 8-22;27(78):437-45.

Scheuringer M, Stucki G, Huber EO. Brach M, Schwarzkopf SR, Kostanjsek N, Stoll T. ICF Core Set for patients with musculoskeletal conditions in early post-acute rehabilitation facilities. Disabil Rehabil. 2005 Apr 8-22;27(7-8):405-10. Review.

Stoll T, Brach M, Huber EO, Scheuringer M, Schwarzkopf SR, Kostanjsek N, Stucki G. ICF Core Set for patients with musculoskeletal conditions in the acute hospital. Disabil Rehabil. 2005 Apr 8-22;27(7-8):381-7. Review.

Stucki A, Daansen P, Fuessli M, Cieza A, Huber E, Atkinson R, Kostanjsek N, Stucki G, Ruof J. ICF core sets for obesity. J Rehabil Med 2004; 44:107-13.

Dreinhöfer K, Stucki G, Ewert T, Huber E, Ebenbichler G, Gutenbrunner C, Kostanjsek N, Cieza A. ICF core sets for osteoarthritis. J Rehabil Med. 2004 Jul;(44 Suppl):75-80.

Stoll T, Huber E, Bachmann S, Baumeler HR, Mariacher S, Rutz M, Schneider W, Spring $H$, Aeschlimann A, Stucki G, Steiner W. Validity and sensitivity to change of the NASS questionnaire for patients with cervical spine disorders. Spine (Phila Pa 1976). 2004 Dec 15;29(24):2851-5.

Steiner W, Ryser L, Huber E, Uebelhart D, Aeschlimann A, Stucki G. Use of the ICF model as a clinical problem-solving tool in physical therapy and rehabilitation medicine. Phys Ther. 2002 Nov;82(11):1098-107.

Stoll T, Huber E, Seifert B, Michel BA, Stucki G. Maximal isometric muscle strength: normative values and gender-specific relation to age. Clin Rheumatol 2000;19(2):105-13.

Schick M, Stucki G, Rodriguez M, Meili EO, Huber E, Michel BA, Brühlmann P. Haemophilic; arthropathy: assessment of quality of life after total knee arthroplasty. Clin Rheumatol. 1999;18(6):468-72.

\section{Book contribution}

OE Huber and PC Meyer. Chapter Therapieberufe. In Gesundheitswesen Scheiz 2015 2017. Editor: Willy Oggier, hogrefe, Berne, Switzerland.

OE Huber, D Monnin, R Paillex, C Boldi-Goetschi, W. Oggier. Physiotherapie im Wandel. Schriftenreihe der SGGP, 2011 Berne, Switzerland.

Stoll T, Huber E, Seifert B, Stucki G, Michel BA. Isometric Muscle Strength Measurement; Thieme flexibook. Thieme, 2002. ISBN: 3-13-127851-X, 9783131627414 


\section{Conference proceedings}

Huber EO, Luomajoki H, Akhbari Ziegler S, de Ruijter R, van Son C, Schämann A: Combining ICF and Clinical reasoning in a single case documentation. $3^{\text {rd }}$ European Congress on Physiotherapy Education of the European Region, Wien 2012

Huber EO, Schämann A: Academic CPD: Teaching as "guide at the side" instead of "sage on the stage": $3^{\text {rd }}$ European Congress on Physiotherapy Education of the European Region, Wien 2012

Huber EO, Hafner M, Steiger A, Blaser A, Bischoff-Ferrari HA: Patientenschulung vor einem Kniegelenksersatz - Erfahrungen aus dem Kantonsspital Olten. physio congress 2010, Basel

Huber EO, Theiler R, Schären S, Dick W, Huber JF, Gautier E, Bischoff-Ferrari HA: Outcome and predictors of early non-response after total hip replacement due to hip OA: physio congress 2010, Basel

Huber EO, Theiler R, Schären S, Dick W, Huber JF, Gautier E, Bischoff-Ferrari HA: Outcome and predictors of early non-response after total hip replacement due to hip OA: Swiss Med Wkly 2009;139(Suppl 169)

Huber EO, Grill E, Gloor T, Stucki G: System oriented pathways in physical therapy in the acute hospital based on the ICF: Musculoskeletal system. $15^{\text {th }}$ International Congress of the World Confederation for Physical Therapy 2007;12-05

Huber EO, Stoll J, Finger M, Stucki D, Cieza A: Identification of intervention categories for physiotherapy on the ICF. $15^{\text {th }}$ International Congress of the World Confederation for Physical Therapy 2007;2491

Huber E, Cieza A, Meyer K, Huwiler H, Uebelhart D, Stucki G: The importance of ICF in work-repated rehabilitation. EULAR 2004

Huber E, Steiner W: Outcome assessment in patients with disability of arm, shoulder or hand undergoing an outpatient treatment. $14^{\text {th }}$ International Congress of the World Confederation for Physical Therapy 2003;1083

Huber E, Kuenzer S, Hartmeier A, Kerkour K, Morini S, Moergeli S: Clinical pathways can be used as a tool for benchmarking. $14^{\text {th }}$ International Congress of the World Confederation for Physical Therapy 2003;1085

Huber E, Moergeli S: Clinical pathways as management tool for inpatients concerning process, quality and costs. $14^{\text {th }}$ International Congress of the World Confederation for Physical Therapy 2003;1084

Huber E: Assessment of health status after total knee arthroplasty in hemophilia. $13^{\text {th }}$ International Congress of the World Confederation for Physical Therapy 1999;0391 
Huber E, Stoll T, Seifert B, Michel BA, Stucki G: Age related patterns of maximal muscle strength differ in women and men. $13^{\text {th }}$ International Congress of the World Confederation for Physical Therapy 1999;0394

Huber E, Steiner W, Meili EO, Stucki G: Assessment of quality of life after total knee arthroplasty in hemophilia. $11^{\text {th }}$ EULAR Symposium 1998 


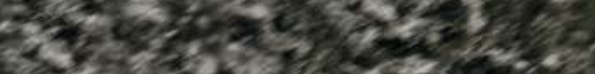

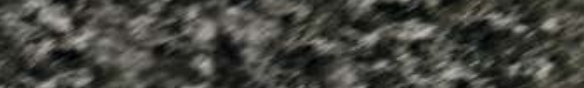

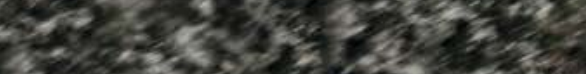
3. $4: 29-352$

$x^{3}=23=23$

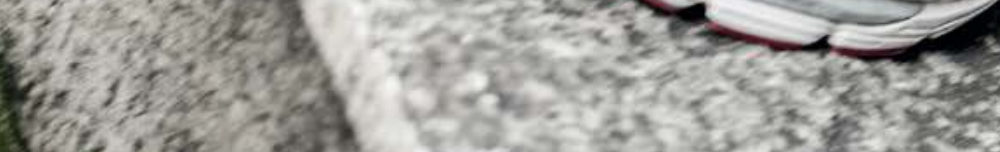

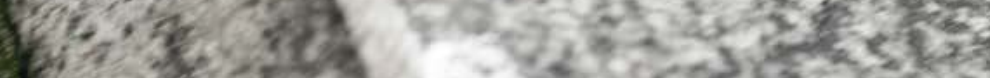

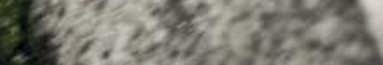
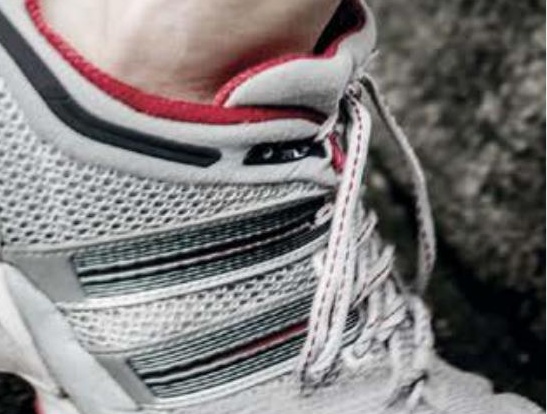